\title{
EXPERIENCE-DRIVEN HERITAGE
}

Sian Du

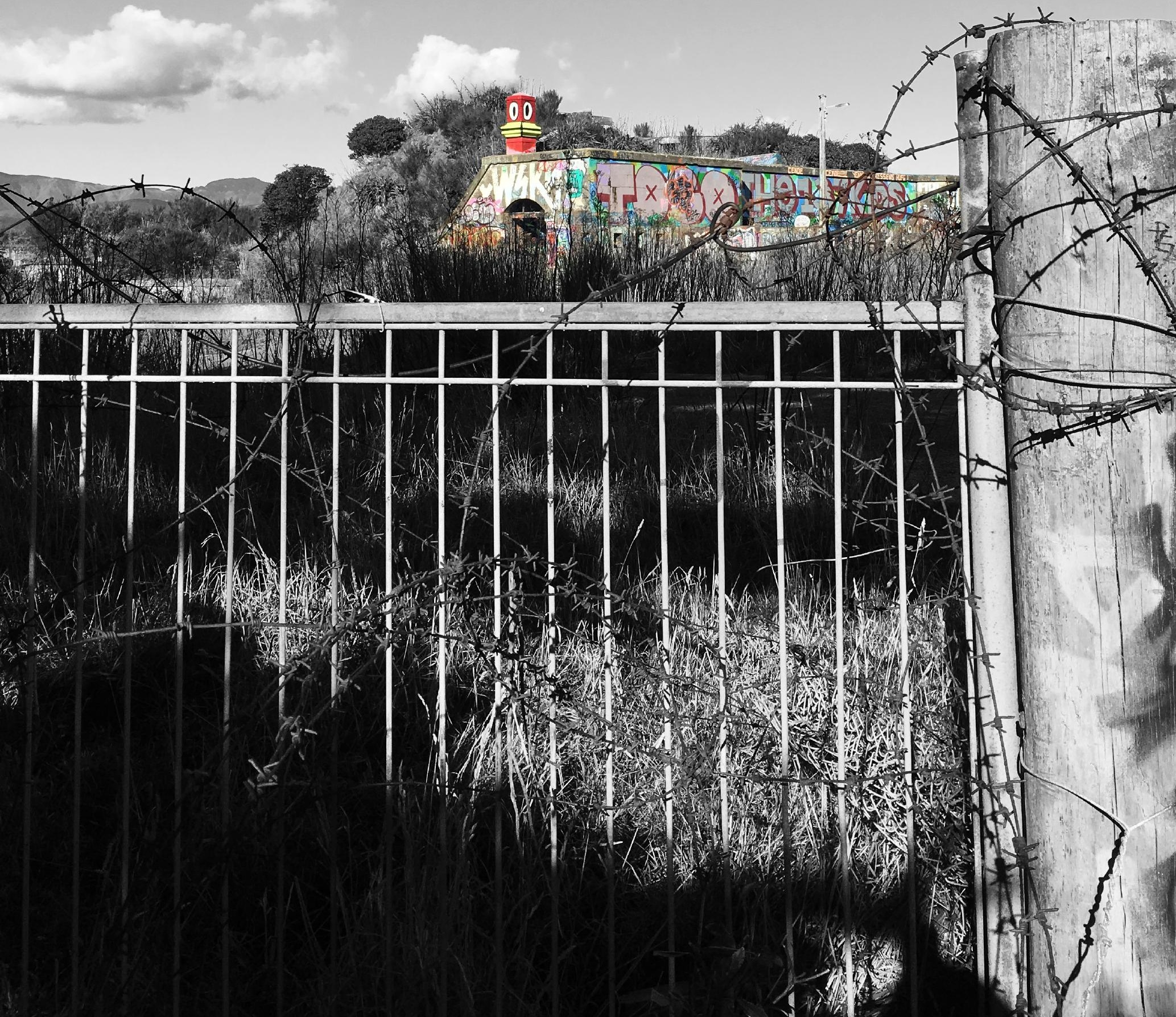


Fig. 0.1 Photograph of investigated site. 


\section{EXPERIENCE-DRIVEN HERITAGE}

By

Sian Du

A 120 point thesis submitted in partial fulfilment of the requirements for the Masters of Landscape Architecture

Victoria University of Wellington, School of Architecture

2017 


\section{ACKNOWLEDGEMENTS}

I want to say thank you to everyone who has helped and supported me in last 5 years at university.

To my supervisors, Peter Connolly and Carles Martinez Almoyna. Thank you for sharing knowledge and pushing me over last 12 months, I really appreciated.

To my friends, it is great having you guys in my everyday life. I can't be happy and enjoyable without friendship supporting and I wish our friendship forever.

Finally, to my family, I love you. I lived by my self since I was 15 and we only see each other once a year, 7 years so far, it was not easy. Big thank you for sending me away for better life, and supporting, encouraging me since I was born. 


\section{Abstract}

Within the Wellington region, there are a number of abandoned military fortifications which were designed as a coastal defence system to protect the harbour from Russian attacks in late 19th Century. Changing circumstances have meant that this coastal defence infrastructure network is no longer functional, and this research aims to bring it back to life. The site chosen for this research investigation is Watts Peninsula, which is enjoyed by only a limited number of the wider public who only visit a small part of the site. The great size and topography of the landscape makes it a serious challenge to manage let alone transform. This site therefore seems to be a great opportunity to explore the disciplinary challenge of how to bring coastal military fortification sites back to life?

Traditionally, the way to bring coastal sites with abandoned fortifications back to life is by treating them as heritage projects. They are protected and sometimes developed as more or less significant tourist destinations that display the significance of military history and heritage. This approach tends to break up the landscape into key areas, with the minimal path system required to connect up the various heritage items and locations on the site. This typical approach severely limits the range and richness of experiencing potential of a site like Watts Peninsula.

This thesis will approach this project by engaging with the countless experiences found within the existing landscape; stepping the normal heritage approach. Topography, slope, vegetation cover, aspect and views were found to produce a great range of effectively separately experienced patches or landscapeexperience zones. This thesis sought to understand how the site produced the involuntary types of movement-experiencing that it did and how it differentiated itself into these experience-zones. The types of experiencing that the site produced seemed to have a great deal to do with the interaction of paths/ movement through the various mosaic of experience-zones. The aim of the analysis was to discover the actual and potential ways that the site is differentiated into these experience-areas and the actual and potential movement experiences that could allow access to these areas. The design investigation would aim to maximise the number and variety of these movement and experience-zones. The resulting development would aim to spread a complex mosaic-network of experiencing across as much of the site as possible.

This network would be intended to develop in a way where the great richness of possible experiences and the mystery of the site are both increased. The project would require significant funds and so a housing scheme on the southern edge of the site seemed the most obvious way to provide income for such a development. The intended housing development was designed to increase the local population who would have access to the site but hopefully in a manner where the housing would not seriously impact on views to, or the experiences and mystery of the site.

Overall, the design development would be intended to transform this landscape into a destination for varieties of adventuring, exploring and experiencing on a remarkable landscape. With the help of the housing, the possibility of this being an urban adventuring destination and the network of paths and experiencing could then provide something of a way to make the heritage transformation of the fortifications themselves a viable prospect. The treatment of the fortifications has not been engaged with in this project. So, it can be said that this research has attempted to avoid the normal way that coastal military fortifications tend to be developed and proposed, instead, an experience-driven approach to the site and to heritage. 


\section{CONTENTS}

Acknowledgements Abstract

1.0- Introduction

+Research Topic

+ Uniqueness

+Problems

+ Positioning

+Research Question

+ Method

+Thesis Structure

2.0- Site

+ Peninsula

+City Engagement

- Infrastructure

- Visual Interaction

+History

+Military Study

+ Network

+ Public

+ Limitation

+ Reflection

\section{Theory}

Page 5

Page 9

3.0- Literature Review

Page 49

+Heritage

+ Assemblage

4.0- Case Studies

Page 55

+ North Head

+ Tudela

+Koko Head

+Diamond Head

+Conclusion 
Field Studies

\section{0- Experience}

+Vegetation

+ Slope

+ Path

+Conclusion

6.0- Context Influence

+Key Locations

+Ownership

+Relationship

\section{Design}

7.0- Housing

+Housing Strategies

- Strategy 1

- $\quad$ Strategy 2

- Strategy

+Strategies Conclusions

8.0- Experience

+ Site 1

+ Site 2

+Design Discussion
10.0- Conclusions

Page 131

+ Discussion

+ Reflection

Bibliography

Page 134
Page 89

Page 103

Page 115 


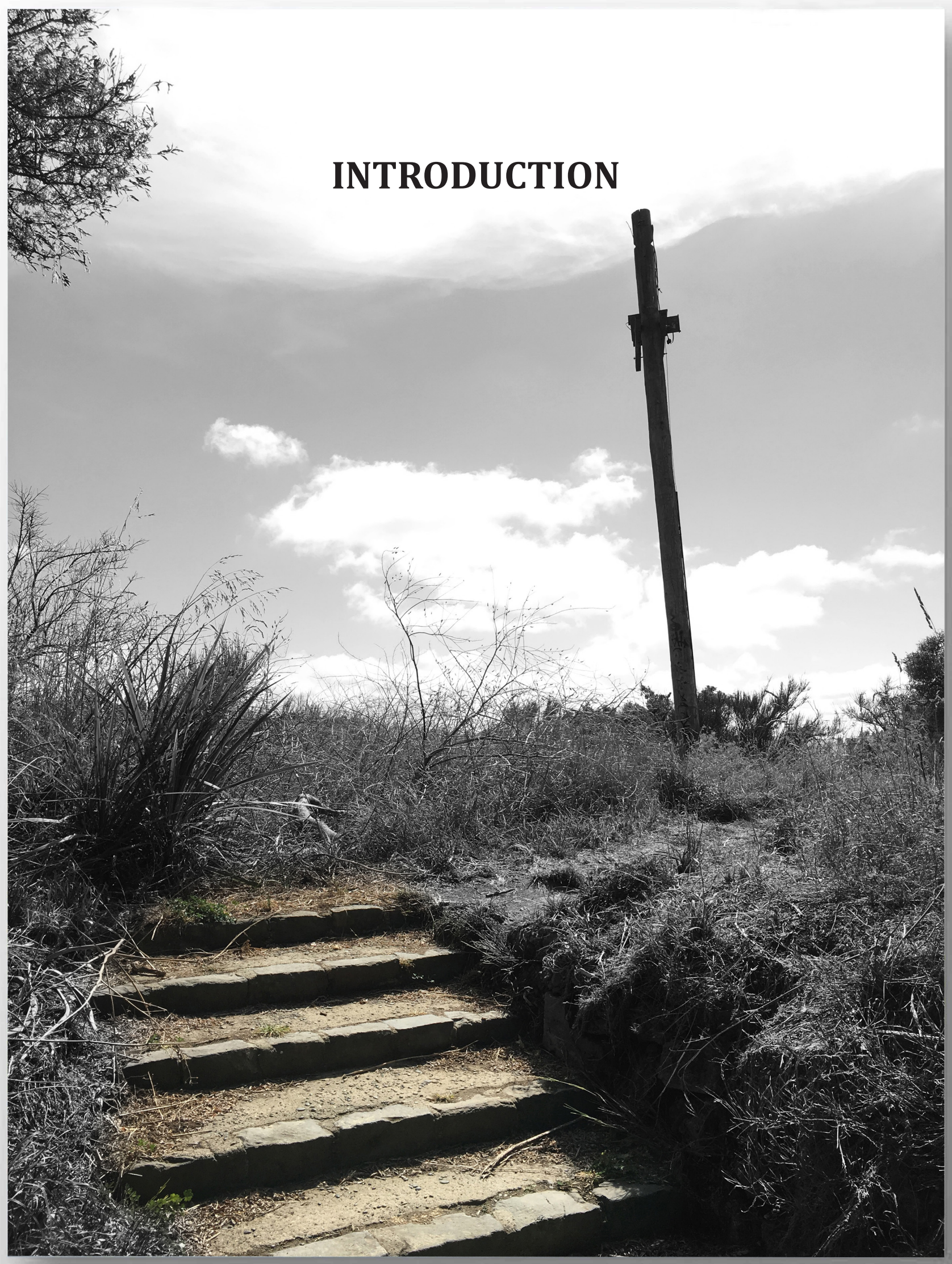


Military Fortification

Past

Coastal Defence

Protect Wellington Harbour

\section{Now}

Abandoned fortifications

No real function

\section{Future}

Military heritage site?

Sculpture park?

National destination?

Reserve?

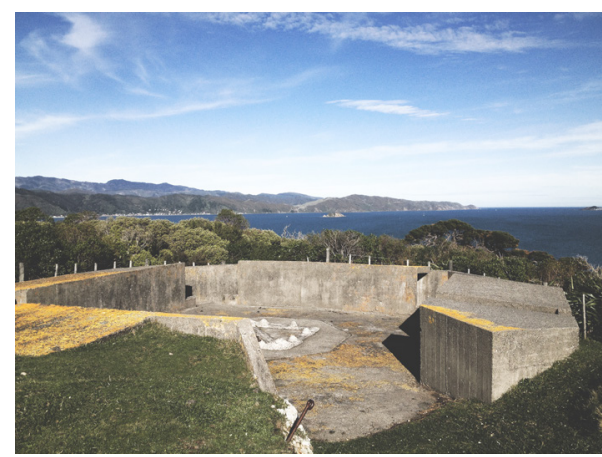

Fig 1.5 Somes Island AA Battery.

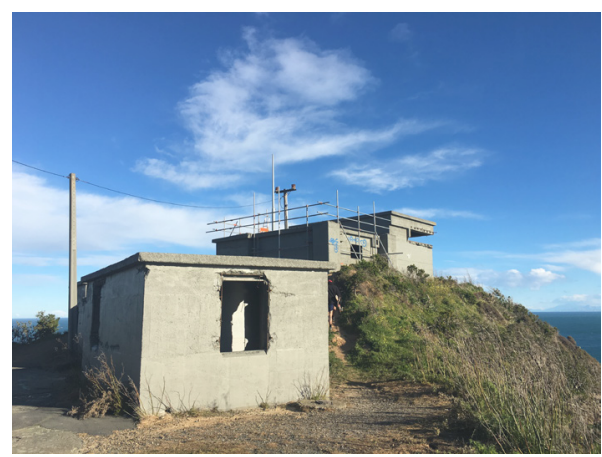

Fig 1.6 Palmer Head Fortress.

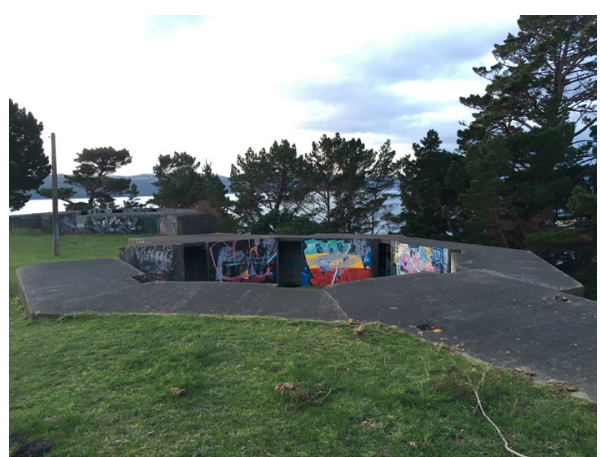

Fig 1.7 Point Halswell.

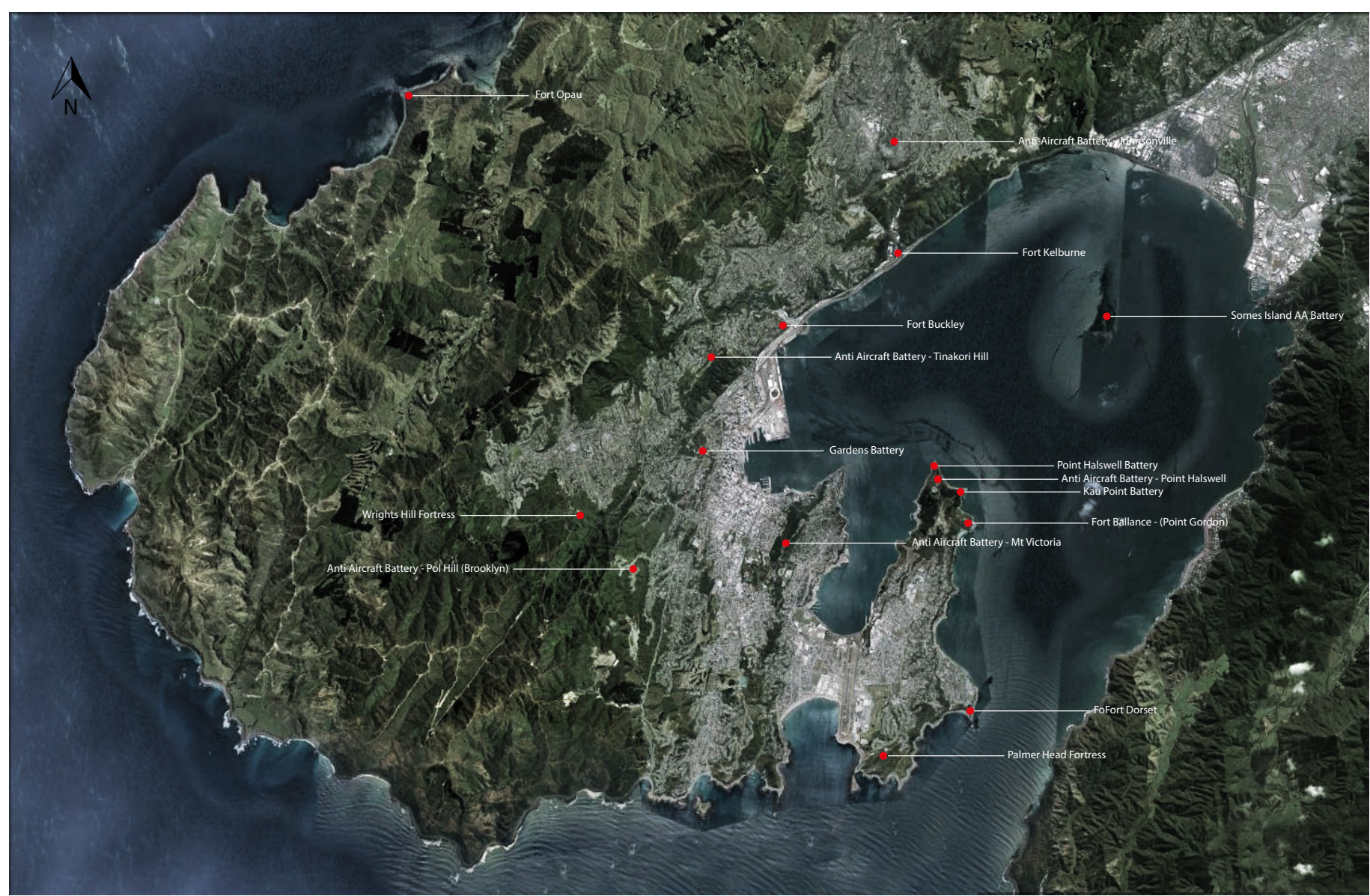




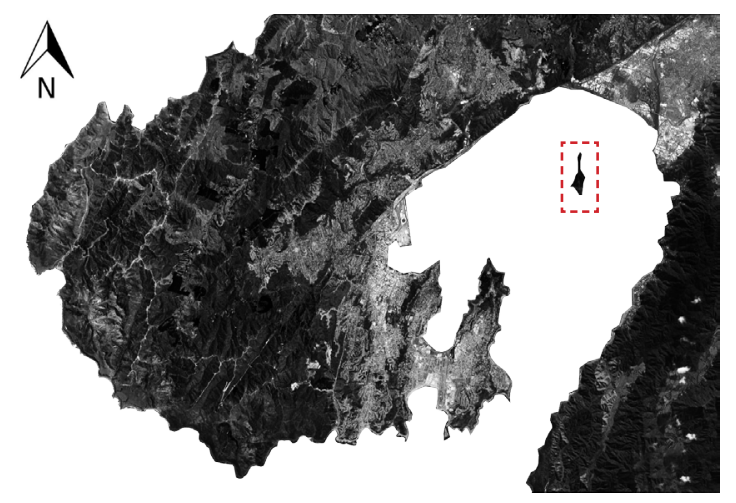

Fig 1.9 Location of Somes Island AA Battery.

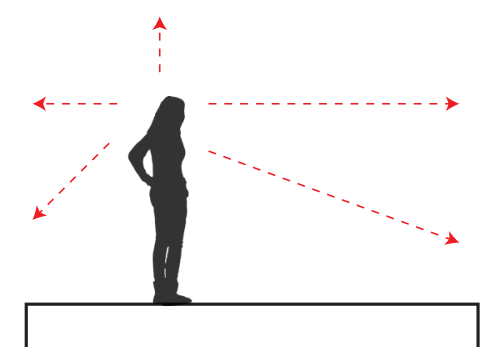

Fig 1.10 External experience of gun emplacement.

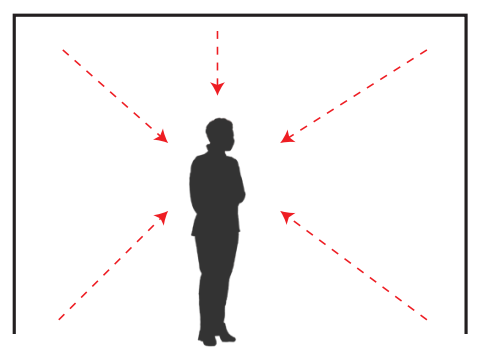

Fig 1.12 Internal space of gun emplacement.

\section{Experience of Shifting Space}

Although each structure differs, spatially there are two common experiences occurring. The external view from the gun emplacement position is highly expansive and maintain wide viewpoints from high ground. This vantage gives a sense of open exposure and defenselessness. The internal space of the gun emplacement structure gives the opposite, where a grounded sense of space is achieved, users are made to feel sheltered, safe and enclosed from the external world. The contrast between these is marked.

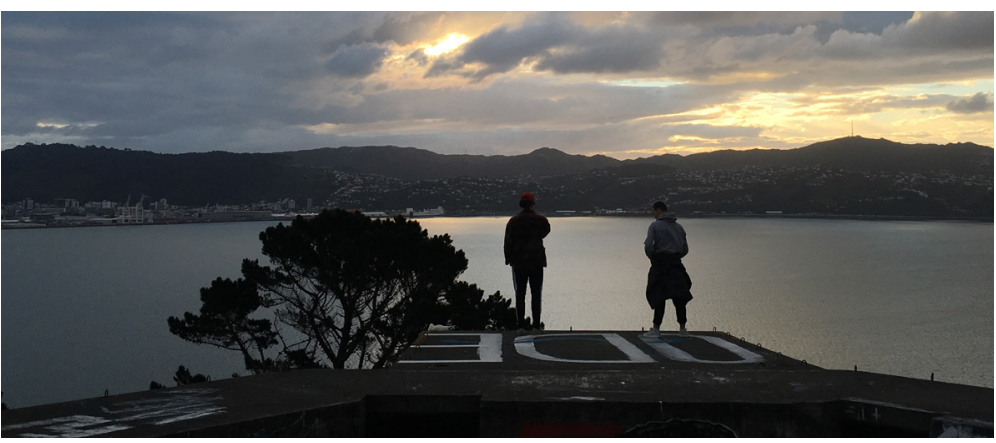

Fig 1.11 Photo of gun emplacement.

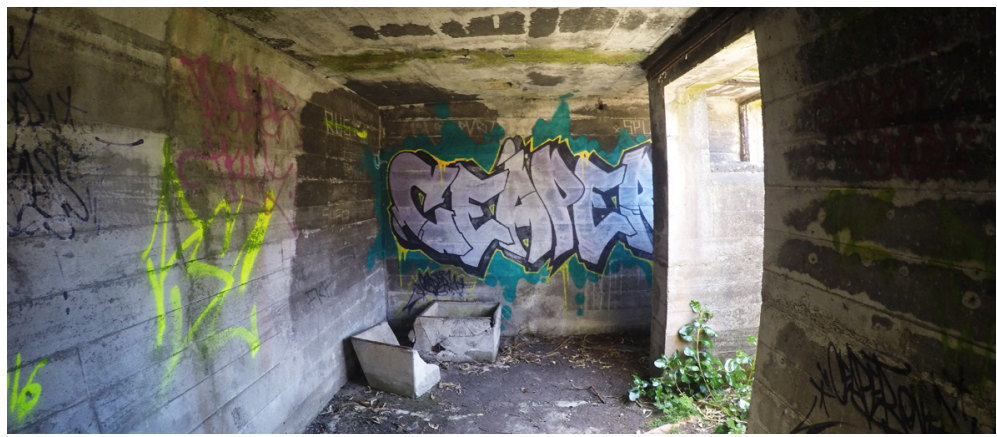

Fig 1.13 Inside of gun emplacement.

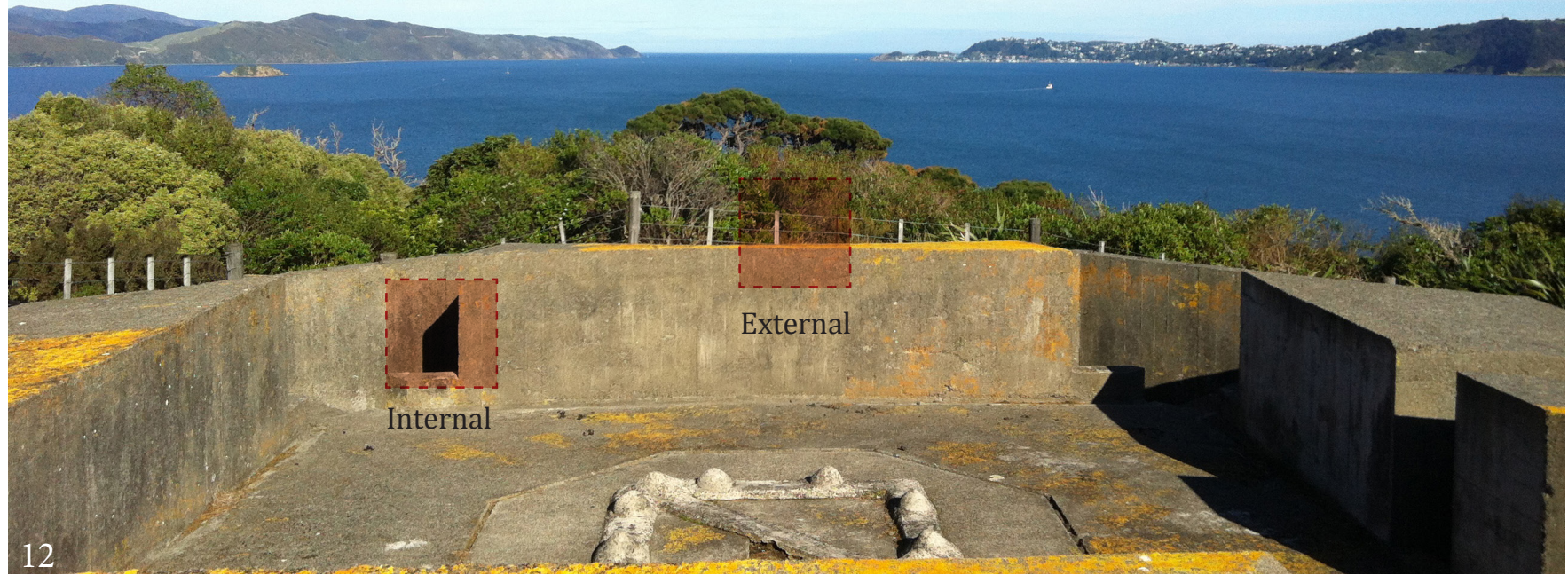




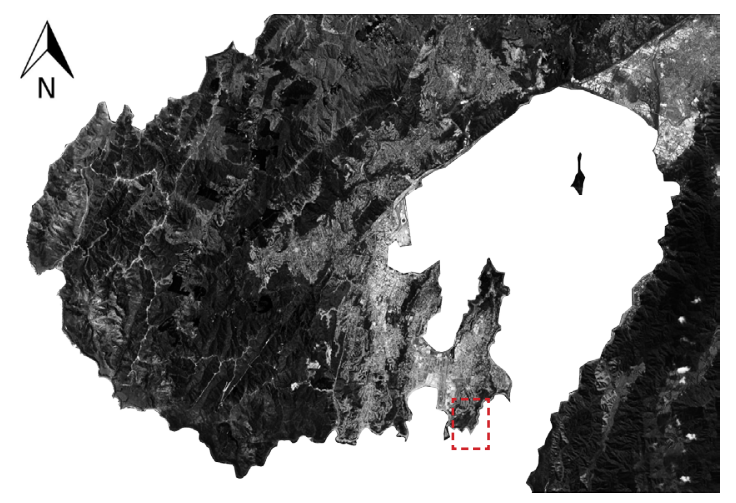

Fig 1.15 Location of Palmer Head Fortress.

\section{Strategic Visual Interaction}

The formation of the defense network and its military fortifications are located at key viewing points within the natural environment. These areas can be found on high ridge-lines of Peninsula usually at a point above a bay which has access to views over and down into the harbor. Looking out from inside of the gun emplacements the visual interaction is limited to a defined viewing strip, much like a portal frame. This portal changes in size and shape between defensive buildings at different locations.
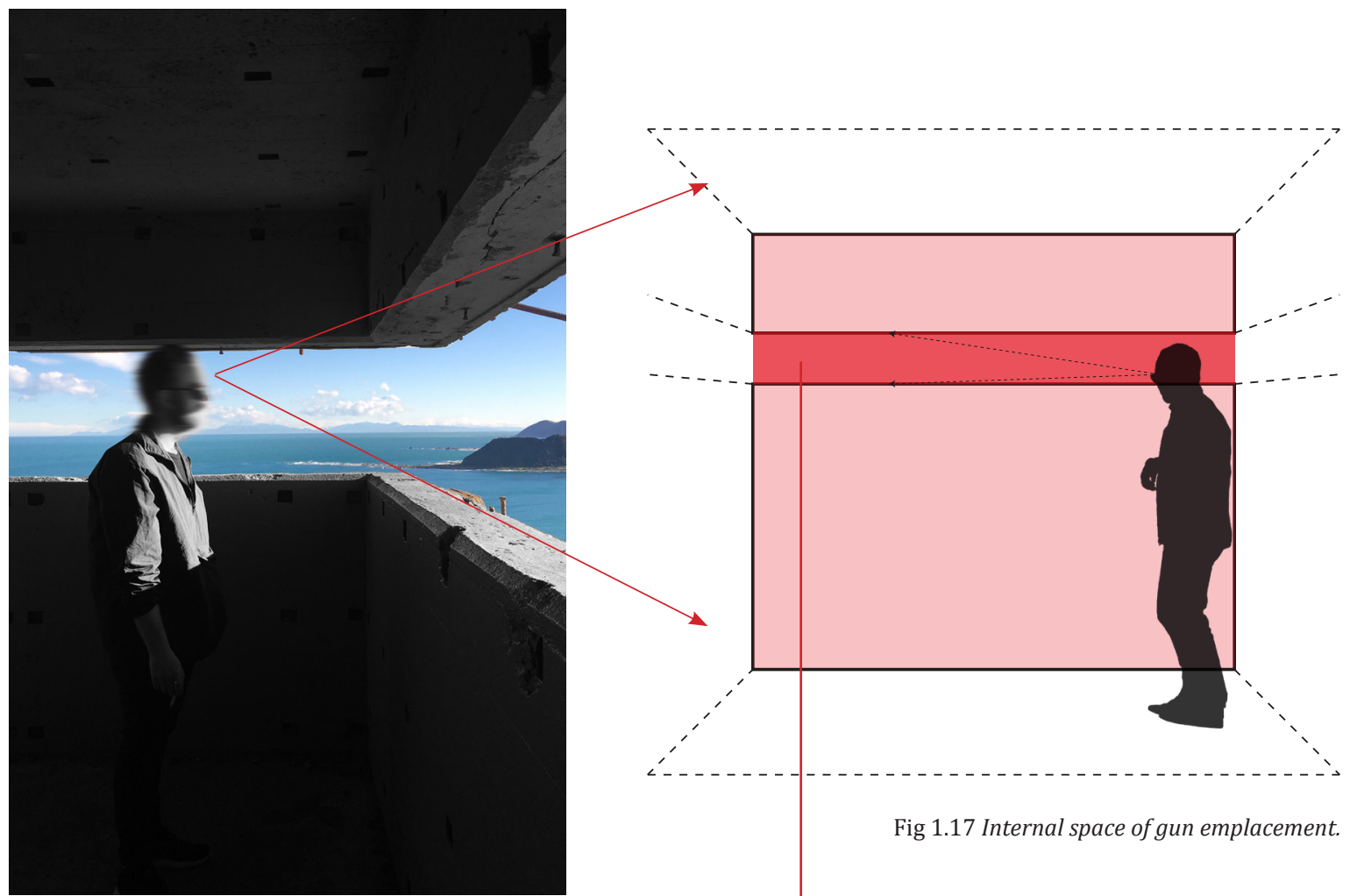

Fig 1.17 Internal space of gun emplacement.

Fig 1.16 Standing inside of gun emplacement.

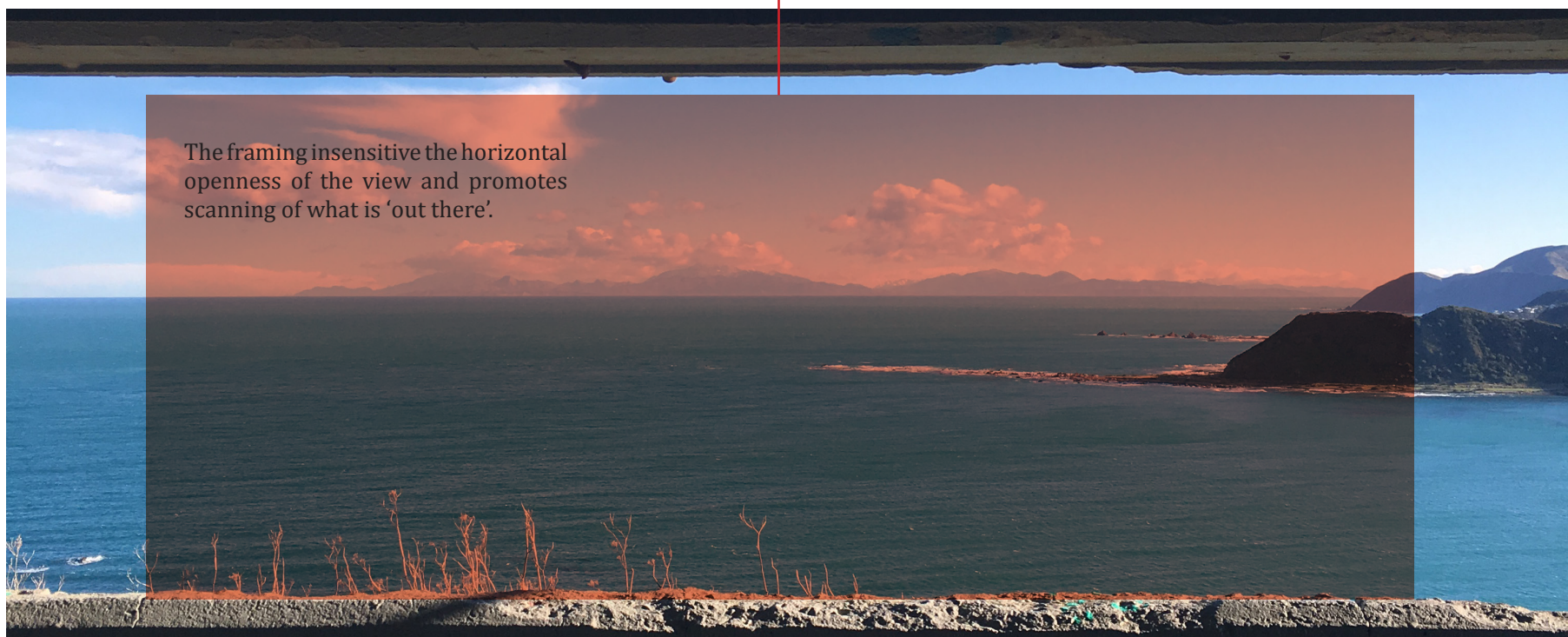




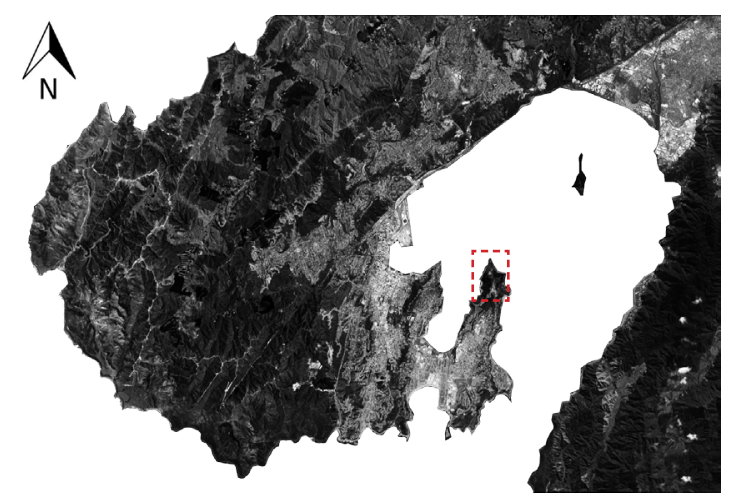

Fig 1.19 Location of Point Halswell.

\section{Landscape surround}

Designed as a coastal defense position, defense structures were purposely disguised and hidden. Areas are highly camouflaged by earthworks, trees and vegetation. The heritage value of these spaces do not just involve the built form of manmade structures but also the environment that surround them. Landscape is an integral part of defense networks and was purposely formed and manipulated to house these military operations.

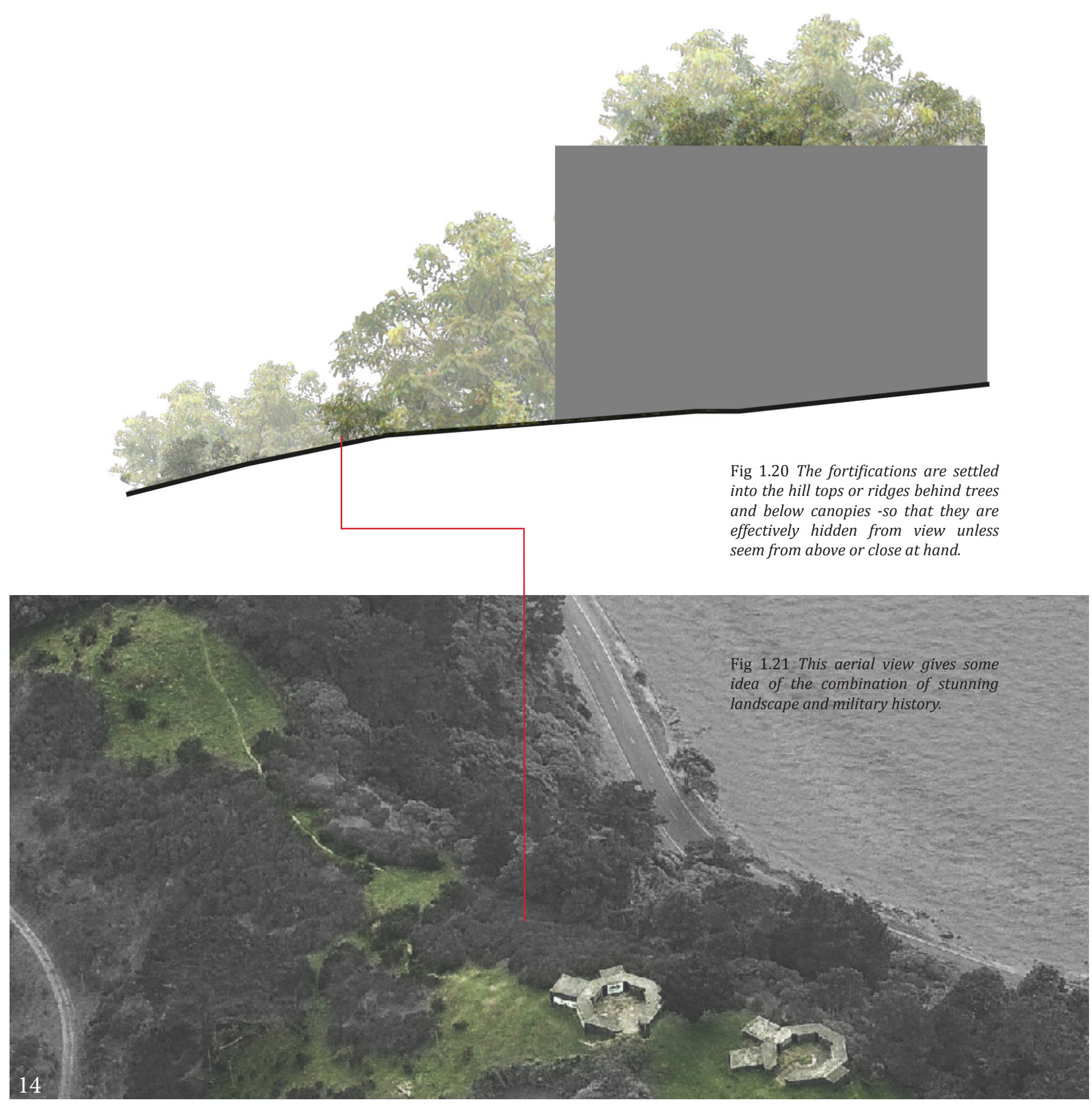




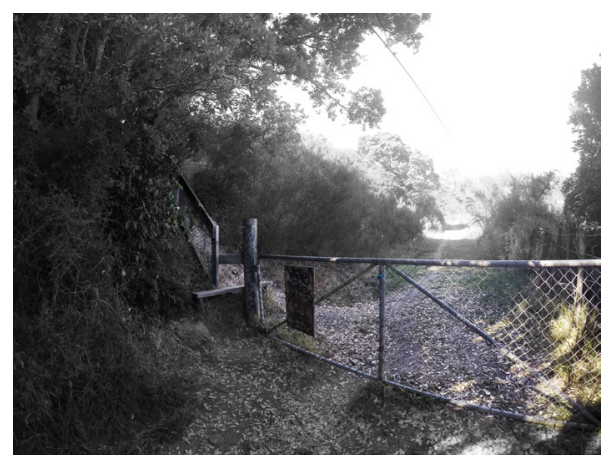

Fig 1.22 Fences across the site.

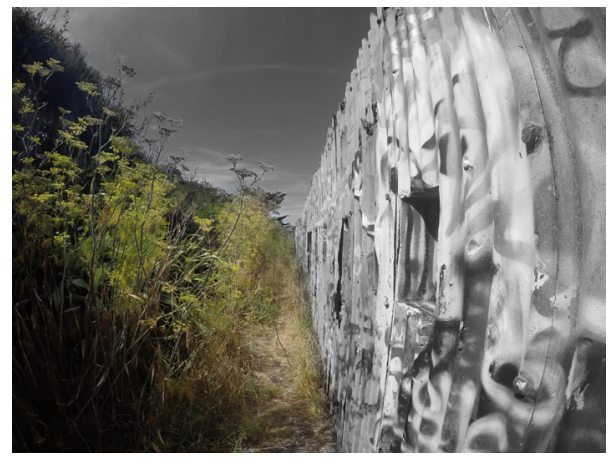

Fig 1.23 Overgrown Vegetation.

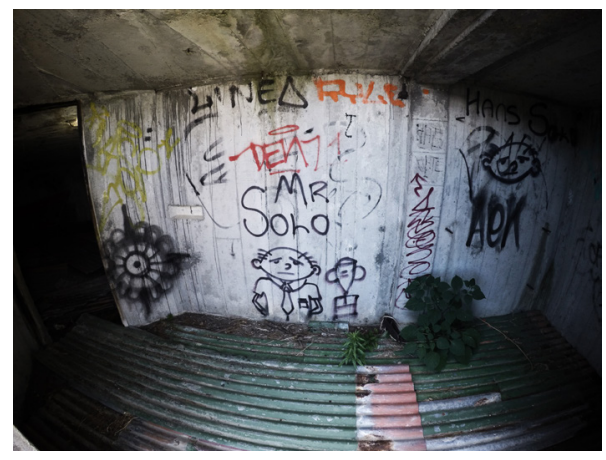

Fig 1.24 Internal space of Gun emplacement.

\subsection{Overall Problem}

The coastal defenses were built to strengthen the major ports of New Zealand against naval attacks in the Pacific. Today, the coastal defense structures have deteriorated, are vandalized with graffiti, and overgrown by vegetation. These sites have lost their defense network role and have little public engagement profile, appear uncared for and undervalued. For most people that visit these sites they are un-aware of this important history.

\subsection{Positioning}

In order to bring the story of coastal defense network back to life, this research investigation suggests a new way of engaging with such sites. Positioning will be discussed in more detail in the literature review, case studies and throughout the thesis. The literature addresses the term assemblage involved in the protection of heritage, and why defense networks functioned as they did. This understanding of factors can then help to drive the focus on landscape experiences where a strategy can be developed that maximises the richness of experiencing the site.

\subsection{Research Question}

How to bring new life to abandoned coastal defense sites? 


\subsection{Research Intention}

This research aims to bring a network of abandoned coastal defense structures back to life by exploring a new method of assessing experience of landscape with a practical design response. Some of the main investigation objectives explored are:

- Understanding the past function and life of the coastal defense network.

- Identifying existing and potential experience of the site and the various thing that combine to produce this.

- Examing past attention at the research question though case studies.

- Understanding the contextual influences and developing a strategy for a viable design.

- Investigating the development of movement opportunities and area in certain path of the site as suggestion for how the whole site might be approached.

\subsection{Thesis Structure}

This thesis is structured to start with an initial introduction into my own personal hunch on military fortifications where overall problems are outlined demonstrating why the defense network was abandoned. An overall study of the entire site, Miramar Peninsula, exploring the backstory and context from a fieldwork perspective in order to understand how coastal defense networks operated spatially. Each site specifying their own issues and apparent problems. Next, a review of relevant literature and best practice heritage studies, identifying how other designers have engaged dealing with similar circumstances in relation to the proposed research questions. Field studies are then detailed and presented in different scales to explore the richness of macro and micro analysis. The design investigation then focuses on exploring the new methods to bring defense network to life in relation to the research aims and objectives. 

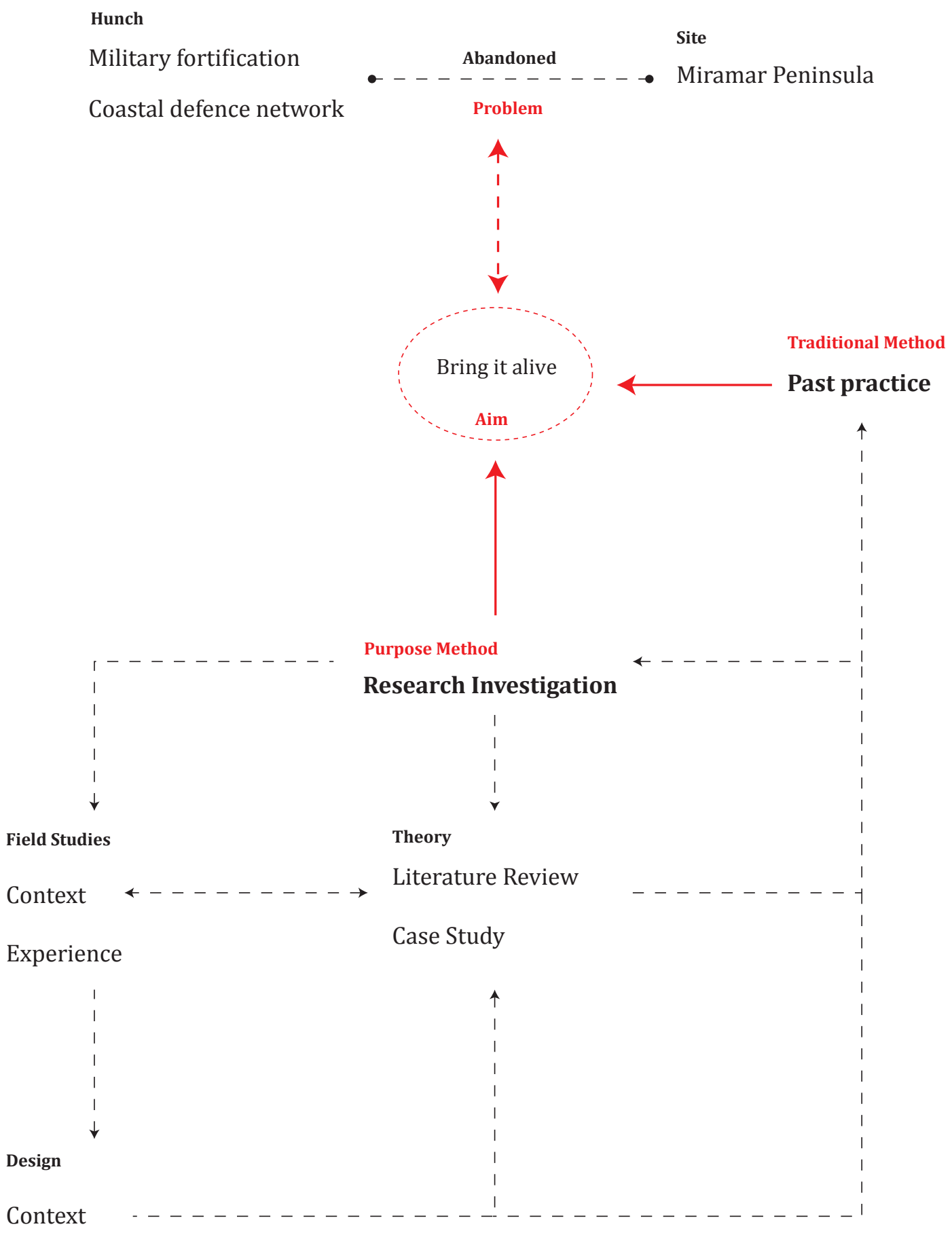

Site Experience 


\section{SITE}

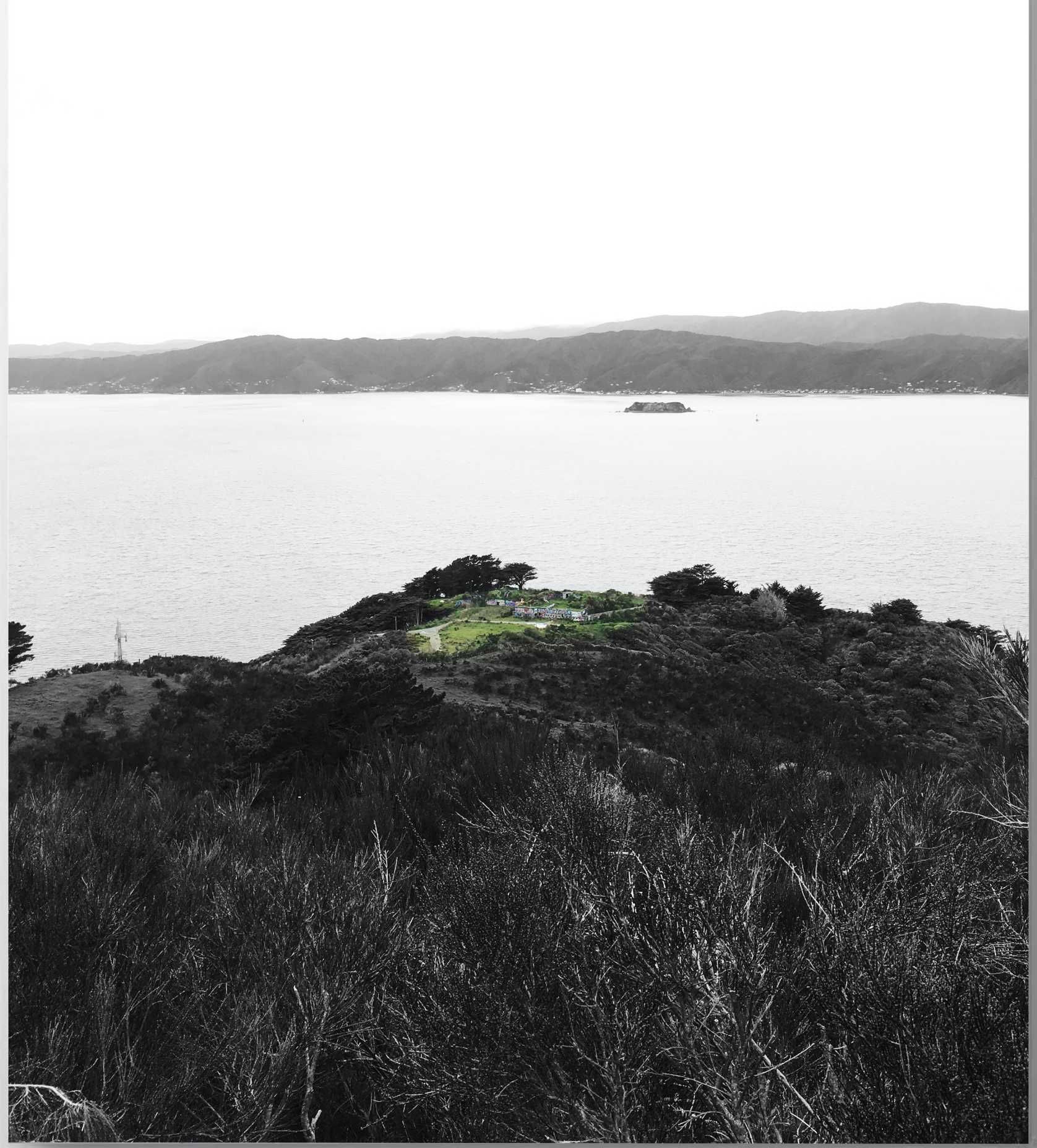




\section{Introduction}

This chapter introduces the historical, physical and social background that has shaped the site. It reveals some of the potentials for bringing the coastal defence network back to life. The research firstly investigates Miramar Peninsula from a macro scale in order to understand its contextual relationships within Wellington Harbour. Following that is a closer study focused on the site specific factors and problems.

\subsection{Peninsula}

After initial site visits and research investigations, Watts Peninsula was selected as the preferred site for the following reasons:

- It fits the profile of a large 'derelict landscape' with its abandoned fortifications.

- It has many characteristics similar to the Wellington town belt, and has been earmarked to become part of a bigger ecological connection. (Fig. 2.3)

- It is situated close to Wellington city, with a variety of transport options.

- It is highly visible to a number of Wellington suburbs.

- It is a place of national significance with a number of historical sites, both Pakeha military and Maori Pa sites.

- It offers an abundance of unique experiences across the site with many different spaces that are interconnected. 
$A_{N}$
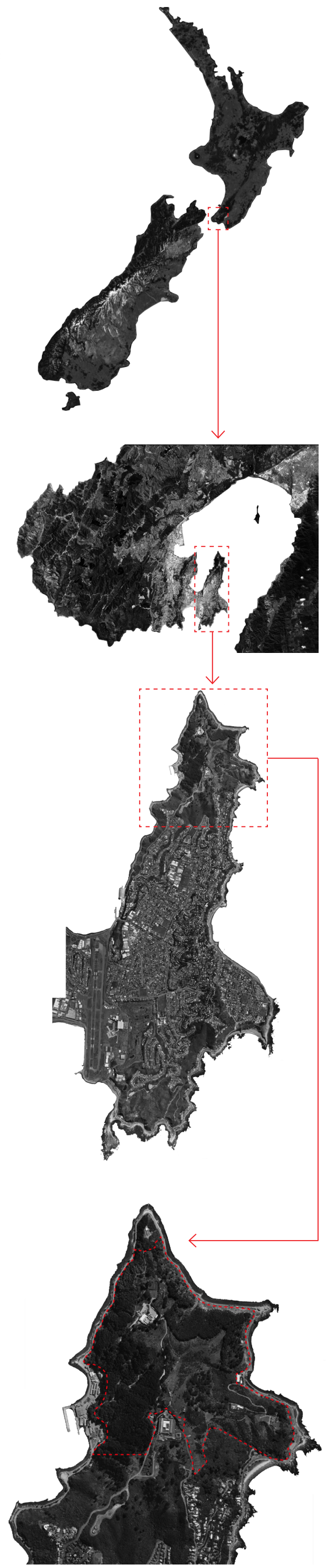

New Zealand

Wellington

Miramar Peninsula

Watts Peninsula is a 76

hectare piece of land on top of the Miramar Peninsula, Wellington.

Watts Peninsula 


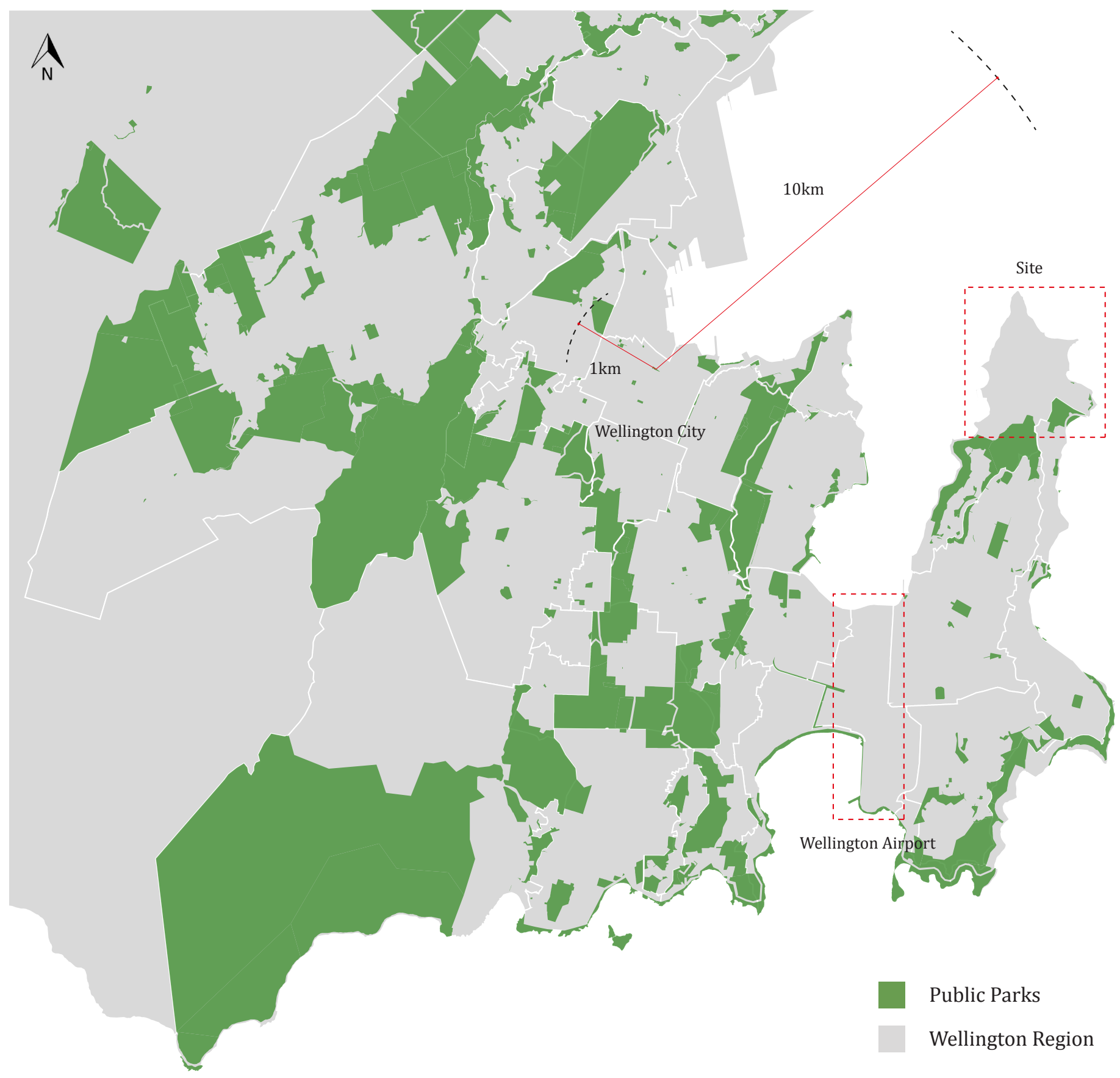

Fig. 2.3 The site has significant physical, cultural, visual, historical, recreational and ecological connections to many parts of Wellington City, the wider Miramar peninsula and neighbouring suburbs.

Above It currently tends not to be regarded as part of the park system of Wellington. If include, it would be the largest addition to the east of city.
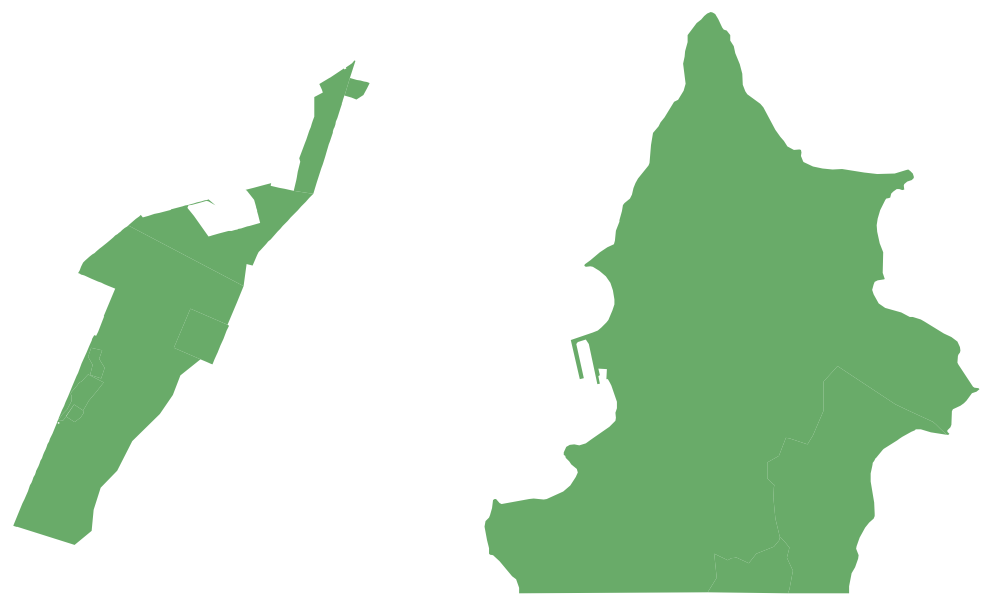
Urban Fabric

seprated from the site
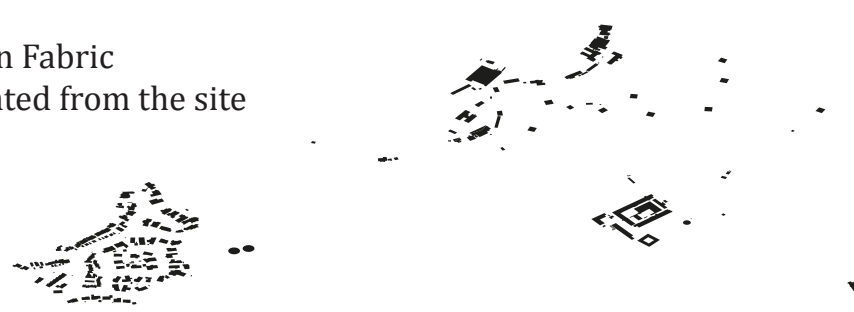

这.

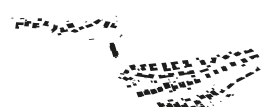

.

an

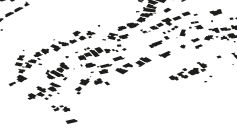

Non-public tracks

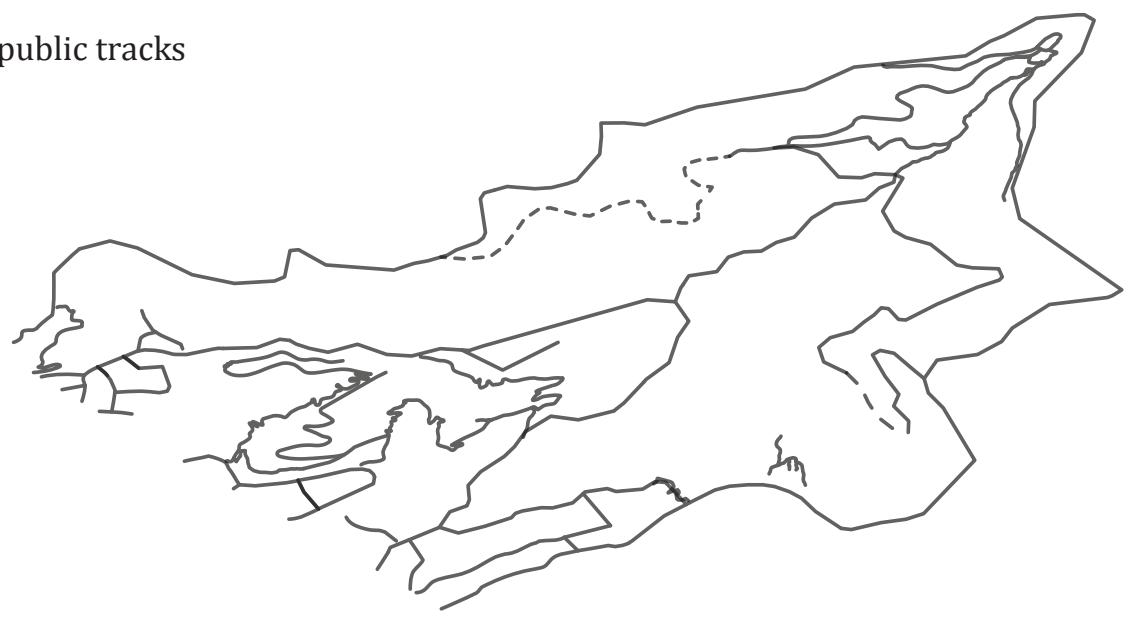

Military sites located at strategic high points

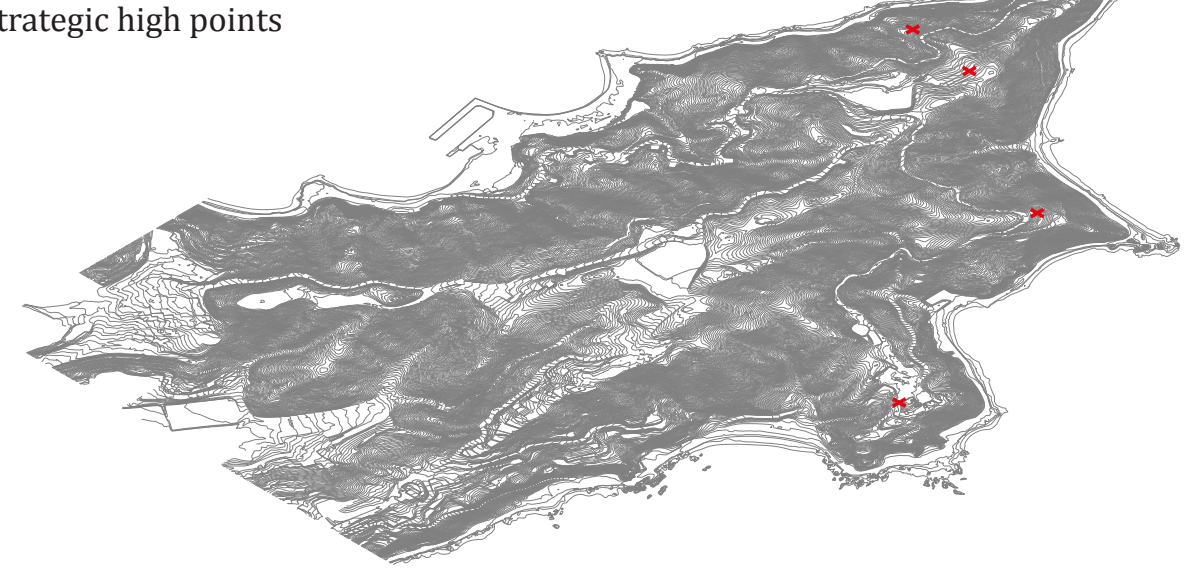

Vegetation site coverage, mainly on steep slopes

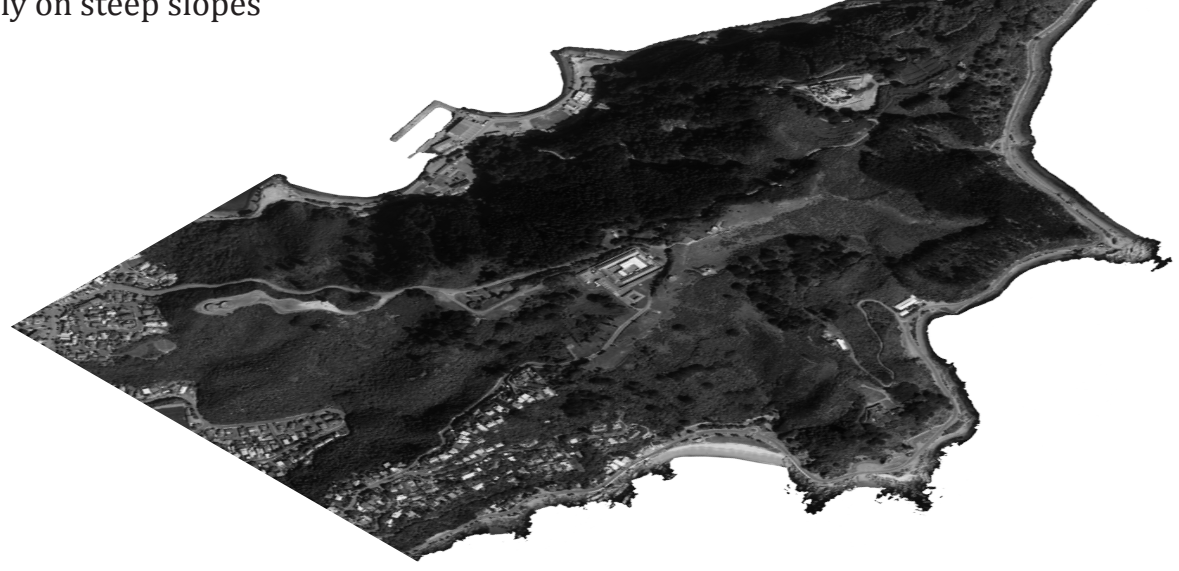




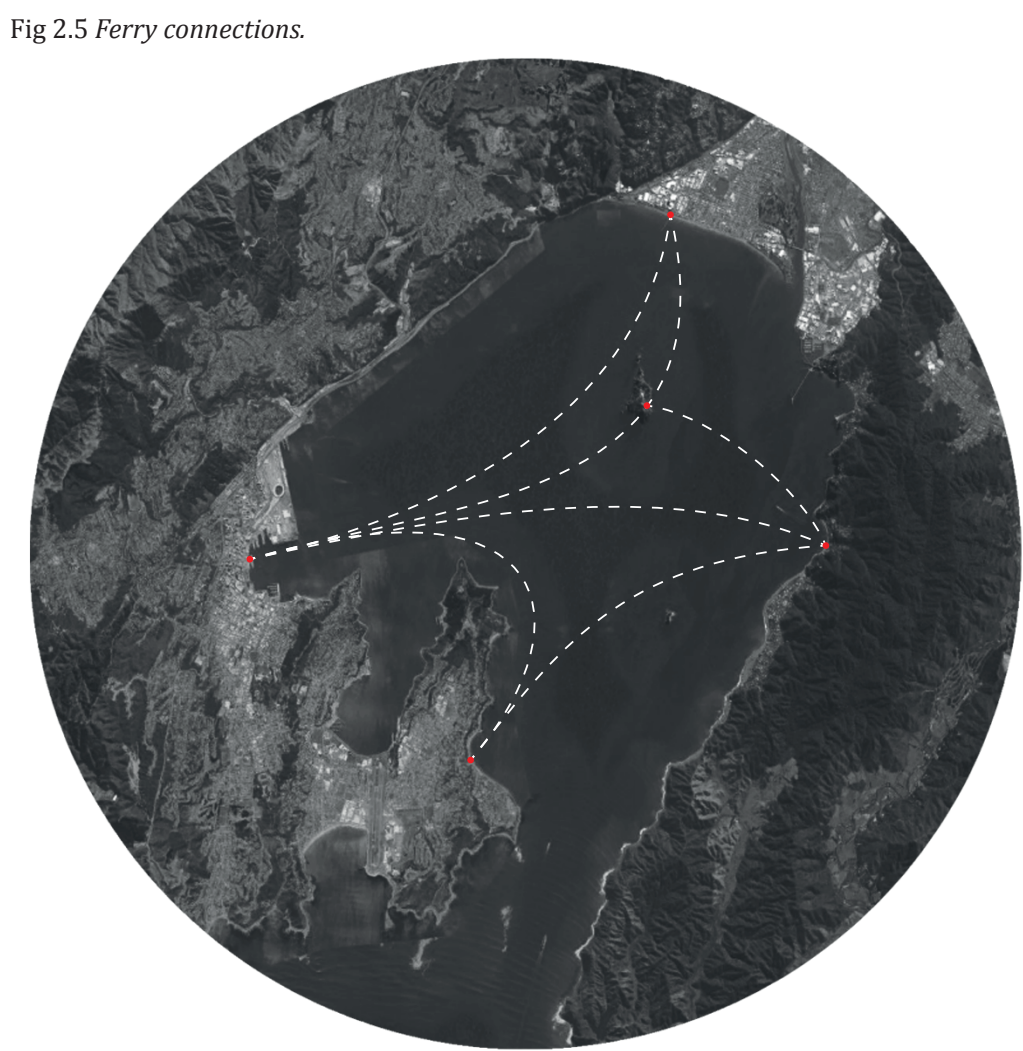

Ferry

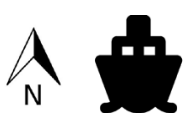

\subsection{City Engagement - Infrastructure}

The population of Miramar Peninsula (include: Miramar, Maupuia, Seatoun, Karaka Bays, Breaker Bay and Strathmore Park) in 2013 was recorded at 19,569 (Idnz, 2013). Currently, Peninsula residents have transport options that are available in and out of the suburb every day. The transport diagrams demonstrate a strong relationship between the site and its surroundings, and show how the existing infrastructure has the capability for a larger number of people visiting site.

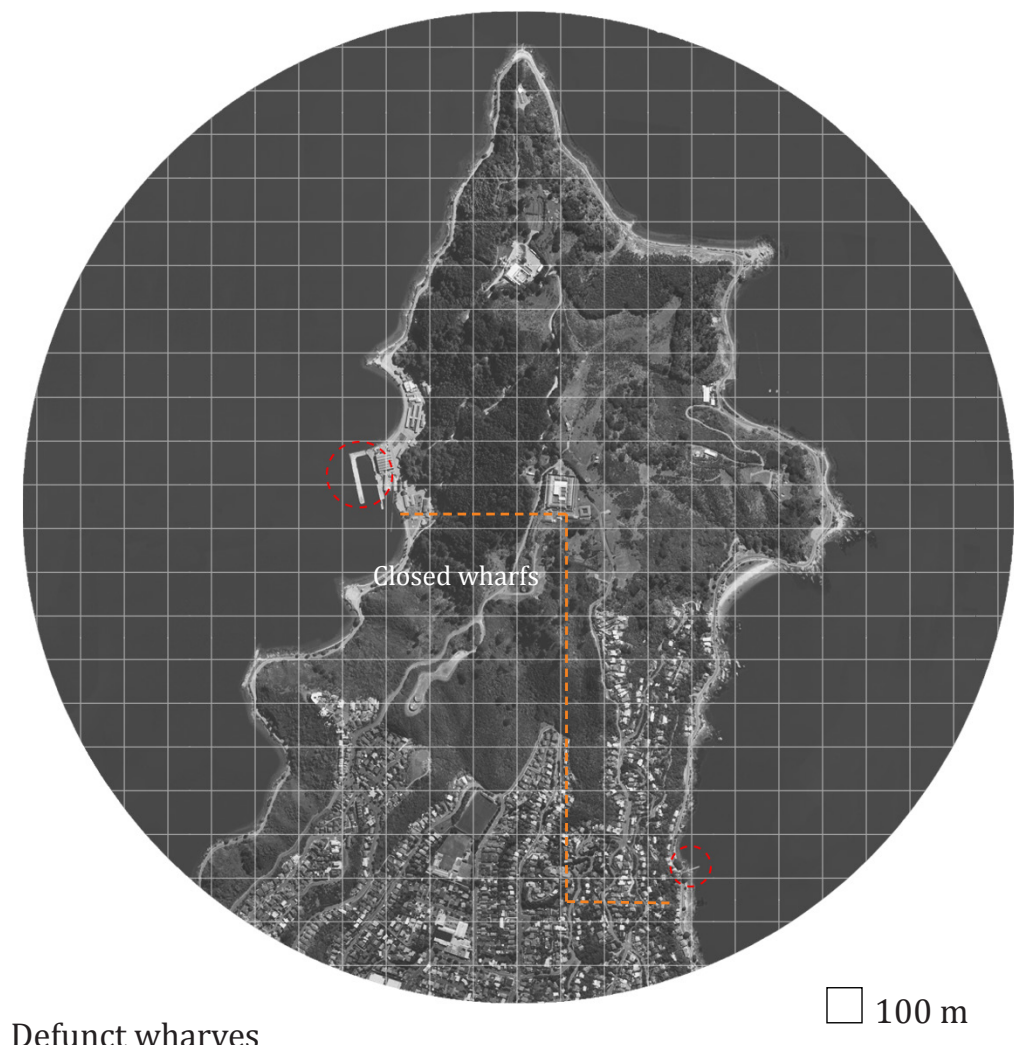

Defunct wharves 
Fig 2.6 Bus connections.

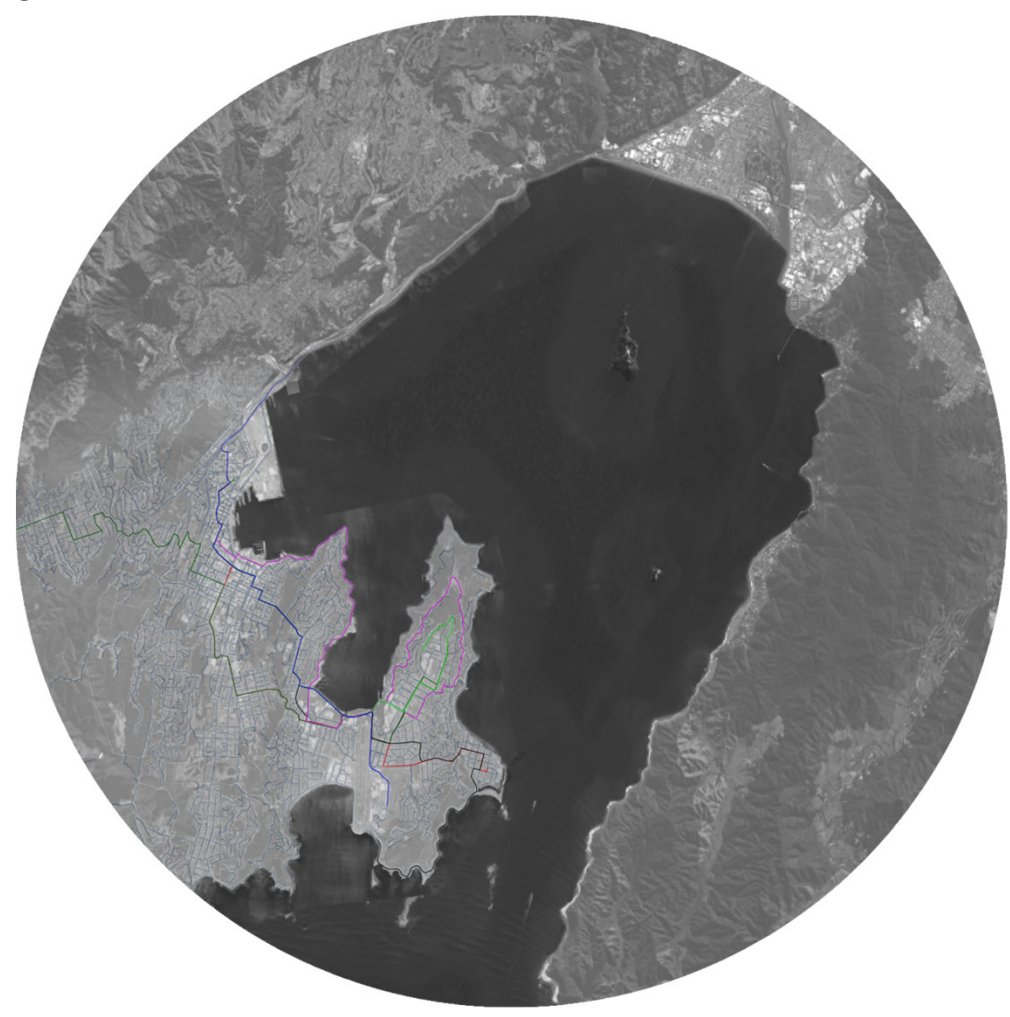

Bus

Bus Numbers
$2,11,18,24,30,31,91$

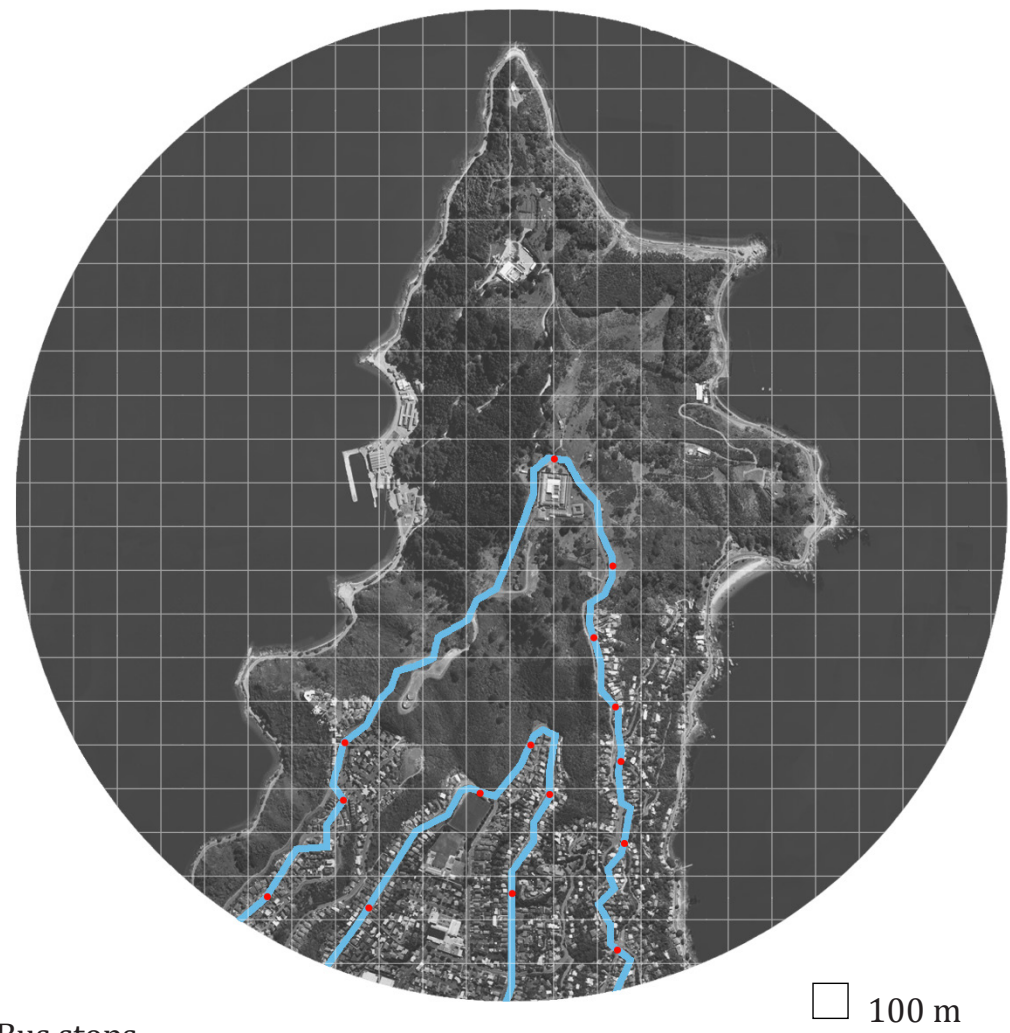

Bus stops 


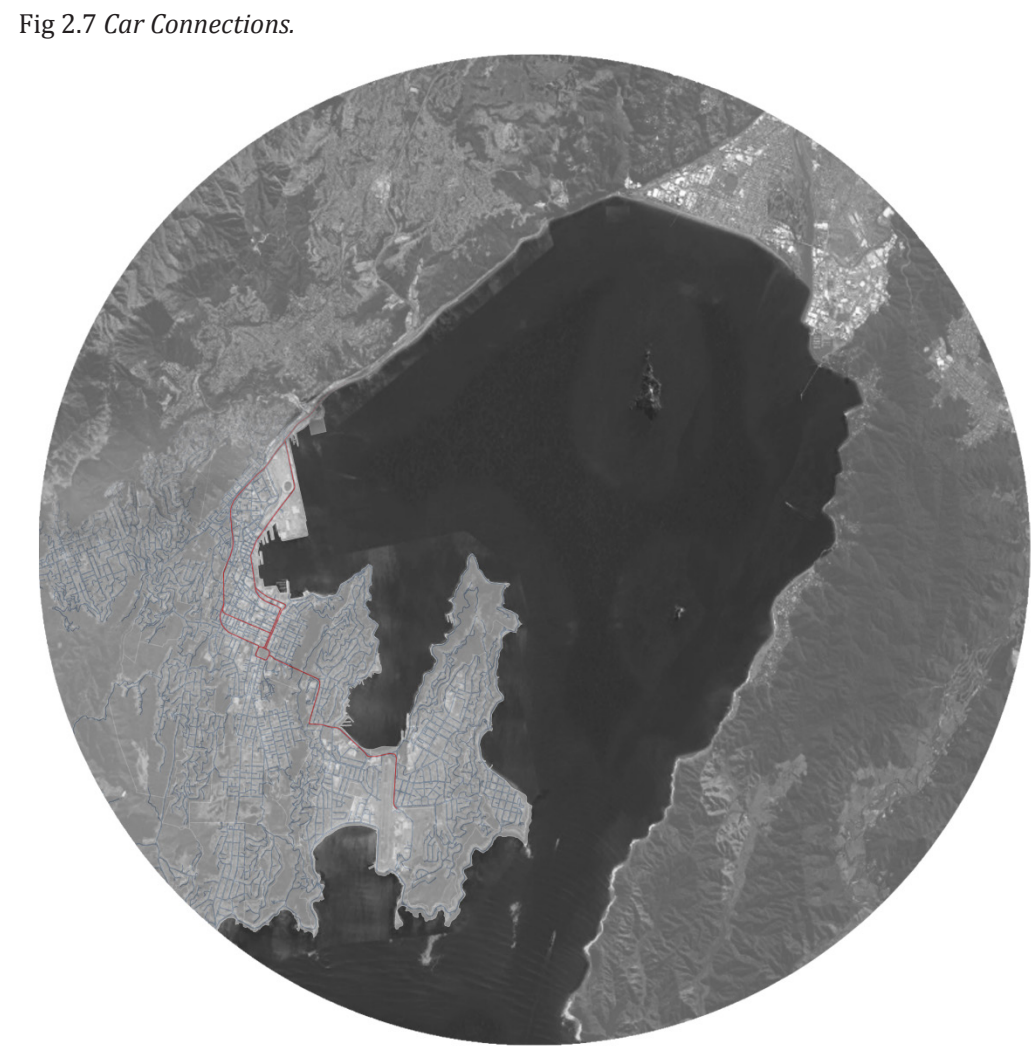

Car

$A$

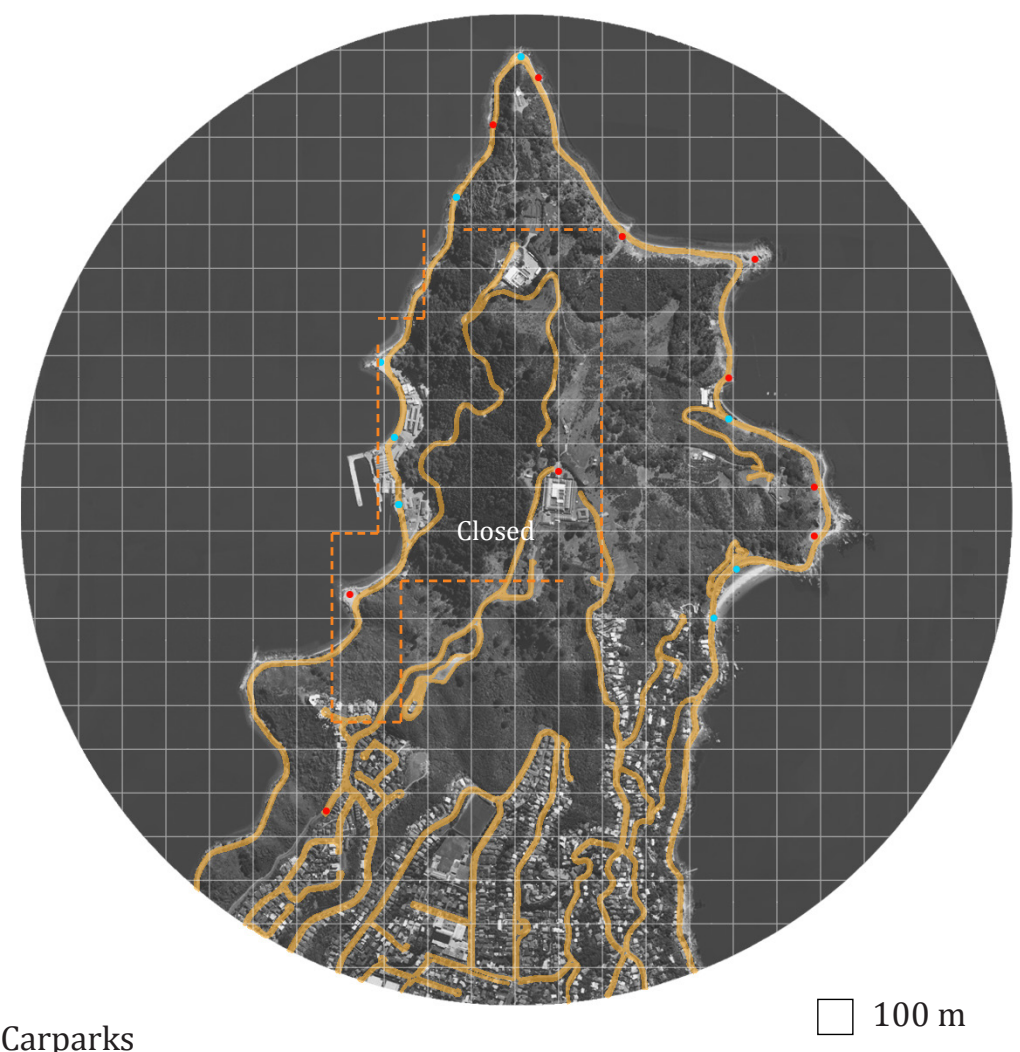


Fig 2.8 Cycling connections.

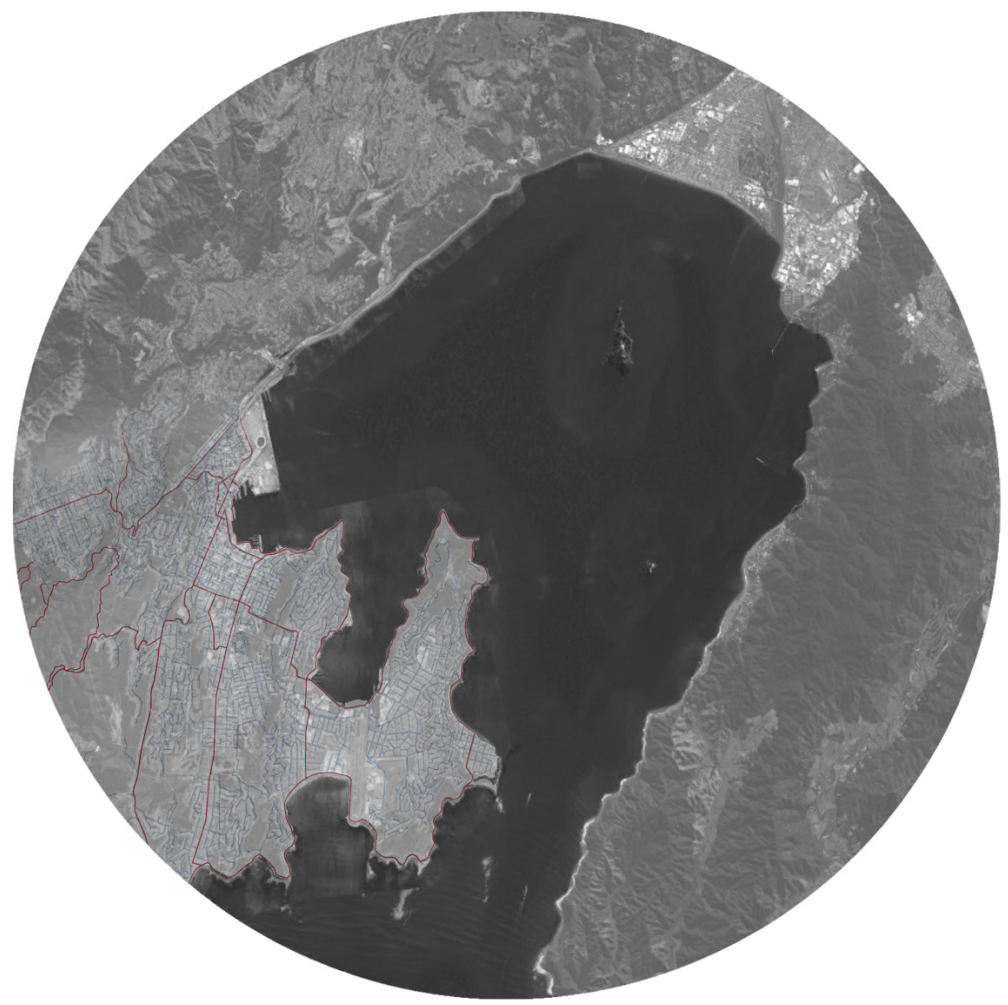

Bike

A

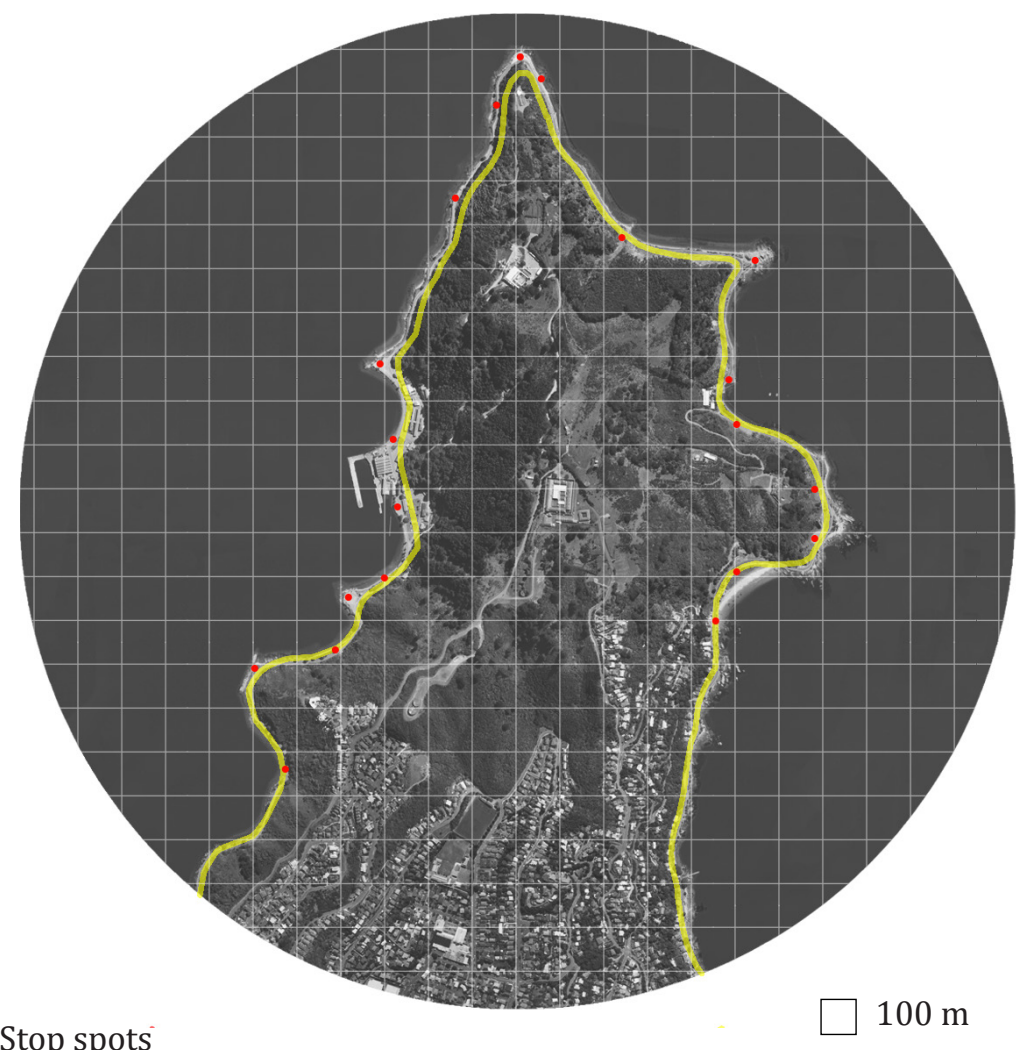

Stop spots 


\subsection{City Engagement - View}

The site is highly visible and can be seen from a number of suburbs in the wider context. Visual connection is key to the site. It is one of the only headlands left in the Wellington harbour that has been left relatively untouched by development. The site in the past had tremendous value as a vantage point for the military positioned at the entry point into the harbour.

Right Fig 2.10 The site creates special visual connections with other Wellington suburbs.

1. Evans Bay 2. Roseneath 3. Wellington Harbour

4. Thorndon 5. Wadestown 6. Khandallah

7. Newlands 8. Horokiwi 9. Petone

10. Somes Island 11. Seaview 12. York Bay

13. Days Bay 14. Eastbourne 15. Muritai

16. Scorching Bay

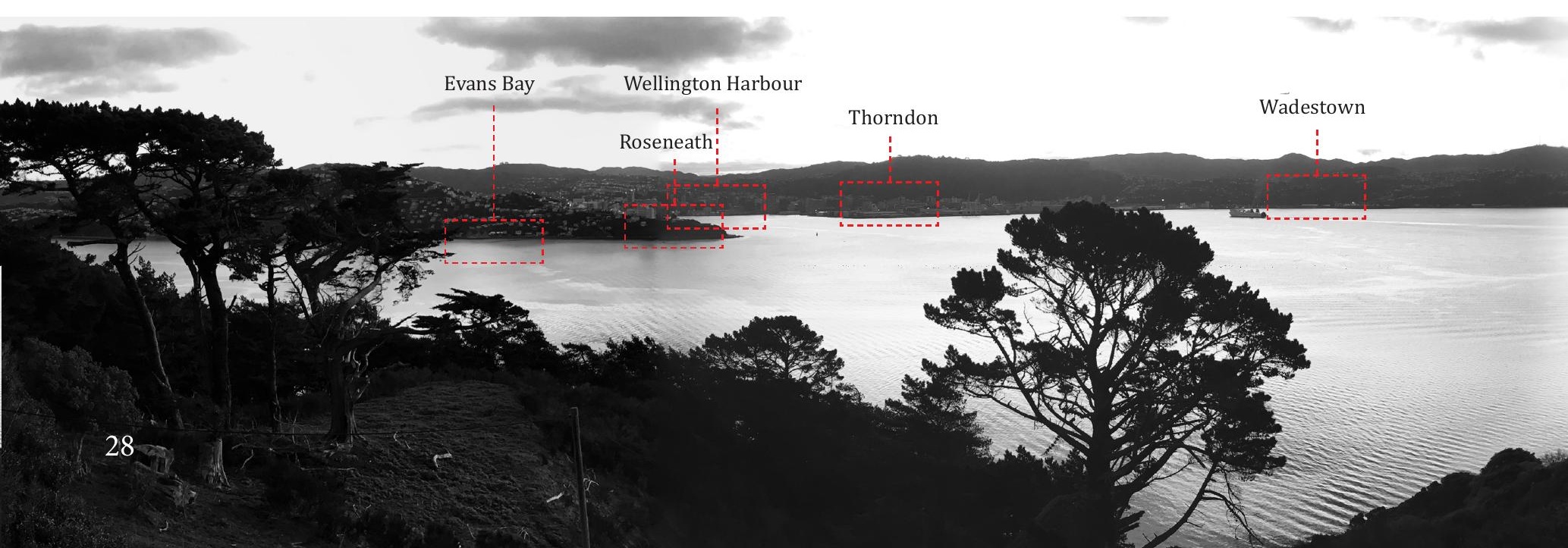




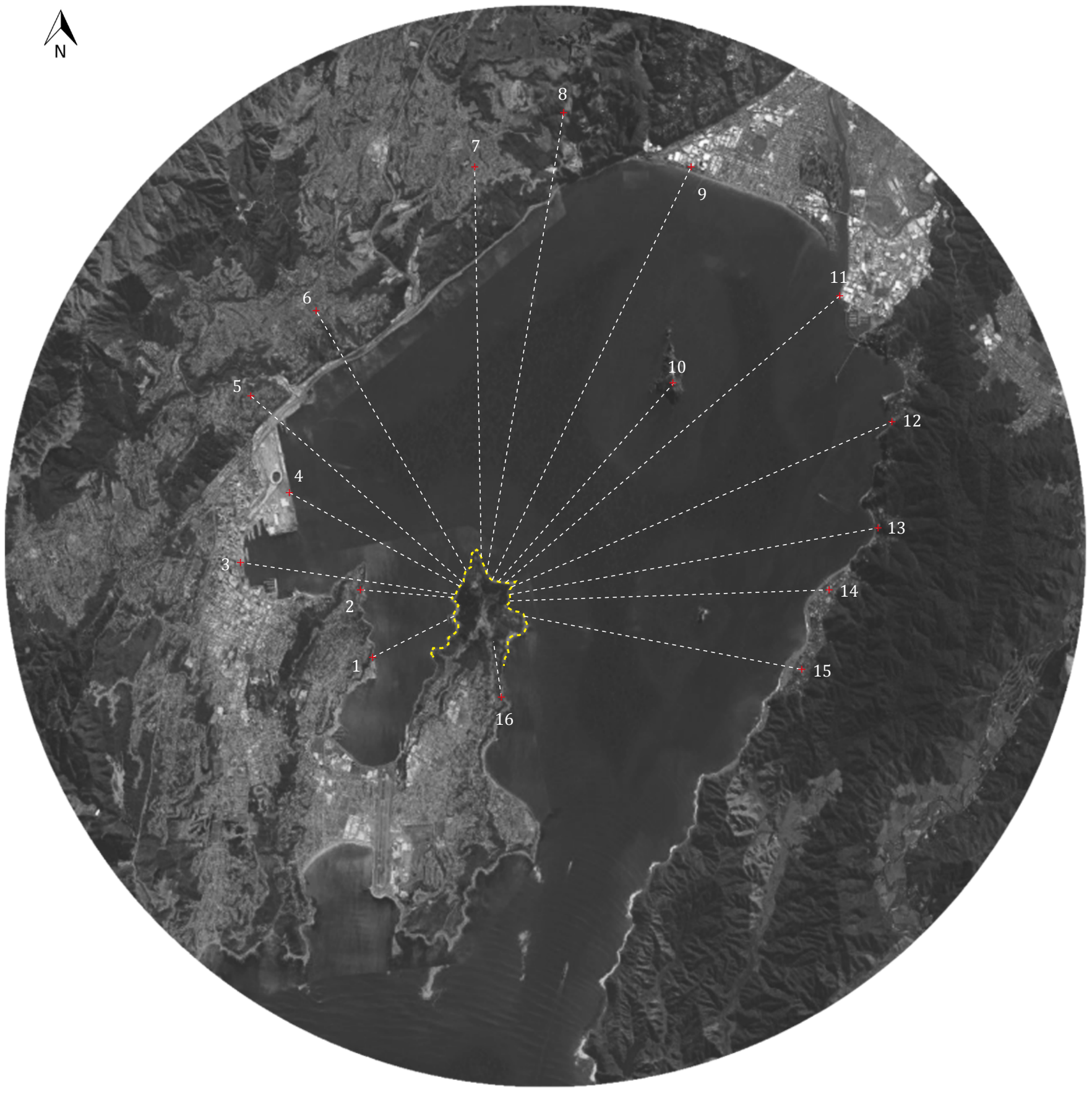




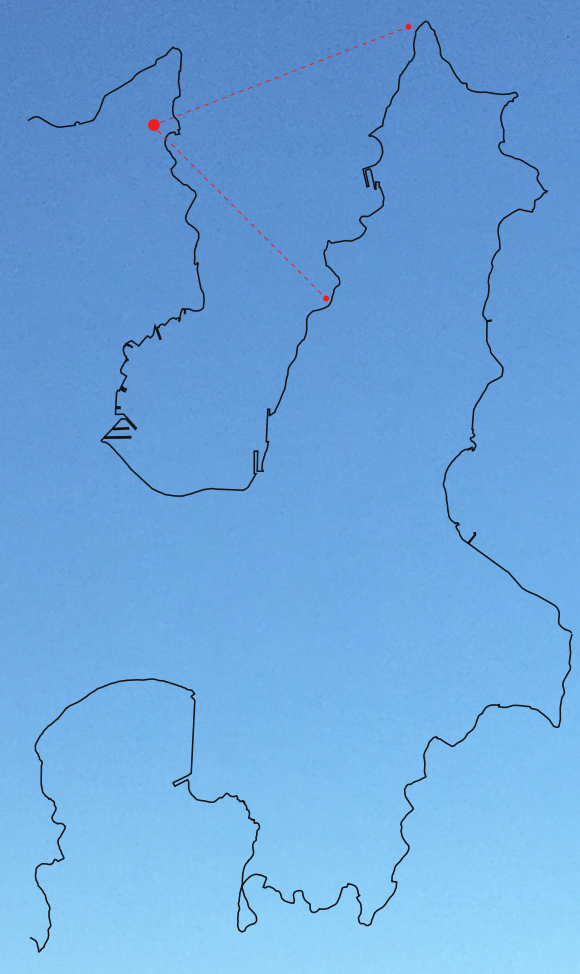

The landscape is highly visible in it's wider context.

Below Fig 2.11 Top of Miramar

Peninsula (Watts Peninsula) can

be viewed from Roseneath

Somes Island

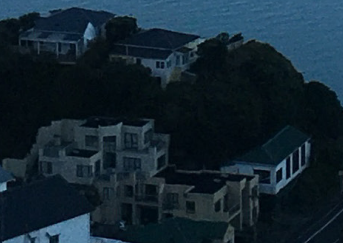

Somes Island

(II)
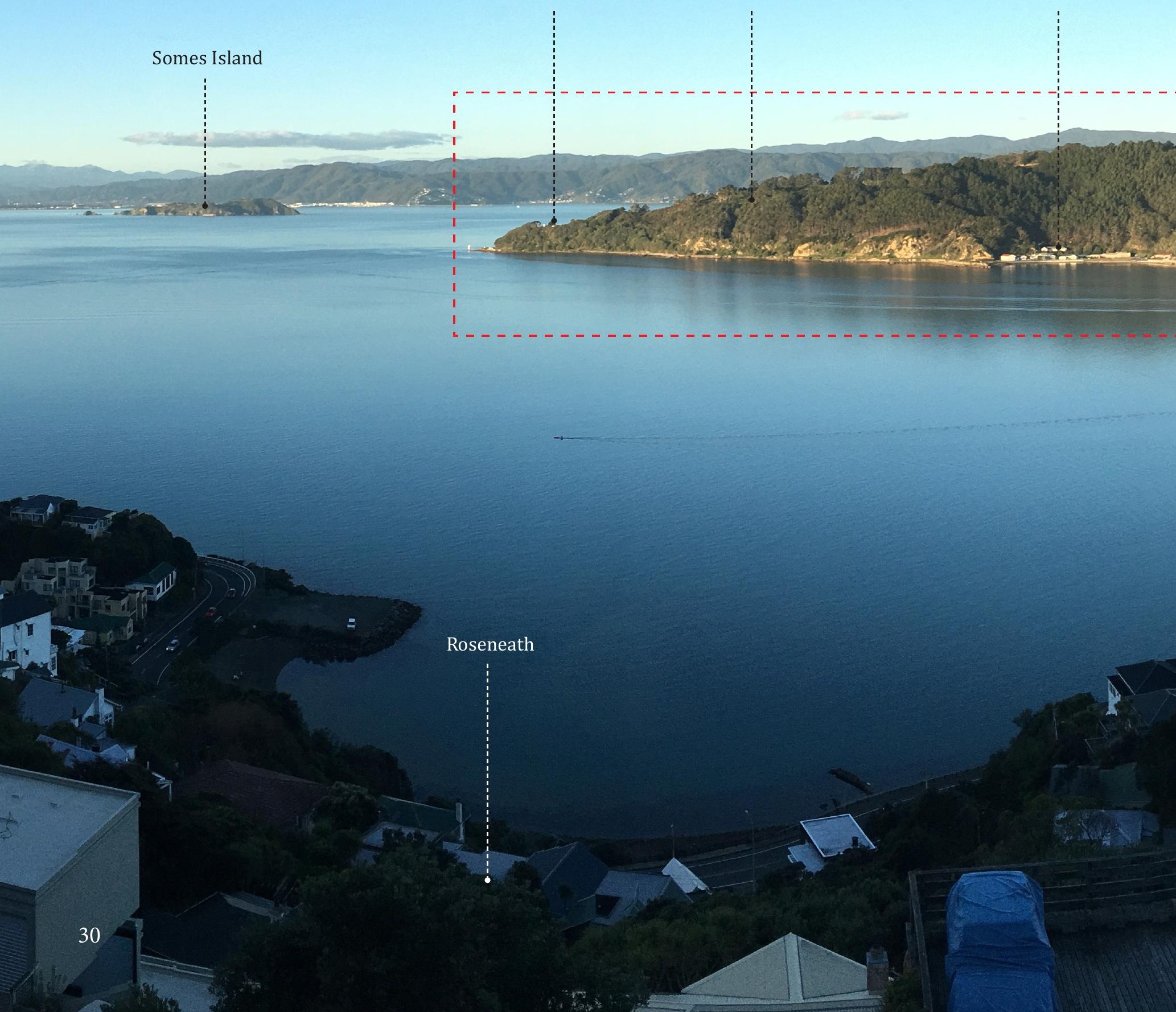
Maupuia Residential Zone

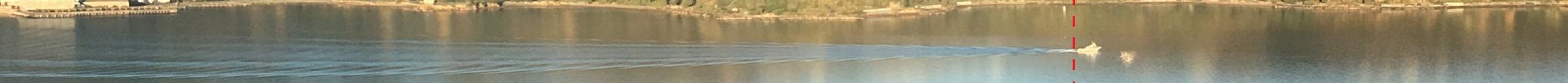

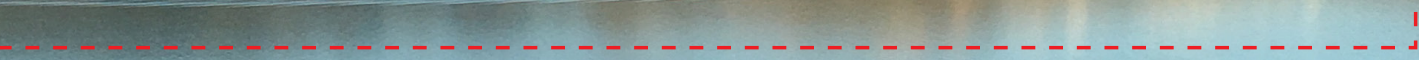

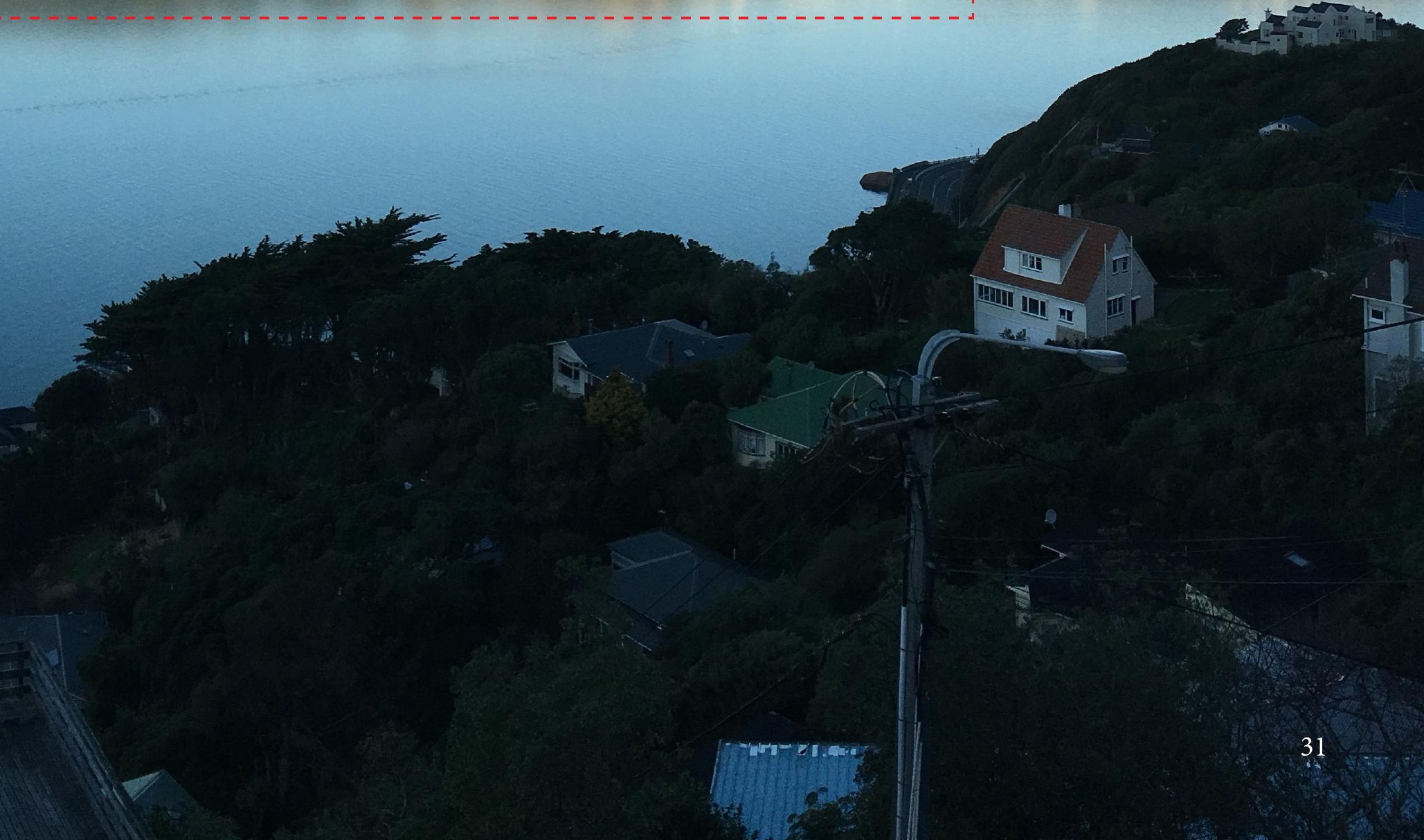




\section{MOTU KAIRANGI pre 1460}

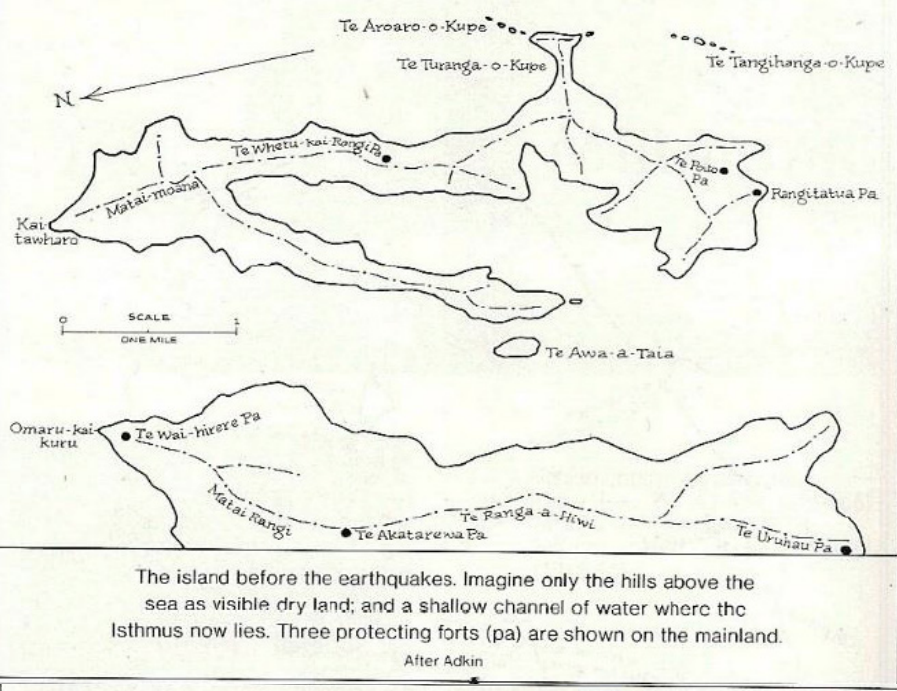

WHATAITAI PENINSULA post 1855

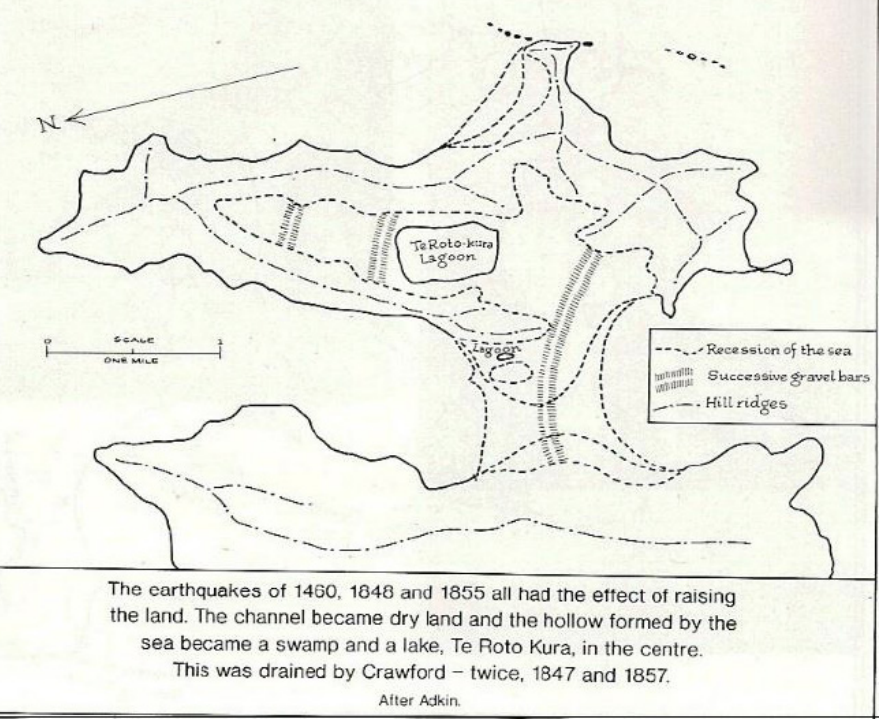

Figure 2.12 Before and after the earthquake of Miramar Peninsula (Blaschke \& Rutherford Environmental Consultants, PAOS Limited, \& TRC Tourism Limited, 2012, p.23).

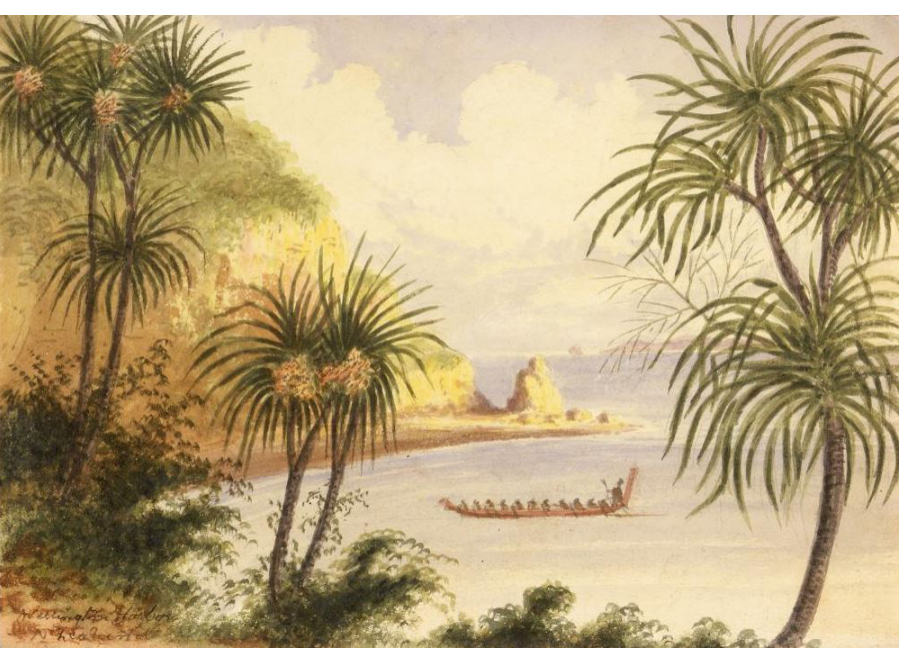

Figue 2.13 The drawing is showing from the lower slope of Mt Crawford looking towards Evans Bay (Blaschke \& Rutherford Environmental Consultants, PAOS Limited, \& TRC Tourism Limited, 2012, p.19).

\subsection{Historic Overview}

Peninsula

Miramar Peninsula has rich and complex history. It is a place of national significance because the land contains sites from different periods in New Zealand history. The Peninsula as a whole was largely an island habitat until the Haowhenua earthquake of 1460 and the later 1855 earthquake permanently formed the peninsula (Fig 2.9).

\section{Maori History}

The site was first discovered and explored by the Polynesian navigator Kupe in 12th Century and his descendants settled on the island. A number of Maori Pa were situated high on the Miramar Peninsula ridges (Fig 2.13), Maori occupied the landscape for hundreds of years, today their key sites lay disturbed and disconnected. It is important to ensure that the Maori history on the site is recognised and there is an opportunity here to collaborate with local iwi stakeholders to revitalise these cultural sites.

\section{European History}

European settlers began arriving in Wellington in the early 1840s, including Scotsman James Coutts Crawford who cleared much of the indigenous vegetation and transformed the Peninsula into farmland by 1890. In 1885 the northern end of the Miramar Peninsula was sold by Coutts Crawford for military defence installations, a settlement of $£ 6000$ being awarded to him in 1886.

\section{Military History}

In late 19th Century, the coastal defence network was constructed to protect Wellington harbour from naval attacks. A number of emergency emplacements were quickly built at Point Halswell, Point Gordon and Kau-whakaara-waru. Most of these batteries survived through World War One, some being added along the way. They were all deactivated by 1925 . Meanwhile, new forts had been, and were being built. In 1910 Fort Dorset was created. In 1933 work began on Palmer Head. After the war, the coastal defence was no longer of use, and Watts Peninsular became largely abandoned. 


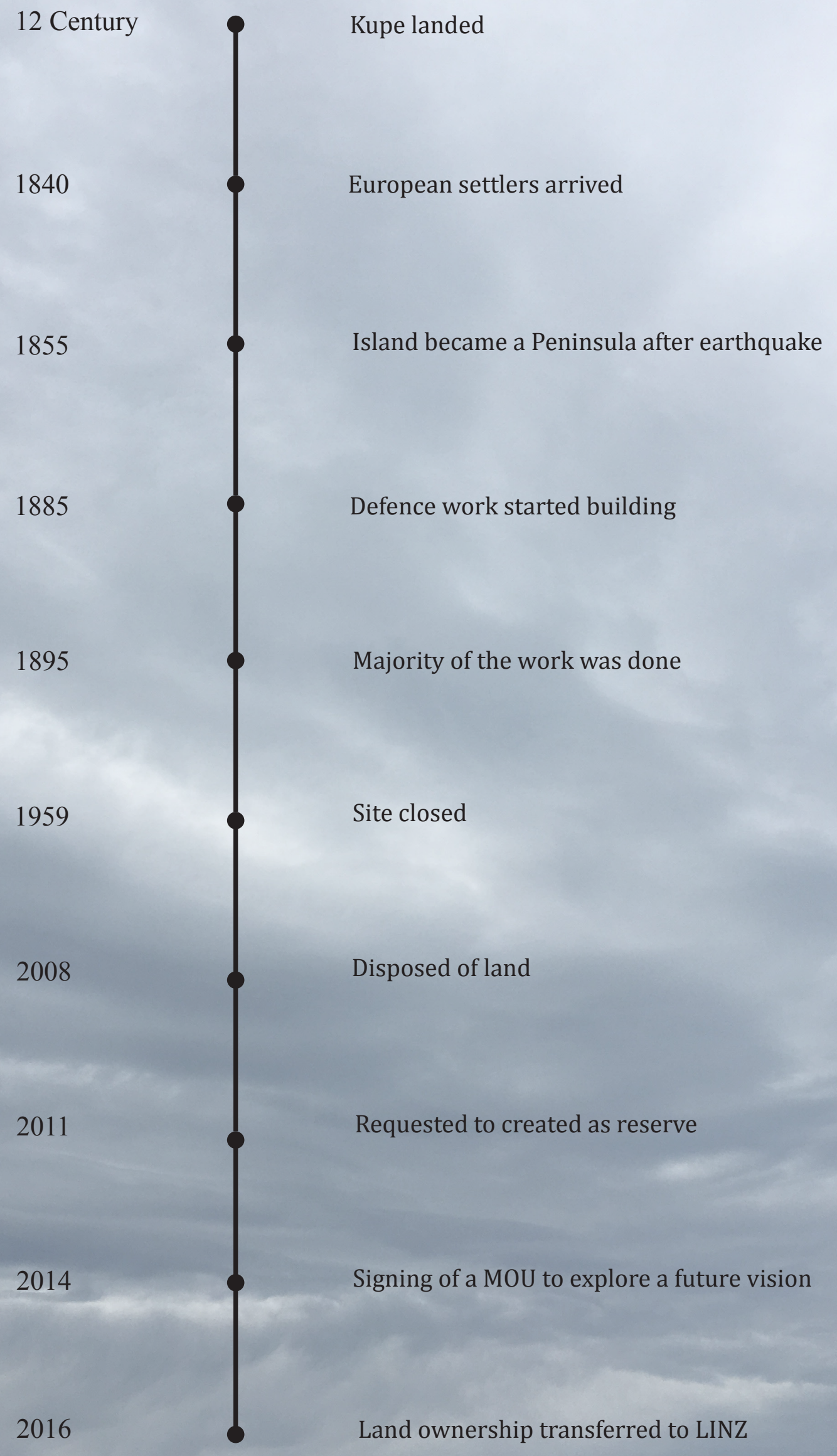




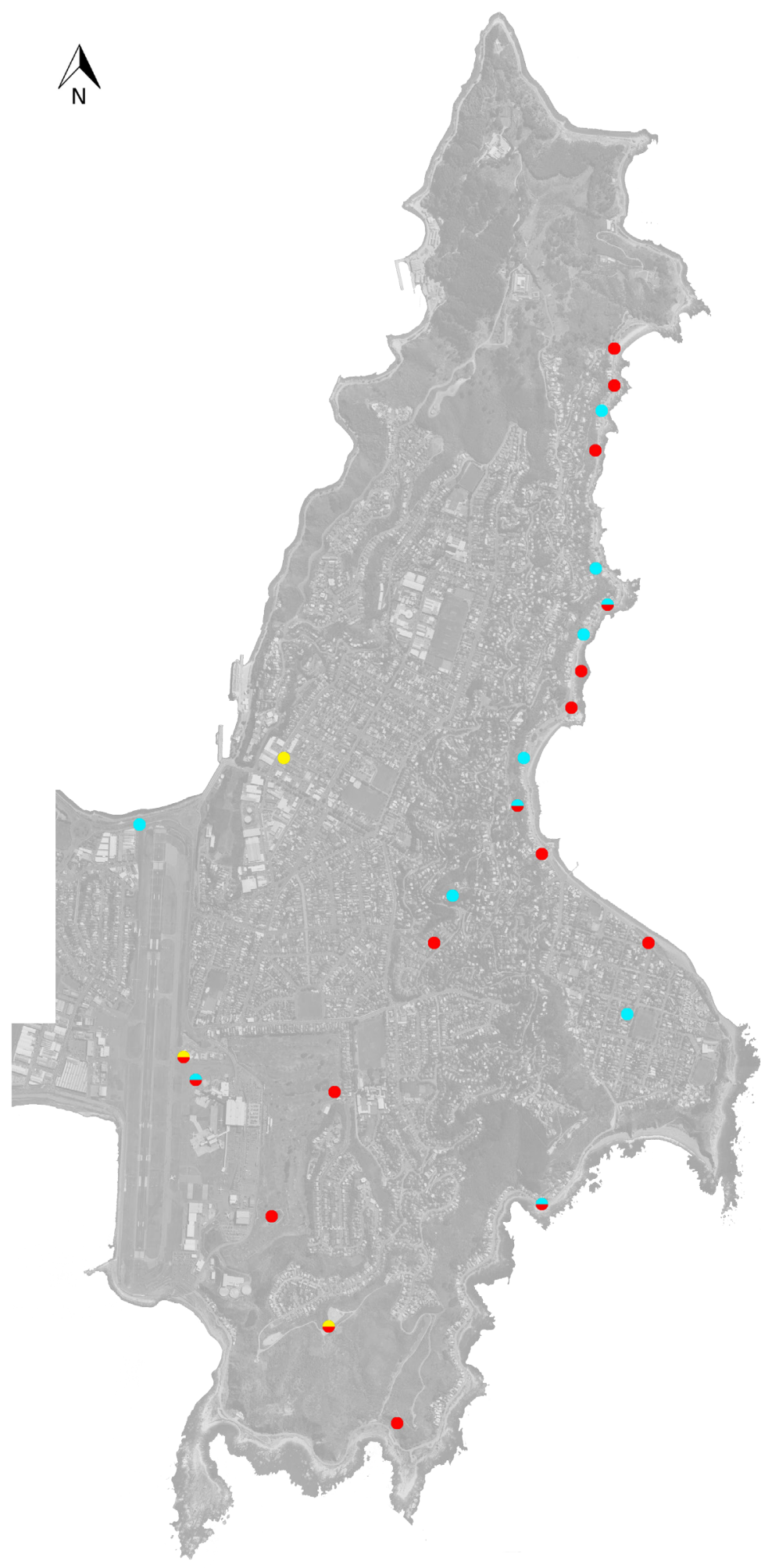

Fig 2.15 Archaelogical remains.
- Human Remains
Umu Remains
Moa Remains

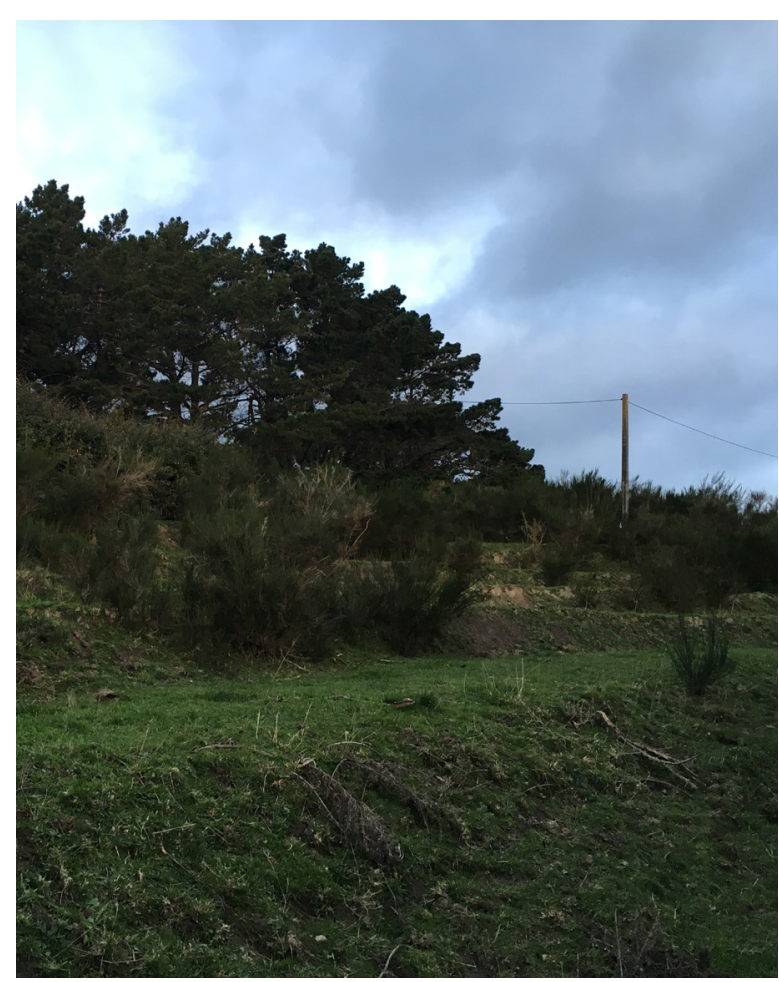

Above Fig 2.16 The topography of past human settlement is obvious in various parts of the site.

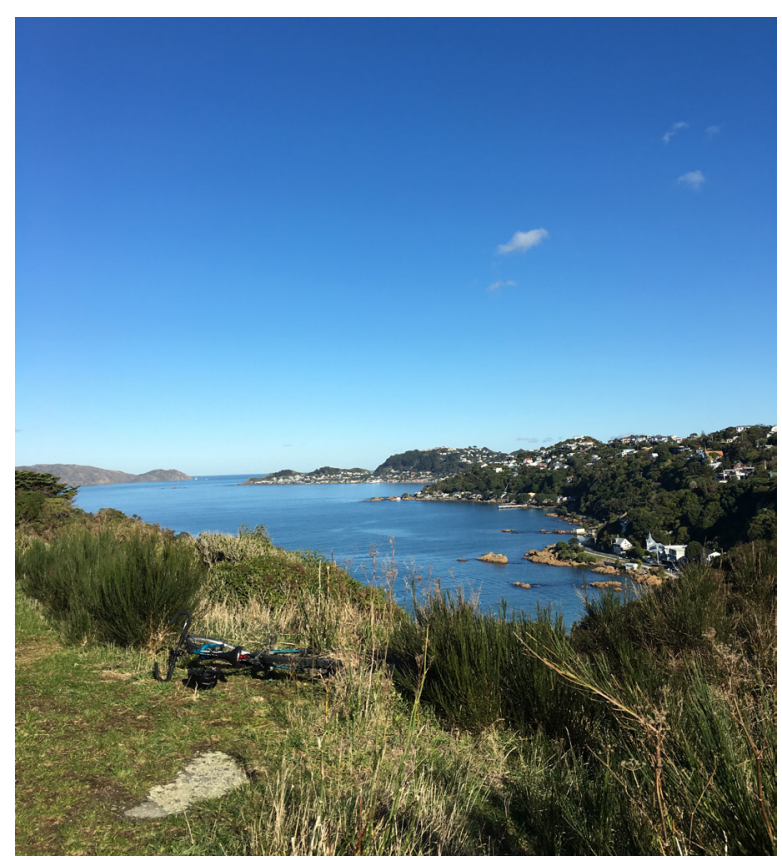

Above Fig 2.17 Site view towards the remain site near Scorching Bay 

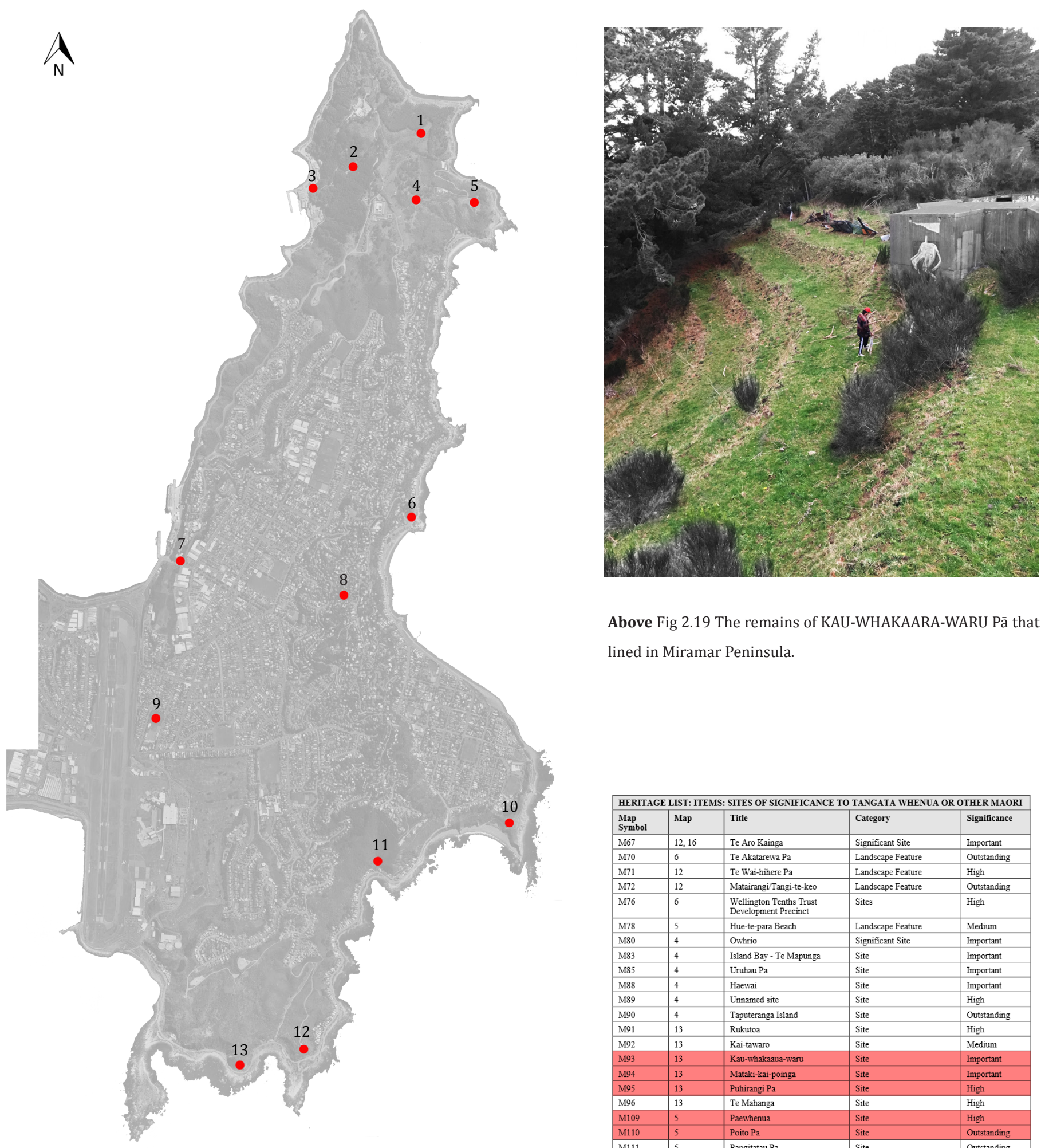

Above Fig 2.19 The remains of KAU-WHAKAARA-WARU Pā that lined in Miramar Peninsula.

\begin{tabular}{|l|l|l|l|l|}
\hline HERITAGE LIST: ITEMS SITES OF SIGNIFICANCE TO TANGATA WHENUA OR OTHER MAORI \\
\hline $\begin{array}{l}\text { Map } \\
\text { Symbol }\end{array}$ & Map & Title & Category & Significance \\
\hline M67 & 12,16 & Te Aro Kainga & Significant Site & Important \\
\hline M70 & 6 & Te Akatarewa Pa & Landscape Feature & Outstanding \\
\hline M71 & 12 & Te Wai-hihere Pa & Landscape Feature & High \\
\hline M72 & 12 & Matairangi Tangi-te-keo & Landscape Feature & Outstanding \\
\hline M76 & 6 & $\begin{array}{l}\text { Wellington Tenths Trust } \\
\text { Development Precinct }\end{array}$ & Sites & High \\
\hline M78 & 5 & Hue-te-para Beach & Landscape Feature & Medium \\
\hline M80 & 4 & Owhrio & Significant Site & Important \\
\hline M83 & 4 & Island Bay - Te Mapunga & Site & Important \\
\hline M85 & 4 & Uruhau Pa & Site & Important \\
\hline M88 & 4 & Haewai & Site & Important \\
\hline M89 & 4 & Unnamed site & Site & High \\
\hline M90 & 4 & Taputeranga Island & Site & Outstanding \\
\hline M91 & 13 & Rukutoa & Site & High \\
\hline M92 & 13 & Kai-tawaro & Site & Medium \\
\hline M93 & 13 & Kau-whakaaua-waru & Site & Important \\
\hline M94 & 13 & Mataki-kai-poinga & Site & Important \\
\hline M95 & 13 & Puhirangi Pa & Site & High \\
\hline M96 & 13 & Te Mahanga & Site & High \\
\hline M109 & 5 & Paewhenua & Site & High \\
\hline M110 & 5 & Poito Pa & Site & Outstanding \\
\hline M111 & 5 & Pangitatau Pa & Site & Outstanding \\
\hline M112 & 5 & Palmer Head & Site & Important \\
\hline M113 & 5 & Te Aroaro-o-Kupe & Site & Outstanding \\
\hline M114 & 5 & Oruaiti Pa & Site & Outstanding \\
\hline M115 & 5 & Te Turanga---Kupe & Site & Important \\
\hline M116 & 7 & Kirikiri-tatangi & Site & Important \\
\hline
\end{tabular}
Those items that are within the Coastal Marine Area will be administered by the
Wellington Regional Council through its Regional Coastal Plan.

Above Fig 2.20 A table from Wellington Regional Council outlines the significance of the Pā sites (Dodd, 2012, p. 27).
1. KAU-WHAKAARA-WARU
2. MATAKI-KAI-POINGA
3. MARU-KAI-KURU
4. PUHIRANGI
5. MAHANGA
6. KAKARIKI-HUTIA

7. MAUPUIA

8. TE WHETU-KAI-RANGI

9. TAPU-TE-RANGI

10. O-RUA-ITI

11. PAE-WHENUA

12. POITO

13. RANGITATAU 


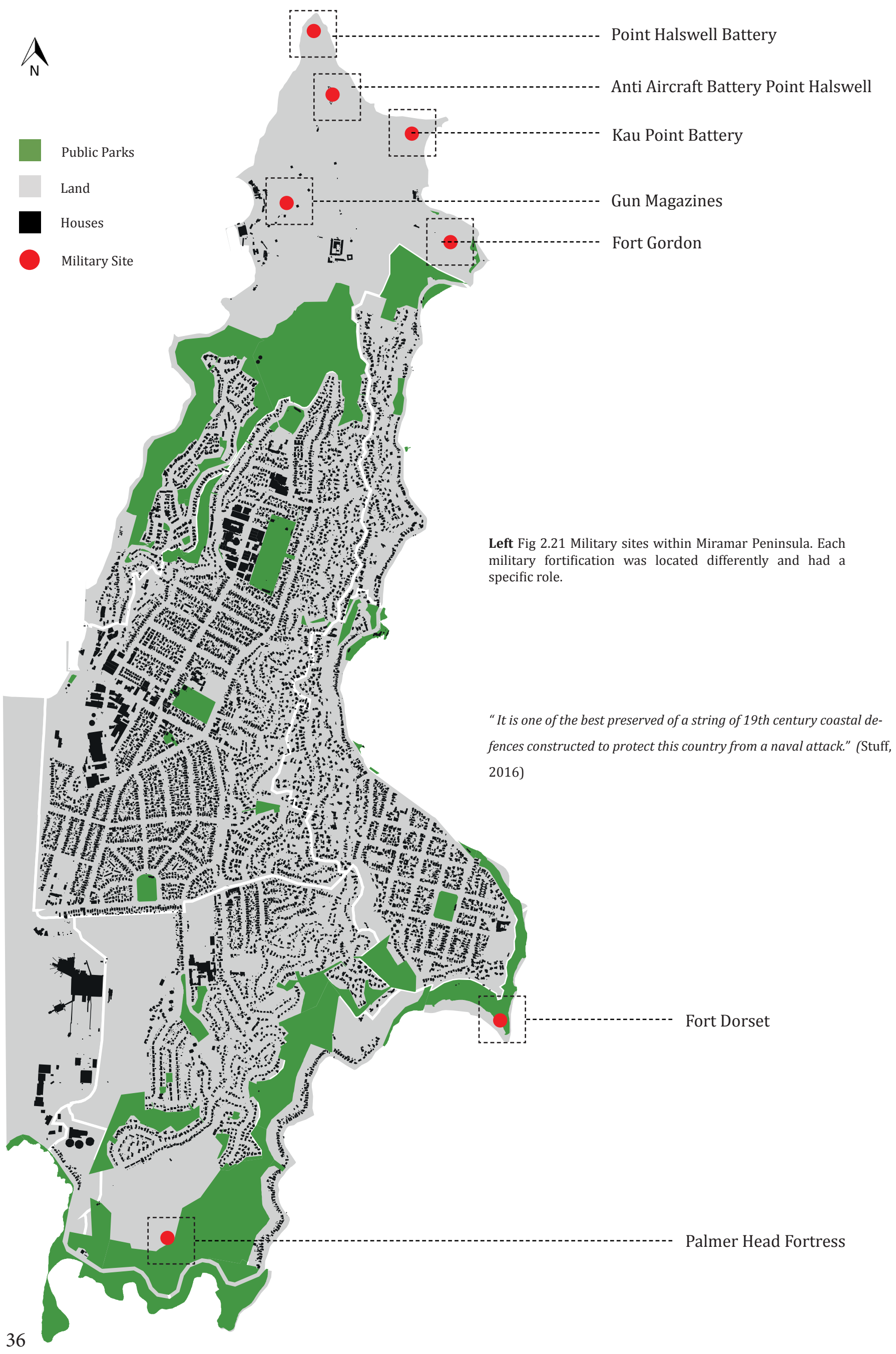




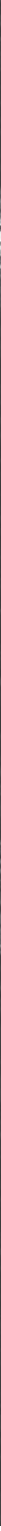

Military sites work simultaneously as a whole coastal defence network, with a $2500 \mathrm{~m}$ gun range.

Above Fig 2.22 Coastal defence network protects the harbour from naval attacks. Other guns (not shown here) close the city completed the system.

Below Fig 2.23 The large guns have gone. The lookout bunkers and gun emplacements still stand.

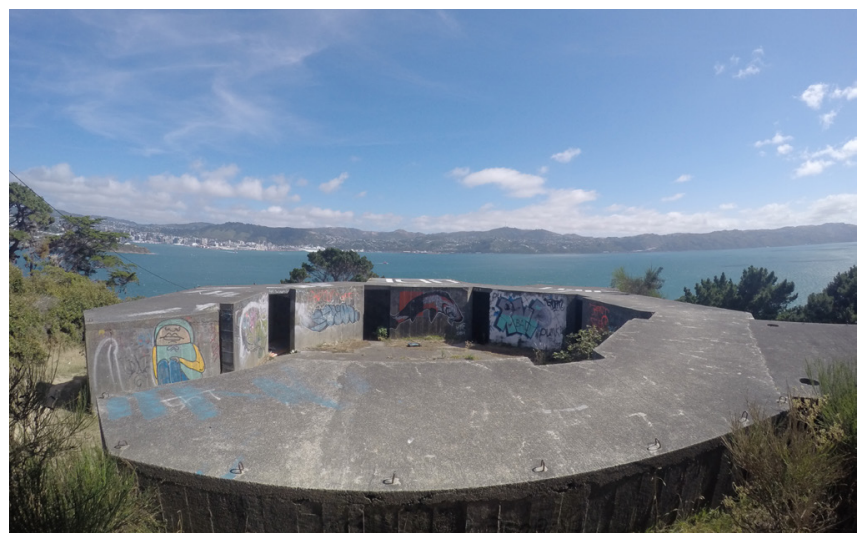

\subsection{Military Study}

The site has been an important defence site since early Maori occupation and many sites are still visible. European settlers also recognised its strategic importance and installed guns and bunkers all over the area. As noted previously, each military fortification has a strategic location that is part of the coastal defence network. It seemed worthwhile to investigate this structure-landscape relationship.

\section{"Halswell Point and Point Gordon provided height} and concealment for the proposed fortifications that were needed to defend the harbour channel." Naus,

Natash, "Motu-Kairangi", 2012, p.10

The research investigation shifted from the hunch of attention to individual military fortification structures to understanding the whole defence network and how each fortification is a part of it. 
The gun emplacements were designed to view the

wider harbour landscape. They each have a specific

relationship to the site itself. Viewshed mapping done

in ArcGis, showing the topography visible from the

gun emplacement. Views from these emplacements

make them important destinations.
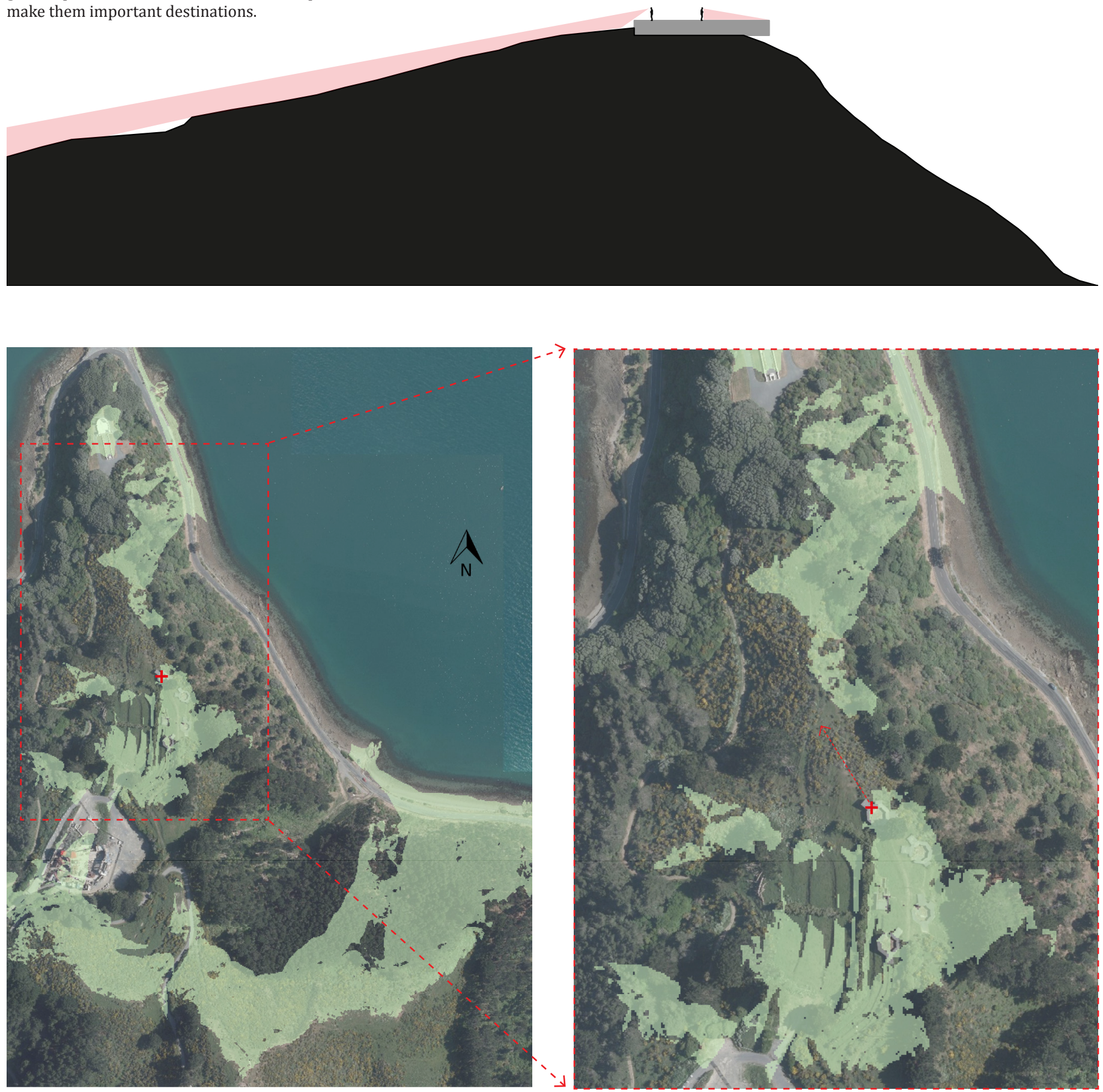

Fig 2.24 Viewshed from Point Halswell.

Fig 2.25 Panorama from Point Halswell.

Fig 2.25 Panorama from Point Halswell.

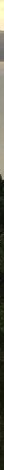



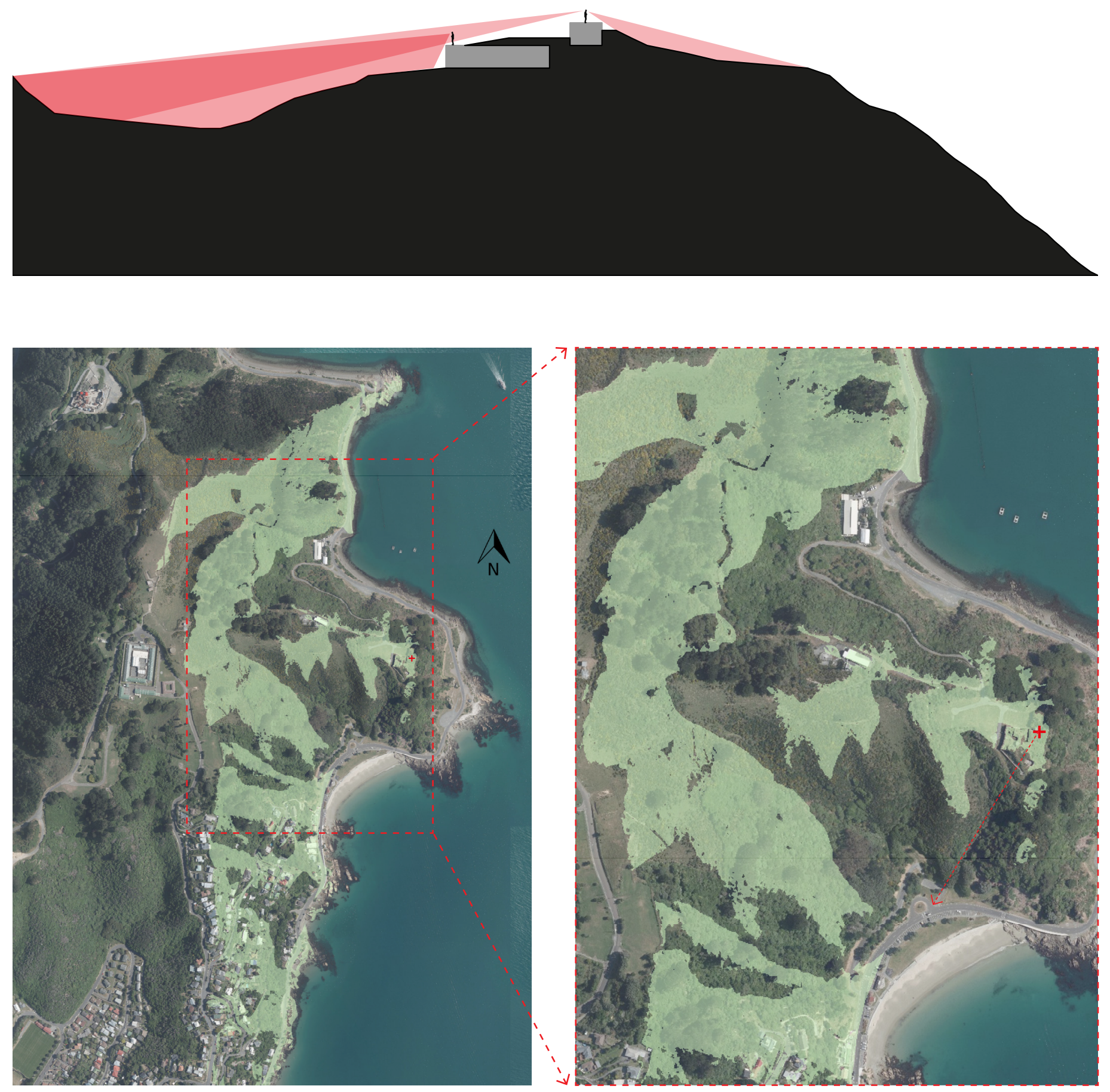

Fig 2.26 Viewshed from Fort Gordon.

Fig 2.27 Panorama from Fort Gordon.

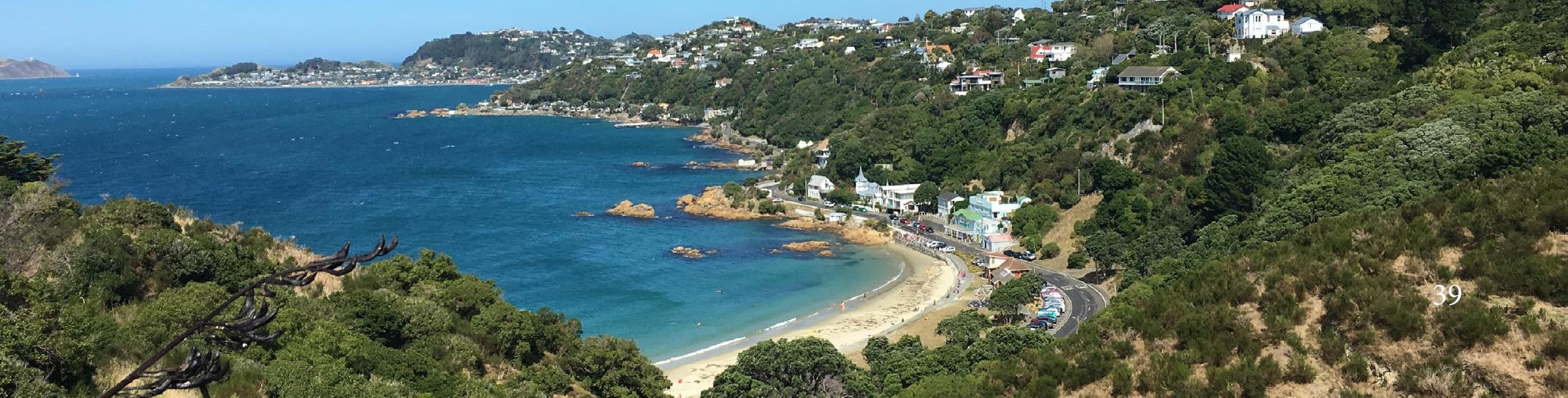




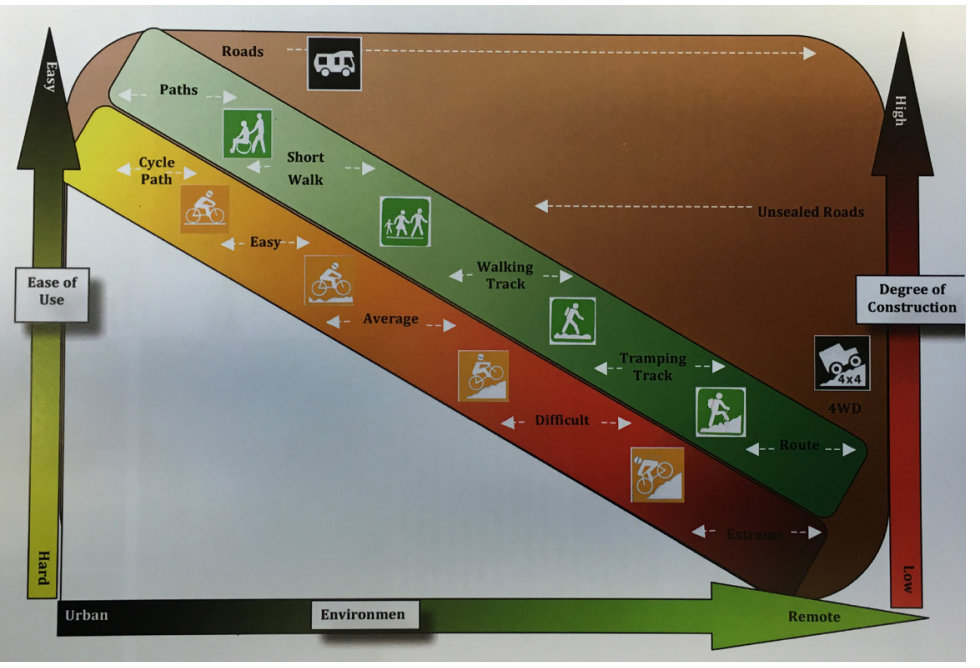

Fig. 2.28 Urban and remote. This diagram discusses urban and remote are opposed to each other. This site brings these usually opposite characteristics together (Loidl \& Bernard, 2014, p. 16).

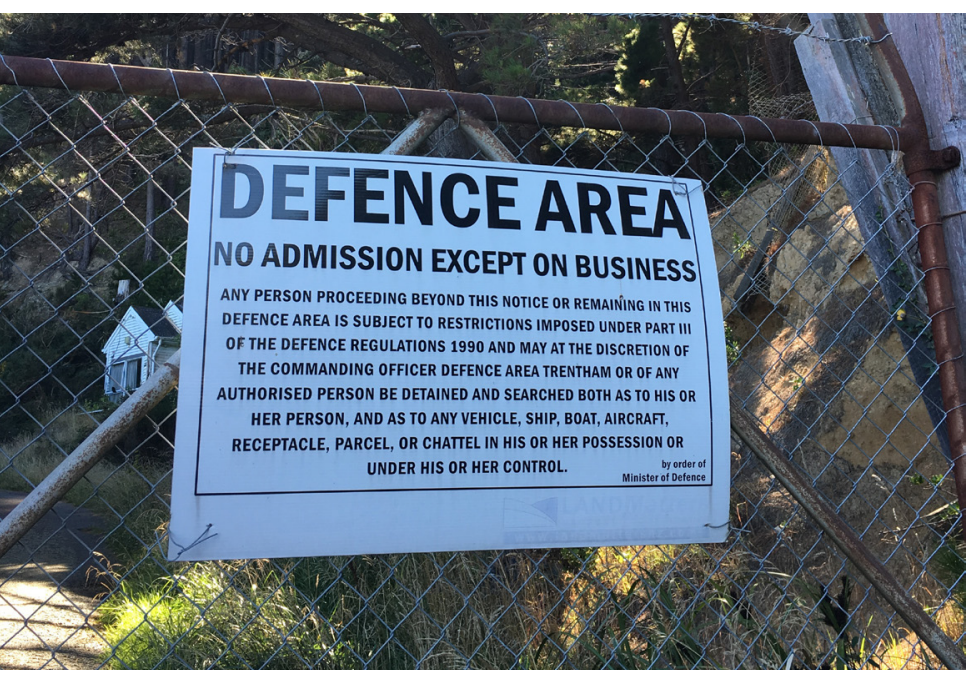

Fig 2.29 Defence signage. Much of the site is currently fenced off.

\subsection{Network}

After several visits to the site, a number of existing and possible options for moving around the site were identified. There are three official entries for people to access the site. The site is for walking only, people need to park their vehicles nearby. There were four initial types of site movement identified-influenced based on physical characteristics: gradient, width, walking surface and vegetation clearness. 

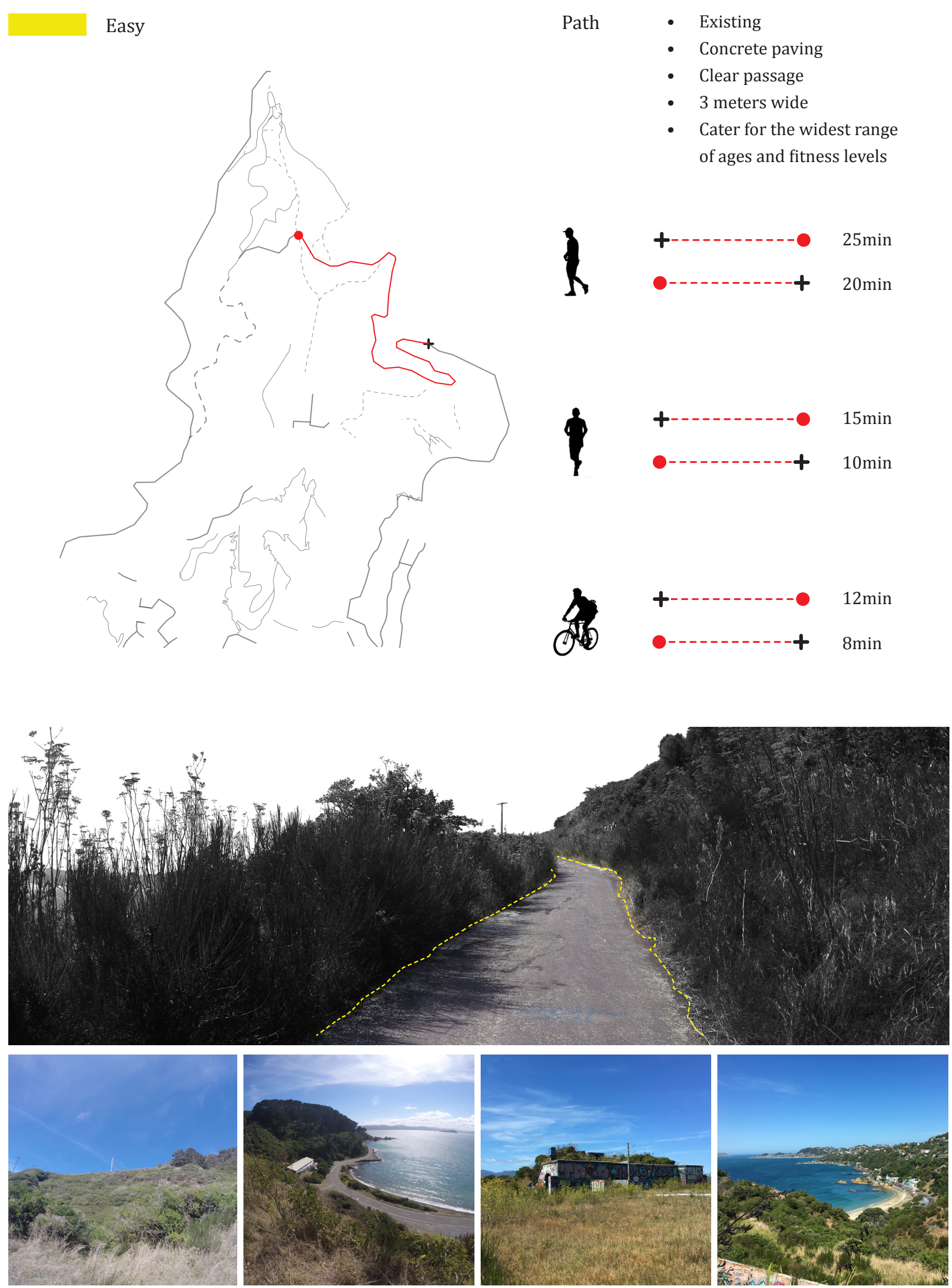


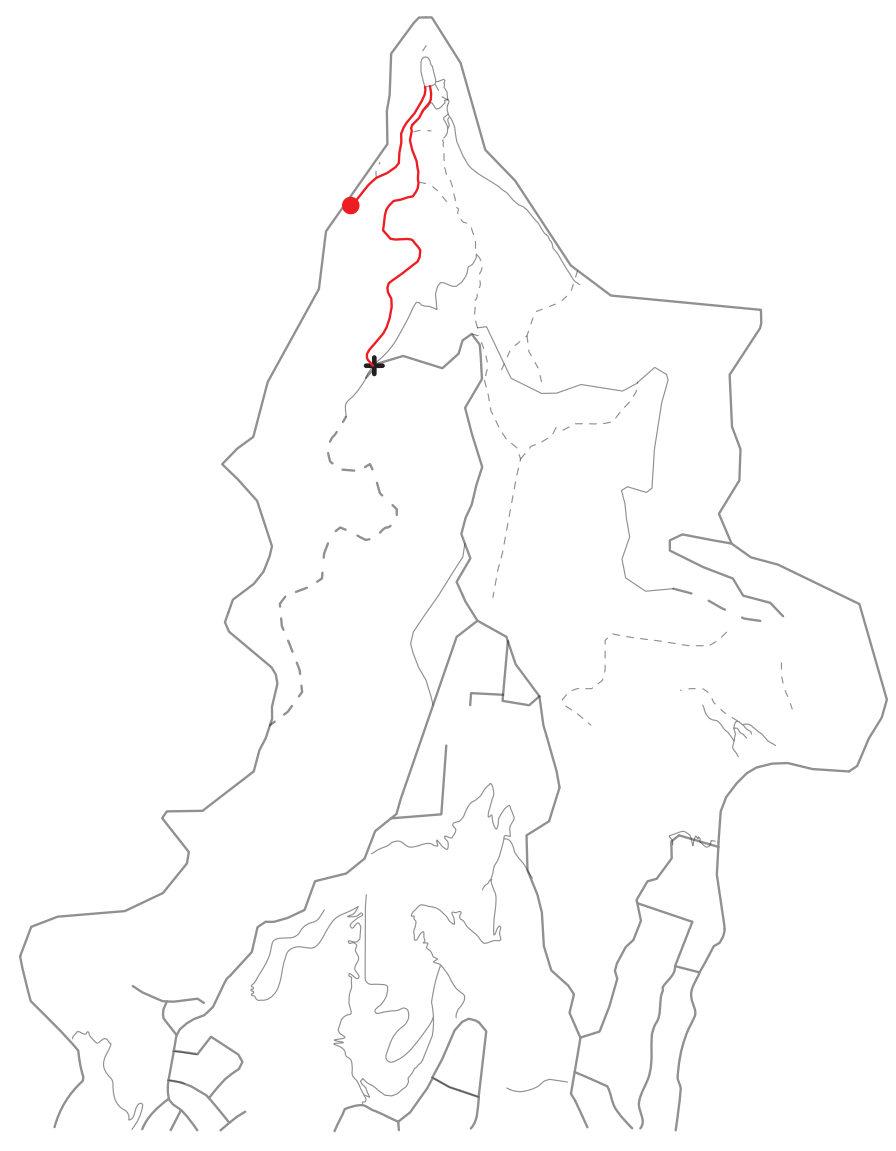

- $\quad$ Earth paving

- 1.5 meters wide

- Cater for all ages and most walking abilities
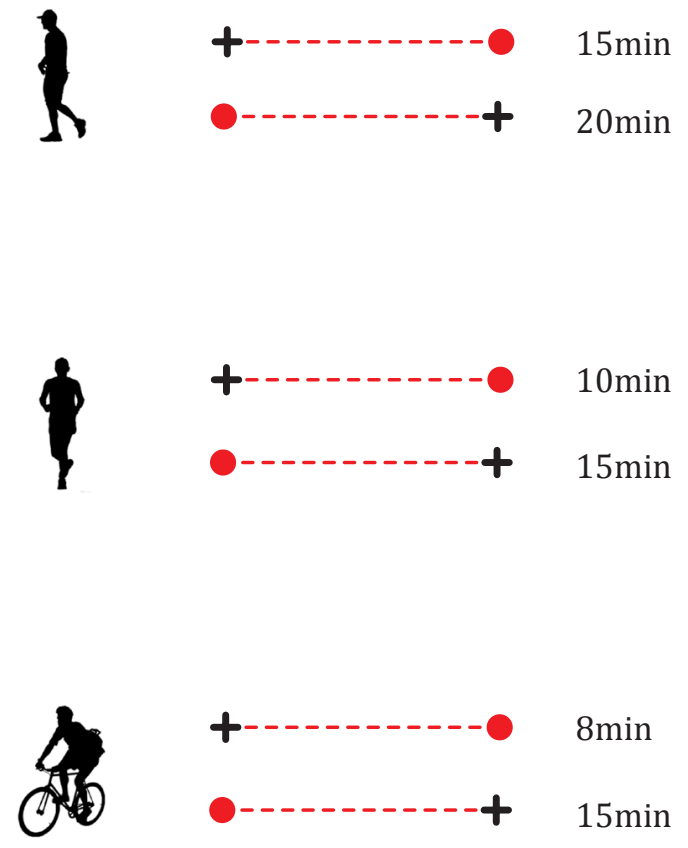
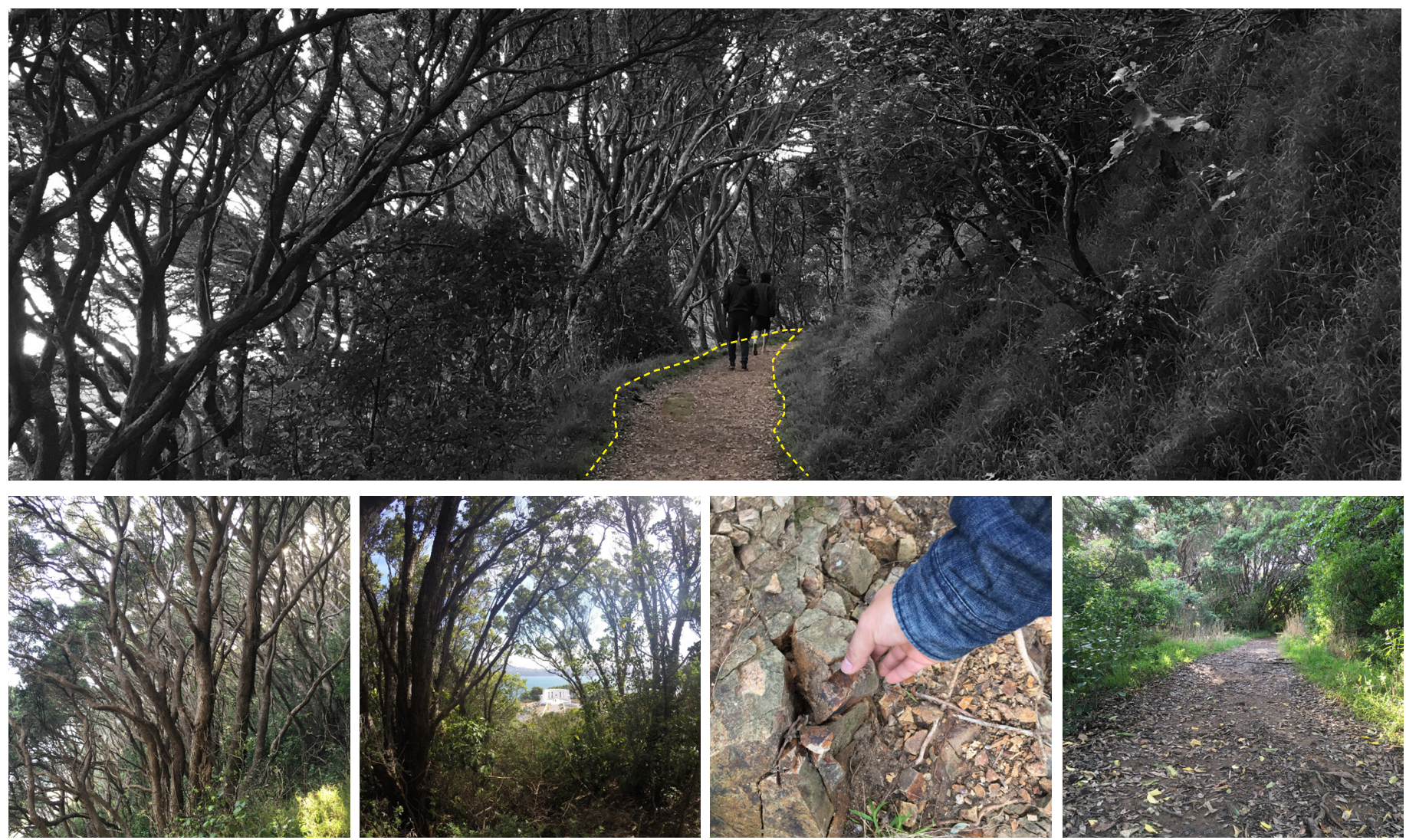

Fig 2.32 Medium walking track

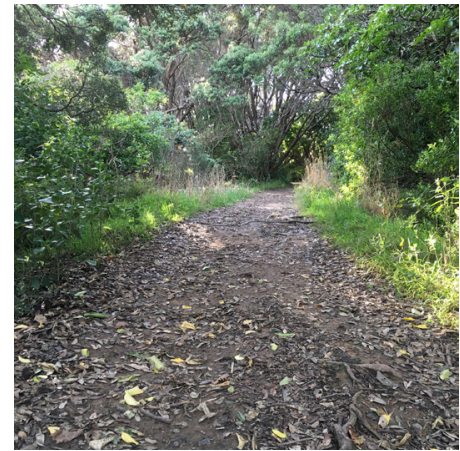


Tramping Track

\section{Hard}

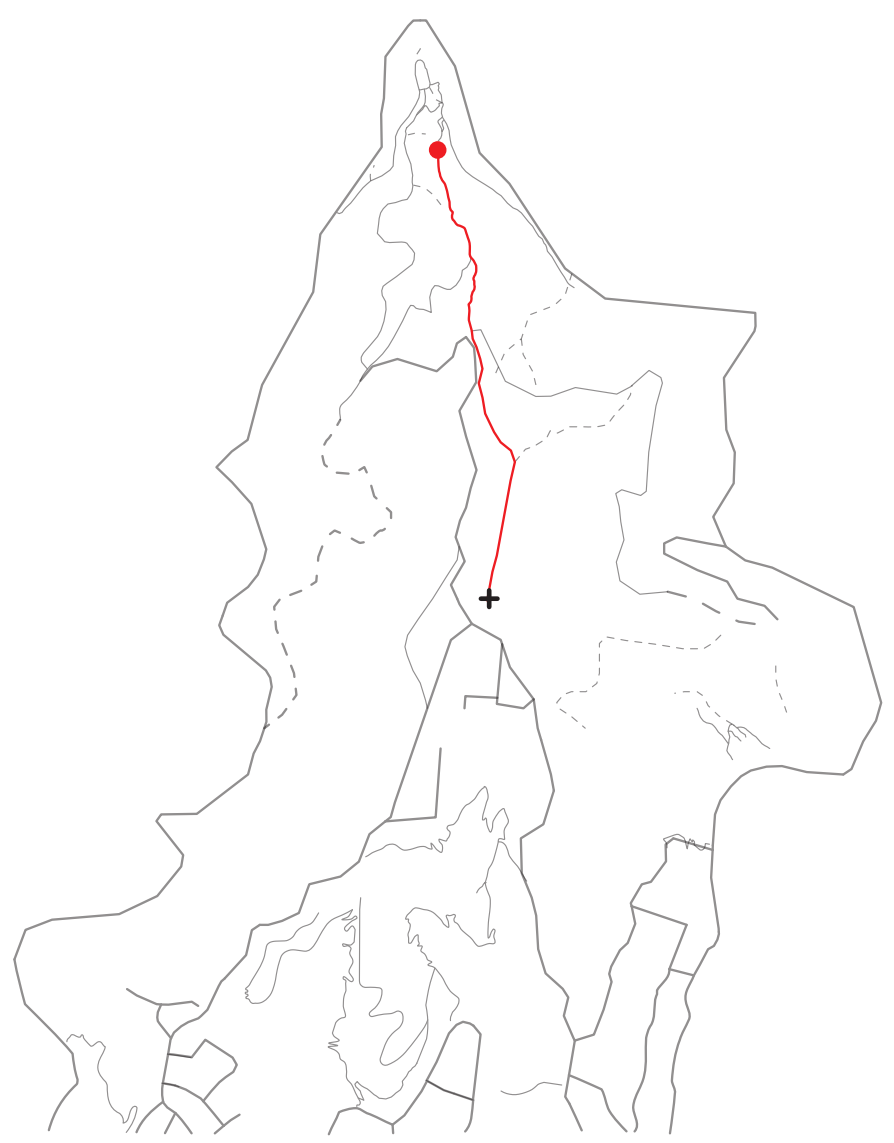

- 1 meters wide

- Consistent steps while walking

- Cater for experienced walkers with a good level of fitness

- Vegetation not clear on surface

- Some surfaces overgrown
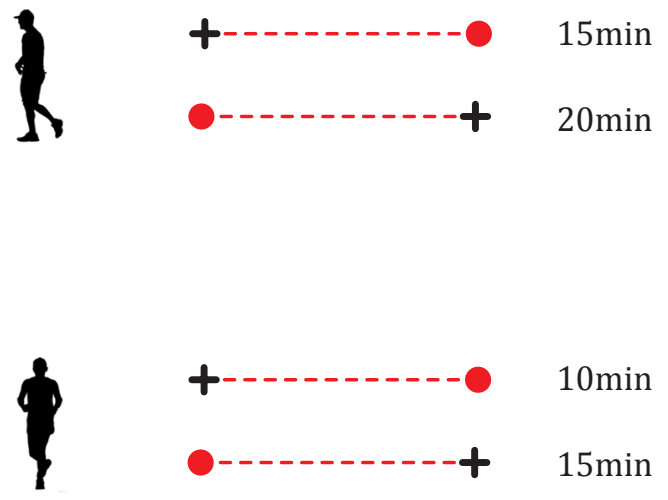

6.
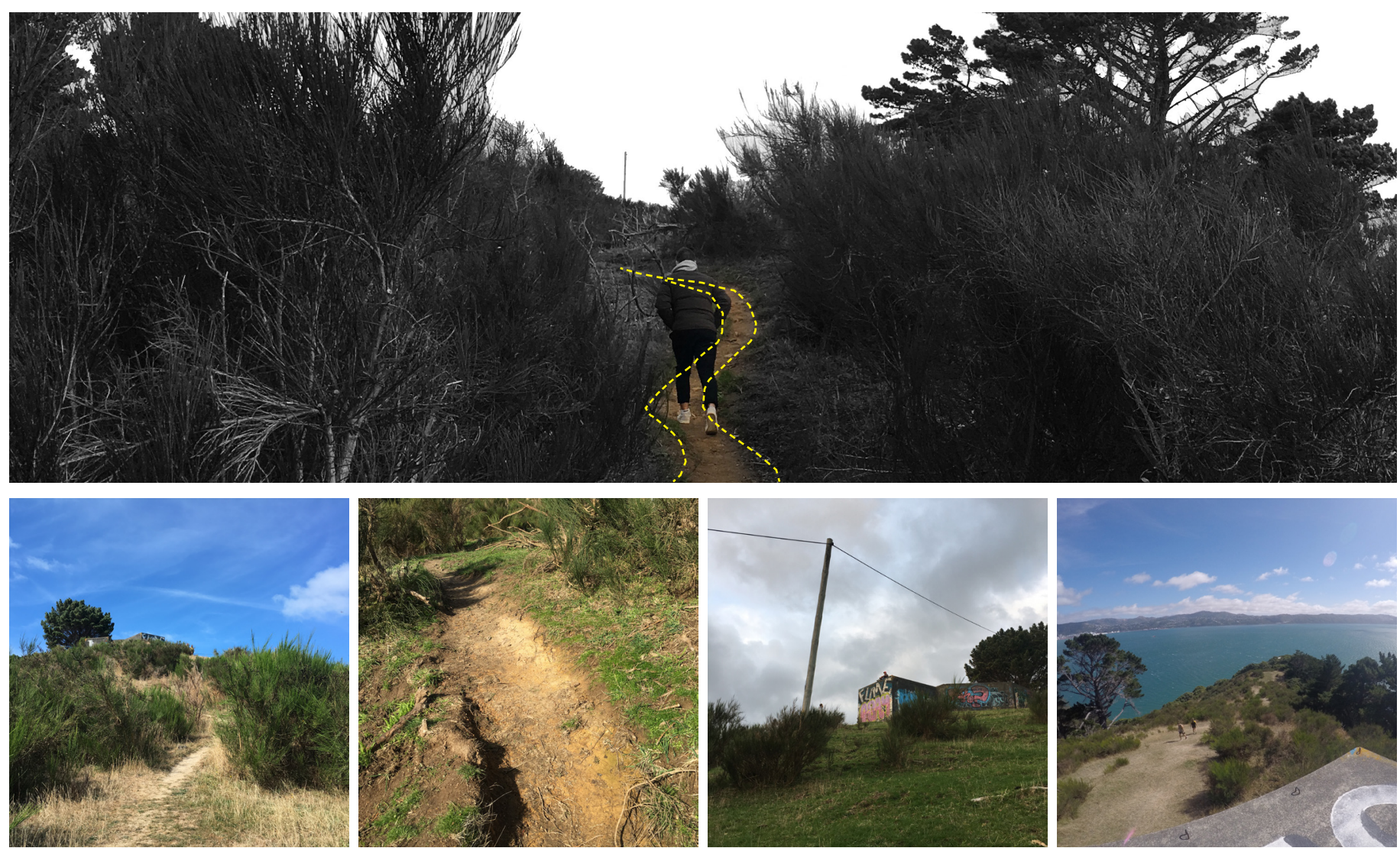
Extreme Hard

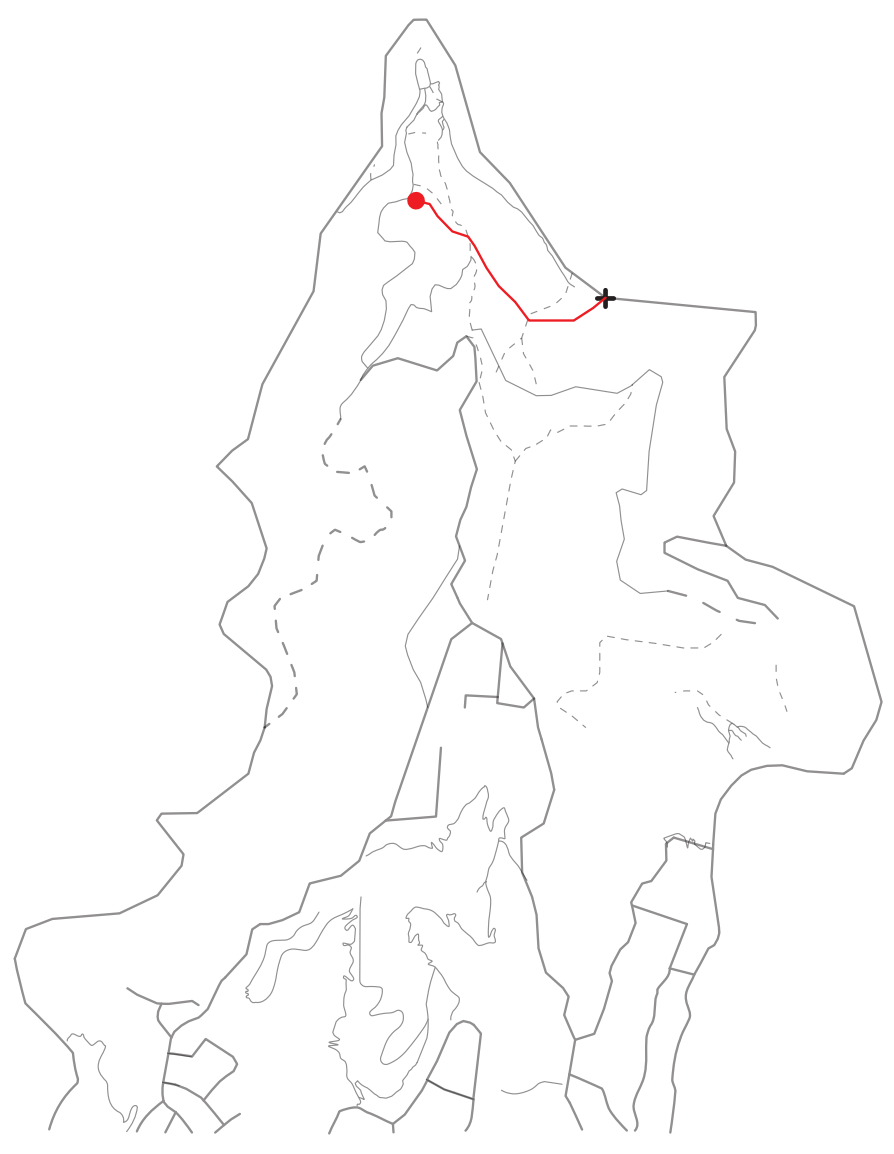

Route

- High density of vegetation blocked

- No obvious destination

- Cater for people with a high degree of fitness and experience

- Not an existing track or route
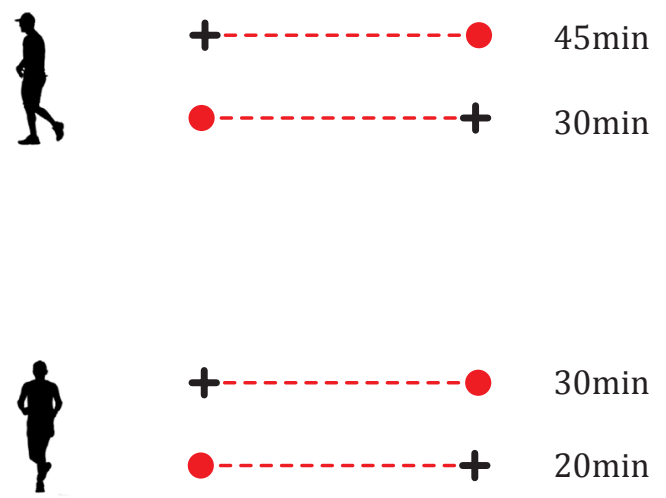

. $20 \mathrm{~min}$

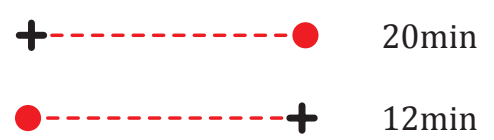

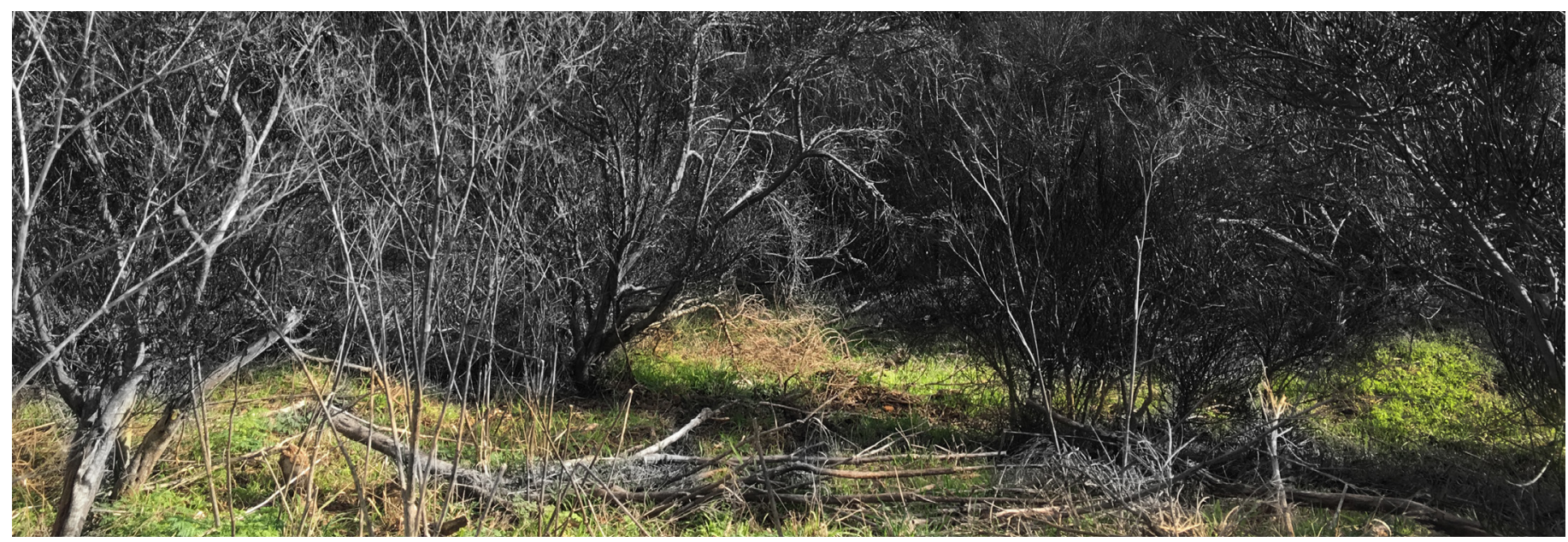

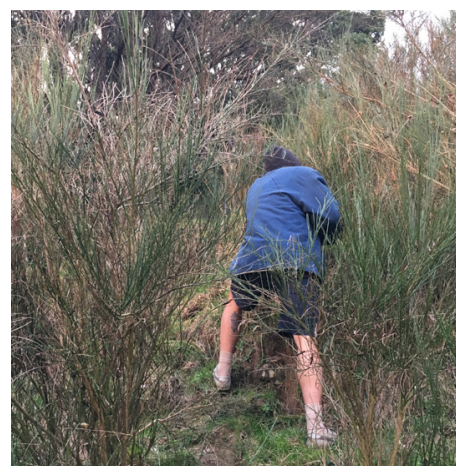

Fig 2.34 Extremely hard route
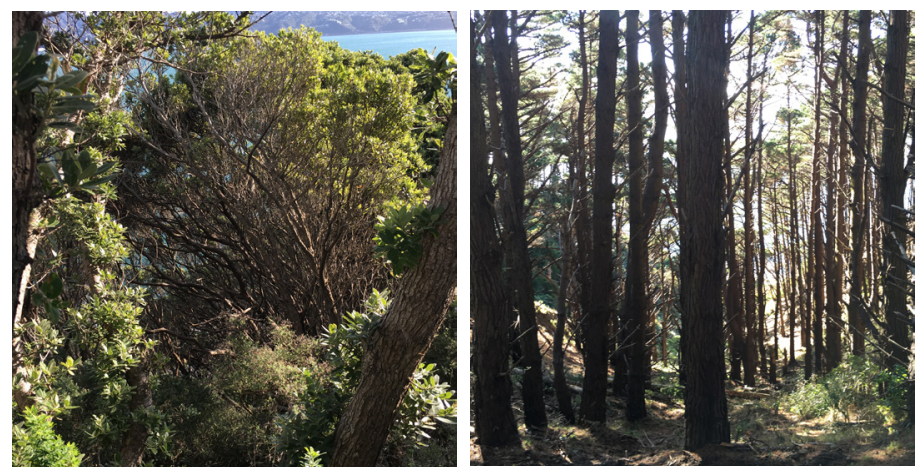

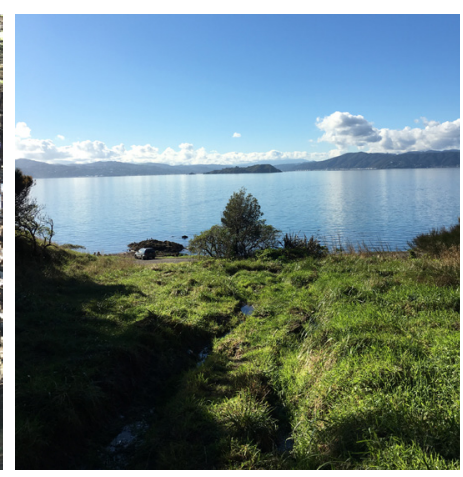


Voices from people helps outline the opportunities and various desires for the site.

- "Great place to walk dogs... It would be great to have a walk way above the road from Fort Balance all the way around to Shelly Bay..." Joanne Rogers.

- $\quad$ "For a place that is drenched in cultural and military history this is such a waste of what should be a great public space for all Wellingtonians and tourists." Seby Reeves.

- $\quad$ "It could be made into a historic site along with a mountain bike park and recreation/walking area for families and their pooches. It's wasted not being able to be accessed by the public." Michele Ricou.

\subsection{Limitation}

A number of factors contribute to the limited engagement with the site:

- The site's forces are palpable but largely invisible given the limited scope of existing interpretation. In particular, the military road between Shelly Bay and the film field is closed.

- The richness of the visitor experience is not fully realised, due to the limitations on movement through the site.

- The site comprises a range of sublime and rich landscape parts of the experiences, with a rolling topography on eastern side, but the trails provide limited access to these areas.

- The site's path network does not read holistically or as a series of unique experiences.

\subsection{Conclusion}

There is a strong relationship between military fortifications and the rich values of the site. They are not separable and communicate with each other. The individuality of any 'one' aspect of them being a product of the whole system. The whole site seems like a multiplicity, made up by various factors. How to bring the whole site back to life is becoming a bigger challenge for this research investigation. 


\section{LITERATURE REVIEW}

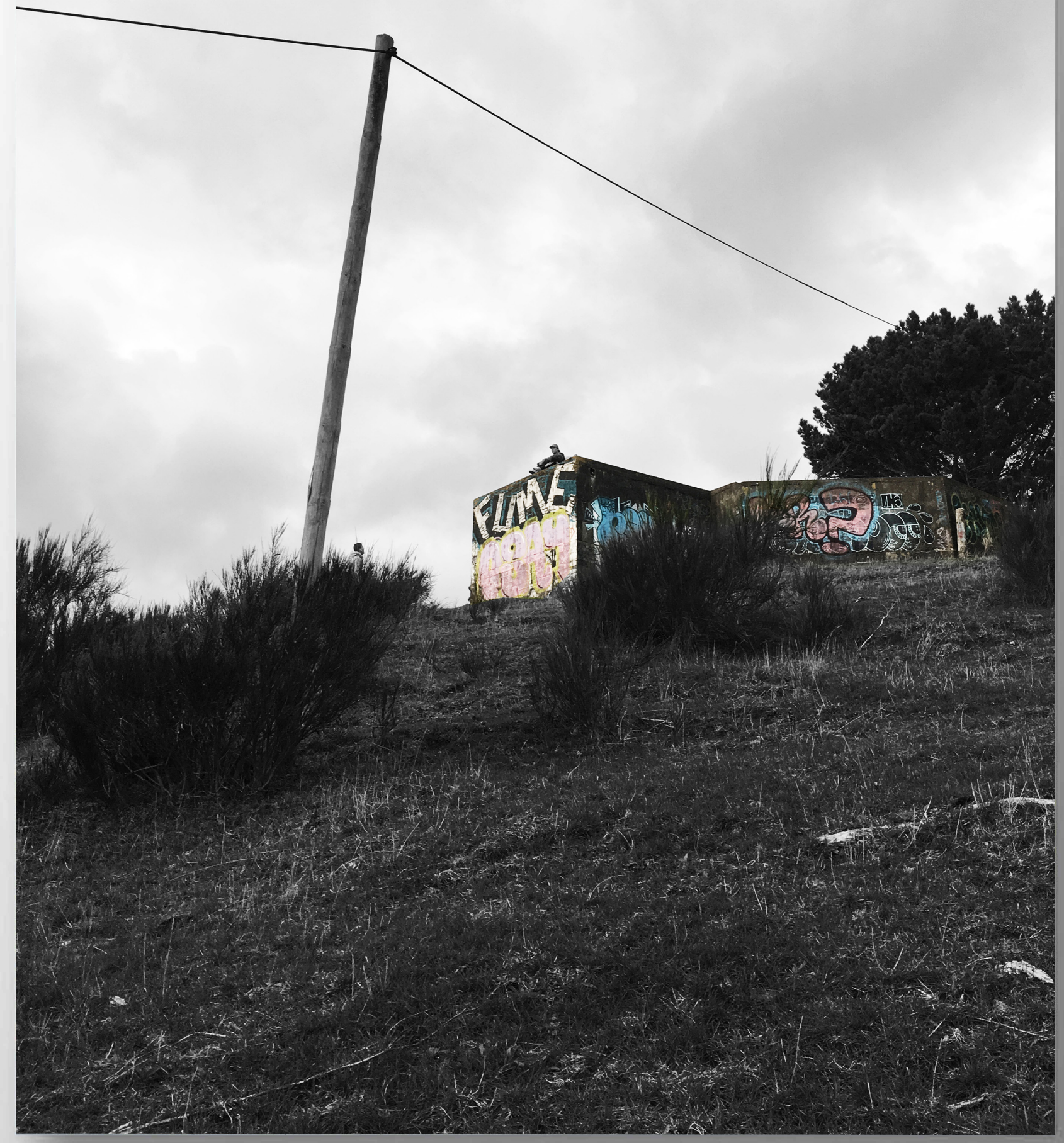




\section{Introduction}

This review focuses on two aspects: approaches to coastal defence heritage sites and the notion of assemblages as a way to understand the types of experiencing of the site. The latter, in particular, will be used to develop an alternative way to approach coastal defence heritage. 


\subsection{Heritage}

The notion of heritage found from the previous chapter identified the study site Miramar Peninsula as a place of rich historical significance. In 2008, the owner of the military site, the New Zealand Defence Force, aimed to bring new life to this site through recreation and open space possibilities. Then in September 2011, the Ministry for Culture and Heritage worked with the New Zealand Defence Force and the Department of Conservation on the creation of the site as a reserve which should be protected, preserved and developed. The Watts Peninsula Feasibility study identified options for further development, including:

- Removal of hazardous trees;

- mprove connections and walking access to Fort Balance from Scorching Bay;

- Initial safety work at military heritage sites;

- A renewed signage system is proposed based on the tracks;

- Consider new large-scale park entry signs or other entry structures to welcome people to the site;

This proposal of Watts Peninsula is similar to the method used on other heritage projects, such as North Head in Auckland, which will be discussed case study chapter.

This approach tends to break up the landscape into key areas, with the minimal path system required to connect up the various heritage items and locations on the site. This typical approach severely limits the range and richness of experiencing potential of a site like Watts Peninsula.

Today, people are intending to focus on the more object-oriented historical value more than bodilyinvolving, expansive and encompassing landscape of a large heritage site. History is generally understood as a story that people understand directly through reading or listening. The history doesn't only reflect on registered historic places or structures, the feeling of experience the site can also be the part of history.
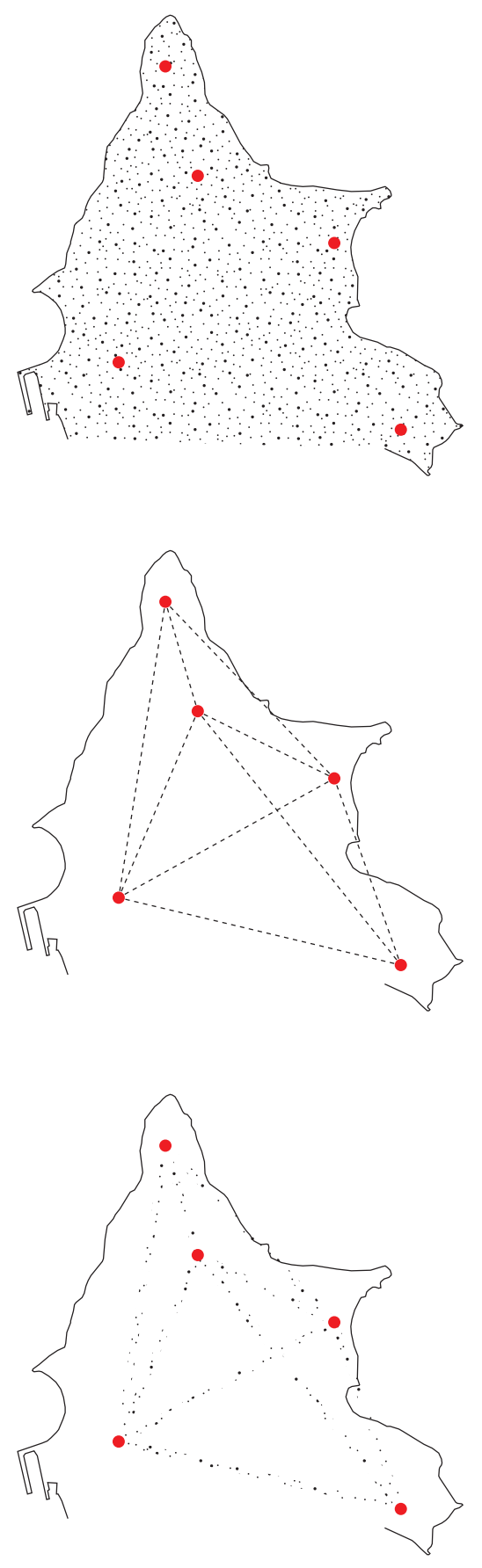

Fig 3.2 Abstract diagrams of the proposal for Watts Peninsula. 


\subsection{Assemblage}

Lu Xun, Chinese writer said: "Originally there is no path in this world, but when there are many who have walked upon it, then a path came into being." This aphorism was using to encourage people in hopeless situations, but it also be used to point to the generally obscured empowerment that comes about when the human organism connects with the environment. Deleuze and Guattari place great emphasis on connecting with such empowerment, such involuntary empowerments.

The research explore the notion of heritage through the understanding of assemblages. An assemblage is a coming together of various elements and relations that make everything working. Gilles Deleuze and Felix Guattari state that the world is made up of assemblages. Deleuze and Guattari (1988) describe assemblages as "a multiplicity which is made up of heterogeneous terms and which establishes liaisons, that is relations between things" that does something.

"Kau Point and Point Gordon provided height and concealment for the proposed fortifications that were needed to defend the harbour channel." Naus, Natash, "Motu-Kairangi", 2012, p.10

An example of an assemblage in the study site is the 'gun emplacement assemblage'. The gun emplacements were designed to 'disappear' between shots, the idea of the disappearing gun was that it retracted below ground between shots so it could be loaded out of sight of any attacking ships. The functioning of gun emplacements were produced by the interaction of heterogeneous elements, such as: topography that provides height and view to shoot the enemy vessels; surrounding vegetation to hide the gun emplacement away from enemies and the location of each gun emplacement influences time taken for weapon transporting. These are the sorts of parts of a coastal gun emplacement that are easily recognised. There is also the team of human gunners, loaders and transporters and those they are communicating with beyond this team. Such teams undergo considerable training to become part of a greater well-oiled machine where it is impossible to separate out the human from the non-human. Whilst there are certainly quantitative measures that can be made of such an assemblage, Eg. Shots per minute etc. It can only really be evaluated in terms of its abilities, its involuntary powers (Deleuze calls these abilities 'affects', JJ Gibson calls them 'affordances' produced ecologically, Bruno Latour calls then 'actions' produced by actor-networks) that the humans feed-off and experiment with. The real efficiency and power of this assemblage is more of an art, where the team as Lu Xun suggests, 'becomes one' with the emplacement. To achieve this have to 'get in the zone'. The individuality of the assemblage relies on the interaction of all of the parts, and it is impossible to not find that each parts plays an active role. The parts communicate with each other, the individuality of any 'one' of them being a product of the whole system. 


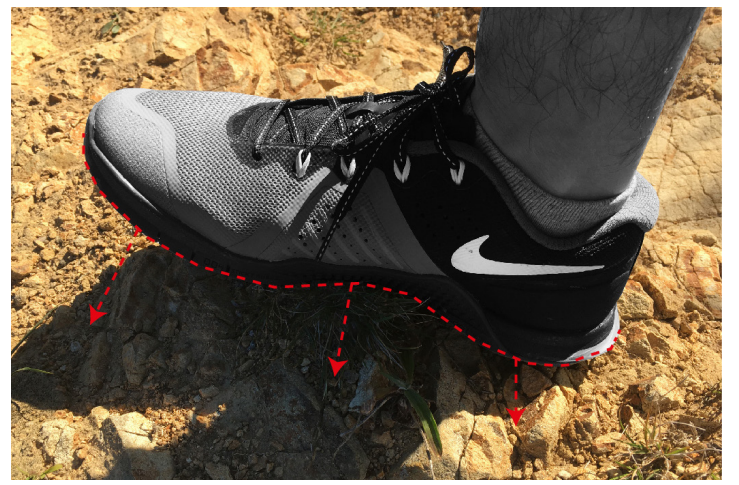

Fig 3.3 Uneven paving effecting the walking experience.
This research found that just as a gun emplacement is not a collection of separate items that Watts Peninsula is more like a rich ecology of humanlandscape assemblages, where a rich heterogeneity of factors - slope, aspect, greater topographic relations, vegetation structure ground surface, existence and type of path or track, obstacles, viewing regimes, shelteredness, types of human expectation and desire etc. - come together to produce types of movement and types experiencing, or types of movement-experiencing. As all of the factors are continually varying across the site a whole range of human-landscape assemblages emerge to produce an interacting ecology of human-landscape assemblages. The whole site becomes a mosaic which is spatially and temporally differentiated and the way that any part of it functions depends on the particular human orientation involved in the particular human-landscape sub-assemblage. Shifts between one part of this ecology can be spatially identified as a transition and what this is pointing to is a shift from one form of assemblage, one form of landscape empowerment to another. Mostly we are not conscious of such empowerments and shifts though we live or surf them. We are continually experimenting with such assemblages in life, and we can develop greater abilities to experiment with them through more conscious and representational engagement with them.

Such movement-experiencing cannot be separated from such things as the social interaction on the site, being a local or a tourist, coming here for the first time or the 100th, whether you bring a dog, and the experience of military history. Such knowledge cannot be discovered through maps, only through being part of such assemblages, on the ground, if we are able to. This research wants to dive into the rich bodily-historical-natural ecology of assemblages that is Watts peninsula, and discover the various ways it can be varied and enriched even further. 


\subsection{Conclusion}

The terms from Deleuze and Guattari: assemblage, affects, and differentiation, formed the research attention to focus the landscape richness of site rather than specific heritage structure. How to identify the differentiation and how to highlight and explore the potential experiences are the challenges for further work. But once people engaging with the site by experiencing the richness, this becomes an understanding of heritage, and this is a way to bring new life to the abandoned coastal defence network and the whole site.

So attention in this project will vary from traditional approaches to coastal heritage focused on heritage structure protection and interpretation to the very great richness and potential of the ecology of movement-experiences of this site - and that by developing up this side of the project the more obvious heritage aspect of the site might return and be transformed as part of a Watts Peninsula movement-experience ecology. 


\section{CASE STUDIES}

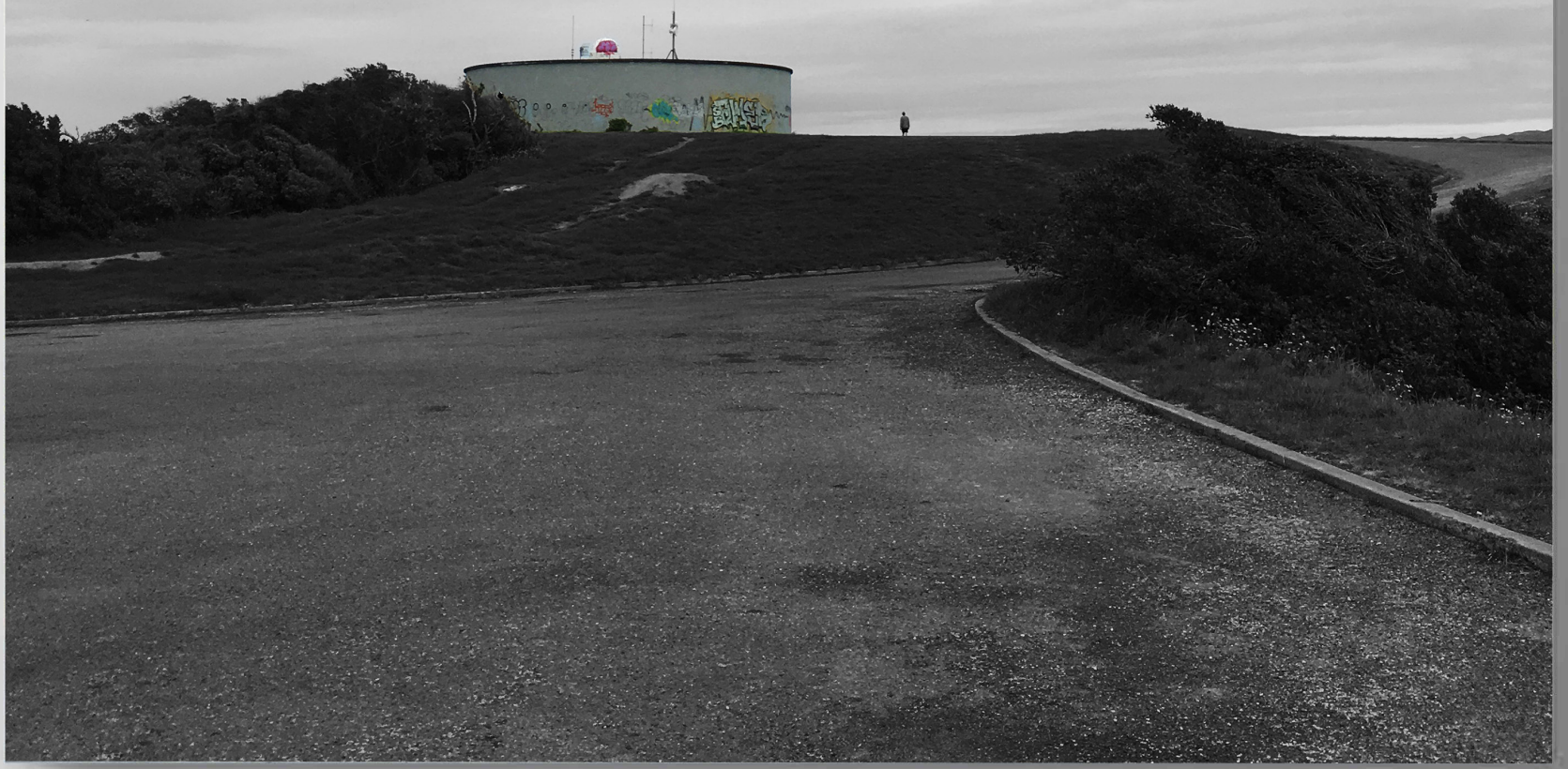




\subsection{North Head}

Location: Auckland, New Zealand.

This case study of part of an existing coastal defence network, North Head, Auckland, is intended to communicate the heritage approach of this site, and as something of a representative of heritage approaches to coastal defence sites more broadly. North Head is a small strategic headland at the mouth of Auckland Harbour. It has been used by the Army since 1885, in response to the Russian scare, through to 1957, when the Coastal Artillery was disbanded. The site at North Head has similar features to those of Watts Peninsula. Both have expansive views over the inner harbour making them an important lookout for early Maori inhabitants and later for European settlers.

The whole of North Head is managed by the Department of Conservation and is publicly accessible but Watts Peninsula, majority-owned by LINZ, still sits abandoned and largely away from people. The housing on the boundary of the North Head site has been height-limited in response to the heritage status of the site. Since the North Head has been open to the public, the heritage elements have become a part of local and tourist lives.

North Head's Self-Guided Walk introduces people to a complex collection of tunnels, guns, searchlights, emplacements and other fortifications. A series of paths at North Head lead people past all the defence structures. Interpretive signage with numbered descriptions introduce the military history. This traditional approach to heritage interpretation and site development tends to suggest that the heritage objects are precious and need protecting. The current loop paths enable a limited way of experiencing such objects and the site. 


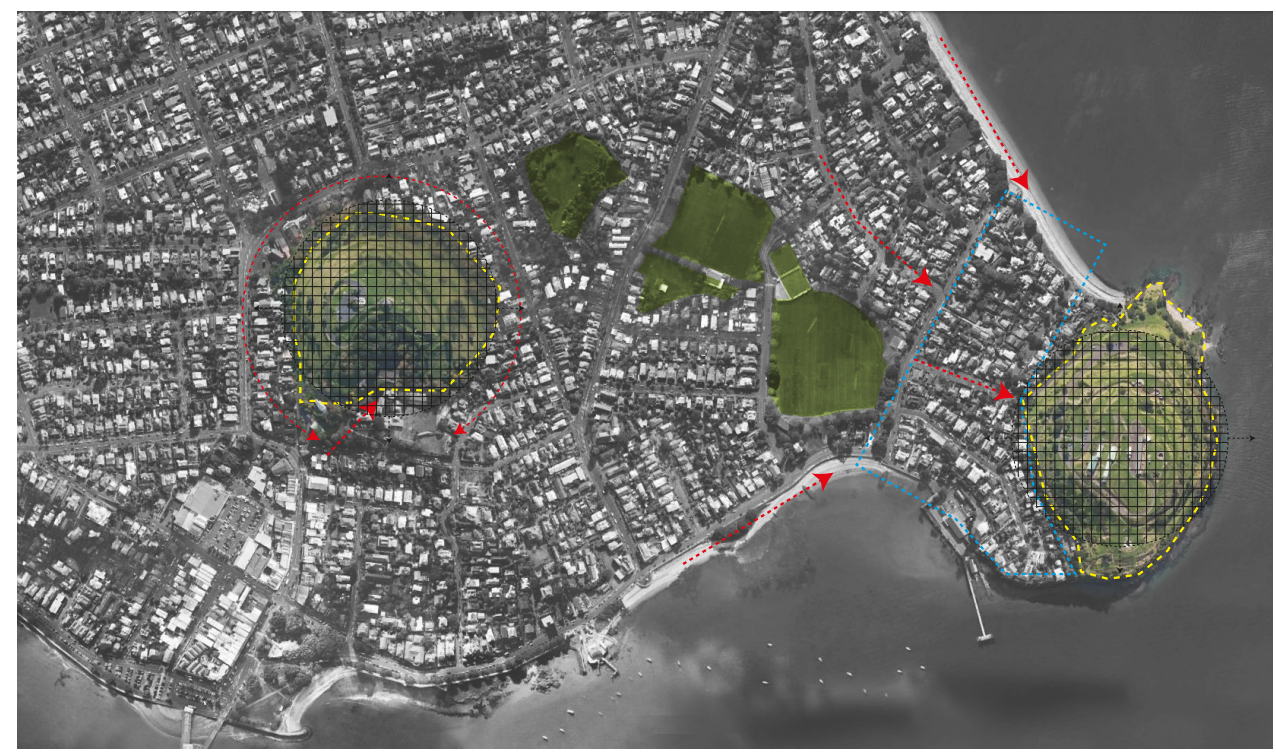

Fig 4.2 North Head in urben setting.

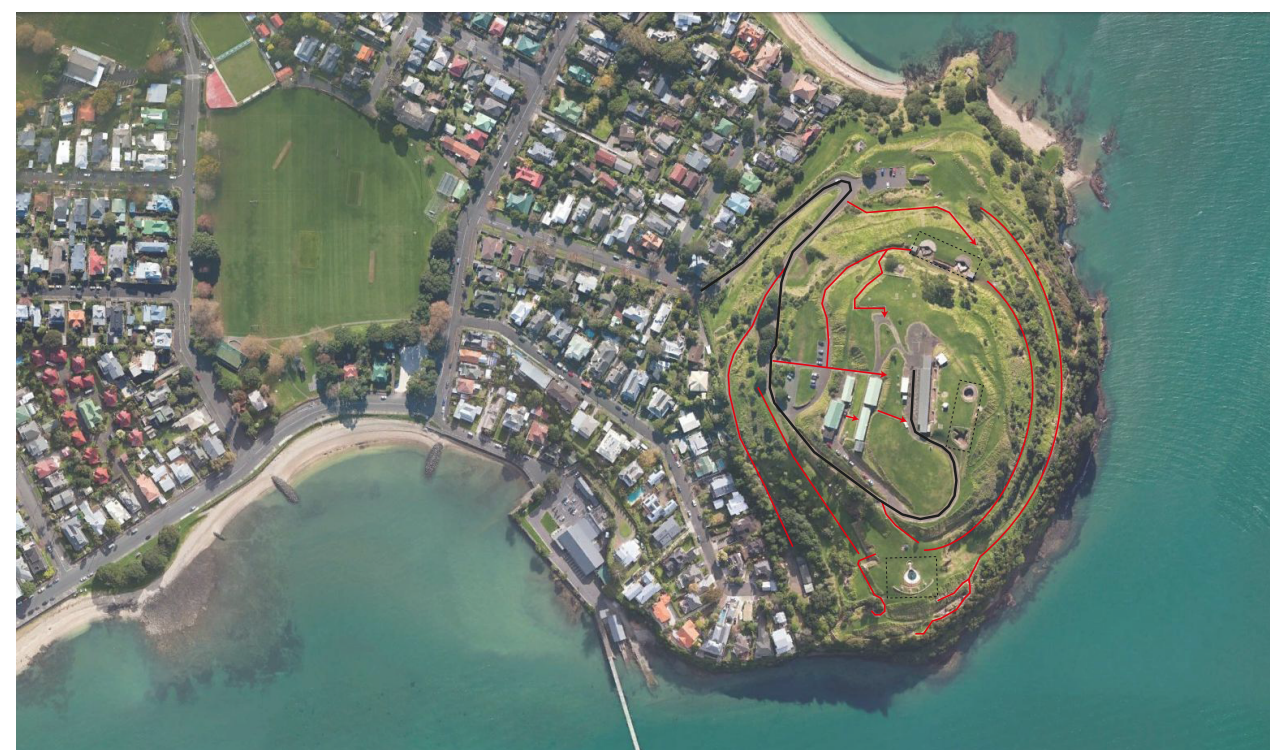

Fig 4.3 North Head Trails.

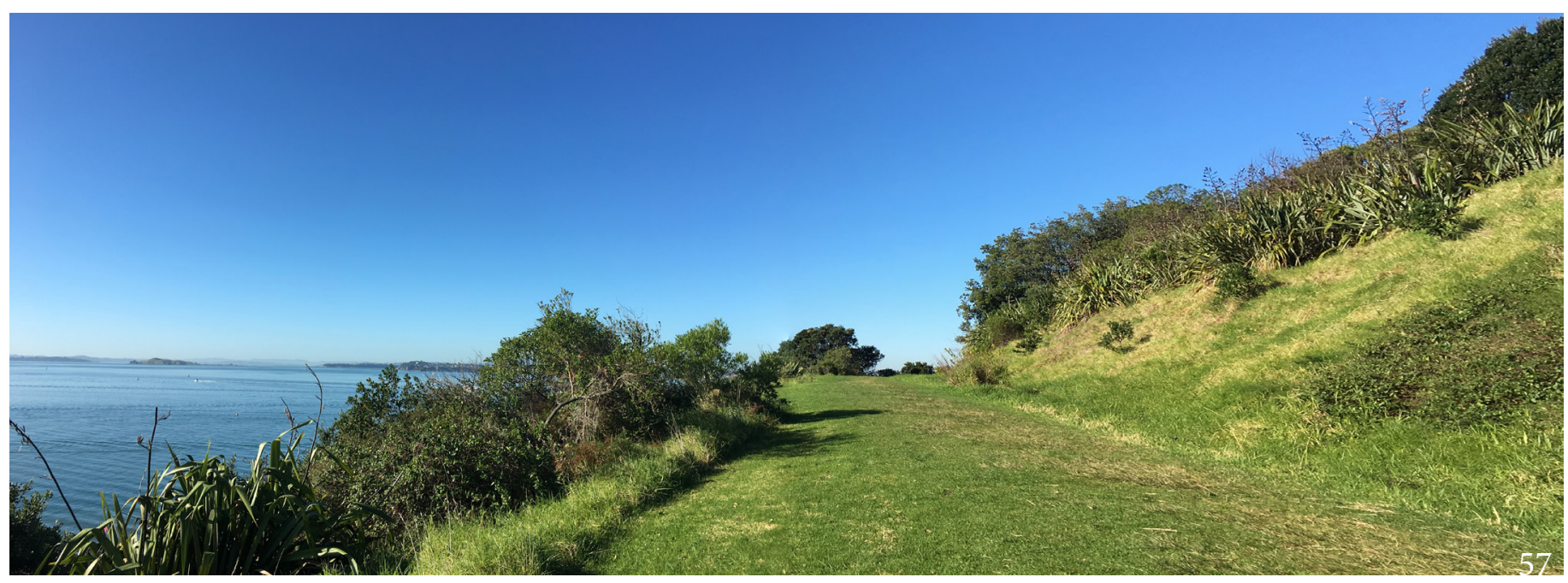




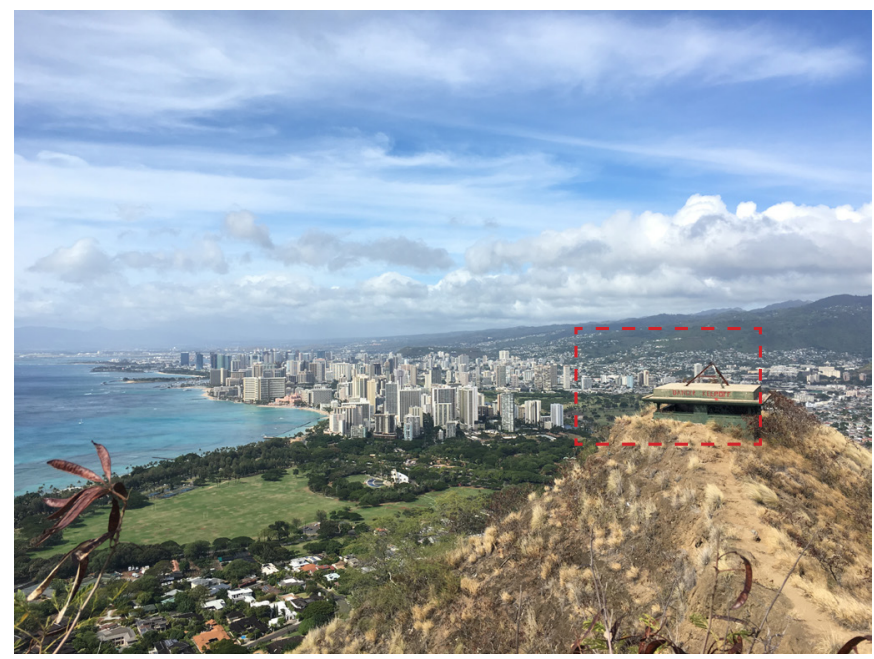

Fig 4.5 View from the rim showing the Waikiki neighborhood and the pillbox at the peak

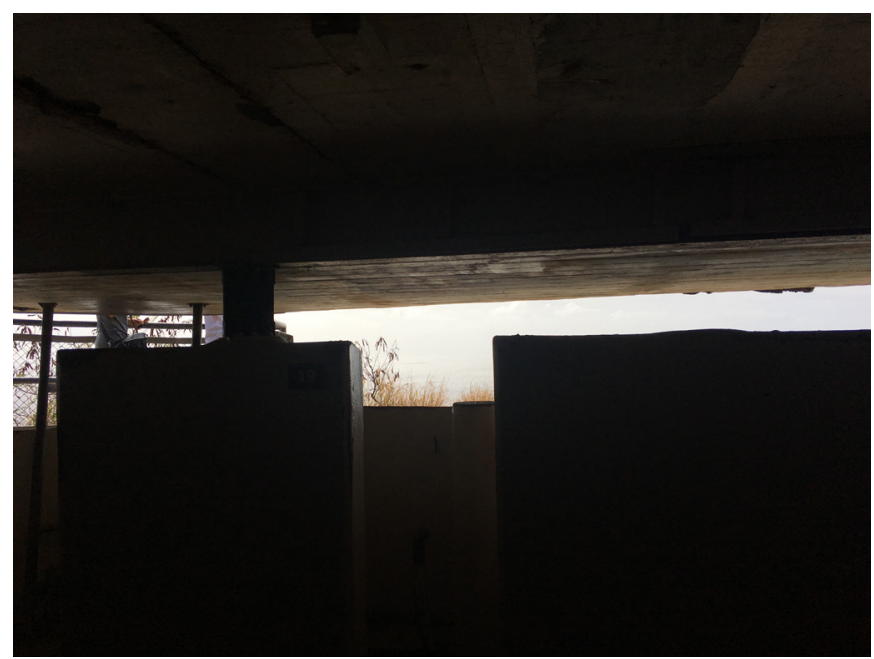

Fig 4.6 Inside the gun emplacement.

\title{
4.2 Diamond Head
}

\author{
Location: Honolulu, Hawaii.
}

The military fortifications of Diamond Head in Honolulu served as the first military reservation in Hawaii. This case study of Diamond Head focuses on the communication of design moves and how to make heritage elements part of people's lives.

Diamond Head is located close to the city with the other coastal defence sites that were designed to protect the city. Diamond Head produces a range of different urban experiences with its surrounding houses, and has become part of their everyday life with local residents allowed to view and walk through it every day. Diamond Head is a popular hiking destination for residents and tourists. The trail run provides opportunities to explore the hidden landscape and its unique site experiences. There is a paved concrete walkway at the start of the hike that then becomes uneven and steep, requiring plenty of caution and the appropriate footwear. Most tend to avoid the inaccessible areas due to the steep slope and safety issues, however, the steep slope and uneven surface also produce a range of types of movements and experiencing for a variety of desires. In this case study, the trail made sure to avoid these factors, adding elements (fig 4.9) such as hand rail, to support people etc. 


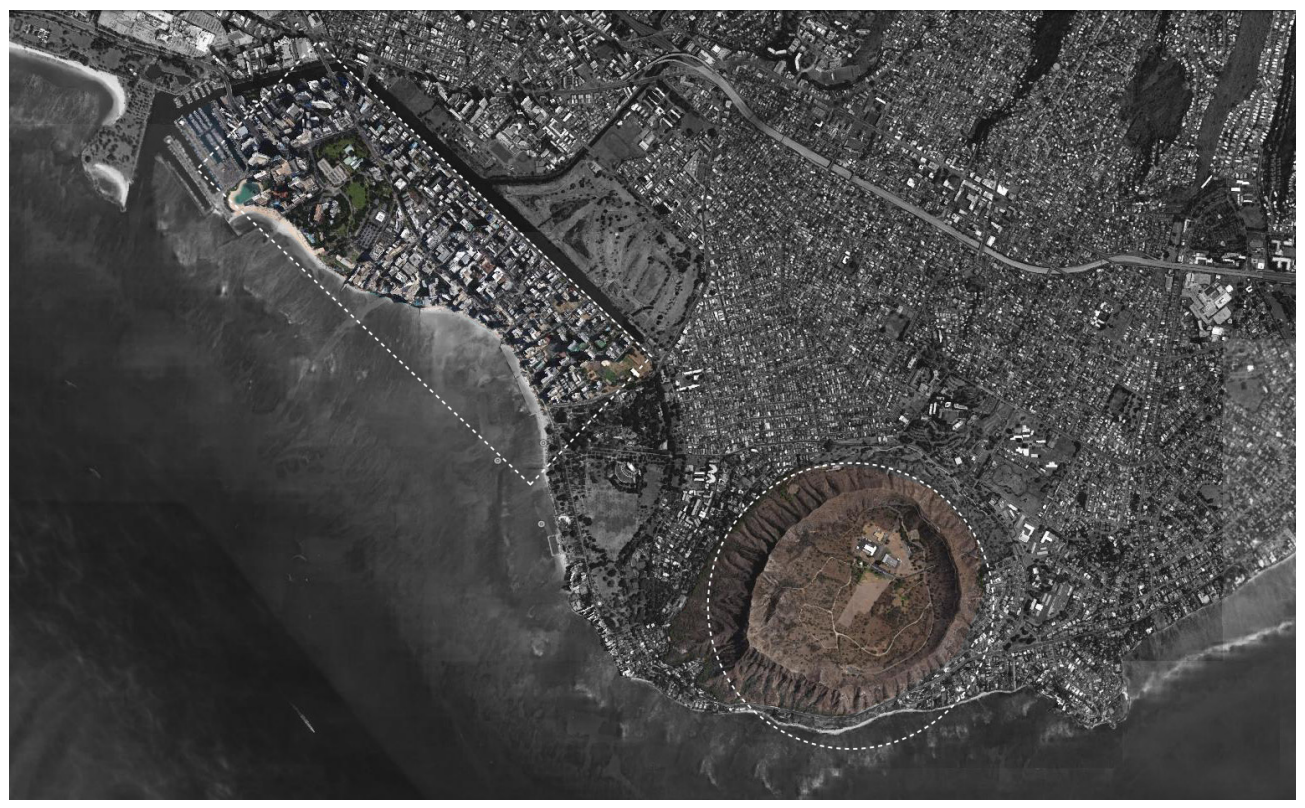

Fig 4.7 Diamond Head Trails.

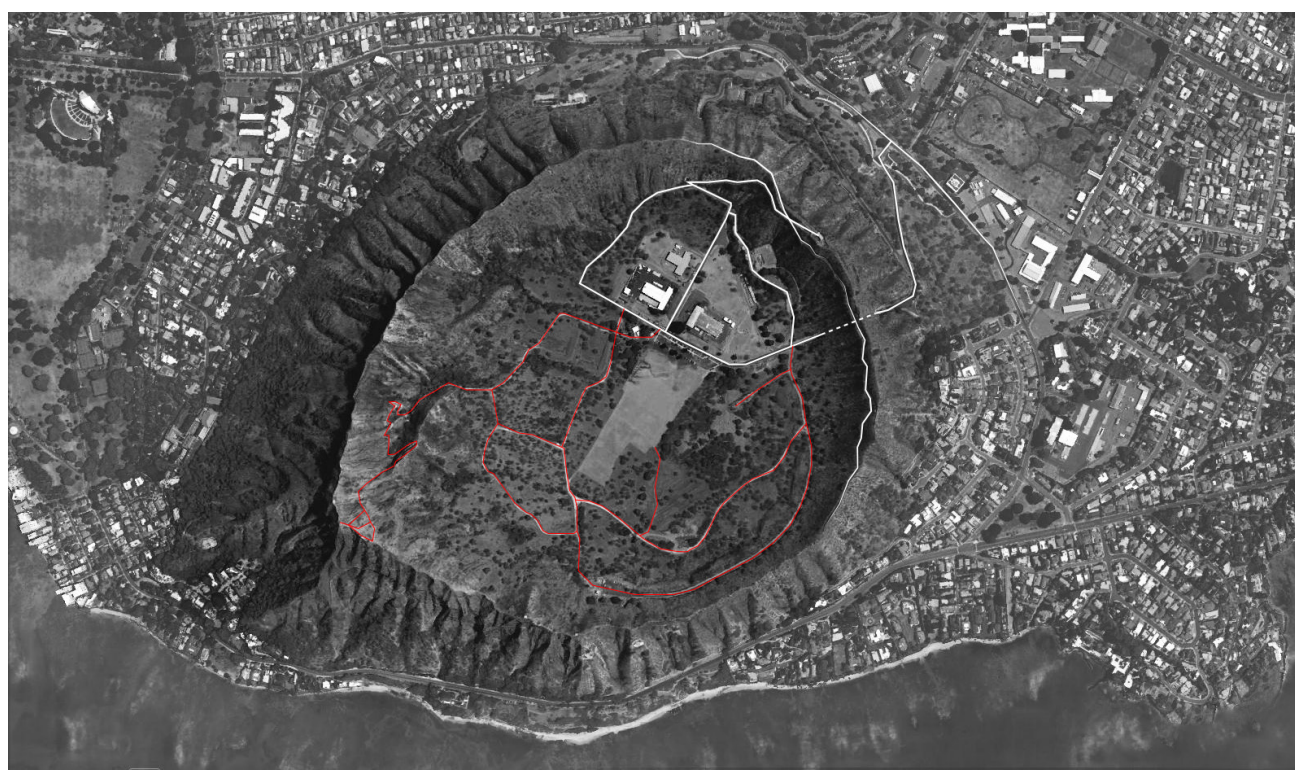

Fig 4.8 Diamond Head in urben setting.
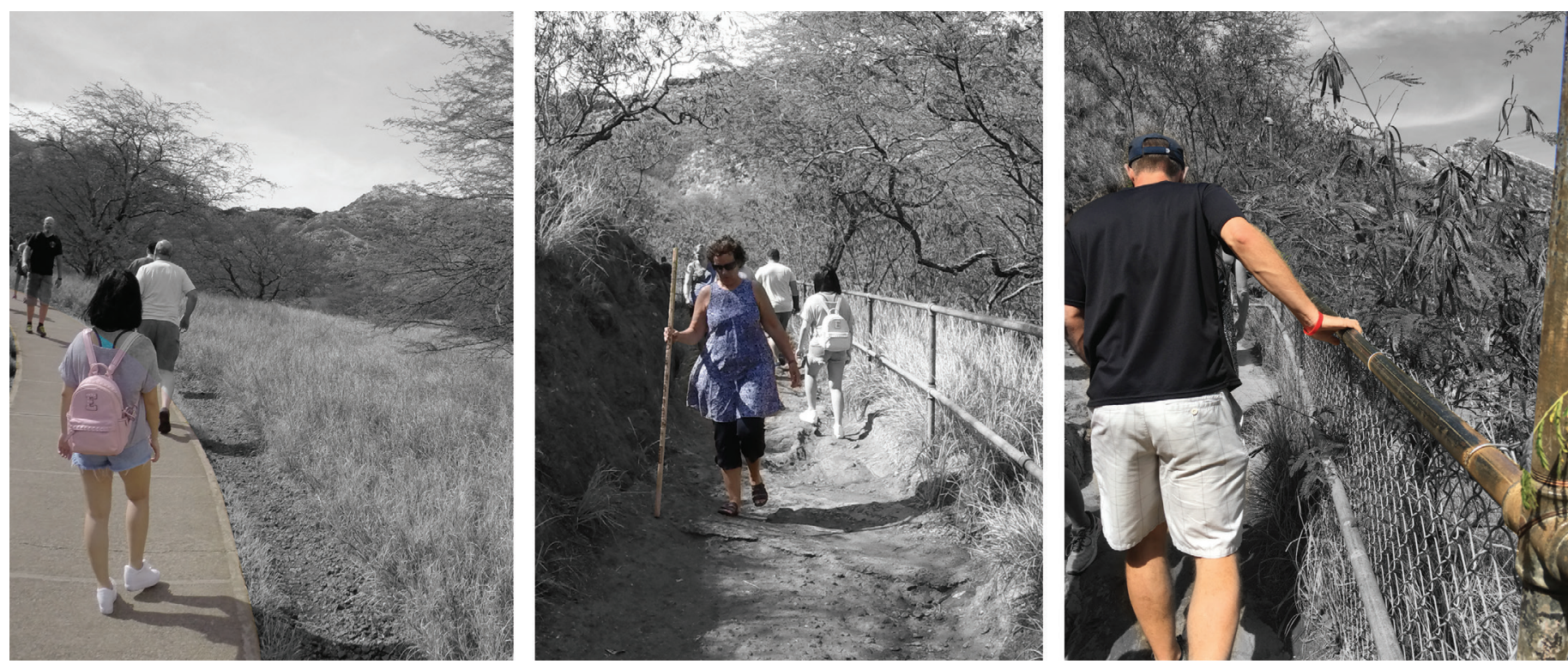


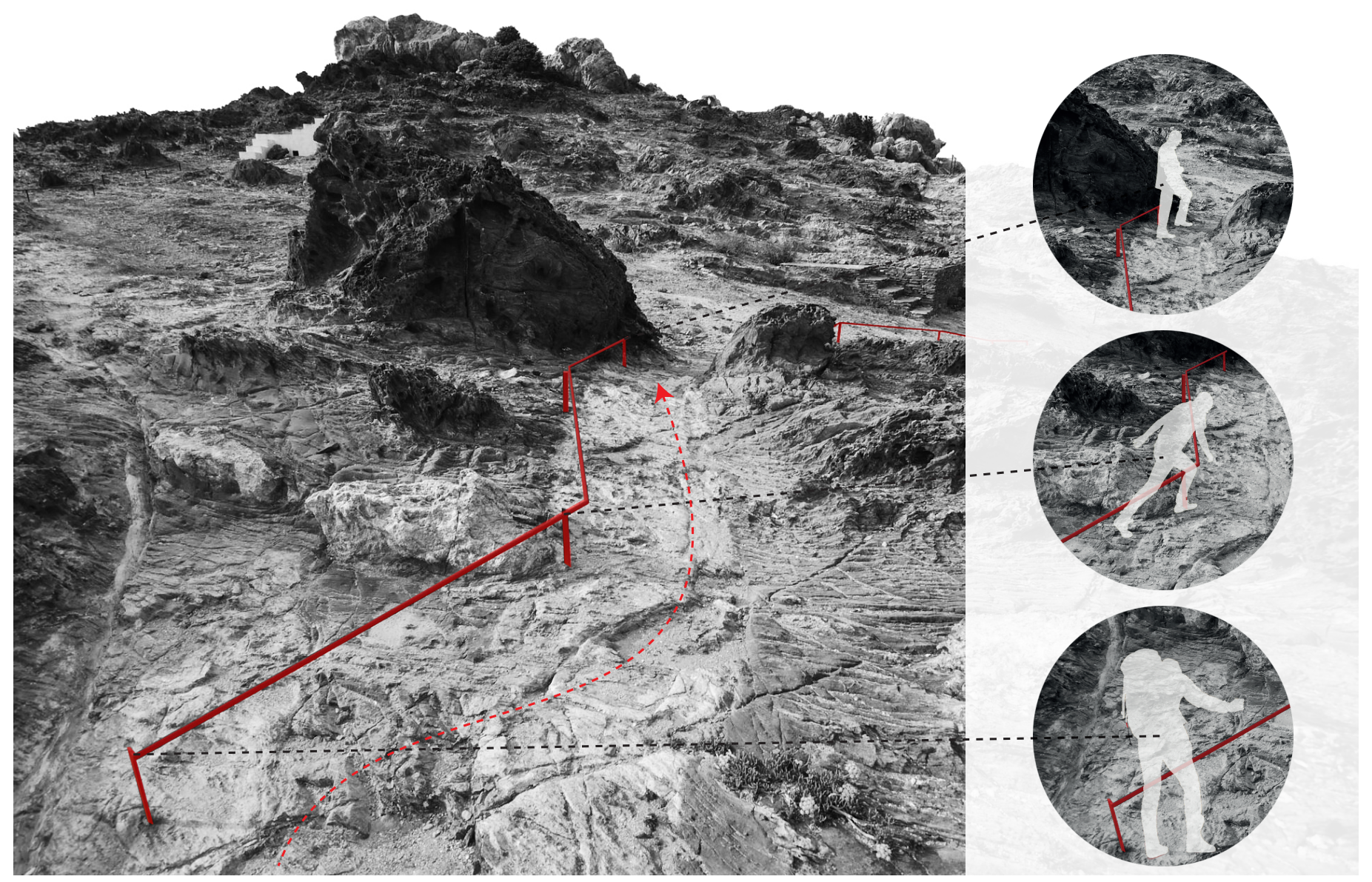

Fig 4.10 The metal rails lead people to walk the unaccessible area.

\subsection{Tudela, Spain}

Location: Tudela, Spain

Tudela is located on the eastern tip of the Iberia Peninsula. Key to the success of this project was the dismantling of 430 Club Med buildings. This removal helped instigate a revival of ecological relations on the site and coastline.

The man-made elements of the final design are employed to highlight the richness of site. Informal routes are defined by ankle-height metal railings (fig 4.10). The zigzagging layout explores the most navigable route giving users visibility. The metal rail creates is a subtle device to orient users focus towards heritage aspects. These elements do not just focus on a heritage item but interact with the whole environment and the other interventions and movement system. 
Thin metal rails on the ground suggest a potential way onto the rock, forcing people to look down, grope and even to crawl on the stone.
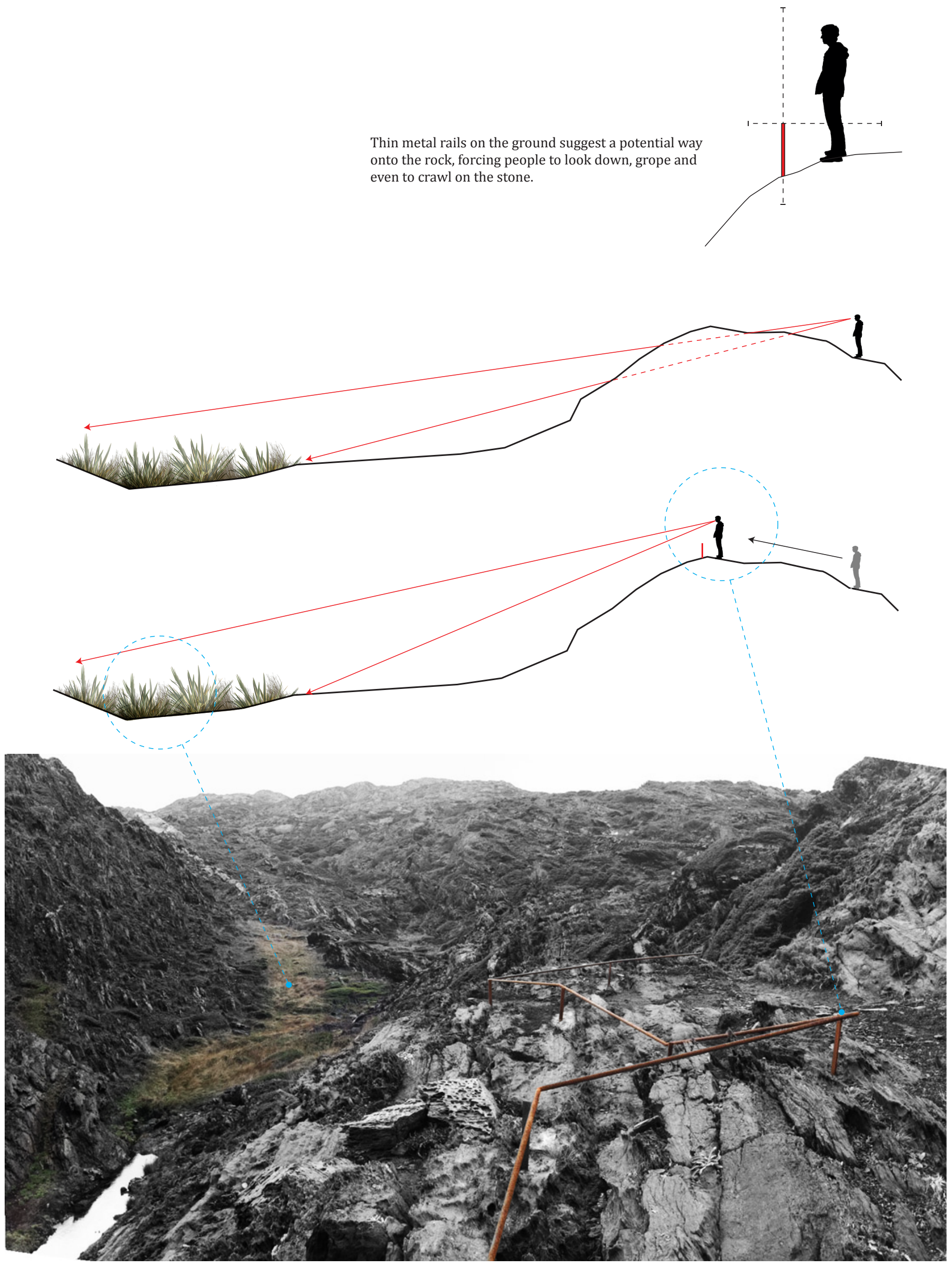


\subsection{Conclusion}

North Head and Diamond Head are relevant to Watts Peninsula for the variety of ways that they interact with people's lives. Each type of interaction adding ways to potentially bring to life the site and its heritage places and structures Diamond Head and Tudela proved alternative means to explore the richness of landscape and types of experiencing, which in turn shifts and intensifies ways to experience heritage. 


\section{EXPERIENCES}

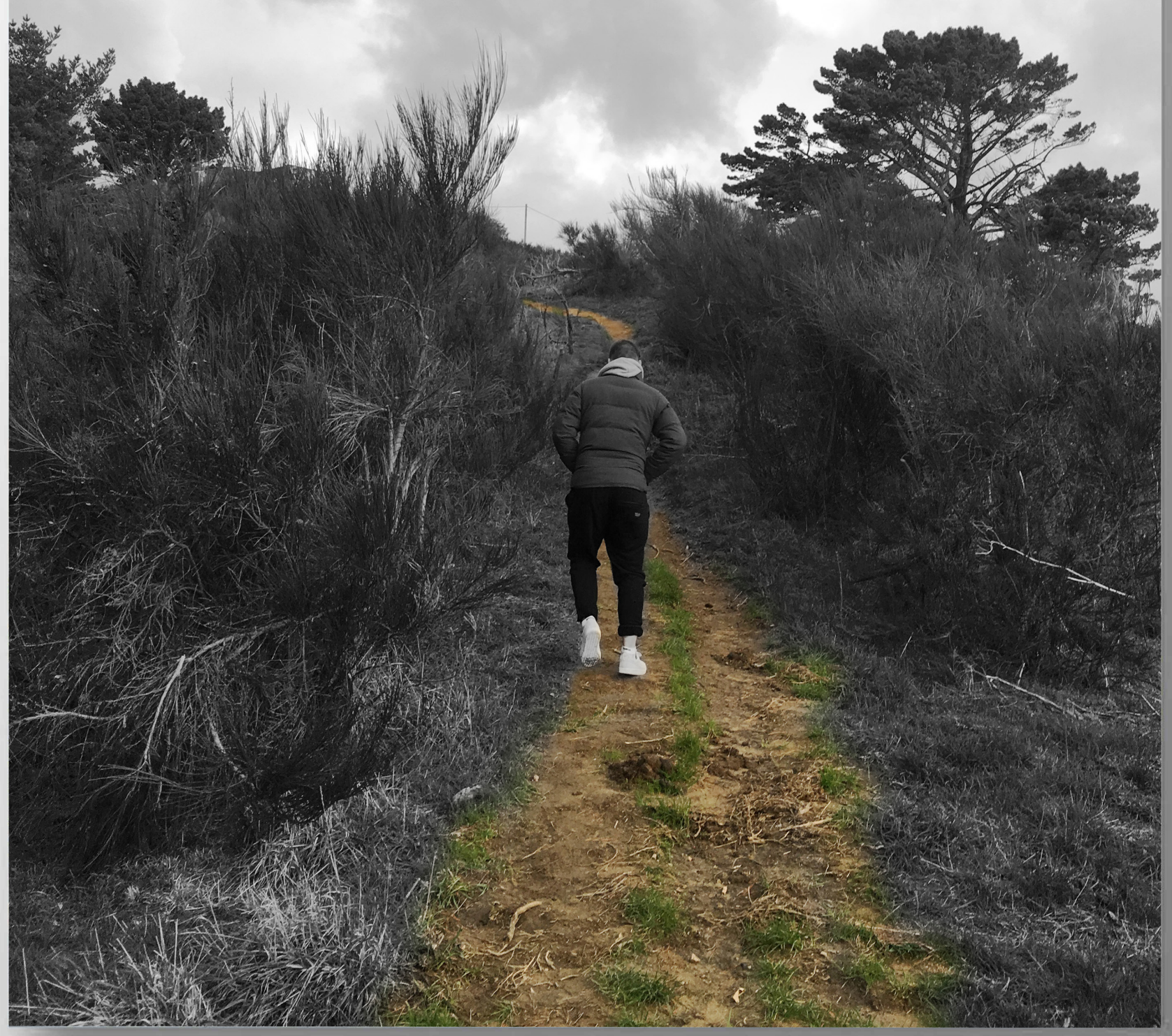




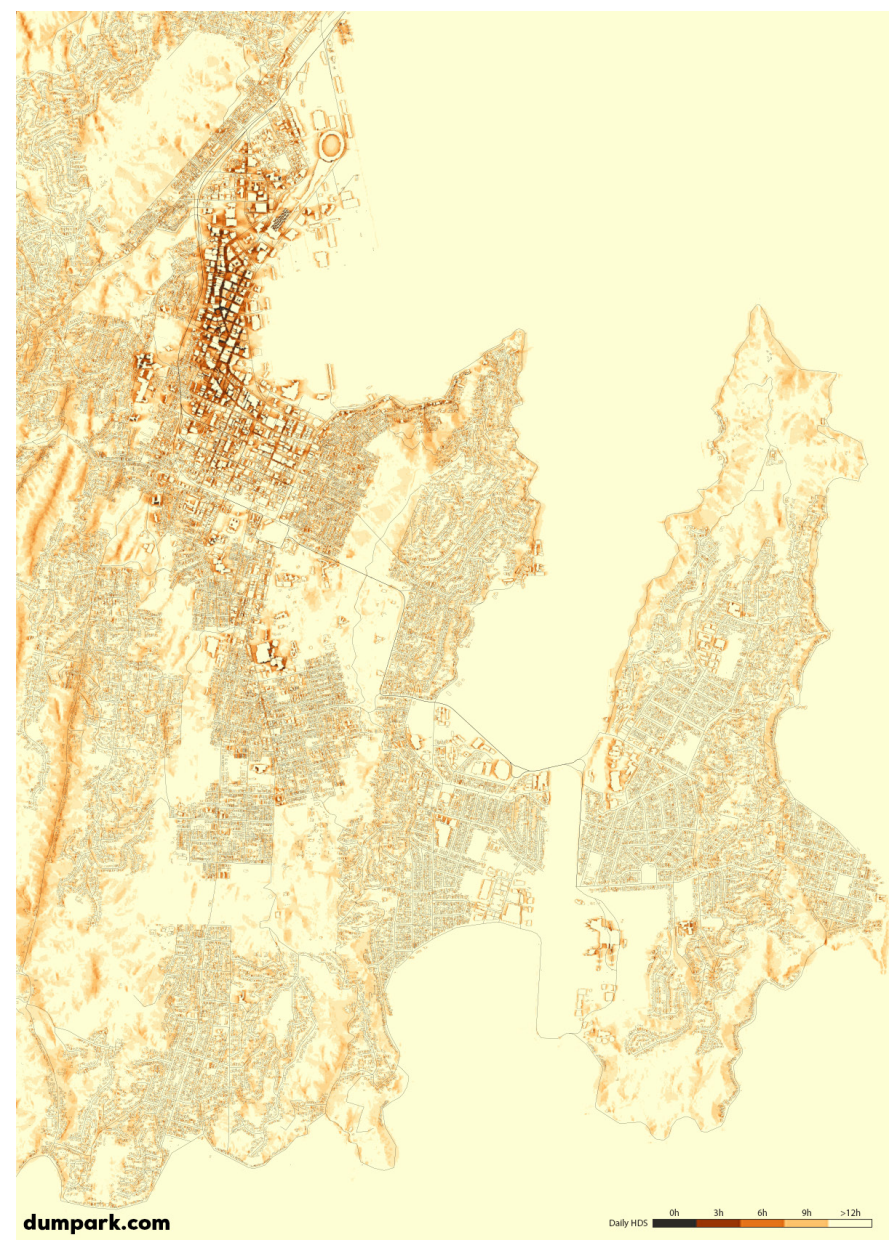

Fig 5.2 December Fullday sunlight

Above The diagrams show the number of daylight hours for Wellington for summer and winter for the city as a whole.

Information sourced from DUMPARK. app. dumpark.com/sunlight.

\section{Introduction}

This chapter explores differenttypes of experiencing produced by the landscape and the various factors involved in their production. The various factors of the site come together with certain human desires and expectations to facilitate certain types of movement and experiencing. These types of movement or experiences are involuntary powers produced by us and our interaction with the world. We enjoy and experiment with their emergent powers more or less consciously.

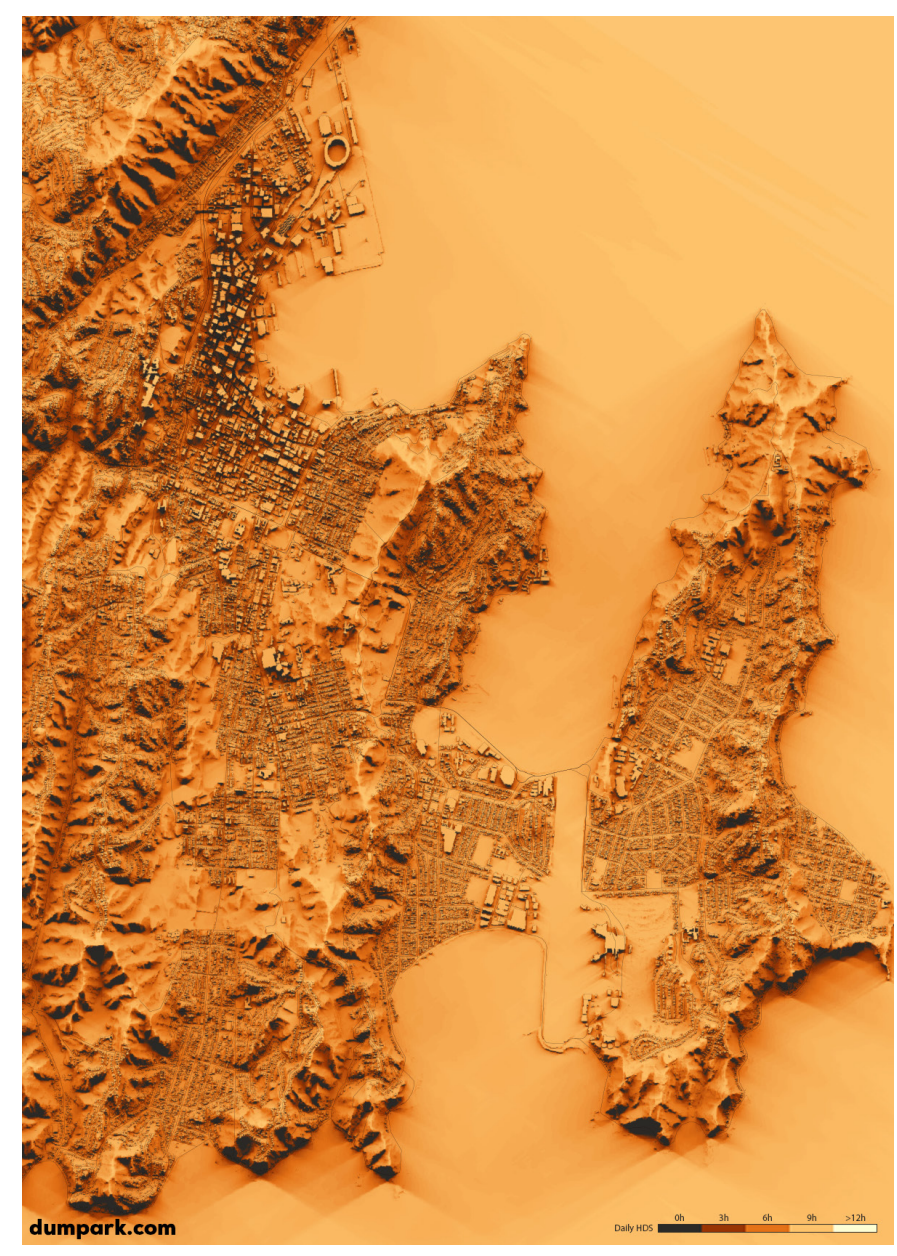

Fig 5.3 June Fullday sunlight

\subsection{Sunlight Analysis}

Right The diagram show sun and shade for various times of the day. The eastern side of the peninsular has more sunlight in the morning and the western side has more sunlight in the afternoon.
Below Right The photo was taken in 26 July, 2016 at 16:30. Sunlight illuminated the western end of Miramar Peninsula and increases it's amenity. 


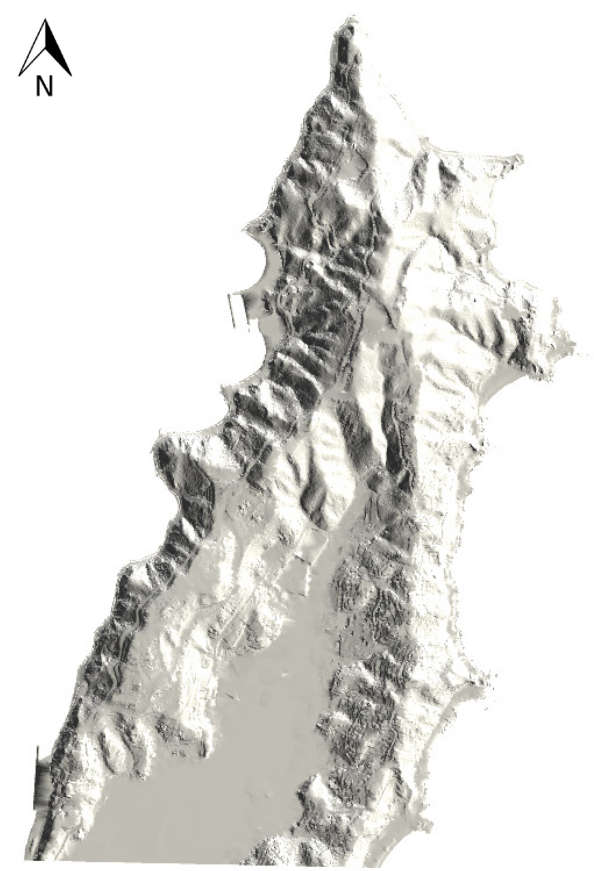

December 8am

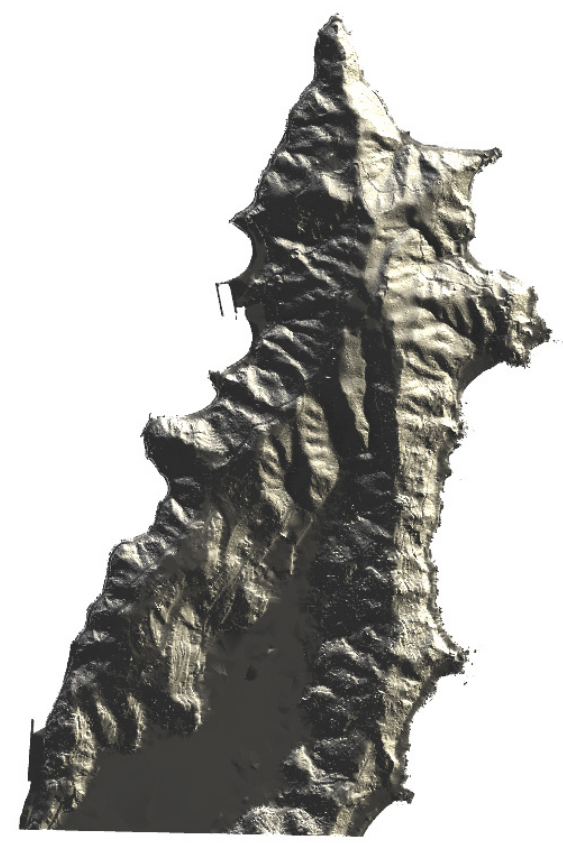

June 8am

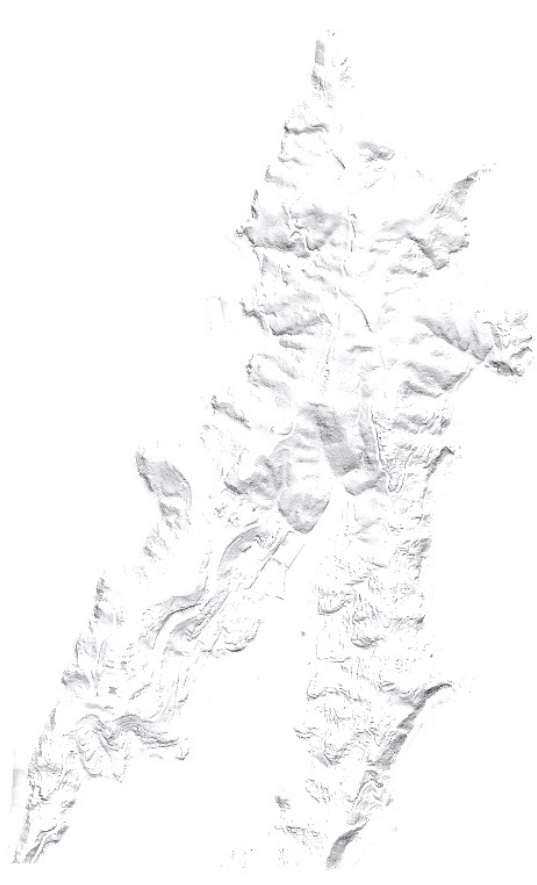

December $12 \mathrm{pm}$

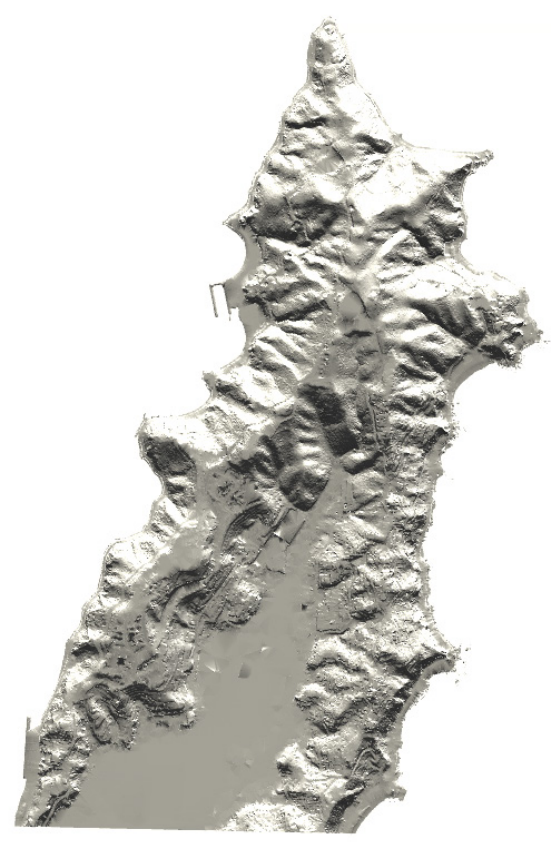

June $12 \mathrm{pm}$

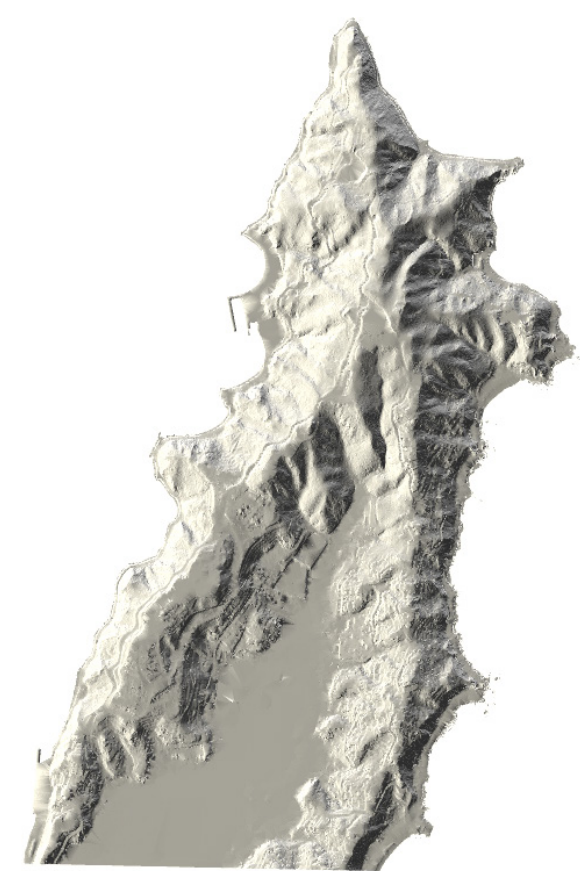

December $5 \mathrm{pm}$

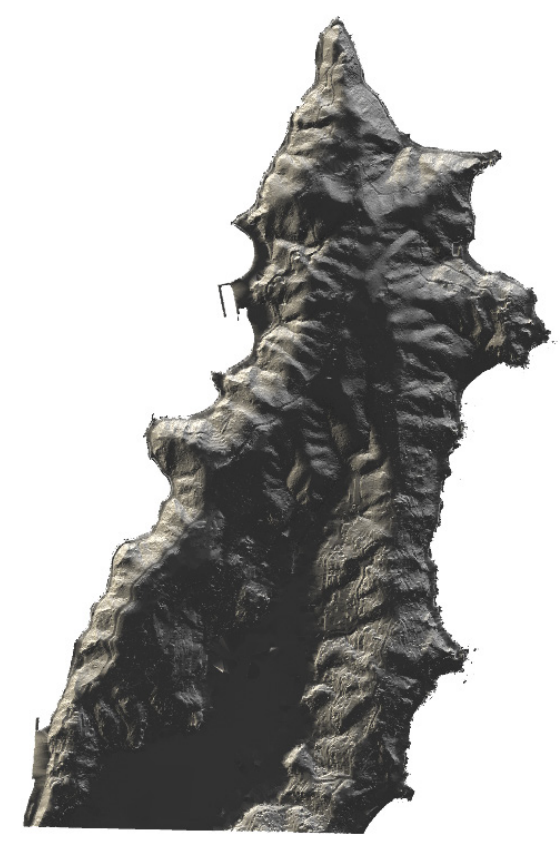

June $5 \mathrm{pm}$

Fig 5.4 Sun and shade of Miramar Peninsula in different time. 


\subsection{Topography}

The physical landform is highly variable, ranging from relatively flat areas on two ridgelines to pockets of gently sloping areas near the central spine of the ridge to steep coastal escarpments. Ridgelines and hilltop spurs tend to be predominantly pastoral and open in nature, whilst the lower slopes and steep escarpments are largely vegetated. Some of the steep and sensitive areas are inaccessible (unsuitable for development). The physical landform is dramatic. It is a landscape that contrasts with the city.

1

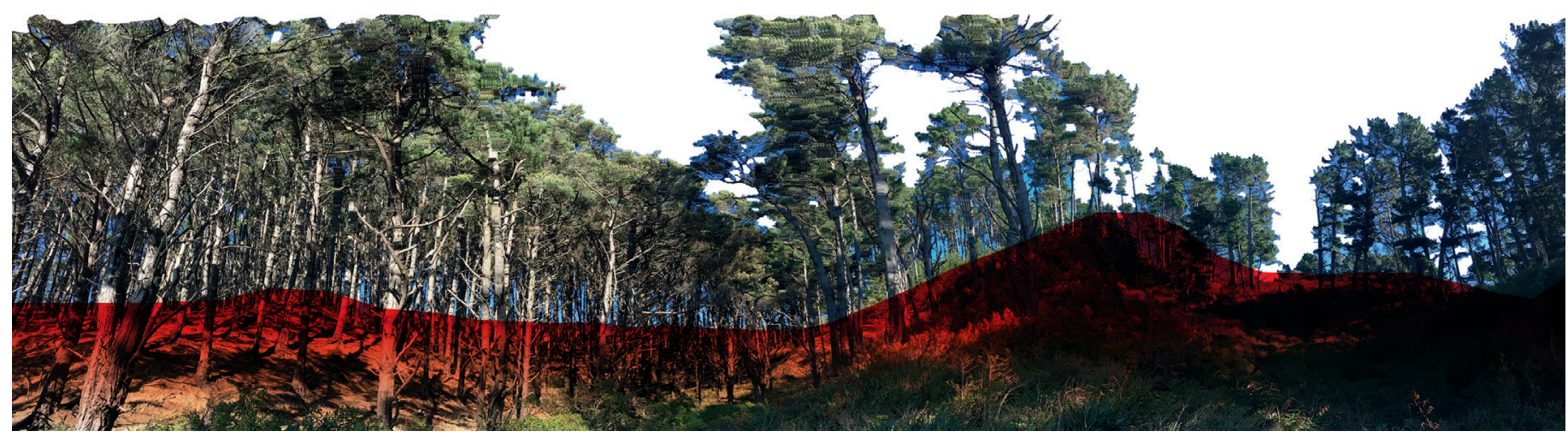

Fig 5.5 The ridgeline orients people towards.

2

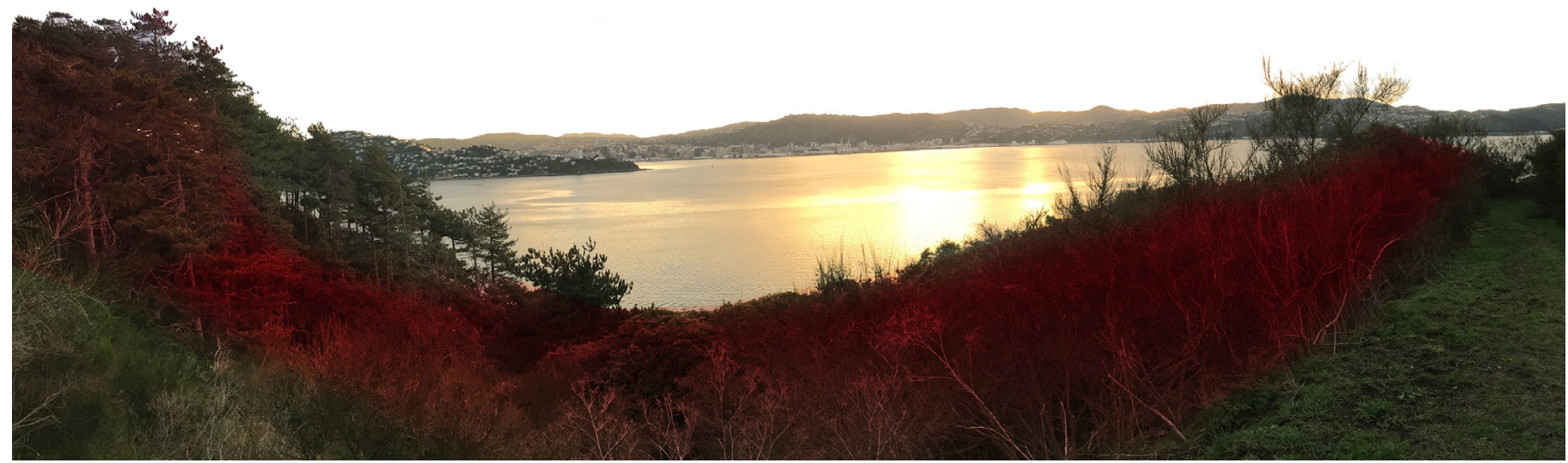

Fig 5.6 The valley covers by vegetation.

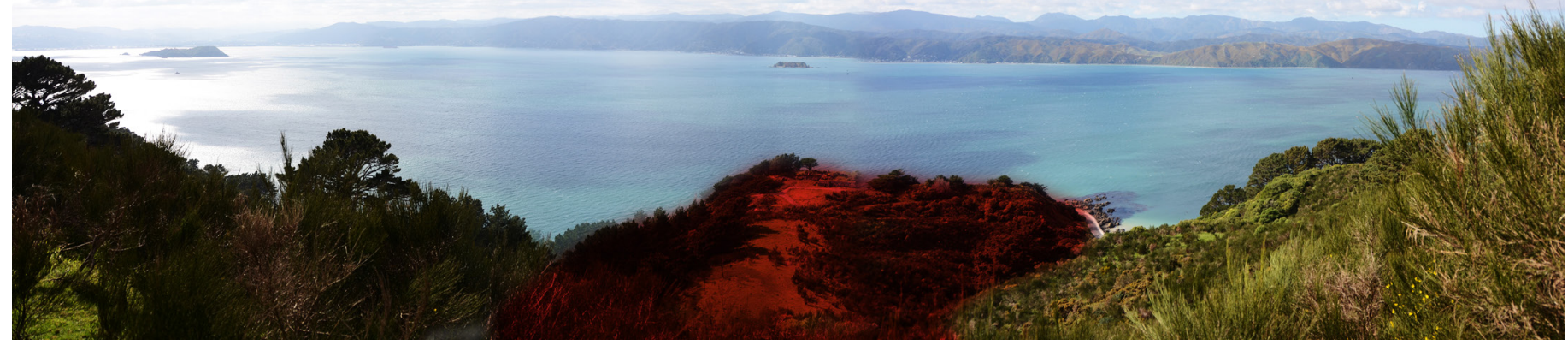

Fig 5.7 Point Gordon view from Mt Crawford.

Above Wherever you are the landscape around you orients you towards other parts of the landscape. 


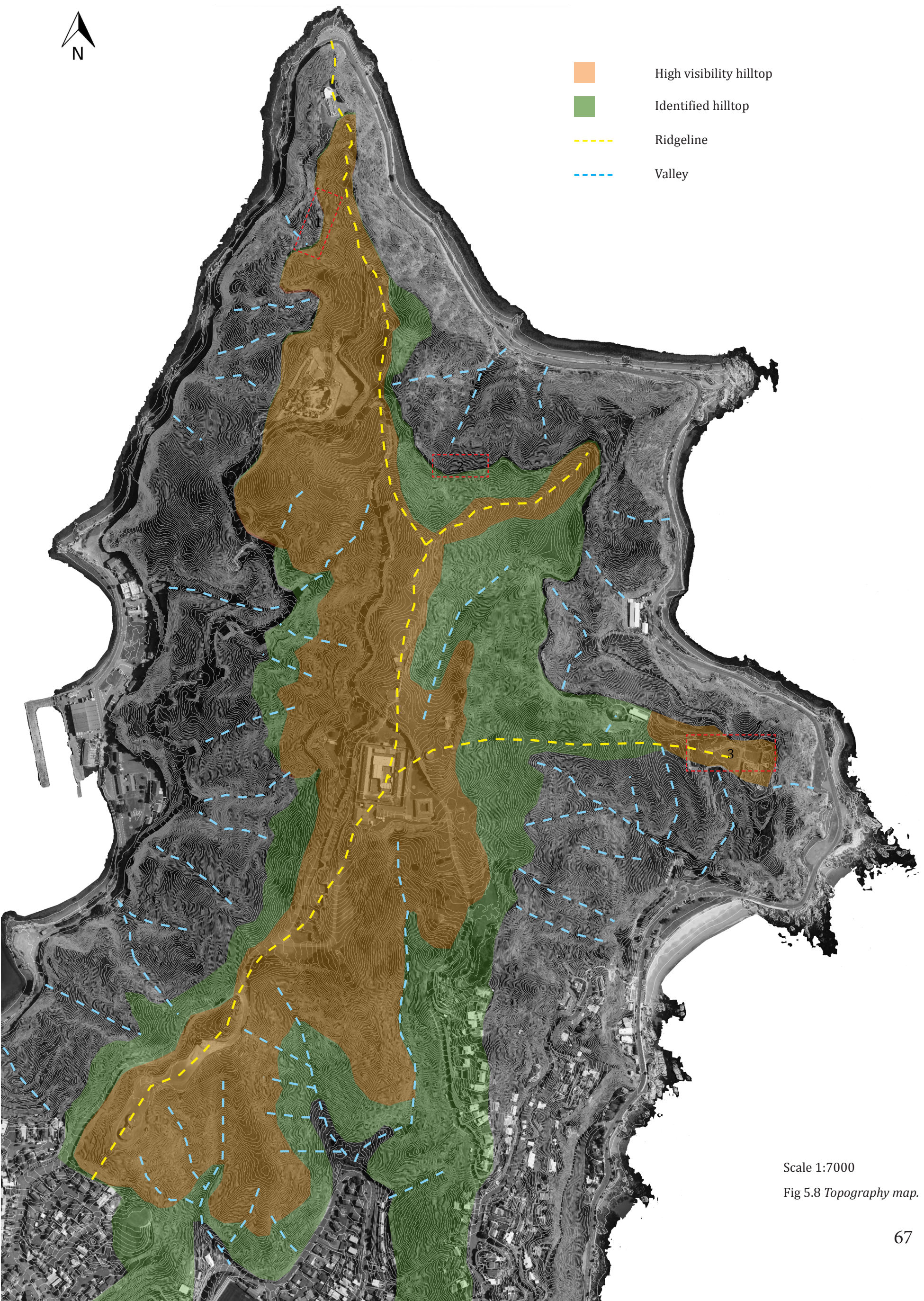




\subsection{Landmark}

A landmark is not just a high visibility landform or object. Massumi argued landmarks are like magnetic poles that vectorise the space of orientation. By this he means that they are set up involuntary movements in the landscape if the landmark suits or incites a particular human orientation or desire. The map shows the landmark points within the site. These effectively get people to move around and create connections between and then facilitate a network generated from the points. A network where the points might facilitate movement but the movement in itself real, an involuntary for a particular to the movement. This suggests an ecology of movements and experiencing.

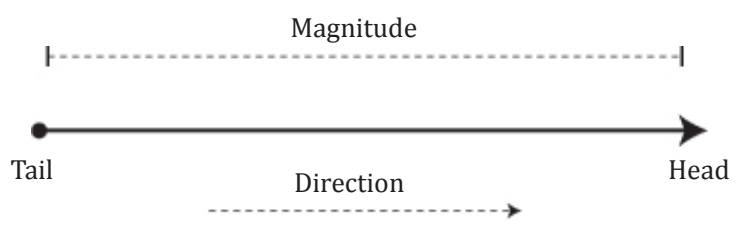

Fig 5.9 Vector in physics.
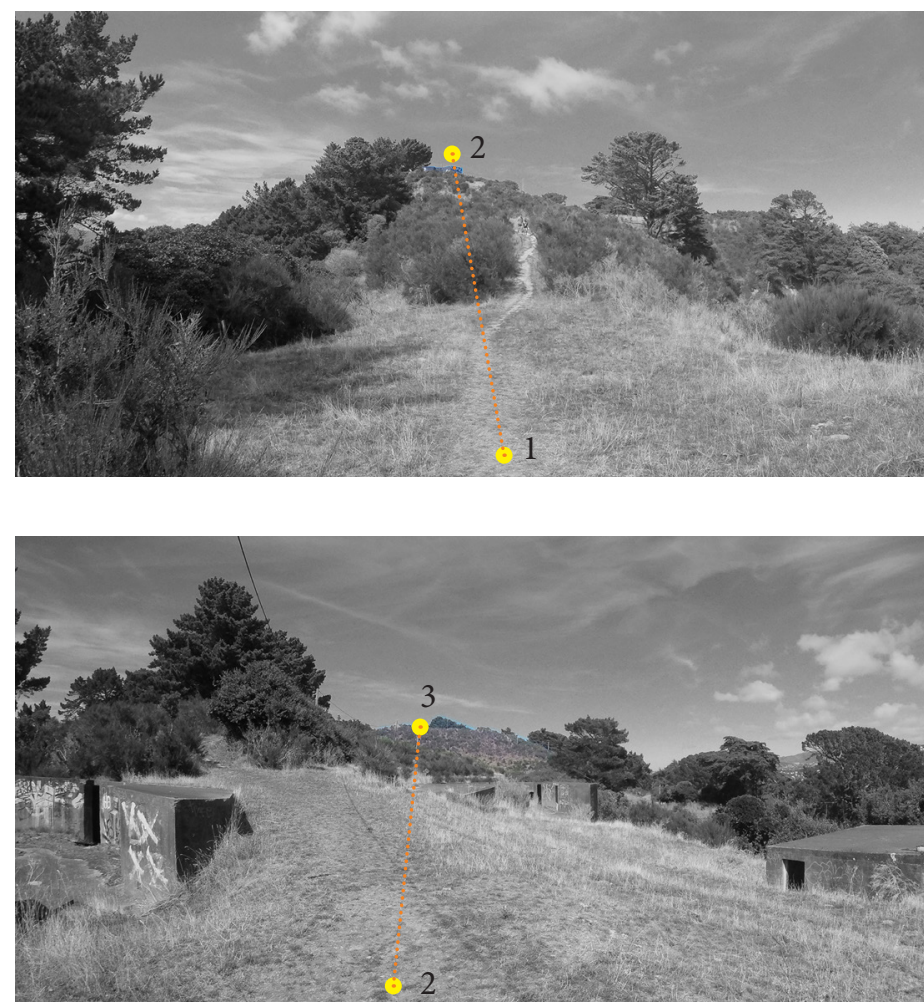

Fig 5.10 Suggested direction.

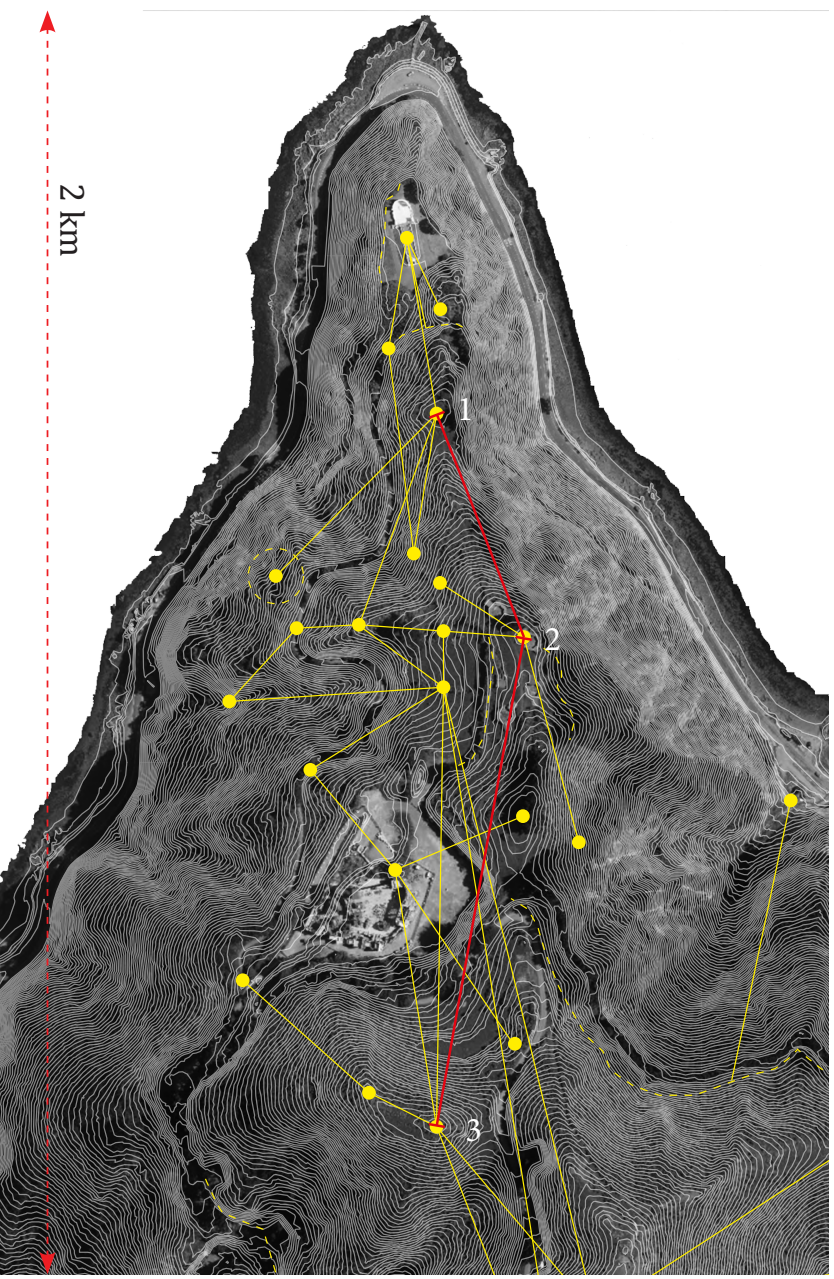

Fig 5.11 Directions on top of site.

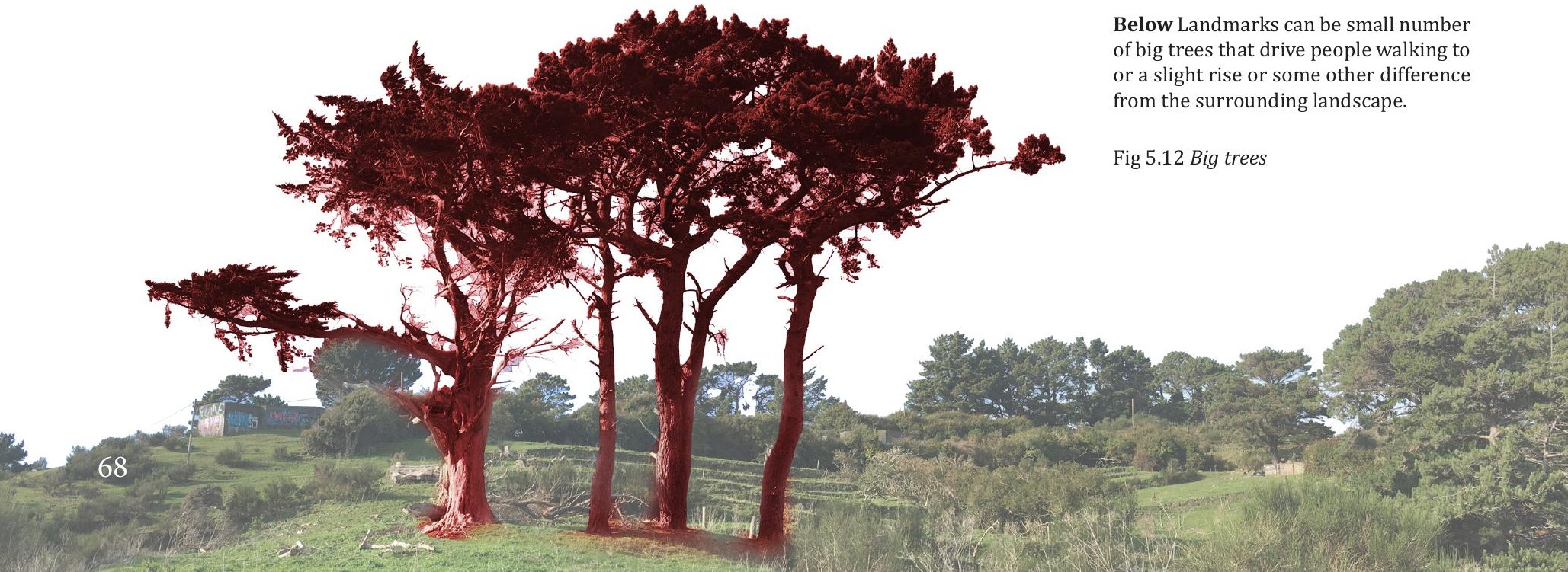


Open Forest

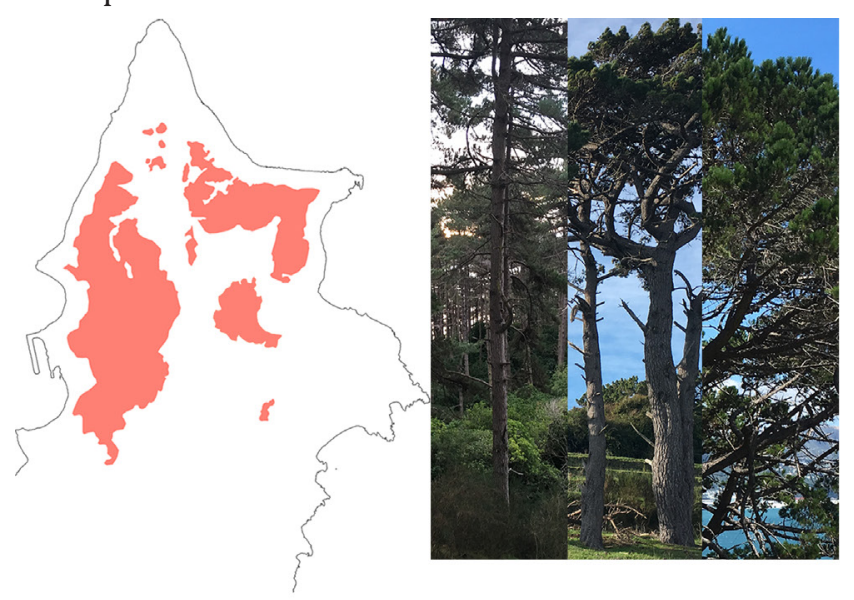

Dense Forest

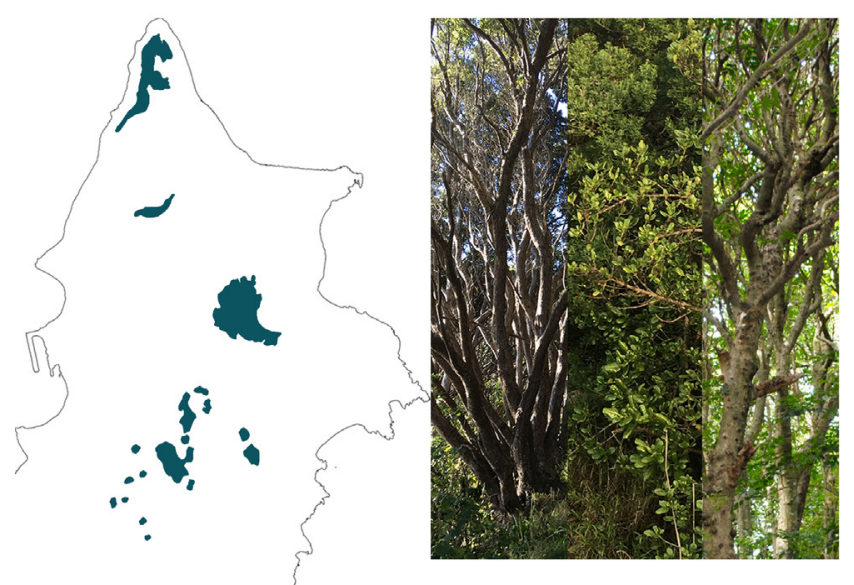

Rich Scrubland
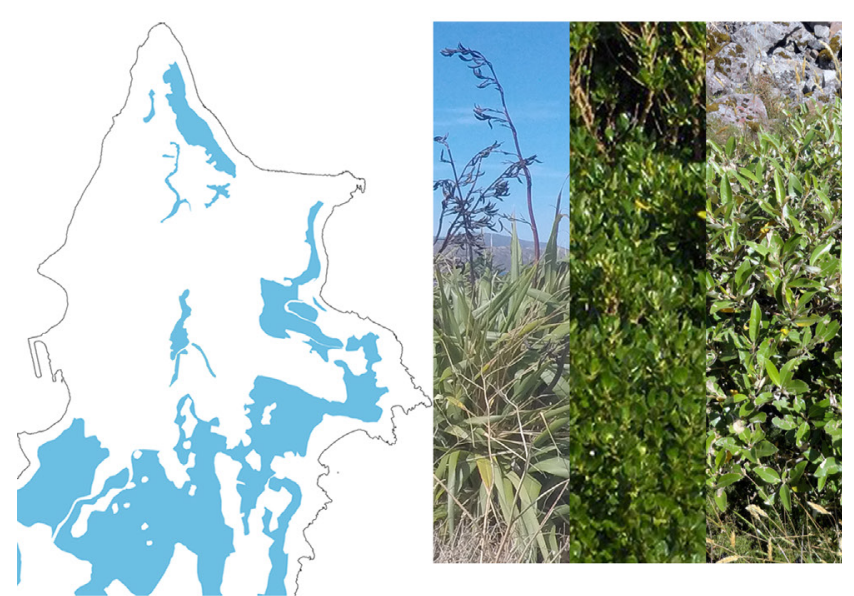

Exposed Shrubland

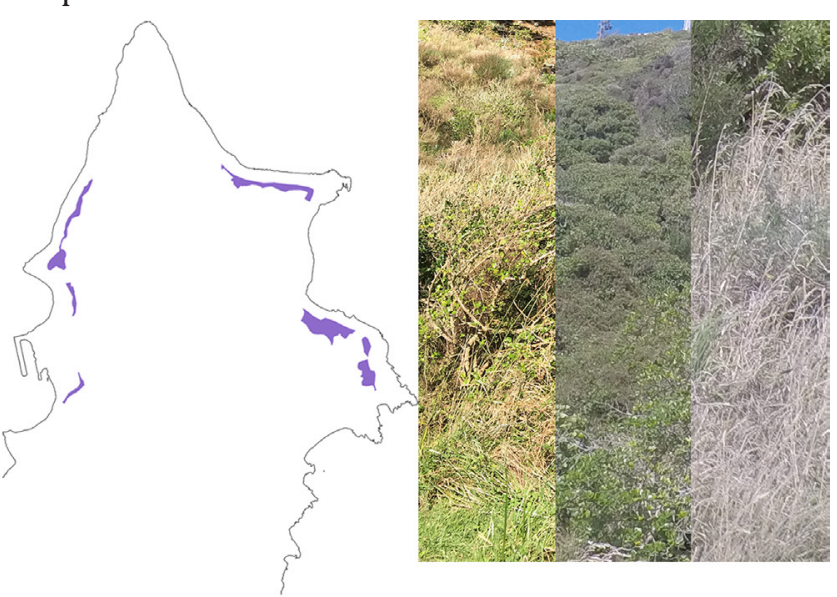

Enclosed Broom

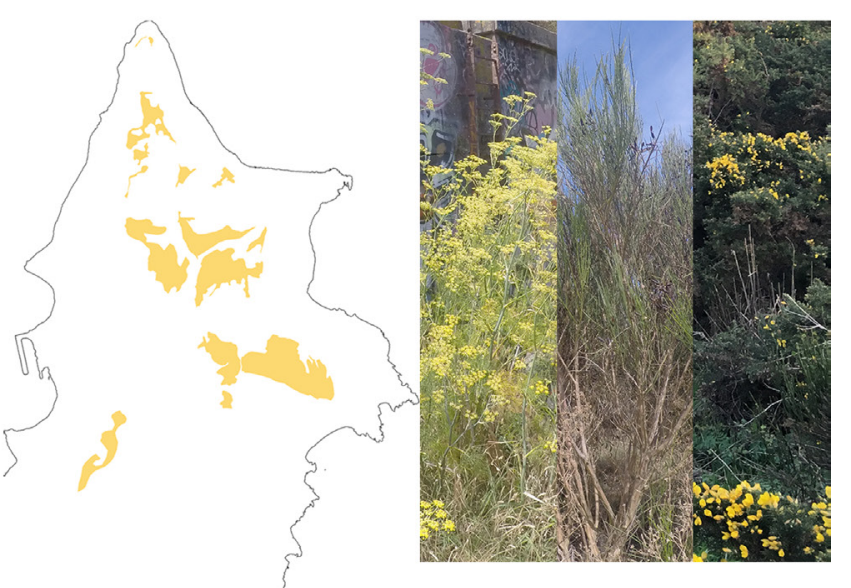

Open Grassland
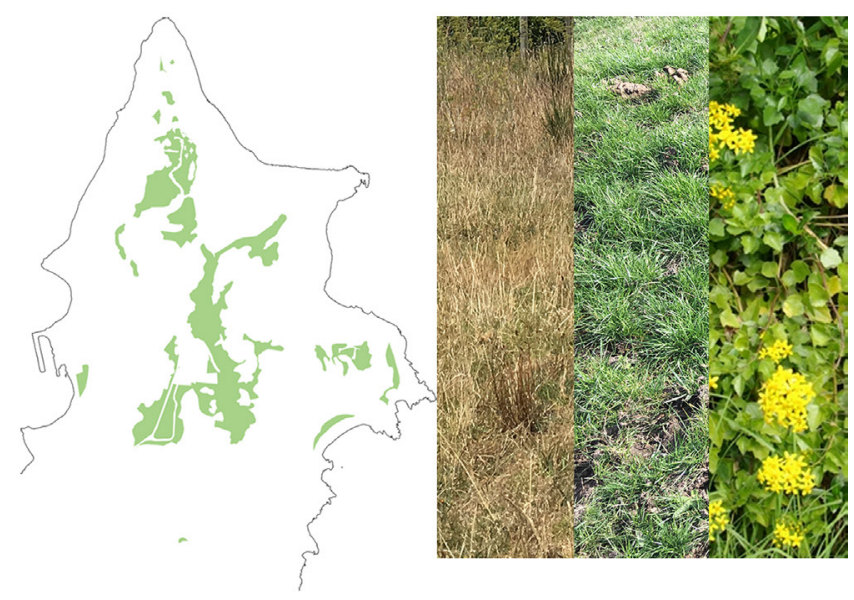

Fig 5.14 Six types of vegetation experience.

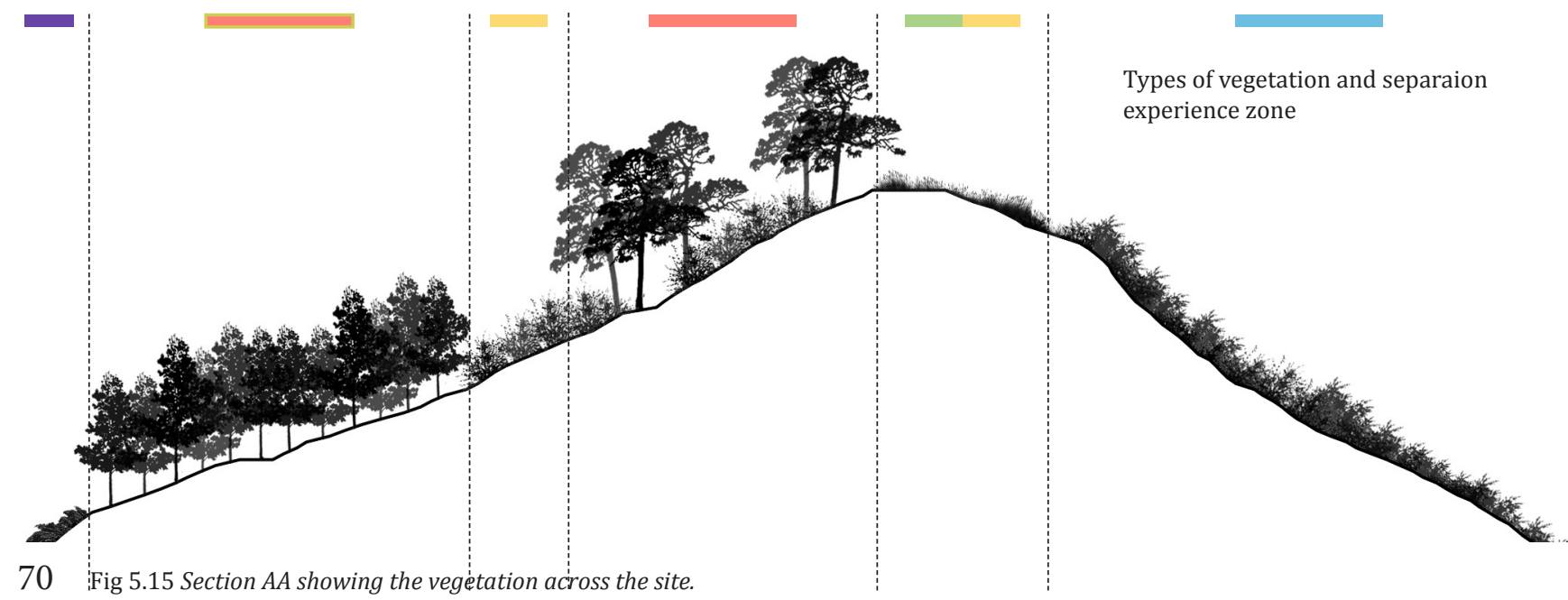




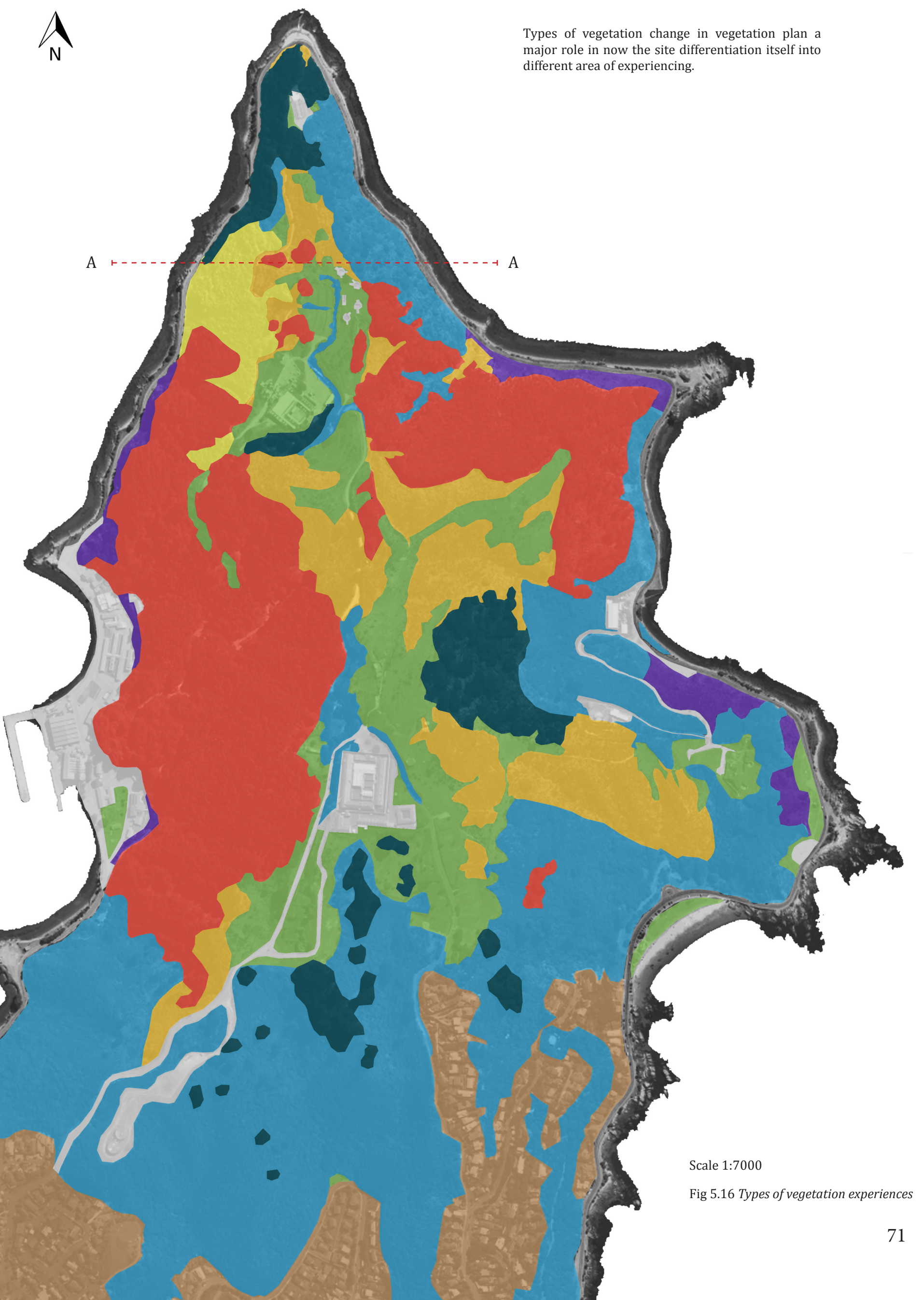




\subsection{Vegetation}

The mapping comprised of six different experience types found within the existing vegetation. Each documentation of a type of experience uses a series of images corresponding to shift in views experienced during walk-throughs of the vegetation. This study focused on the description of both the conscious and involuntary experience of a walk-through of different vegetation-space.

Walking on grass is differentiating from walking in broom area
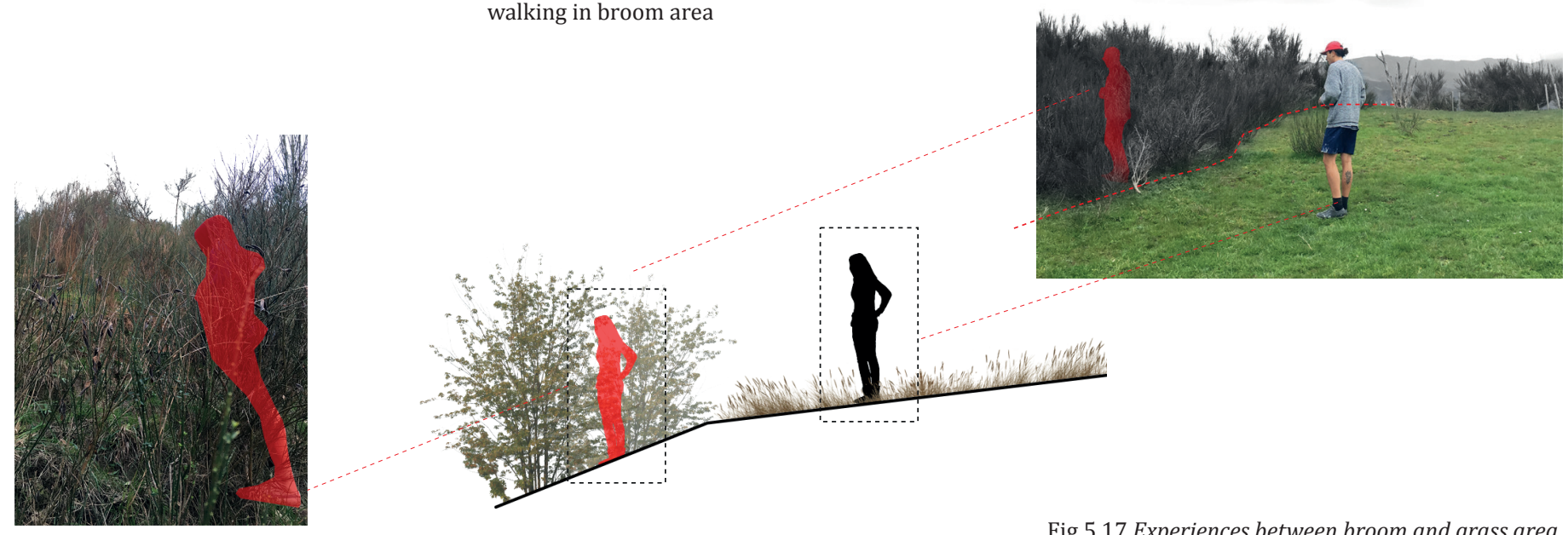

Fig 5.17 Experiences between broom and grass area.

Fig 5.18 Patches on site.

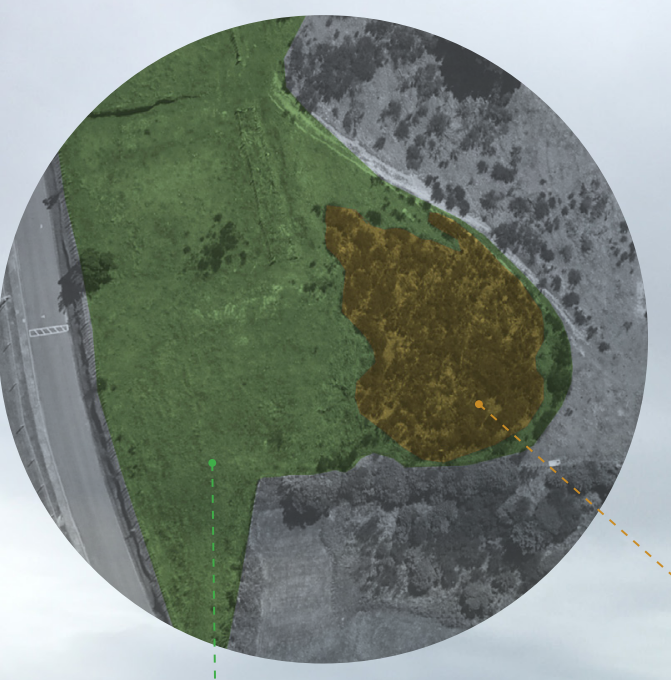

Patches

'Patches represent a landscape or habitat type that is distinct from surrounding conditions. Depending on the scale at which the landscape is observed, patches can be as small as a single tree in a sagebrush prairie, or as large as a forested slope on the side of a mountain.'

-Ecological design p. 68 

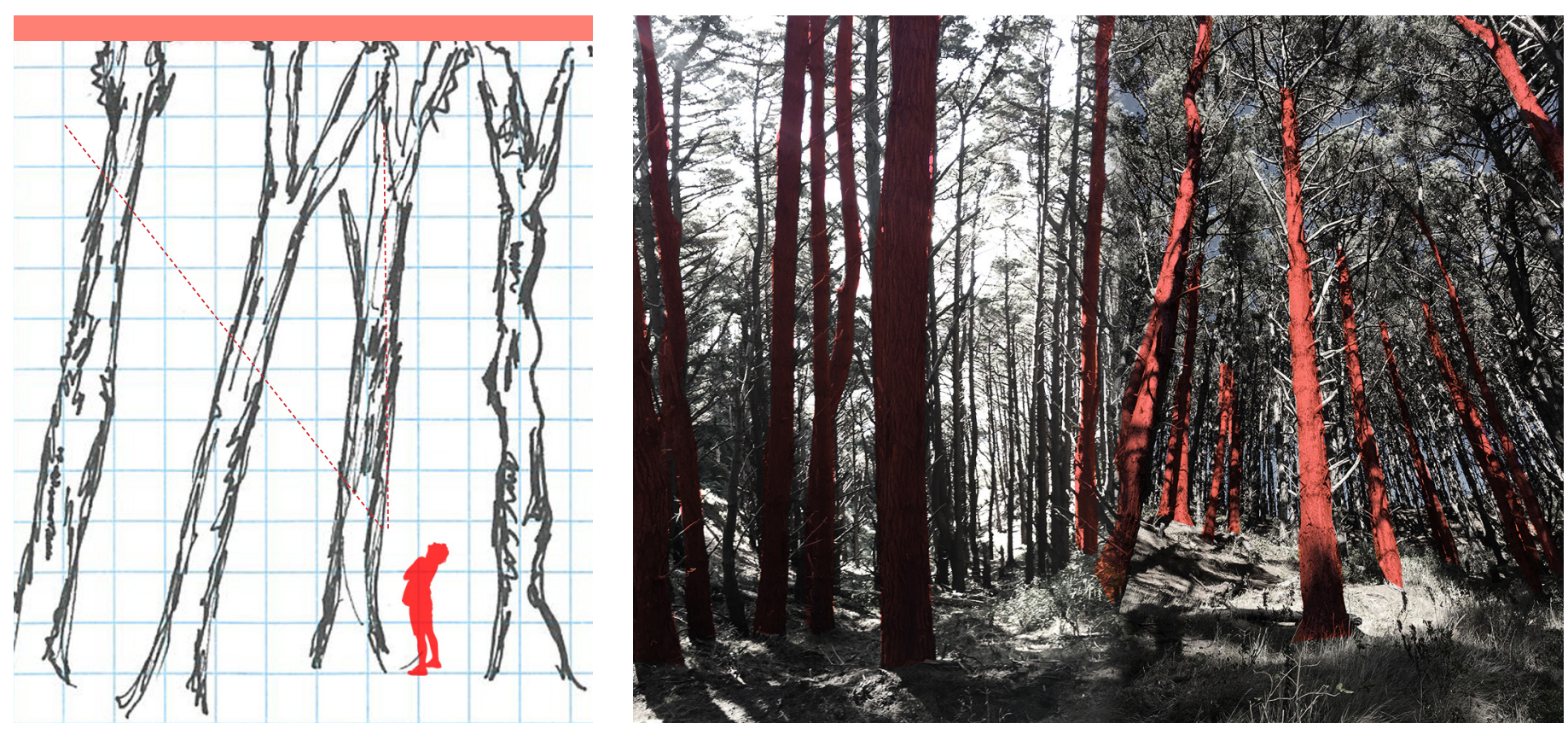

- Sheltered environment

Fig 5.19 Experiences in pine forest.

- Create powerful landscapes which can enclose the person

- Have clear spaces underneath allowing access and views

- Steep slope

Types:

Pine, Red pine, Totara
Facilitate a movement up or down slope seeking strategic tree in the distance to provide the next destination. Movement zig-zag up or down slope between an encompassing canopy on an open-ish undulating floor.
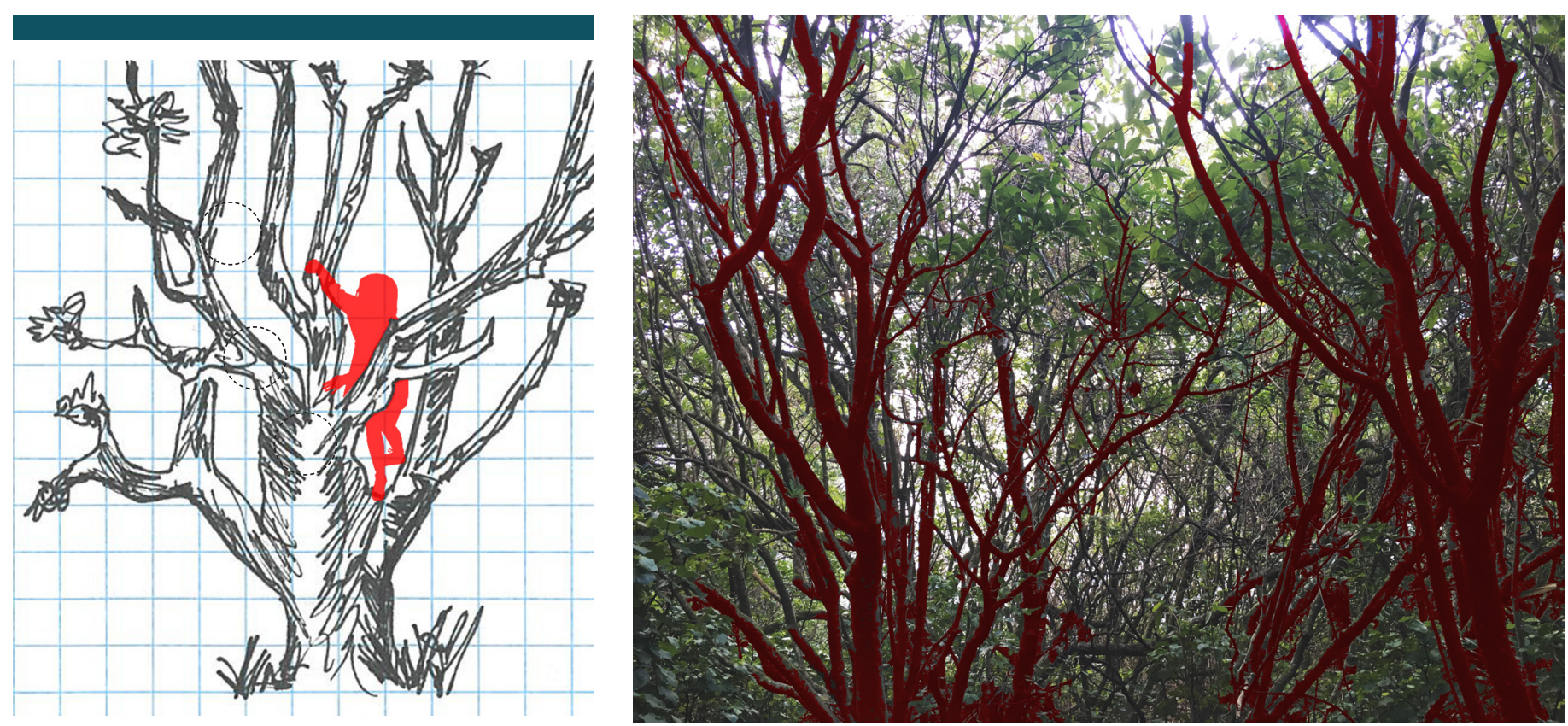

- Big sizes of trees with many branches

Fig 5.20 Experiences in Puhutukawa area

- A single tree becomes a symbol of identity, representing place

- Multiple Movement and rich body language while walking through.

- Hard and steep

- Occupied

- Narrow space between

Facilitate a movement which pays close attention to foot and hand-hold. Very slow and careful focusing attention on detailed ground flora and

Types: object with occasional experiencing of the space within the canopy. 

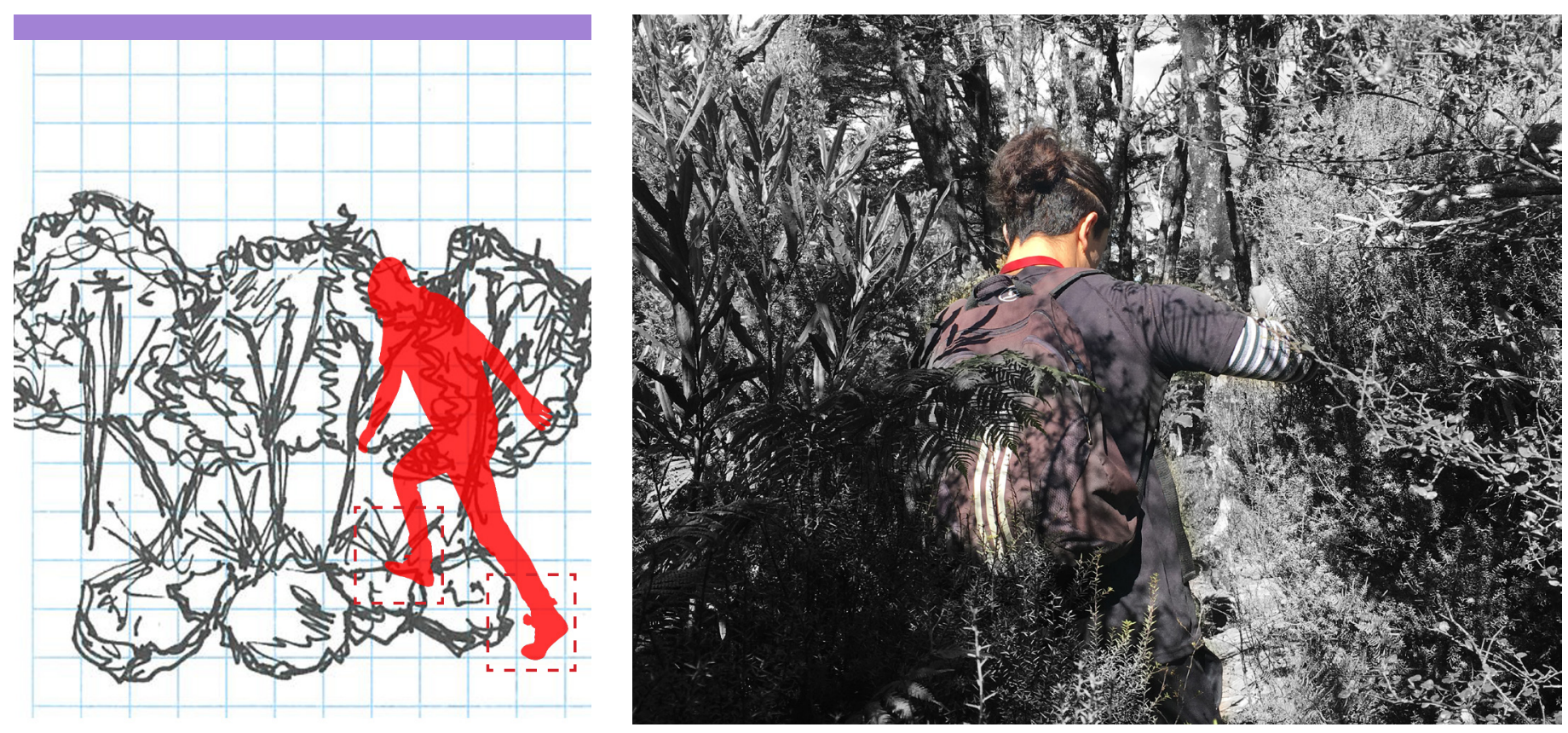

- Locate in steep slope, under forest

Fig 5.21 Experiences in dense planting area.

- Strong wind zone, dry soil and rocks

- Hard ground, significant effort to walk

- Scrambling among rock

- Strong feeling from the feet

Types:

Pingao, Coastal flax

Facilitate very close attention to only bodily what is around you, with a sense of the greater task.

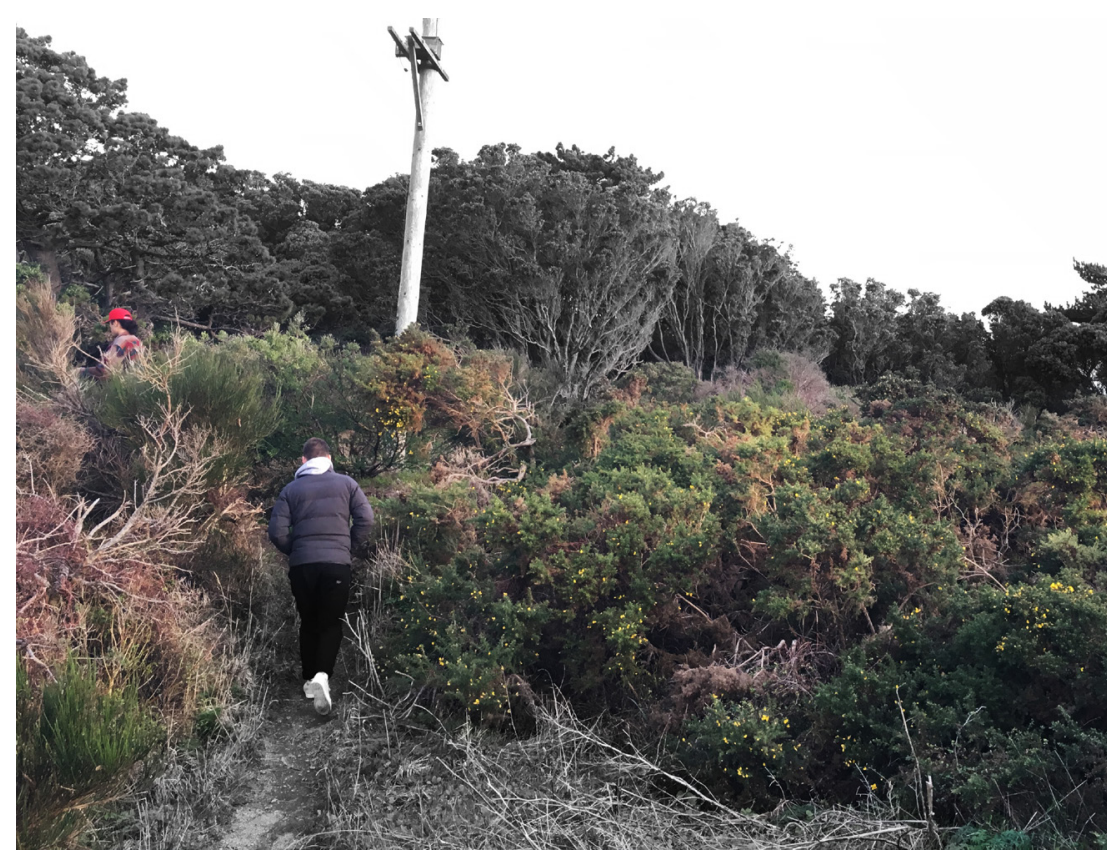

- Create dense shrubland, rich patterns

- Narrow space between, hard to walk through

- Rich feeling of each plants while walking through

- This rugged shoreline offers a sense of escape

Fig 5.22 Experiences in dense shrubland.

- Dramatic

Types:

Taupata, Mahoe

Facilitate a faster less intense attention and movement which move between close and medium distance orientation. Attention to texture of vegetation masses. 

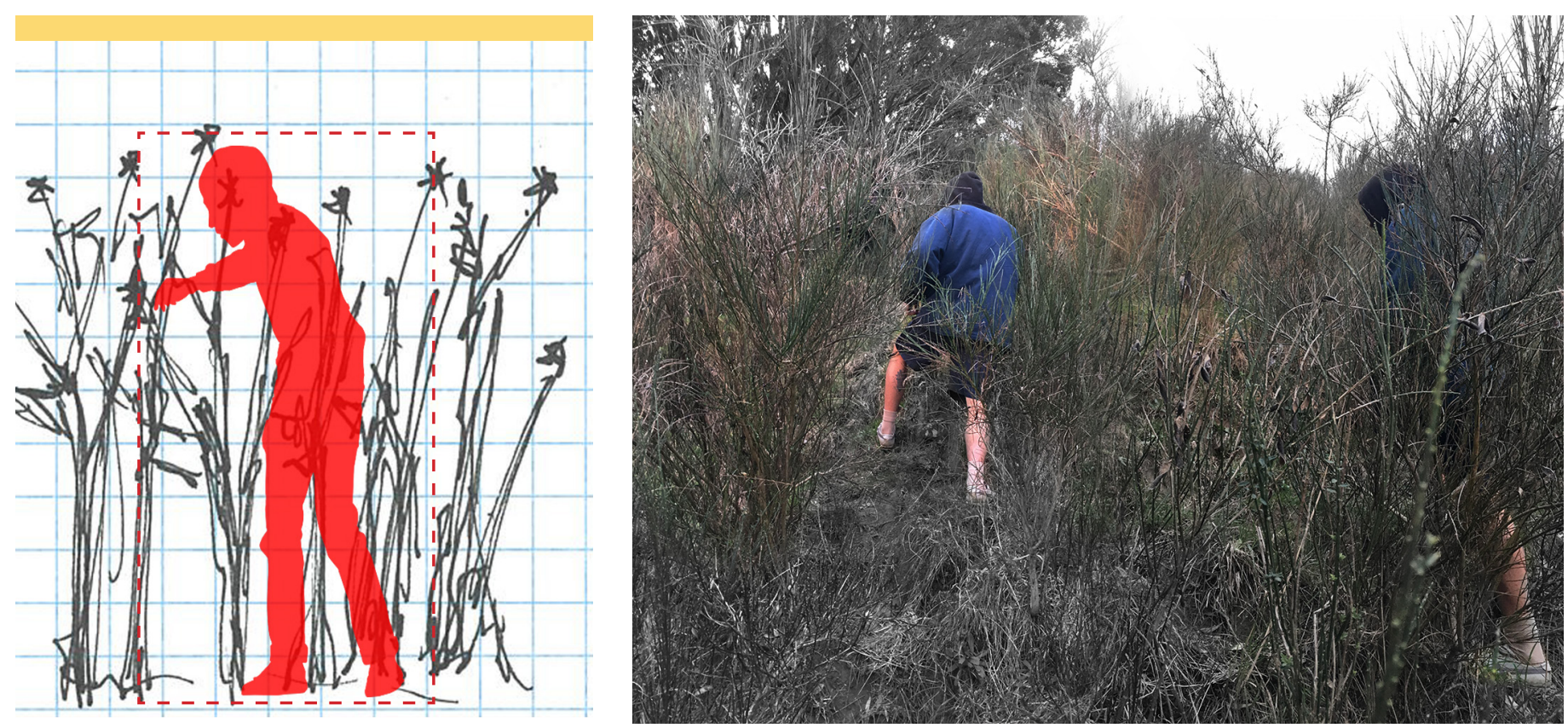

- Human height with high density create enclosed space

Fig 5.23 Experiences in dense broom area.

- Create a strong sense of escape, away from the world

- Prickly feeling when body touch it

- View blocked, no directions to go

Types:

Broom, Gorse
Facilitate close attention and seeking directions to go. Attention to texture of broom.
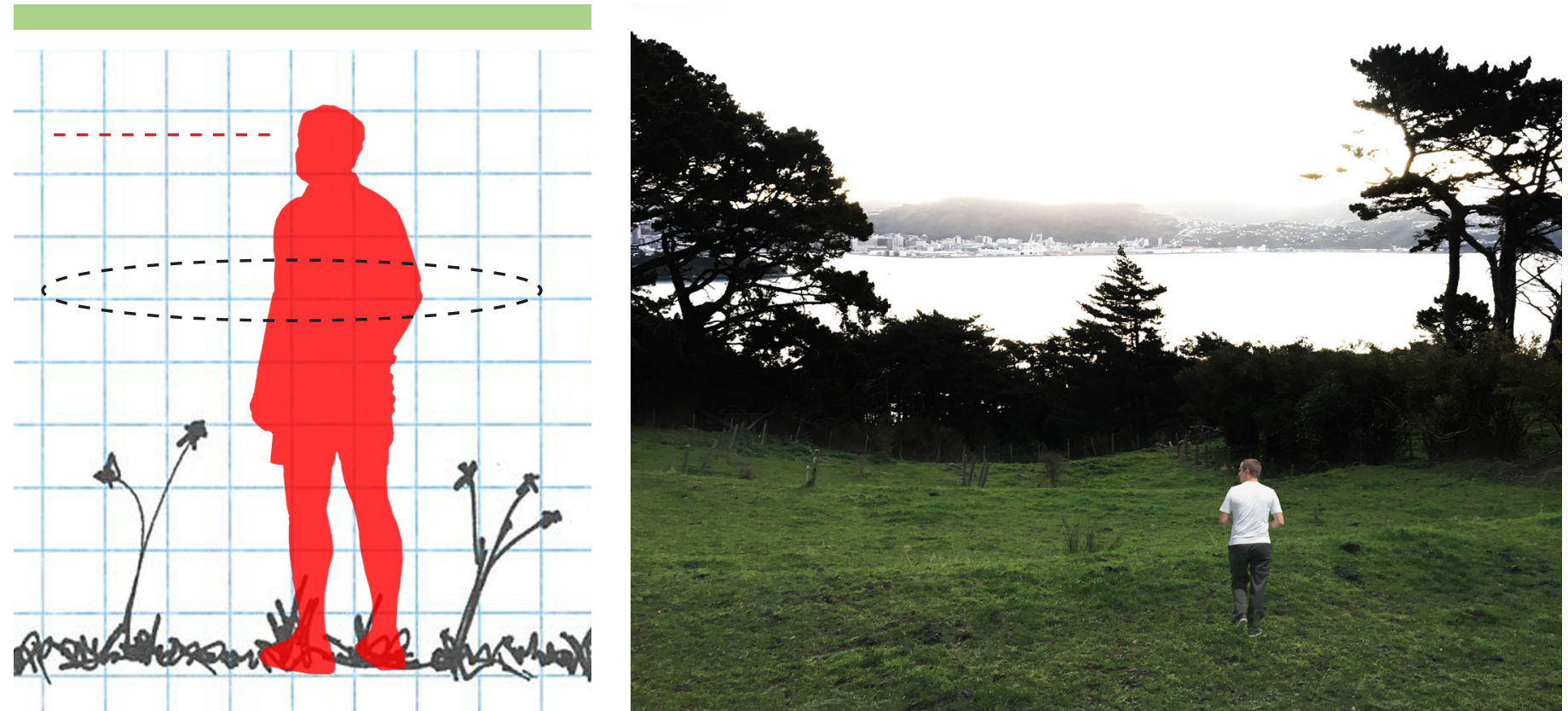

- $\quad$ Exposed feeling

Fig 5.24 Experiences in open grass area.

- Create a clear boundary

- Open space with open view

- Low slope landform, offers opportunities for picnicking

- Simple movement

Types:

English grass, Cape ivy 
Section AA
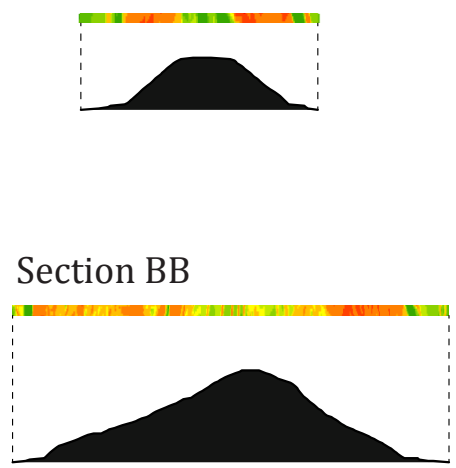

Section CC

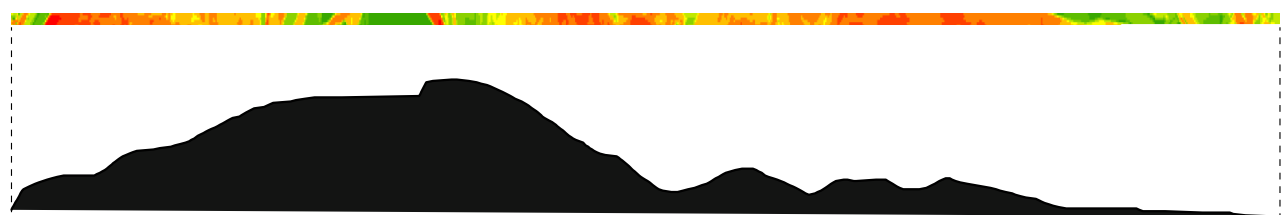

Section DD

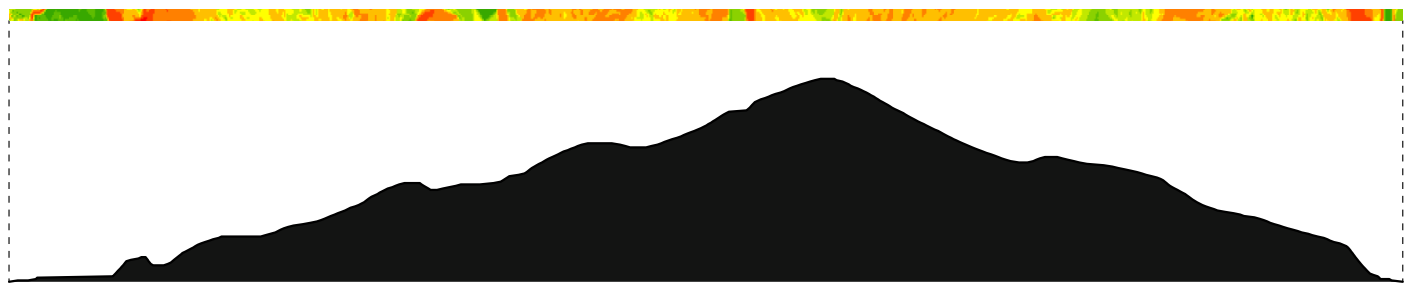

Section EE

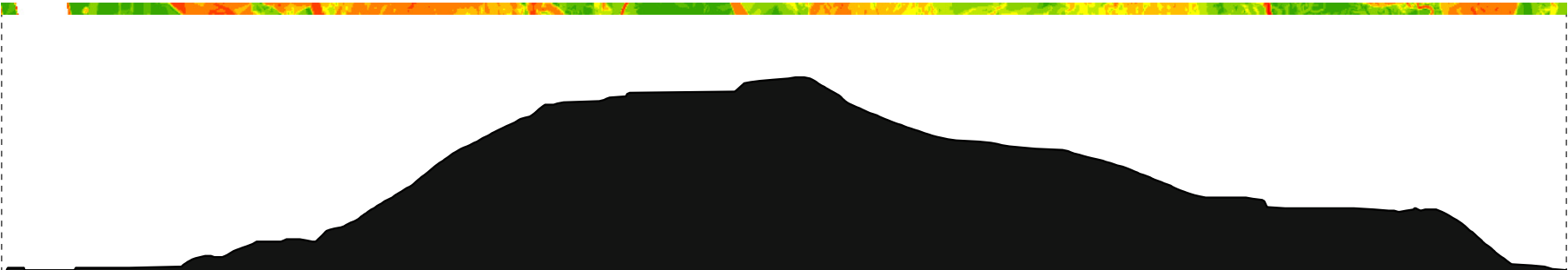

Section FF

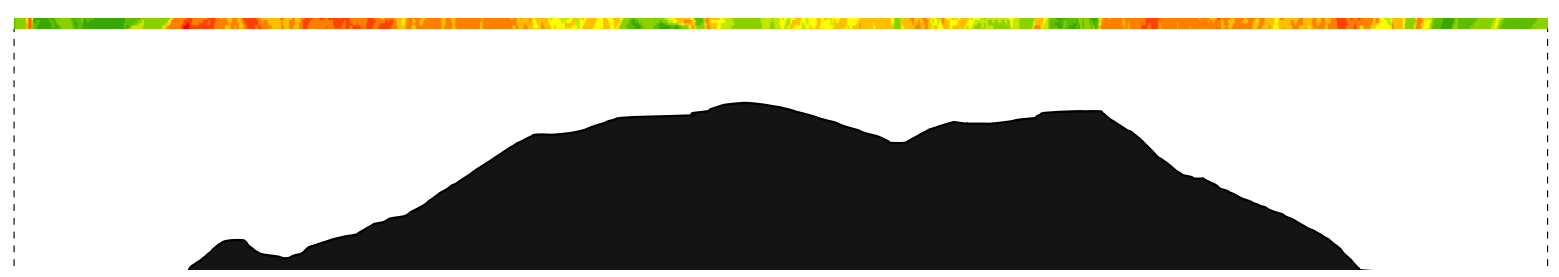




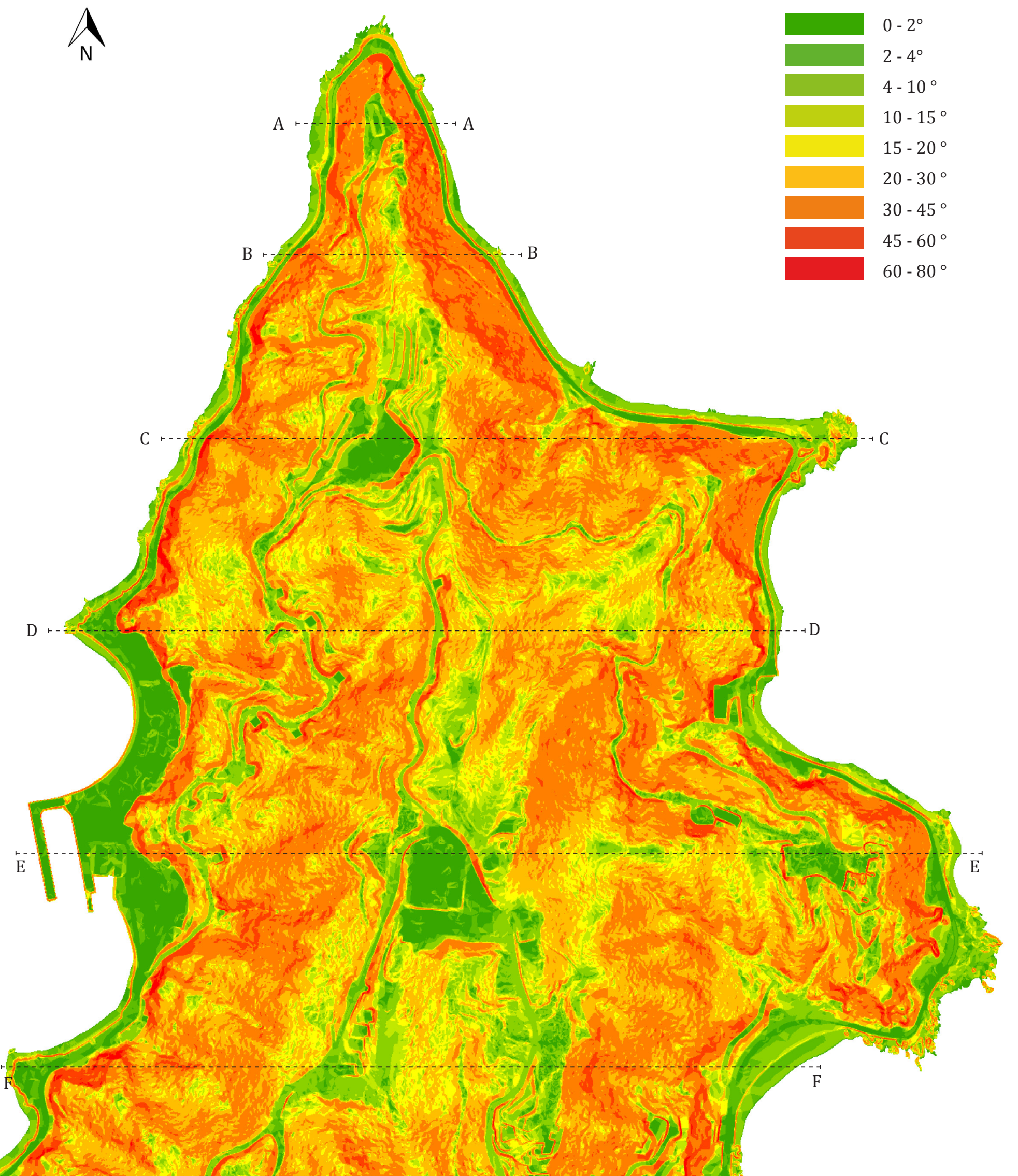

Fig 5.26 Tyoes of slope experience. Slope differentiation are chosen for how they correlate with felt experience of slope change

Scale 1:7000 


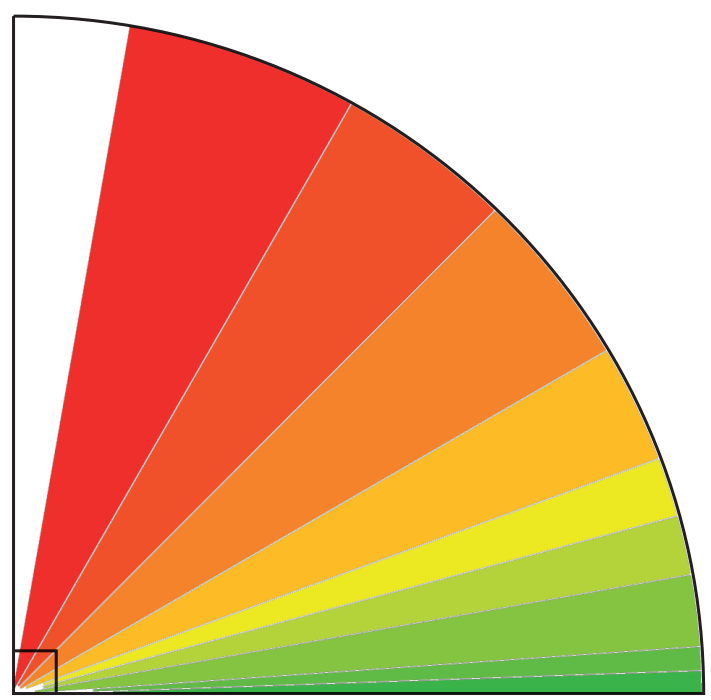

$60-80^{\circ}$

$45-60^{\circ}$

$30-45^{\circ}$

$20-30^{\circ}$

$15-20^{\circ}$

$10-15^{\circ}$

$4-10^{\circ}$

$2-4^{\circ}$

$0-2^{\circ}$

Fig 5. 27 Diagram shows the slope angle for each colour.
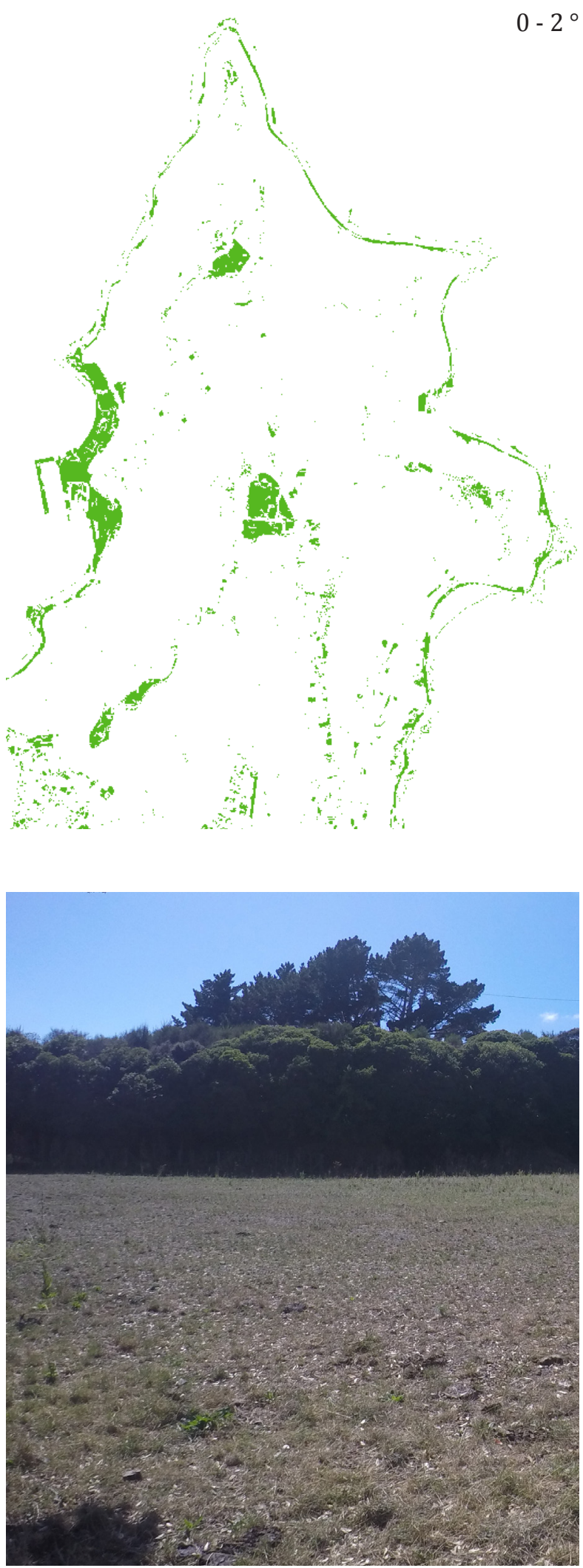

Fig 5. 28 Site's condition between 0 - $2^{\circ}$

- Gently sloping

- Flat

- $\quad$ Easy access

- Achieved without much effort

- On edge and centre of site the site has slopes that are experienced as challenging (15-80 degrees).
Orientation and types of bodily movement

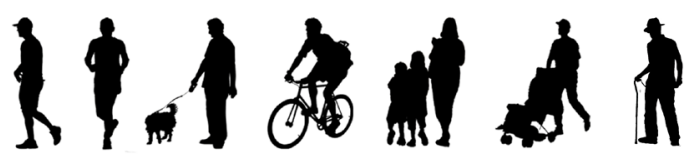



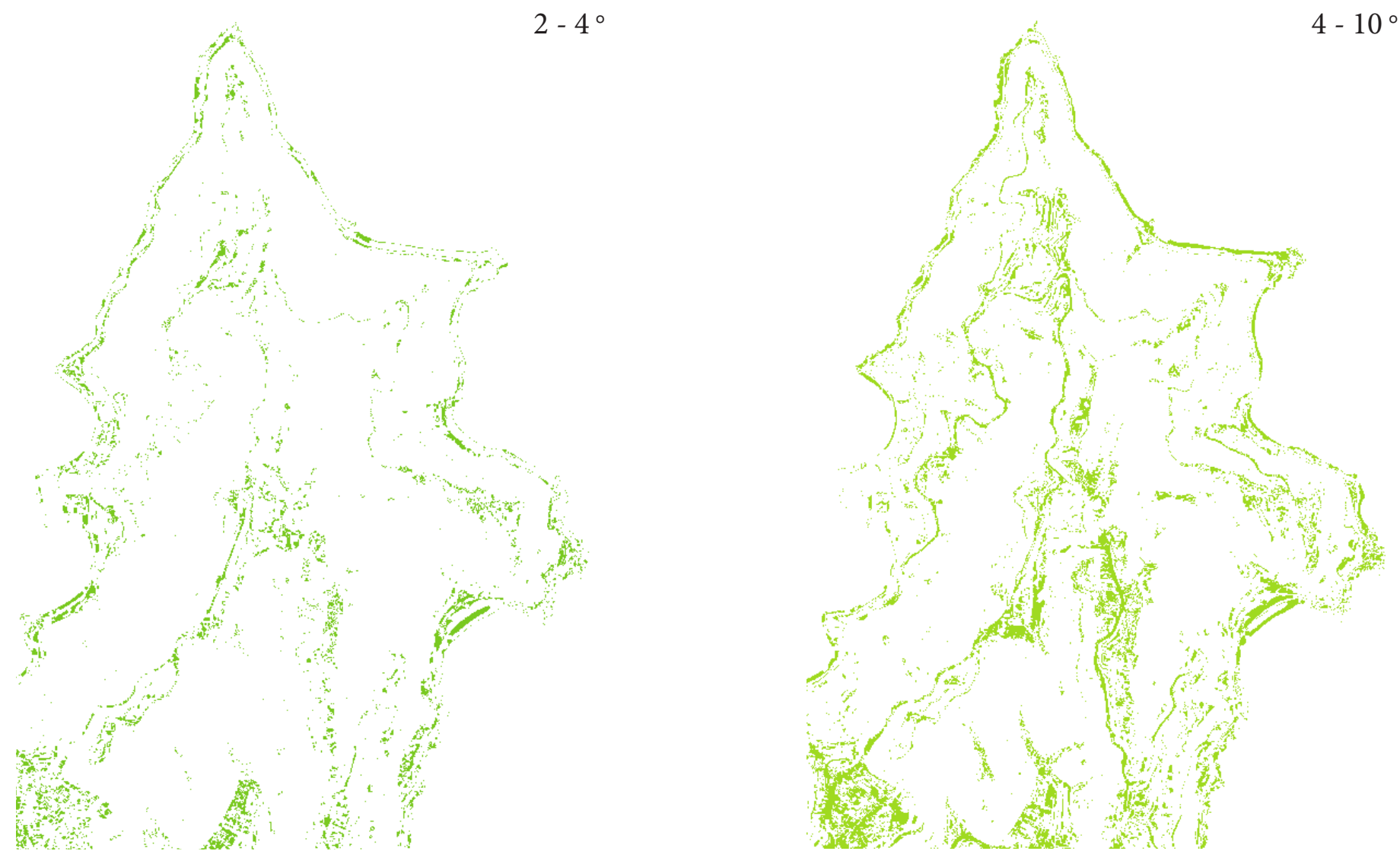

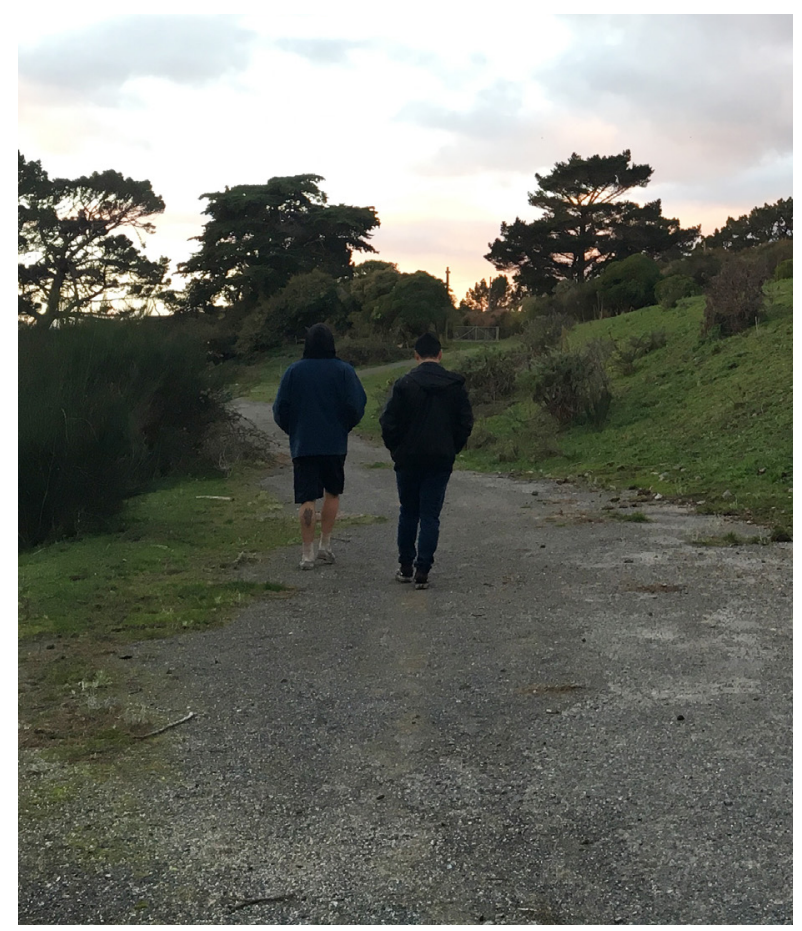

Fig 5. 29 Site's condition between 2 - $4^{\circ}$

- Undulating

- Starting to require some effort

- High speed if needed

- On edge and centre of site

- Mid and long range navigation

Orientation and types of bodily movement

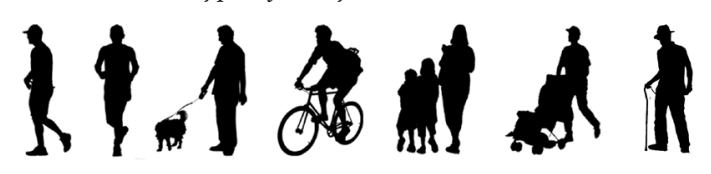

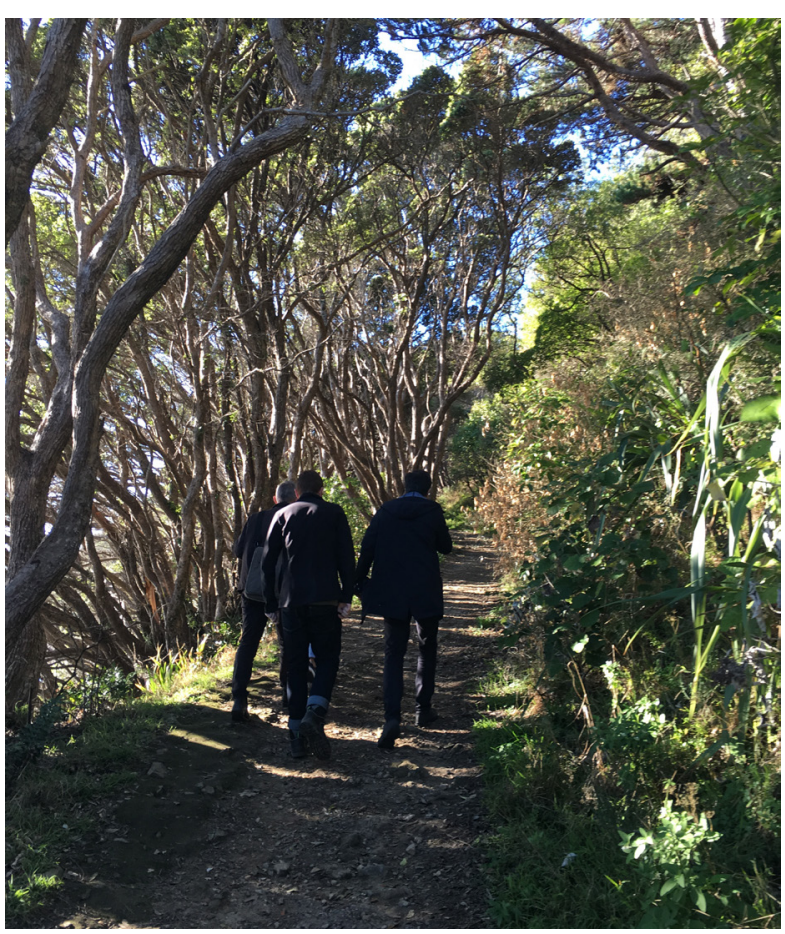

Fig 5. 30 Site's condition between 4 - $10^{\circ}$

- Rolling

- Significant effort - you wouldn't want to be doing it for too long

- On edge and centre of site

- Mid and short range navigation

Orientation and types of bodily movement

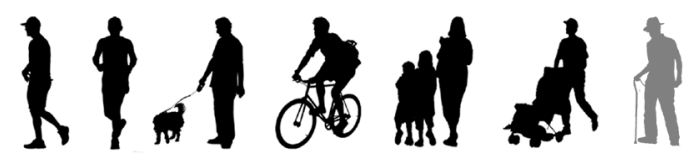




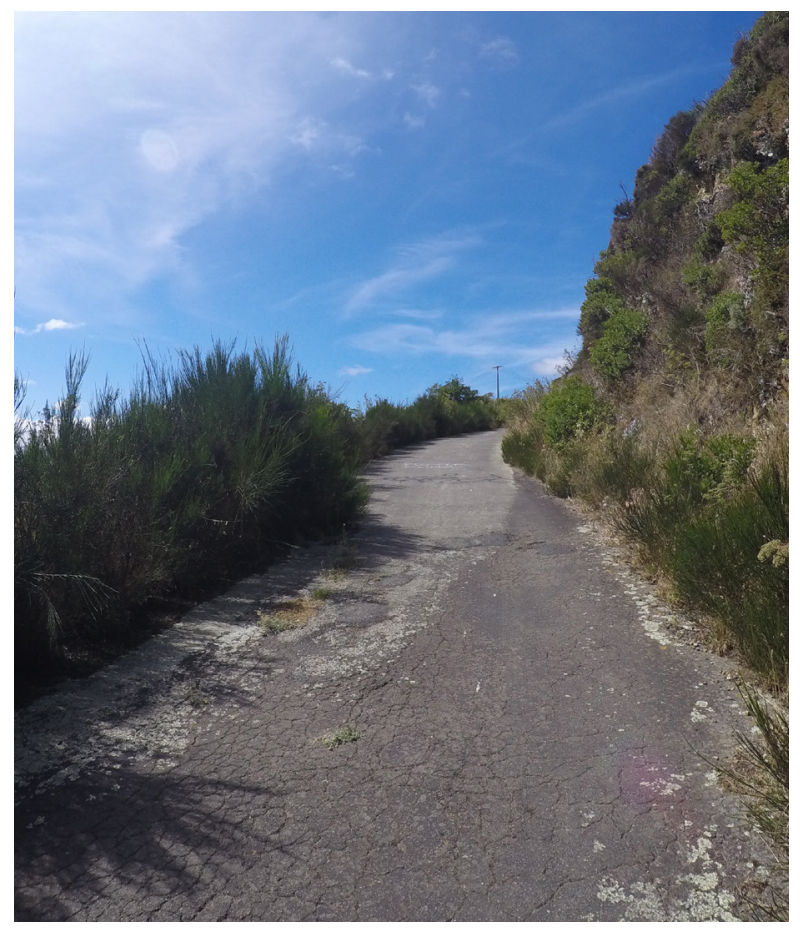

Fig 5. 31 Site's condition between 10 - $15^{\circ}$

- Moderately steep

- Significant work (certainly prefer to go across slope)

- Eyes focus to view

- Distributed across the site

- Mid and short range navigation

Orientation and types of bodily movement

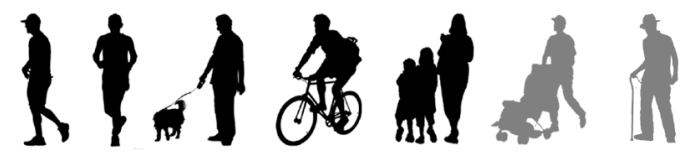

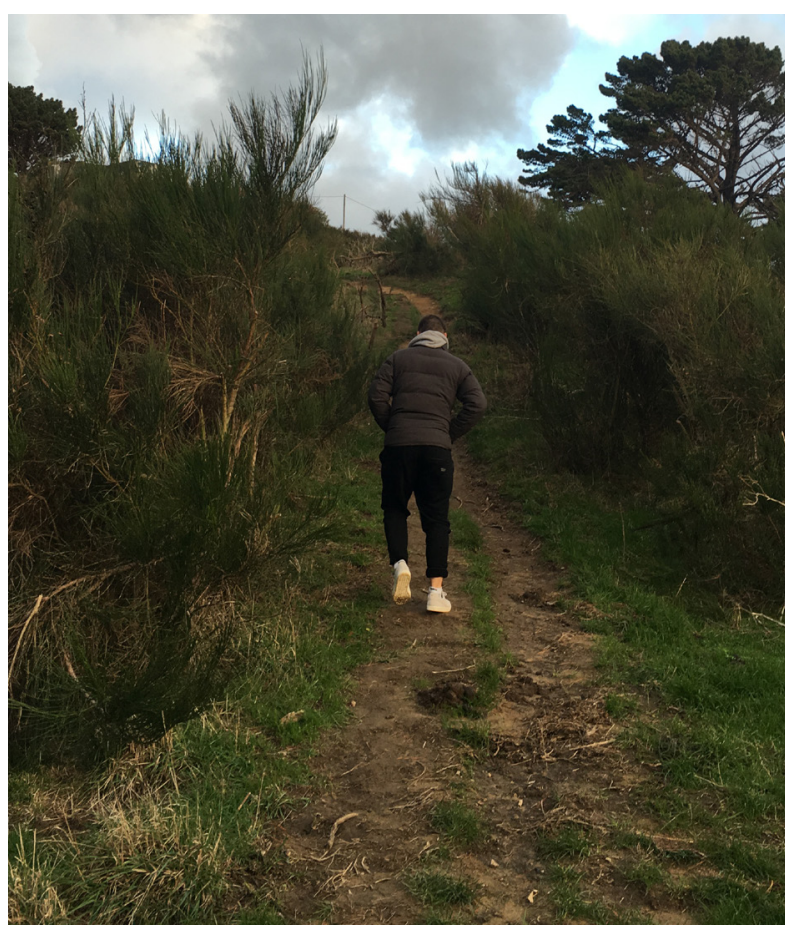

Fig 5.32 Site's condition between $15-20^{\circ}$

- Strongly steep (20 is the steepest section for road, Dunedin, New Zealand) - downland

- Distributed across the site

- Navigation tends to the restricted to what in below hard height 

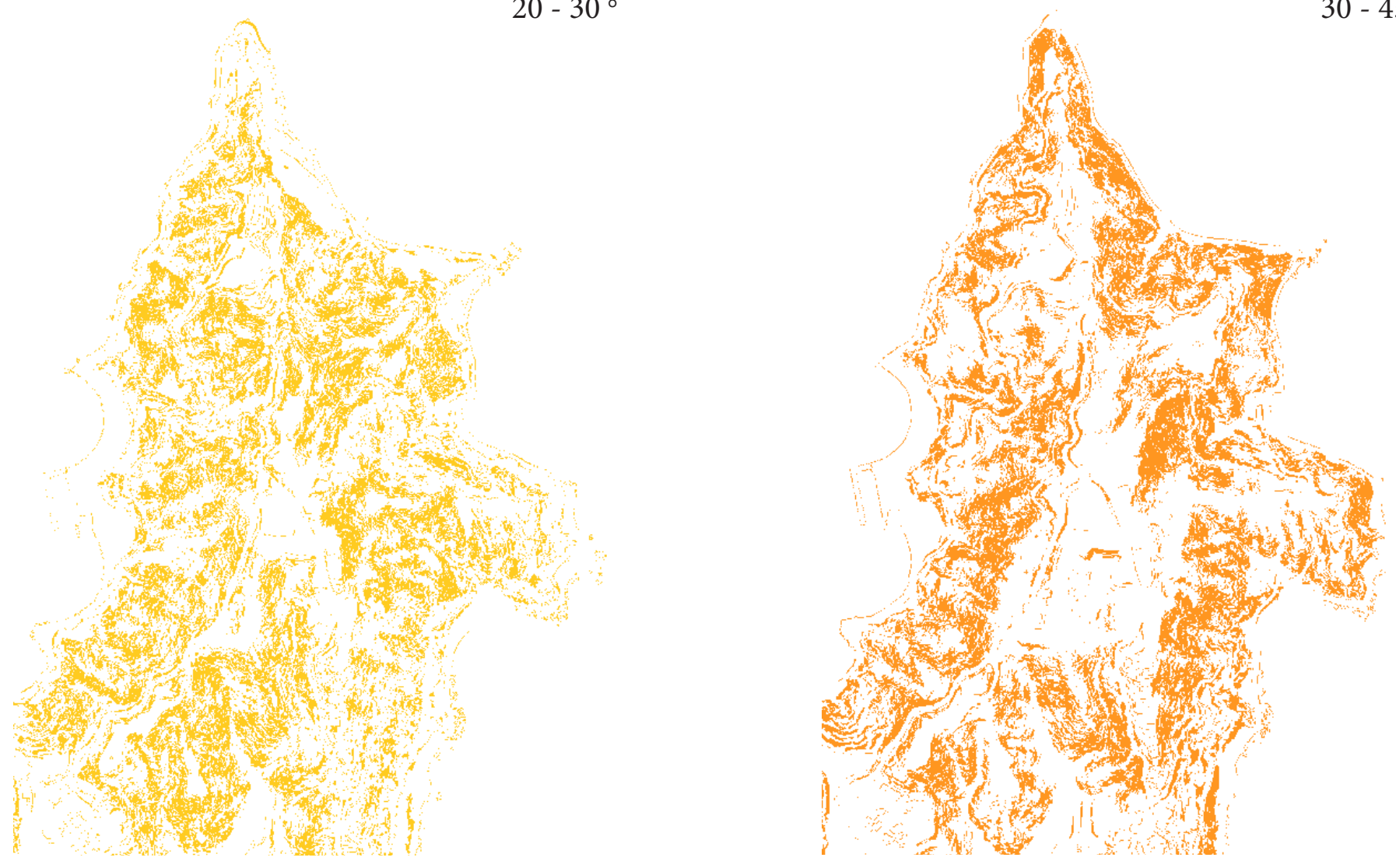

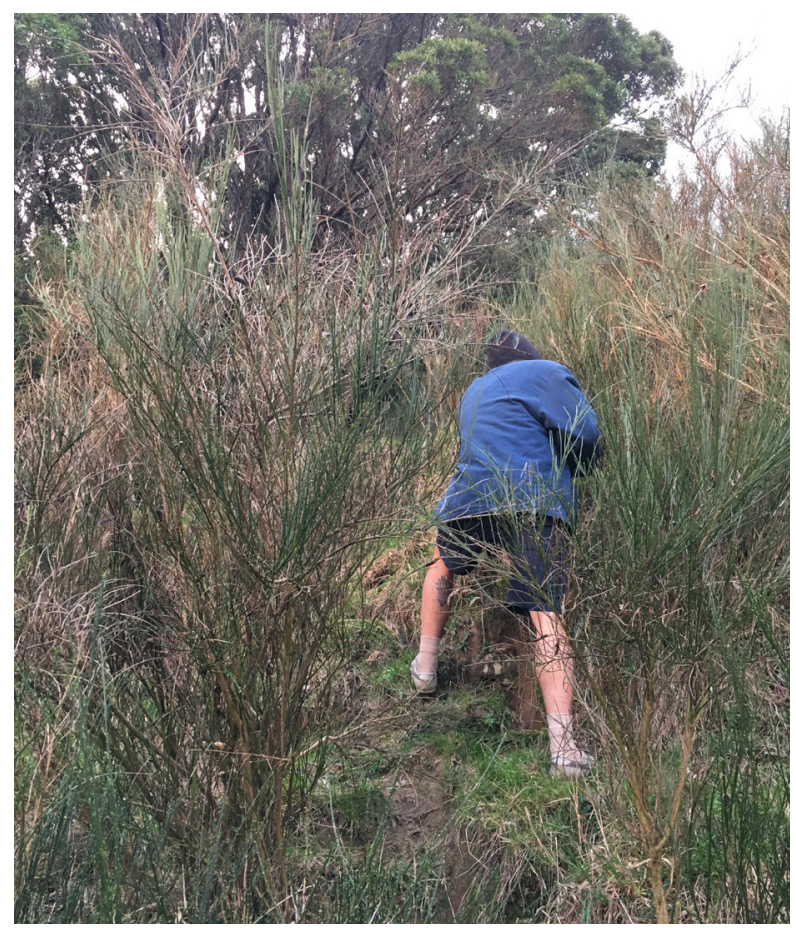

Fig 5. 33 Site's condition between 20 - 30 ${ }^{\circ}$

- Steep - hill country

- Start to focus on feet while walking

- Distributed away from the centre of site

- Close navigation

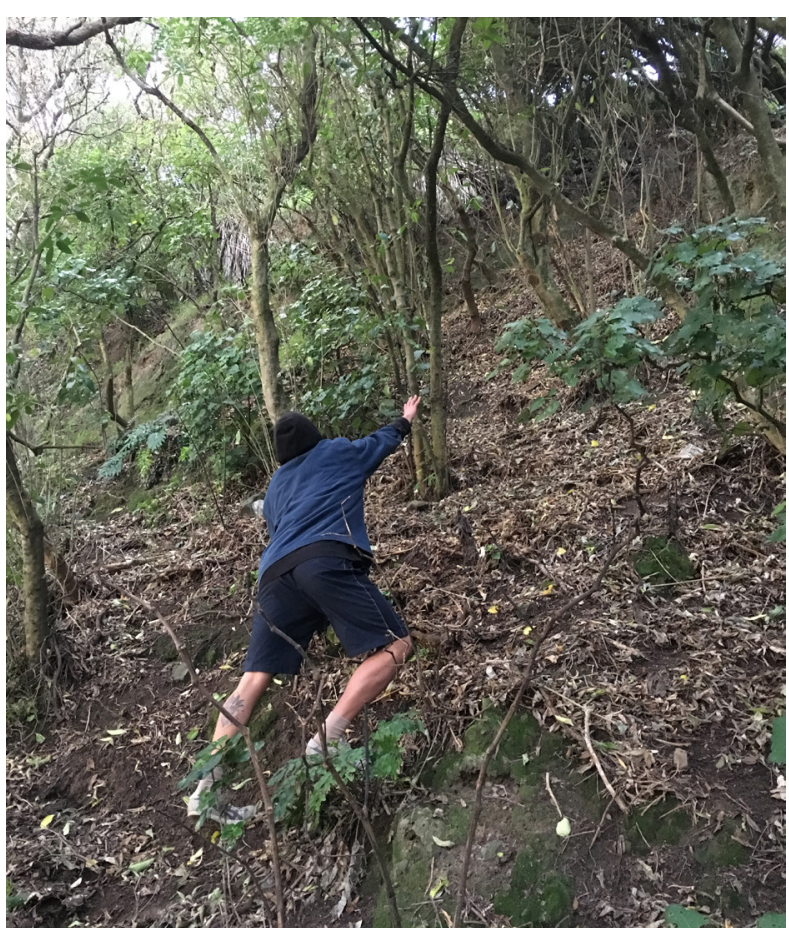

Fig 5. 34 Site's condition between 30 - $45^{\circ}$

- Very Steep-steepland

- Decrease speed while walking

- The whole body involve to the movement

- Distributed away from the centre of site

- Bodily navigation 

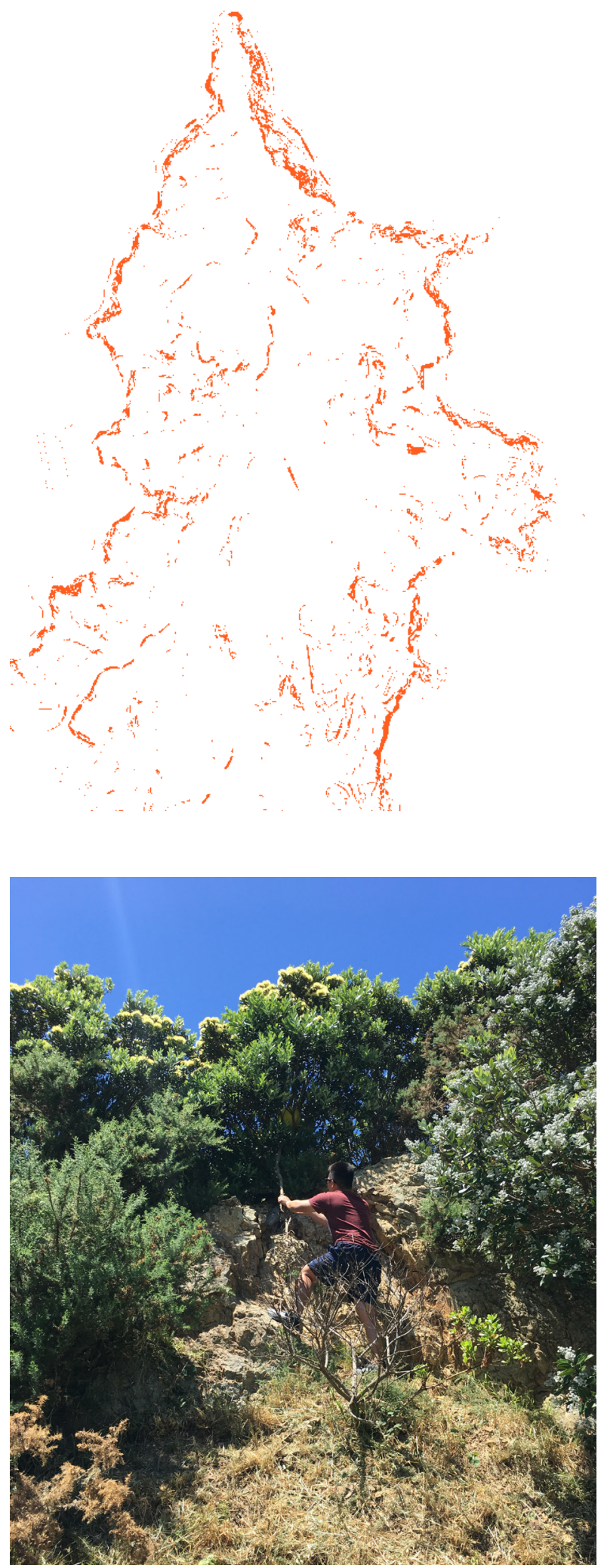

Fig 5. 35 Site's condition between $45-60^{\circ}$

- Extreme Steep

- Low speed

- Eyes focus the ground

- Stop spots needed

- Appreciate after

- Bodily navigation

Orientation and types of bodily movement

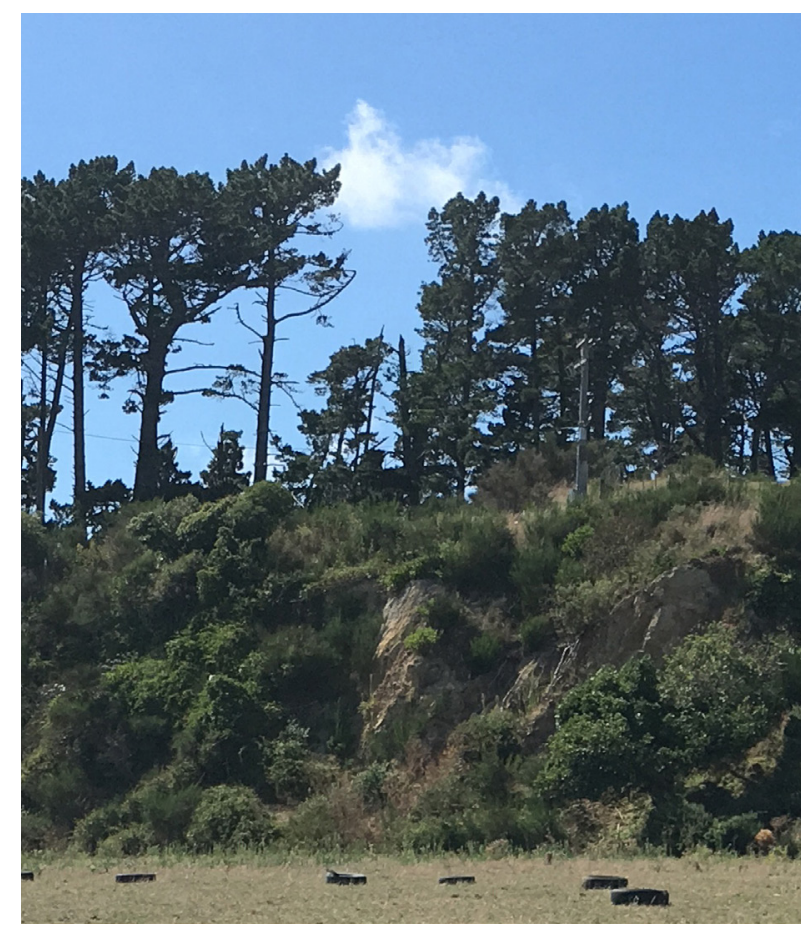

Fig 5. 36 Site's condition between 60 - $80^{\circ}$

- Not available to access-cliff

- Very dangerous to try to access 


\section{$0-2^{\circ}$}
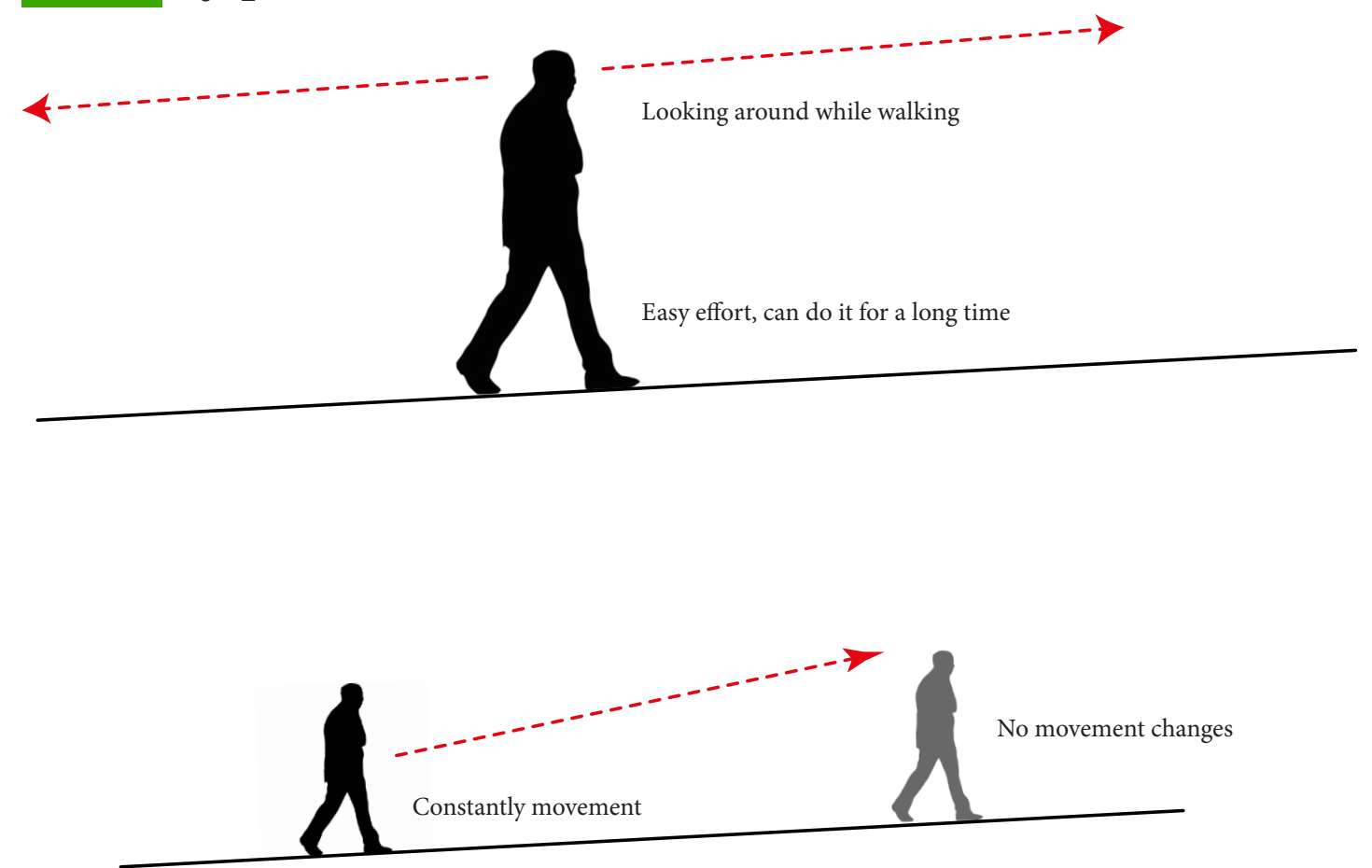

Fig 5. 37 Walk on $0-2^{\circ}$ slope.

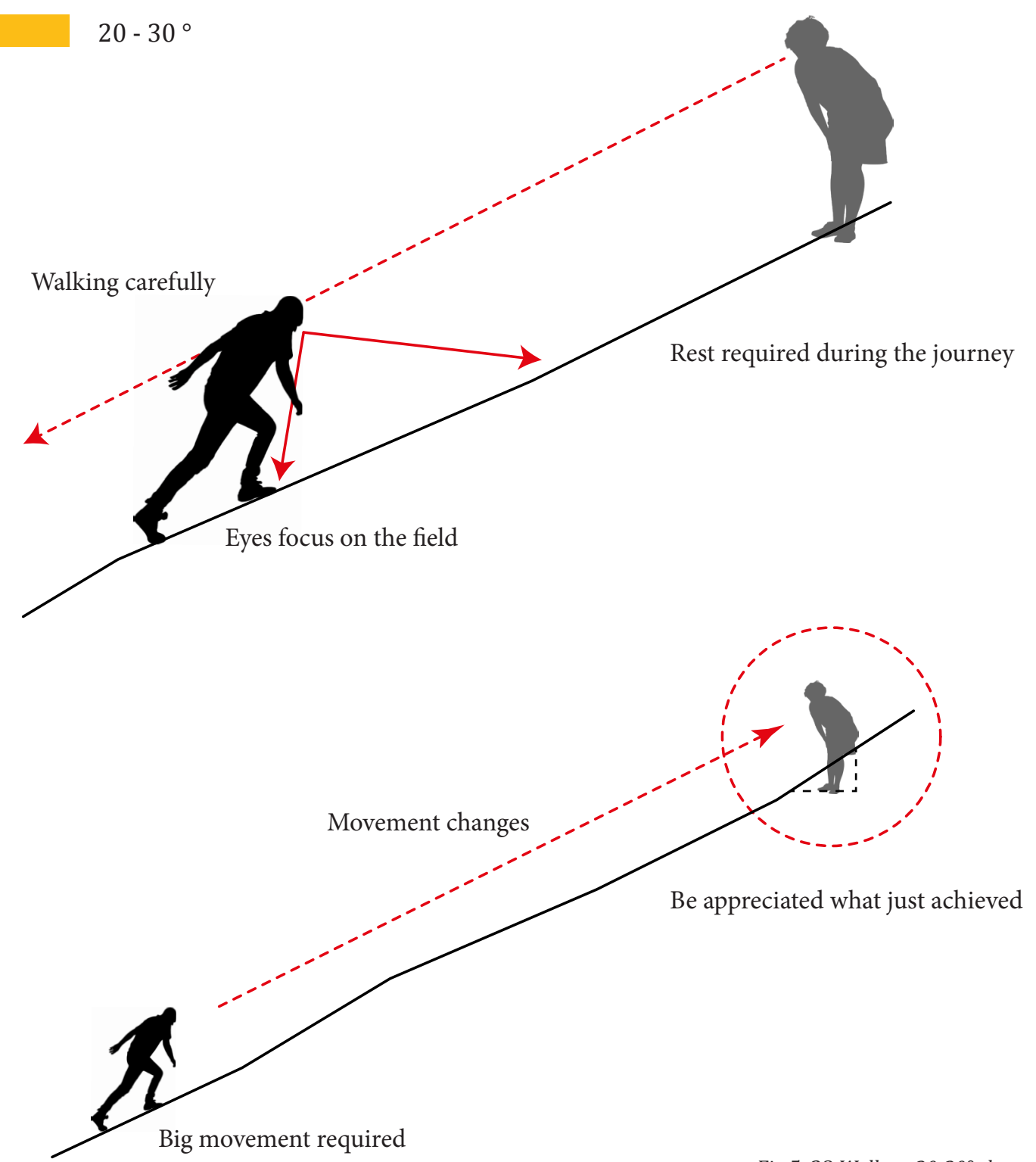

Fig 5. 38 Walk on $20-30^{\circ}$ slope. 


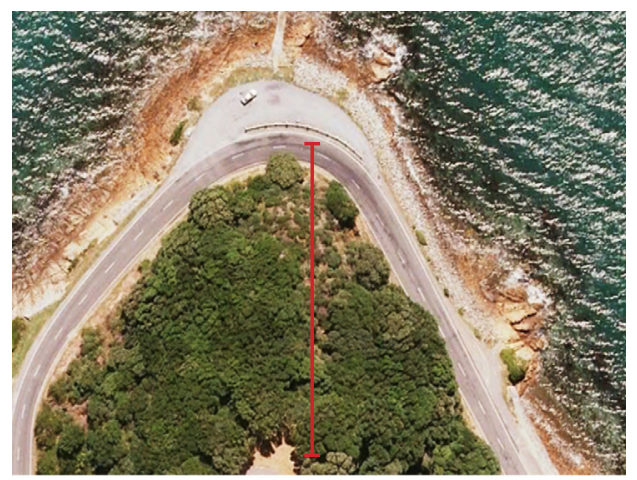

Fig 5. 37 Assemblage 1 plan

\subsection{Pohutakawa Slope Movement Assemblage - 1}

There are three different types of movement-experiencing in each of the sections marked out below. They involve variation in slope and vegetation density and canopy heights each sporting a unique experiencing assemblage of open and closed spaces.

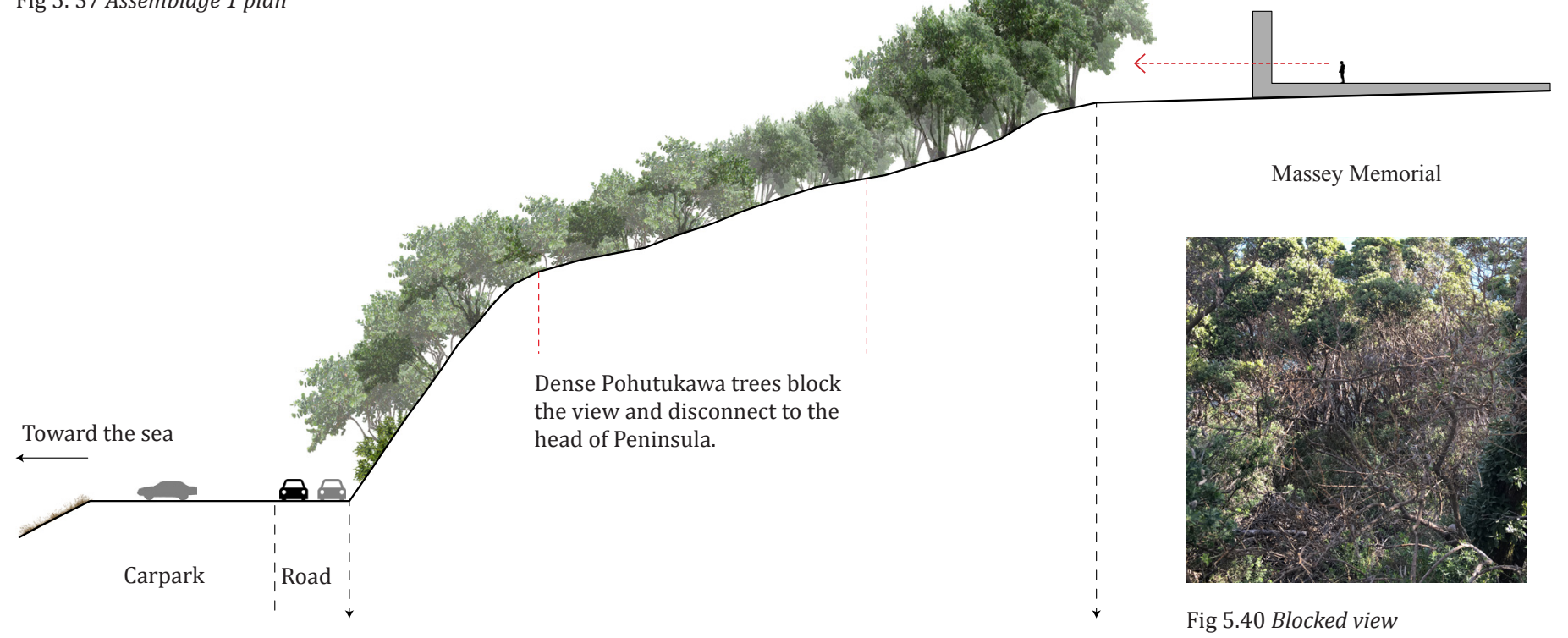

Fig 5. 39 Assemblage 1 Section 1:500

The following four pages show different 'movement' experiencing assemblages. Each associated with a particular location as a result of topography, slope, vegetation, ground surface, provision of paths/tracks, human expectations and desires at this location etc.

Fig 5.40 Blocked view

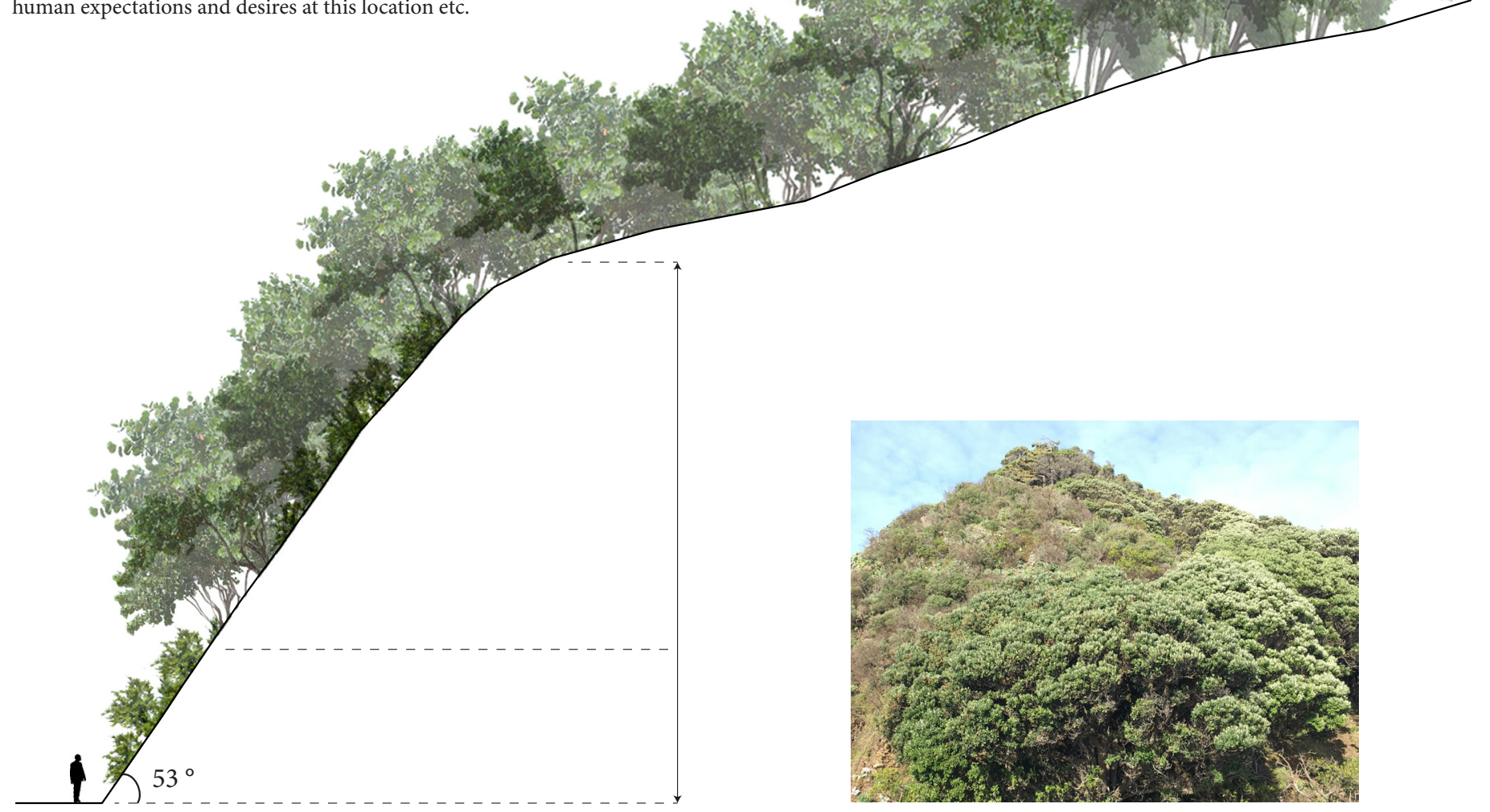




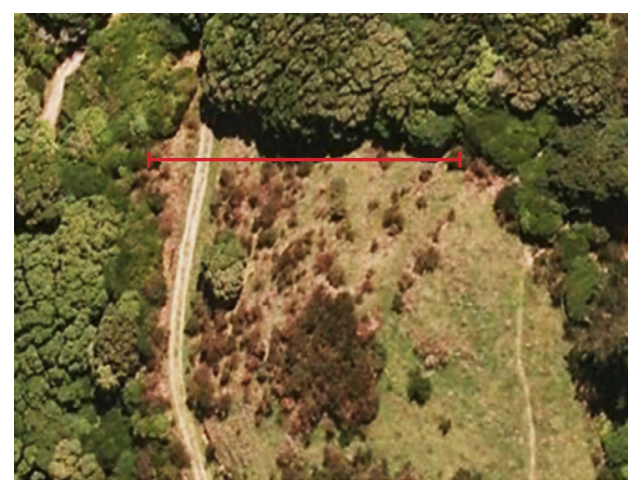

\subsection{Shrubby Rolling Topography Movement Assemblage - 2}

The movement assemblage is very tactile and is experienced through touch and feel. In particular with hands and feet. Vegetation is very dense and sparse, and if stood on can bounce back into shape straight away.

Fig 5. 43 Assemblage 2 plan
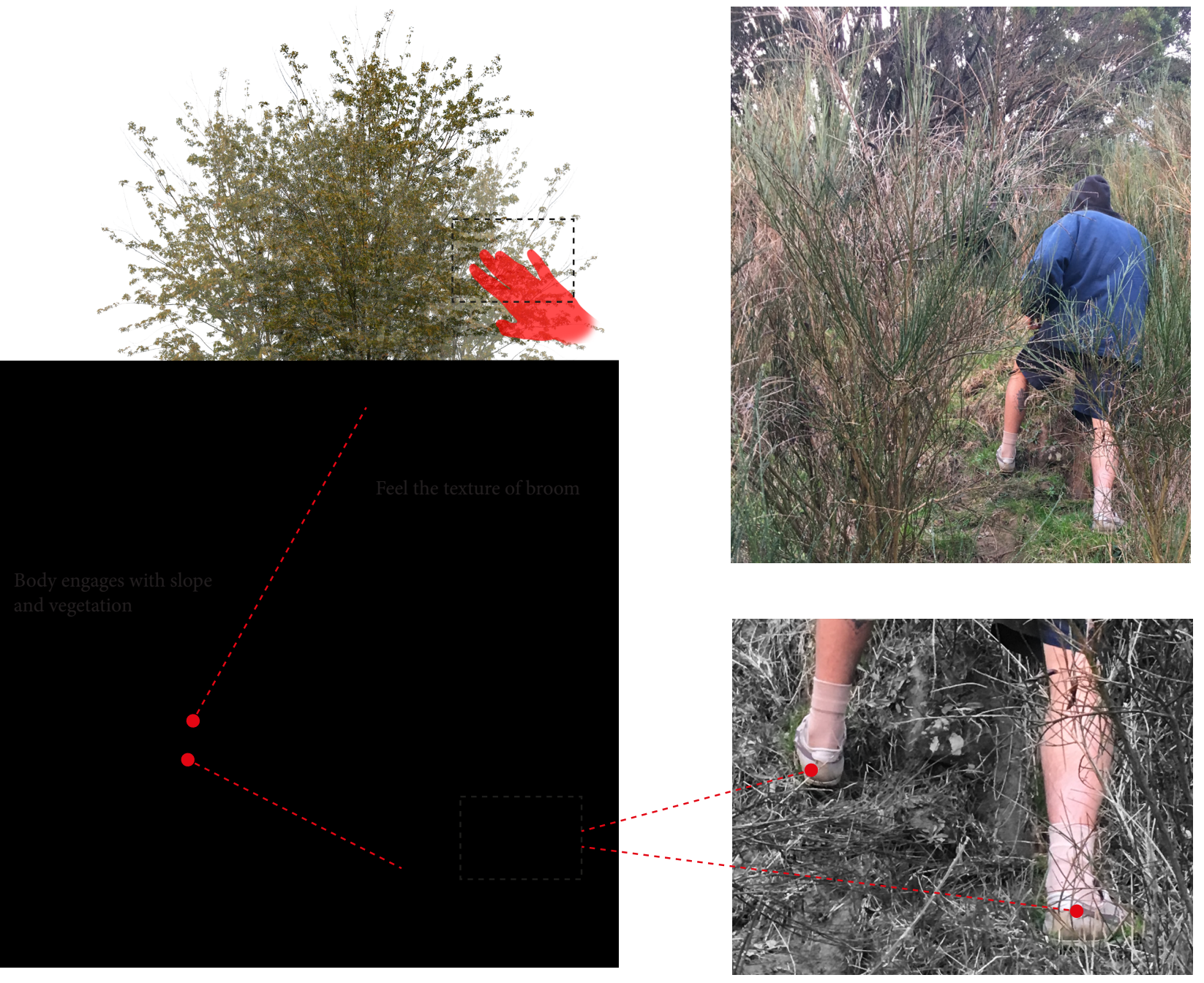

Fig 5. 44 Assemblage 2 Elevations

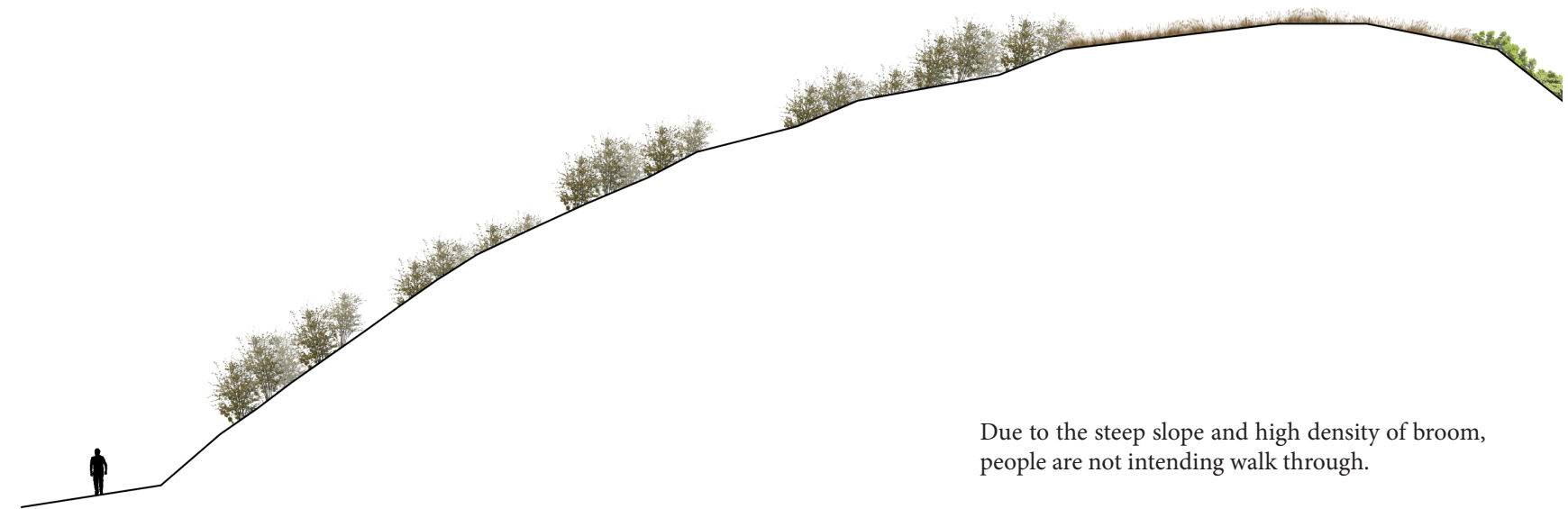




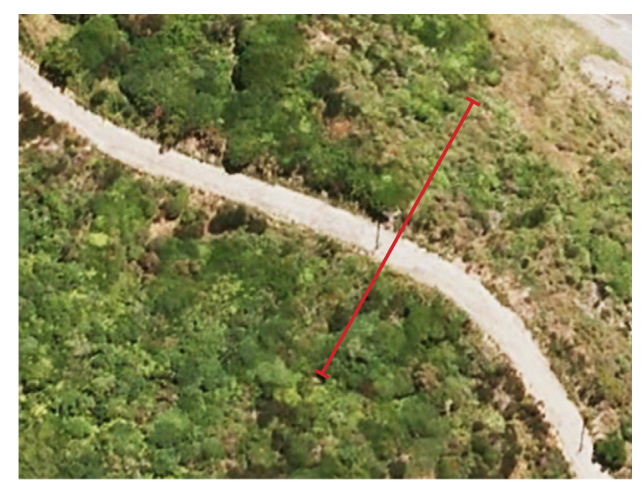

\subsection{Access Path Movement Assemblage - 3}

Relaxed movement requiring little effort. Slow removal away from outside world as the path takes you further into the site.

Fig 5. 46 Assemblage 3
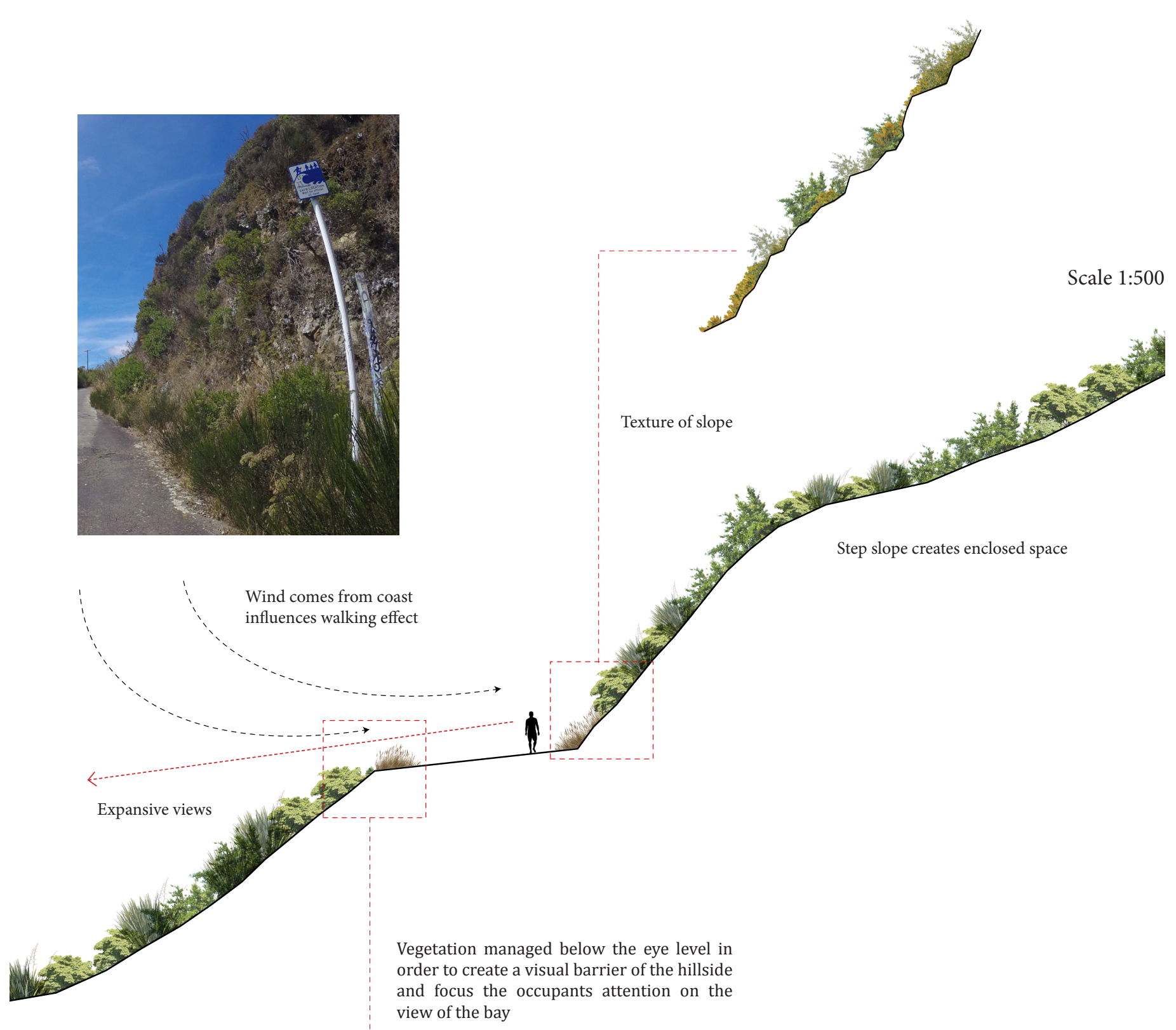

Scale 1:500

Scale 1:500
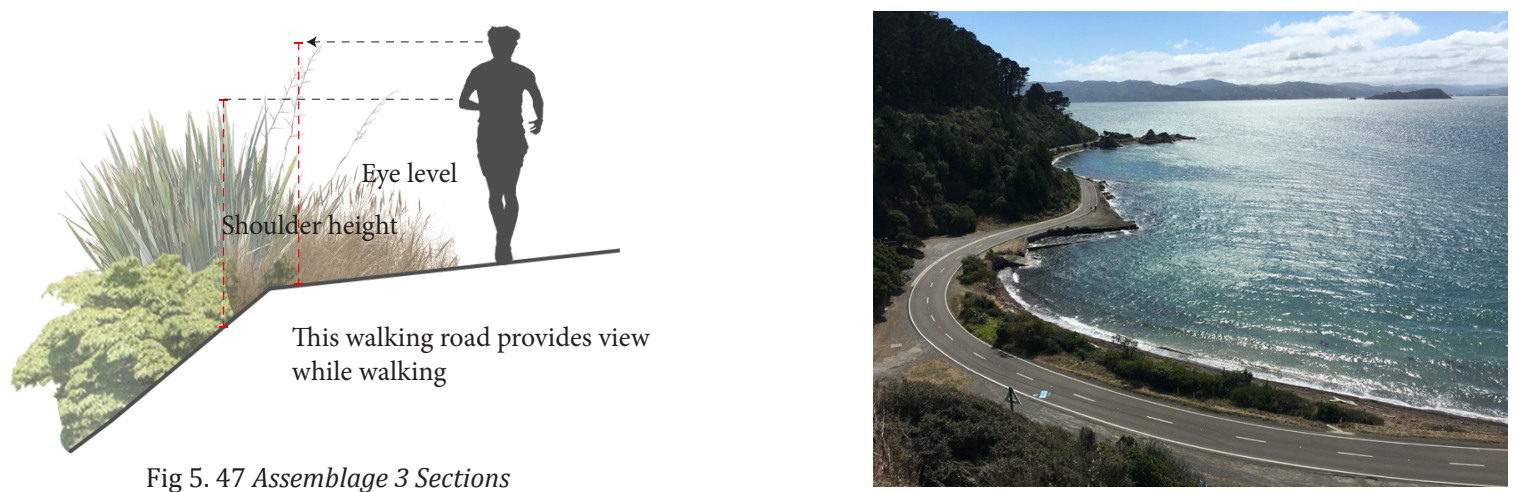


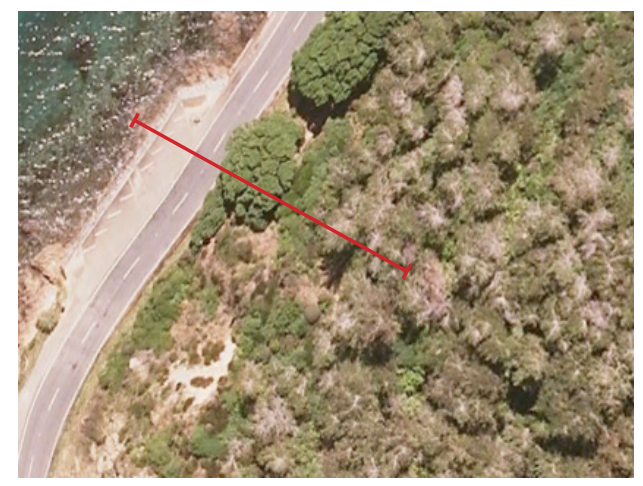

\subsection{Site Assemblage - 4}

Relaxed movement requiring little effort. Sheltered and enclosed making you feel away further away from the road then you actually are.

Fig 5. 48 Assemblage 4
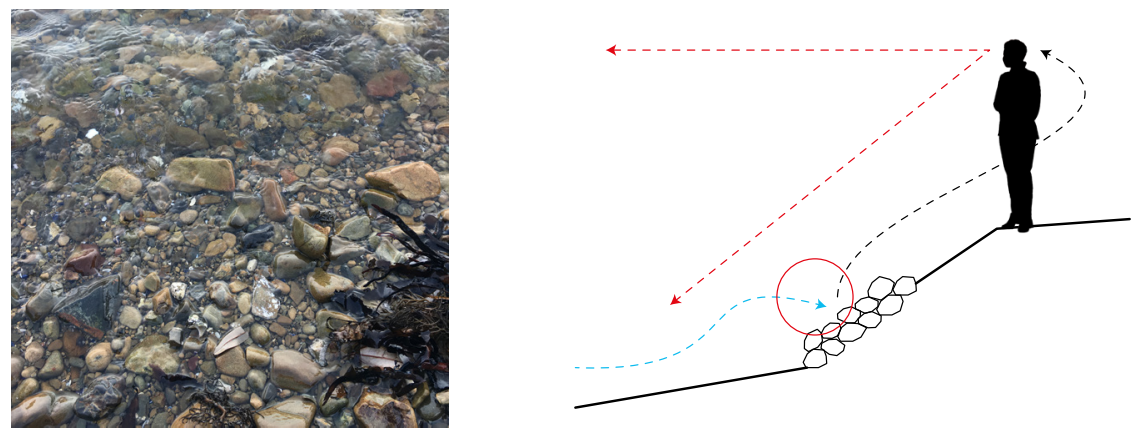

Moment created by sound

from water hitting the rocks
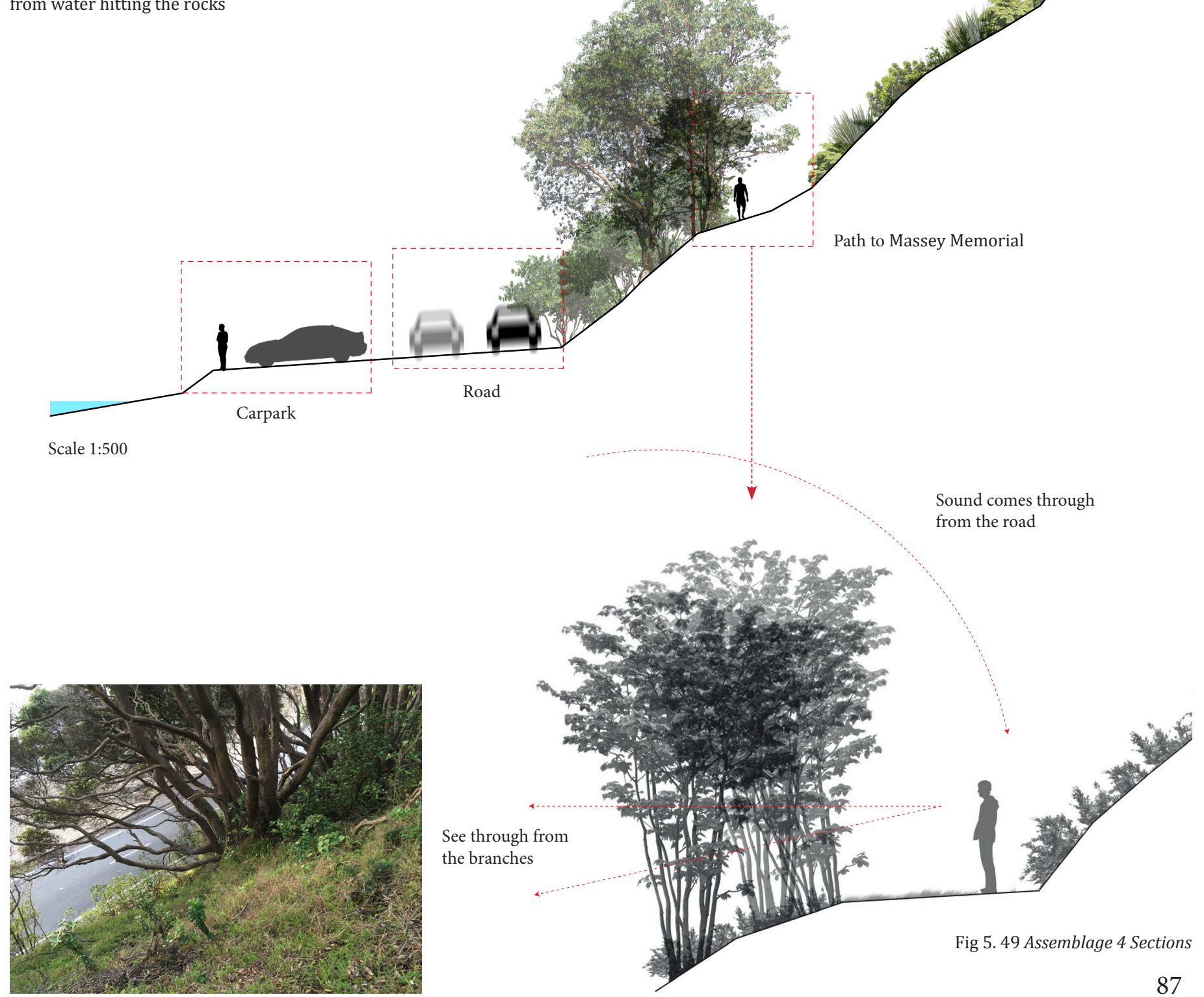


\section{CONTEXT INFLUENCES}

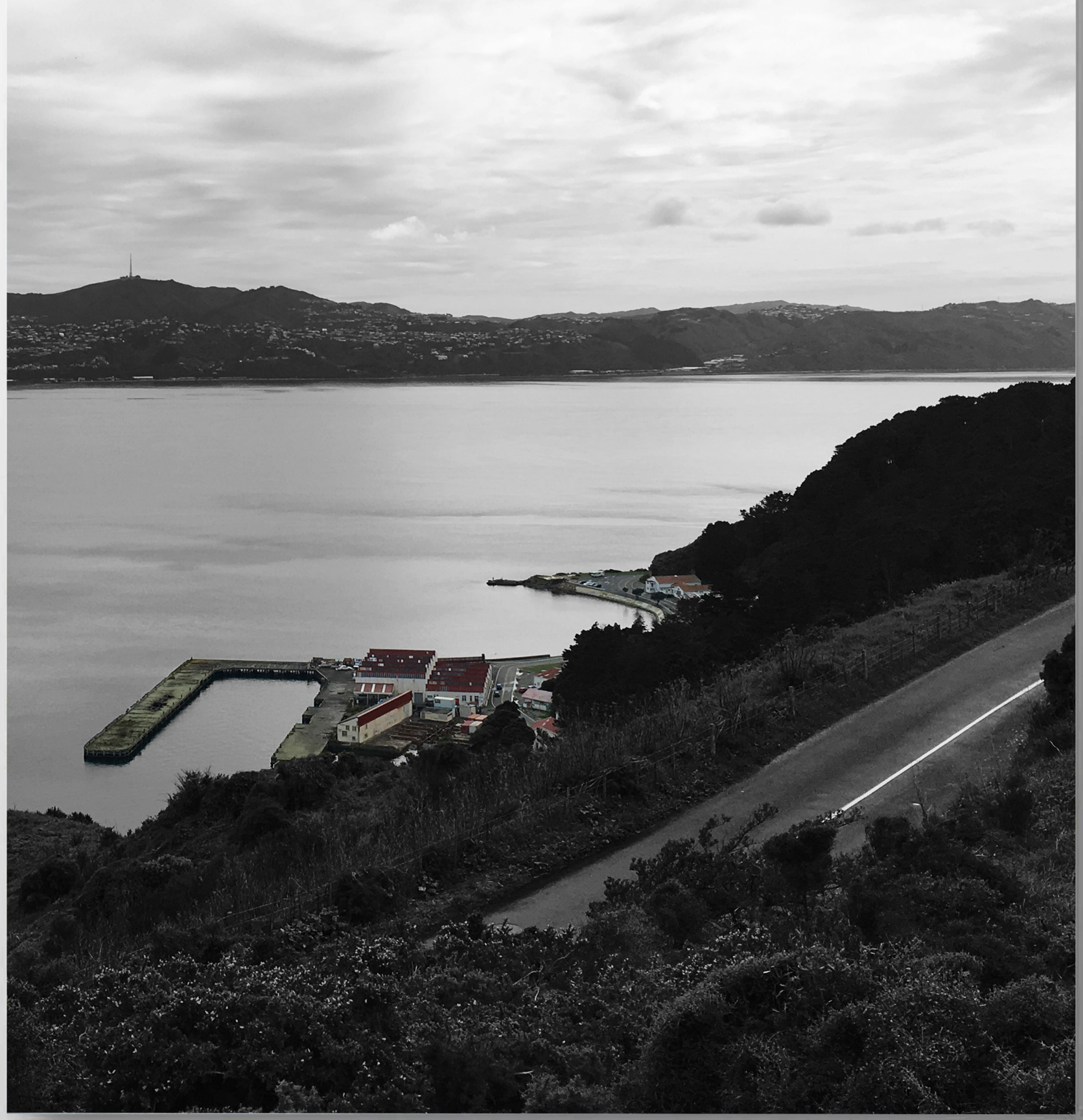




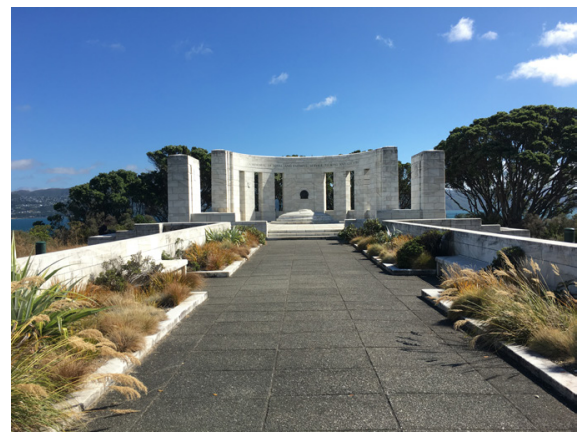

1. Massey Memorial

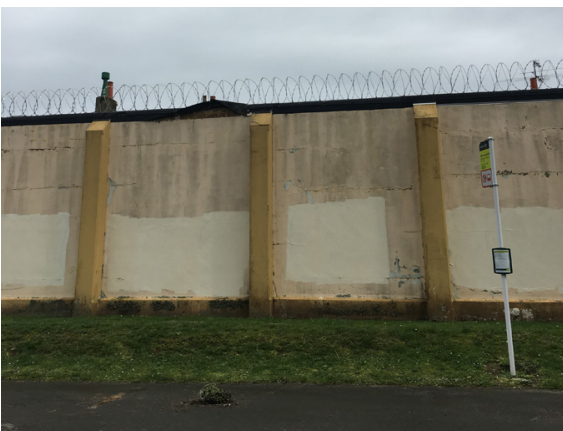

4. Mt Crawford Prison

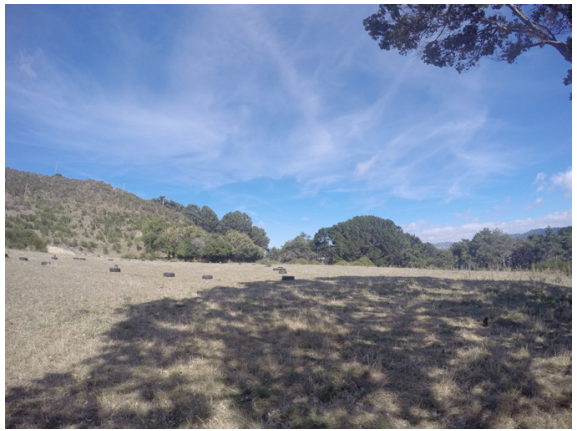

2. Old site of Womens Reformatory

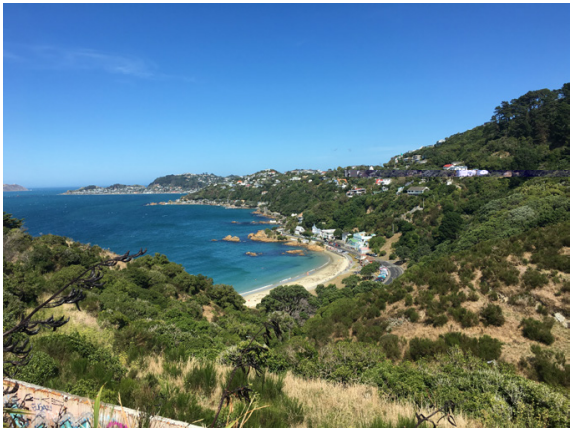

5. Scorching Bay

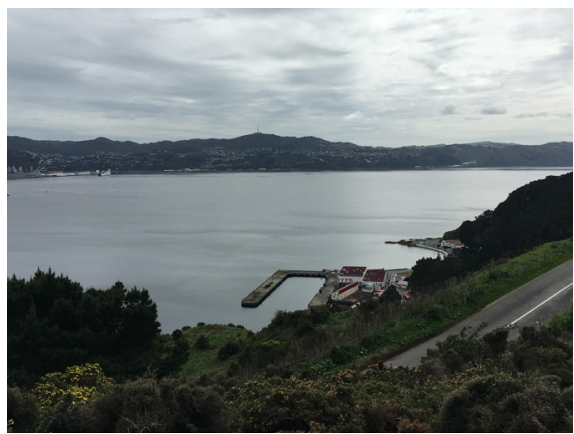

3. Shelly Bay

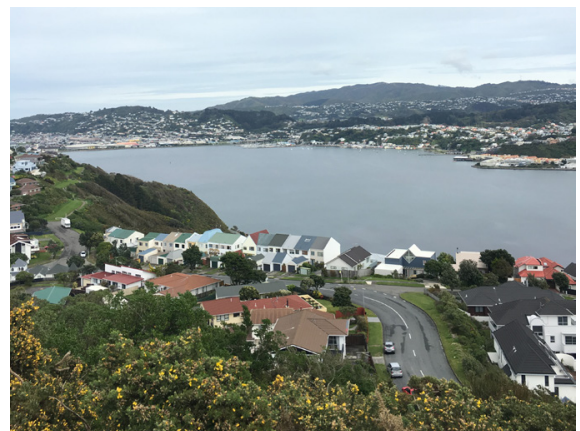

6. Maupuia Residential area

Figure 6.2 Photos of key locations

\subsection{Wider Influences}

Watts Peninsula has strong relationship with its surrounding which directs attention to look at the context of the site. This aim. Watts Peninsula sits alongside Mt Crawford Prison, the Massey Memorial and the Point Halswell and another three key locations interacting with site, the influences from them could motivate the design.

The main access points to the Watts Peninsula site are from the coastal road at Shelly Bay, Kau Bay, Mahanga Bay and Scorching Bay. This is likely to put pressure on the informal walking routes and car parking adjacent to the road particularly on the eastern side of the peninsula.

1. Massey Memorial

2. Old site of Womens Reformatory

3. Shelly Bay

4. Mt Crawford Prison

5. Scorching Bay

6. Maupuia Residential area 


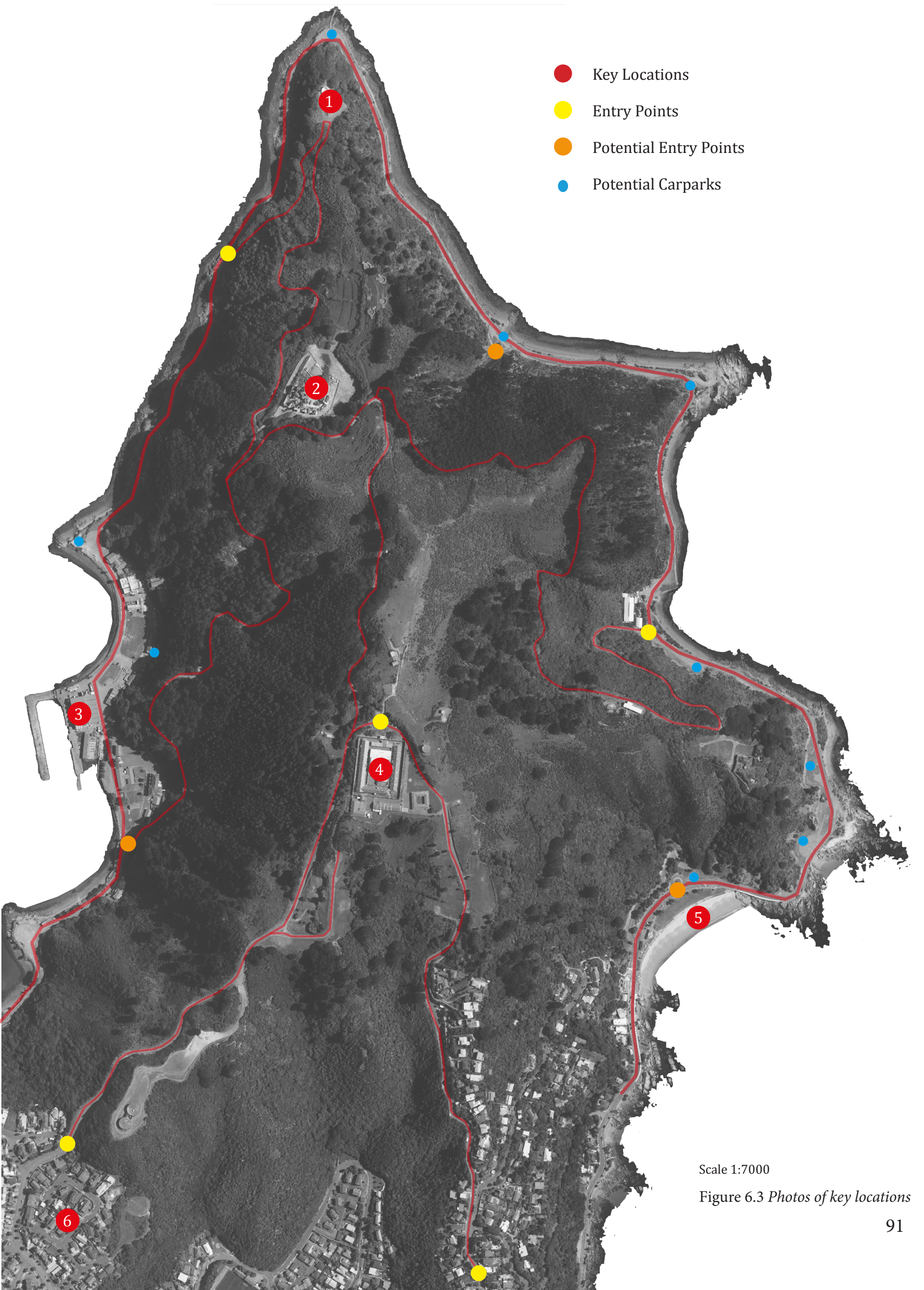




\subsection{Shelly Bay}

Shelly bay locates on the western side of Watts Peninsula currently own by Shelly Bay Ltd. Shelly bay was a navy base from 1907 to 1946 (WCC), and now is a place with local café, art galleries, and shops. There are plans for revamping Shelly Bay, could be given a new lease of life. The future shape of Wellington's Shelly Bay revamp is becoming clearer, with new plans hinting at more than 350 homes, a boutique hotel, a brewery, a rest home and a ferry service. (Stuff, 2016). This plan will influence how the study site will be used and offer an opportunity to re-open the military road from Shelly bay to Old site of Womens Reformatory.

Right Figure 6.4 Showing how Shelly bay is intended to interact with the surrounding.

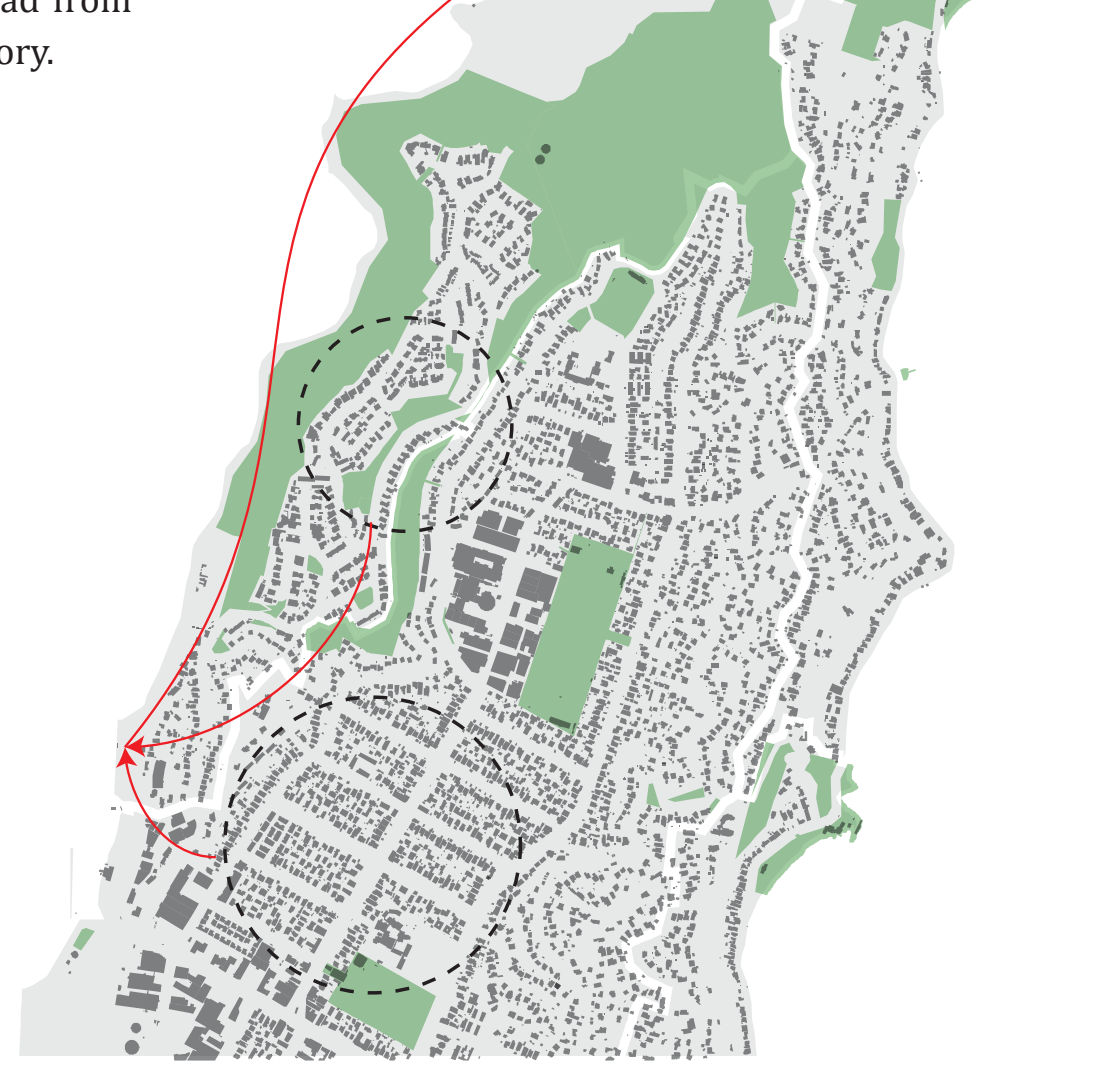

Below Figure 6.5 Relationship between shelly bay and site: people find good spot within study area to take photos of Shelly bay. 


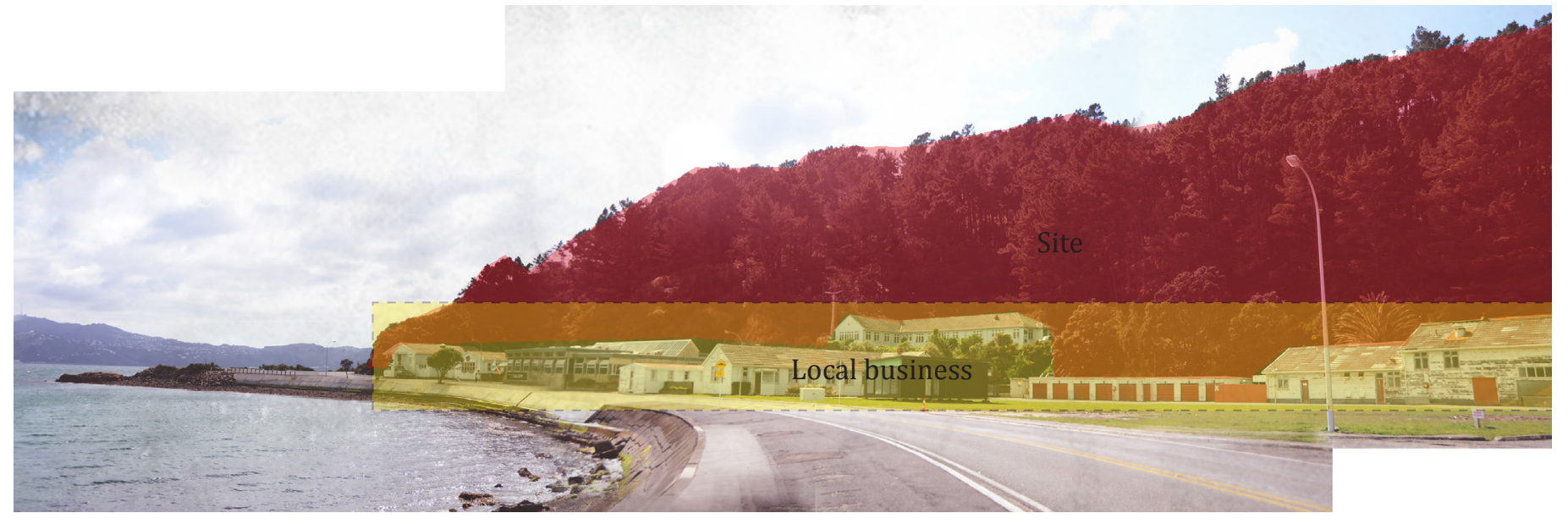

Figure 6.6 Shelly Bay businesses

Figure 6.7Showing the potential of re-opening the closed path.
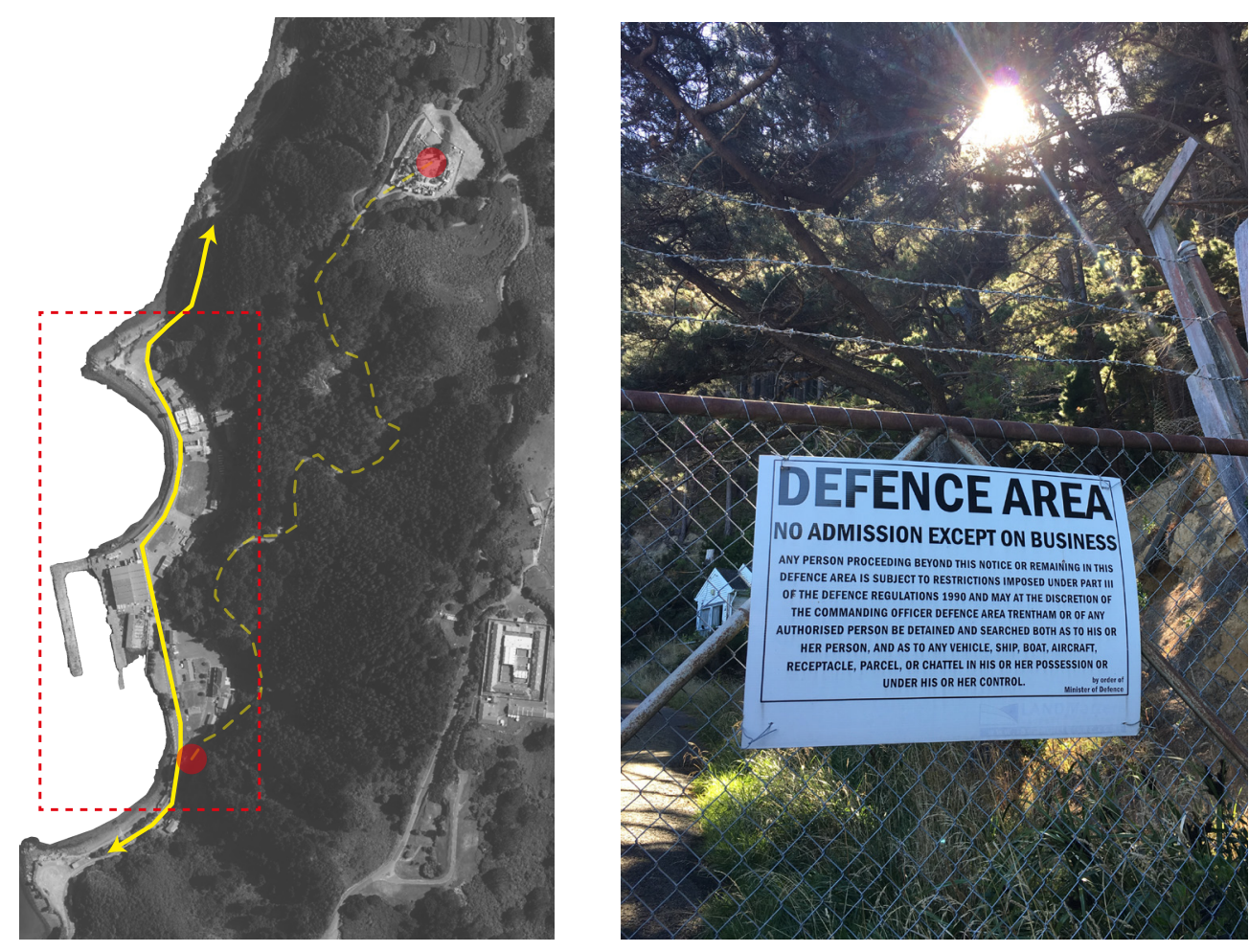

Figure 6.8 Shelly Bay access.

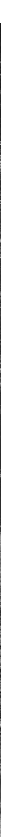




\subsection{Massey Memorial}

Massey Memorial locates on Point Halswell at the northern tip of the Watts peninsula. The entrance is at the bottom end, about $0.5 \mathrm{~km}$ north of Shelly Bay. A track leads people walk to the memorial, and continue leading to military sites. Beware that the steps at the bottom of this track are virtually on the edge of the road and a small parking area directly opposite the track entrance which is easy to miss when people drive around the coast. This presents an opportunity to improve walking access from the coastal road and connect to the wider track network.

Below Massey memorial is a grand stone memorial as a resting place of Prime Minister William Massey who died in 1925, and later his wife, which is a popular destination that people intend to visit.

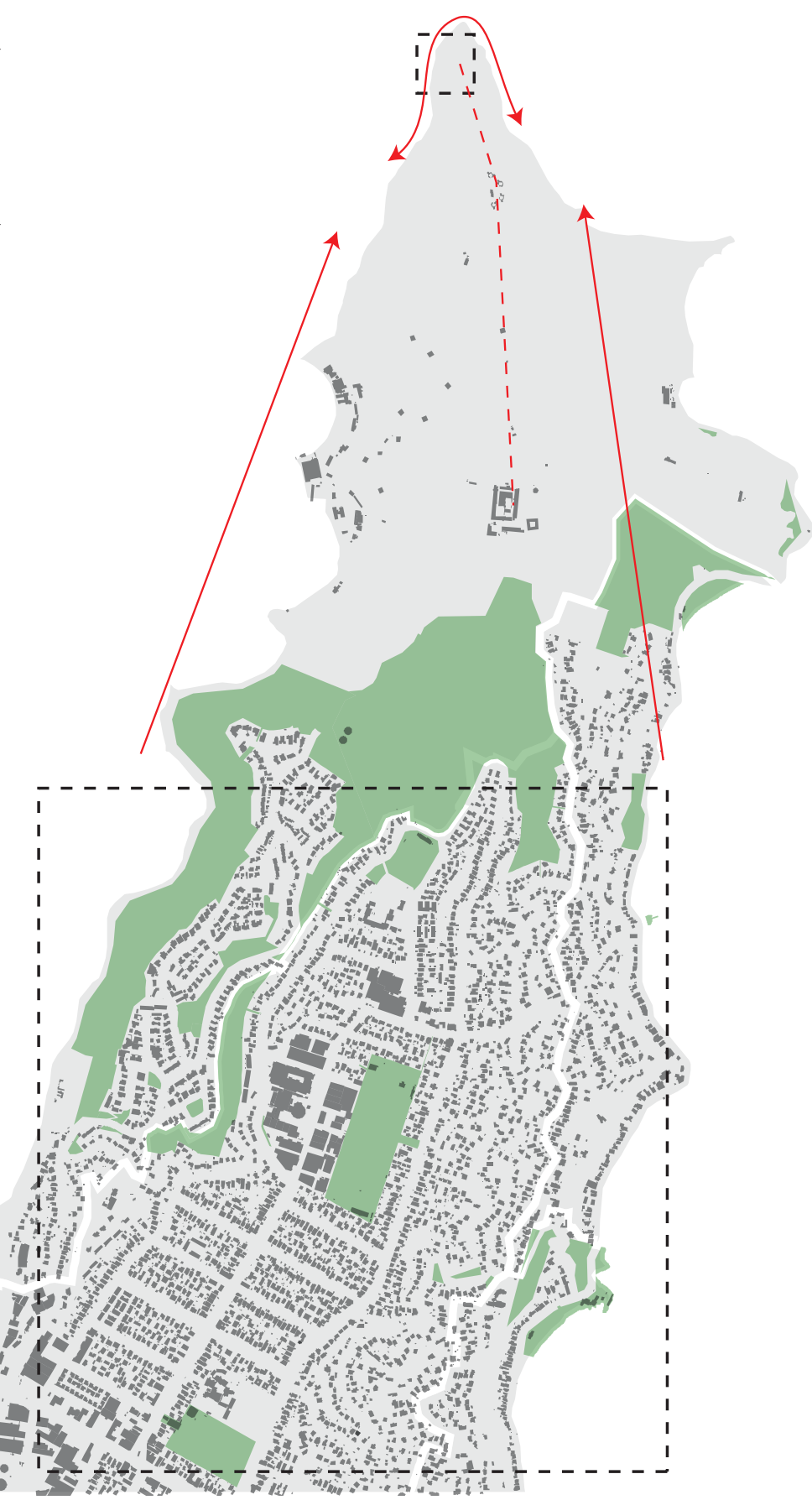

Figure 6.9 Massey Memorial interactions.

Figure 6.10 Massey Memorial North Panorama

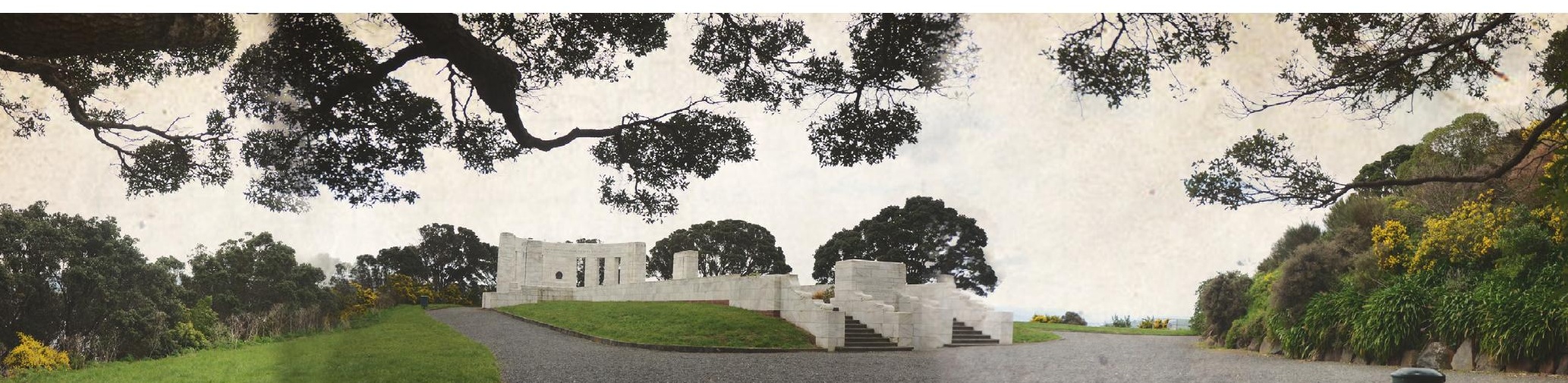




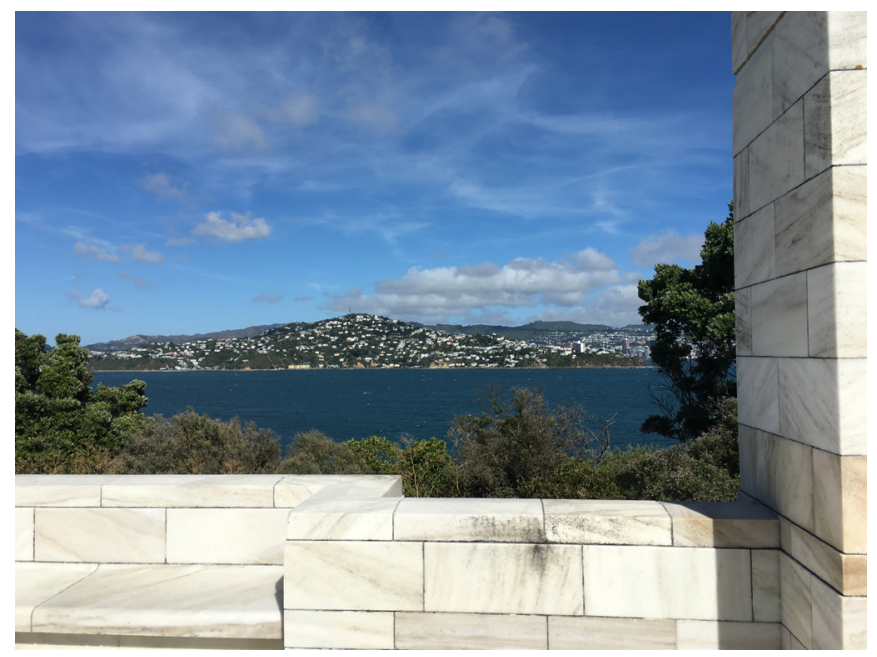

Figure 6.11 Massey Memorial interactions.

Manage vegetation to retain important views out from site.

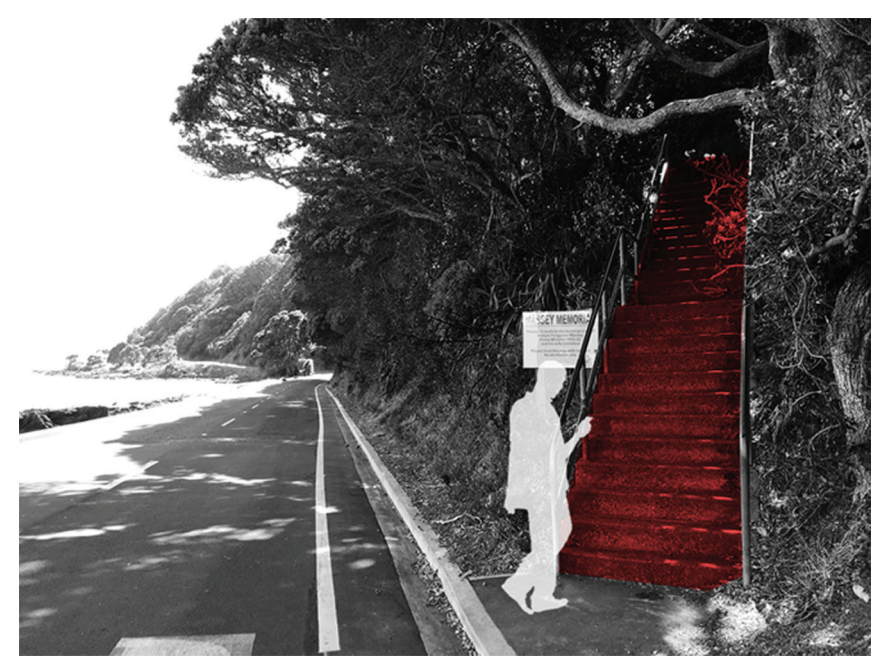

Figure $6.12 \mathrm{~A}$ small entrance on the edge of the road.
Right Figure 6.13 Connections to the Massey Memorial could be significantly improved to enhance visitor experience to and at the site.

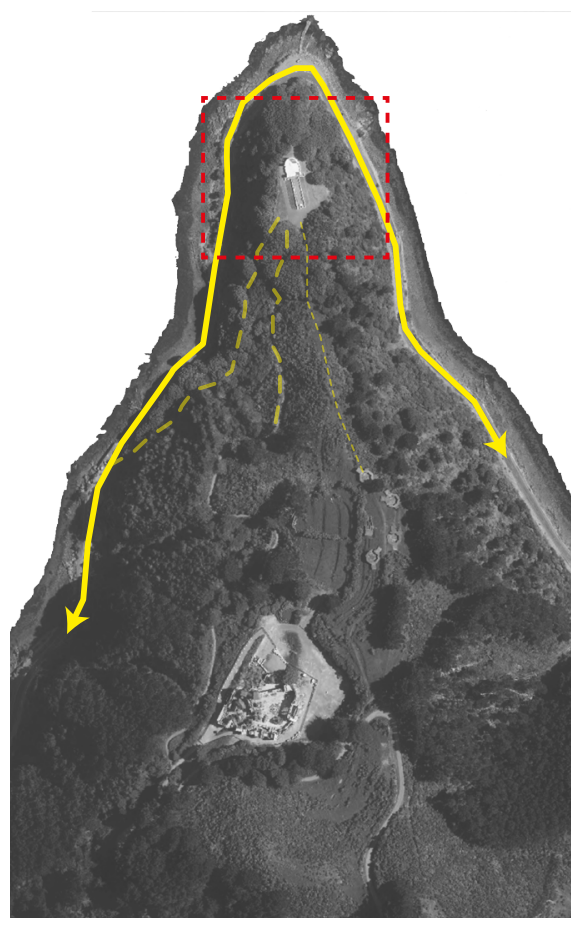

Below Figure 6.14 Combined management of Massey Memorial and the site will offer efficiencies.
A rough track leads up the ridge behind to military sites

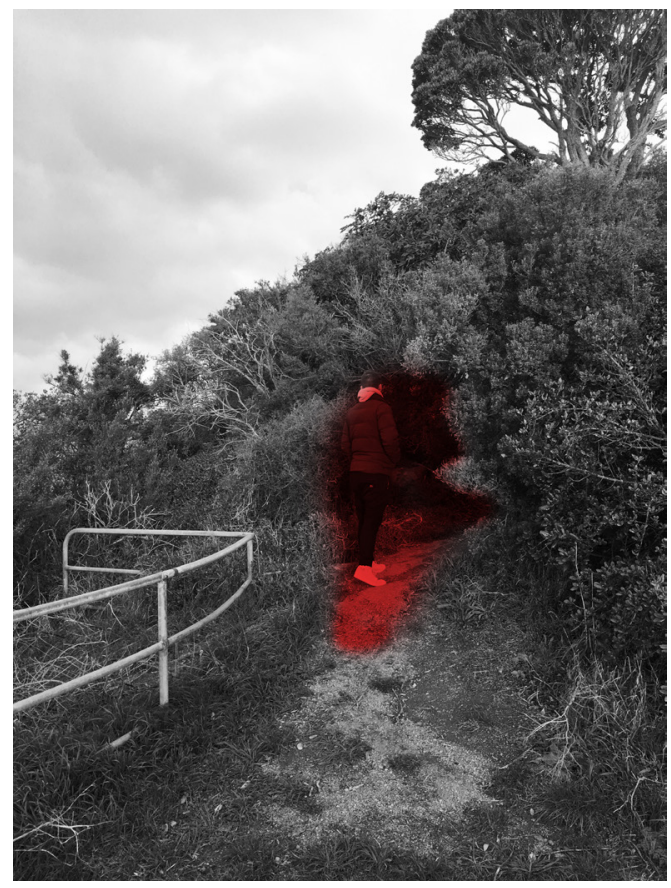

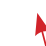

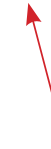




\subsection{Maupuia Residential Area}

Maupuia is a residential and open space area on the eastern side of Miramar Peninsula. Most of houses locate on the hill side, overview the harbour which settle the harbour is a part of their life. Maupuia residential area locates close to Watts peninsula, it has potential to open up for Maupuia residents and involve in their everyday's life.

Maupuia

2013 Population: 1503

Population density: 7.92 person/hectare

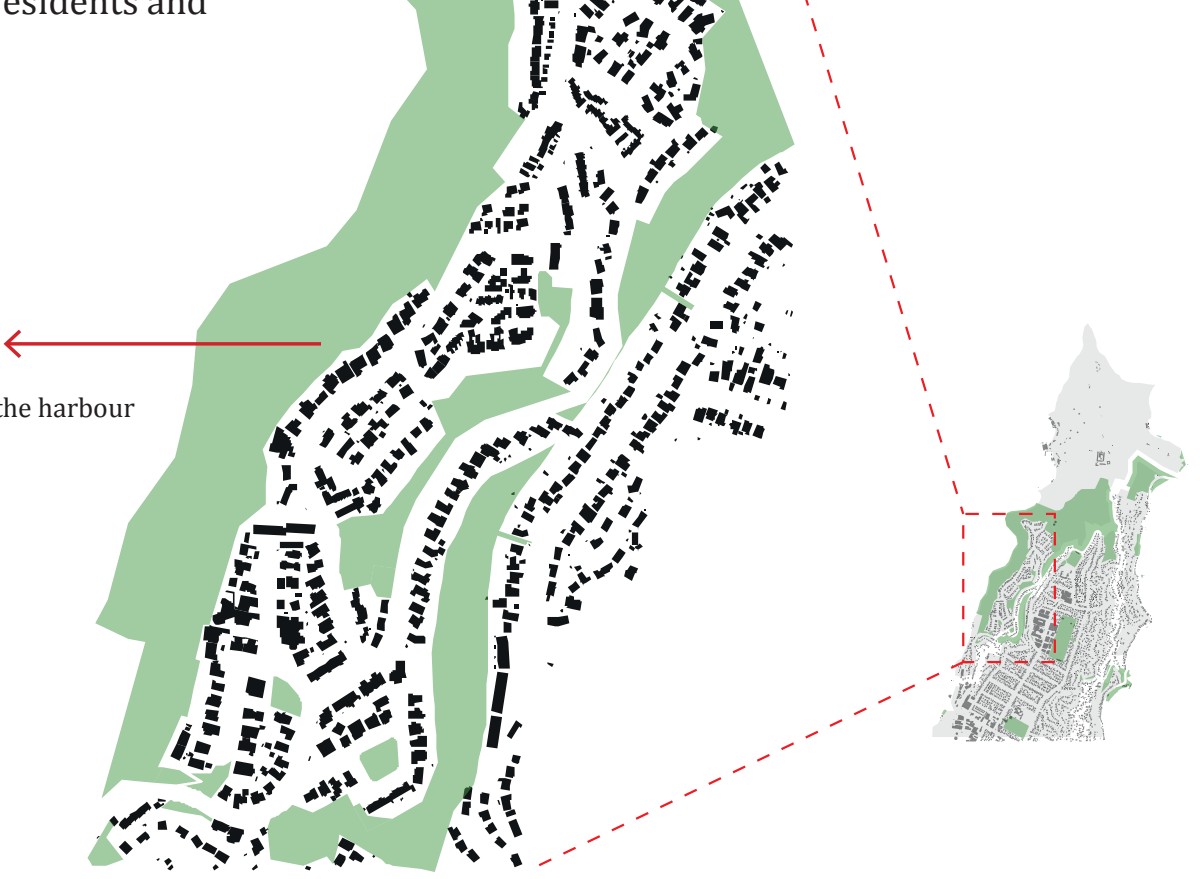

Figure 6.15 Maupuia Residential Area

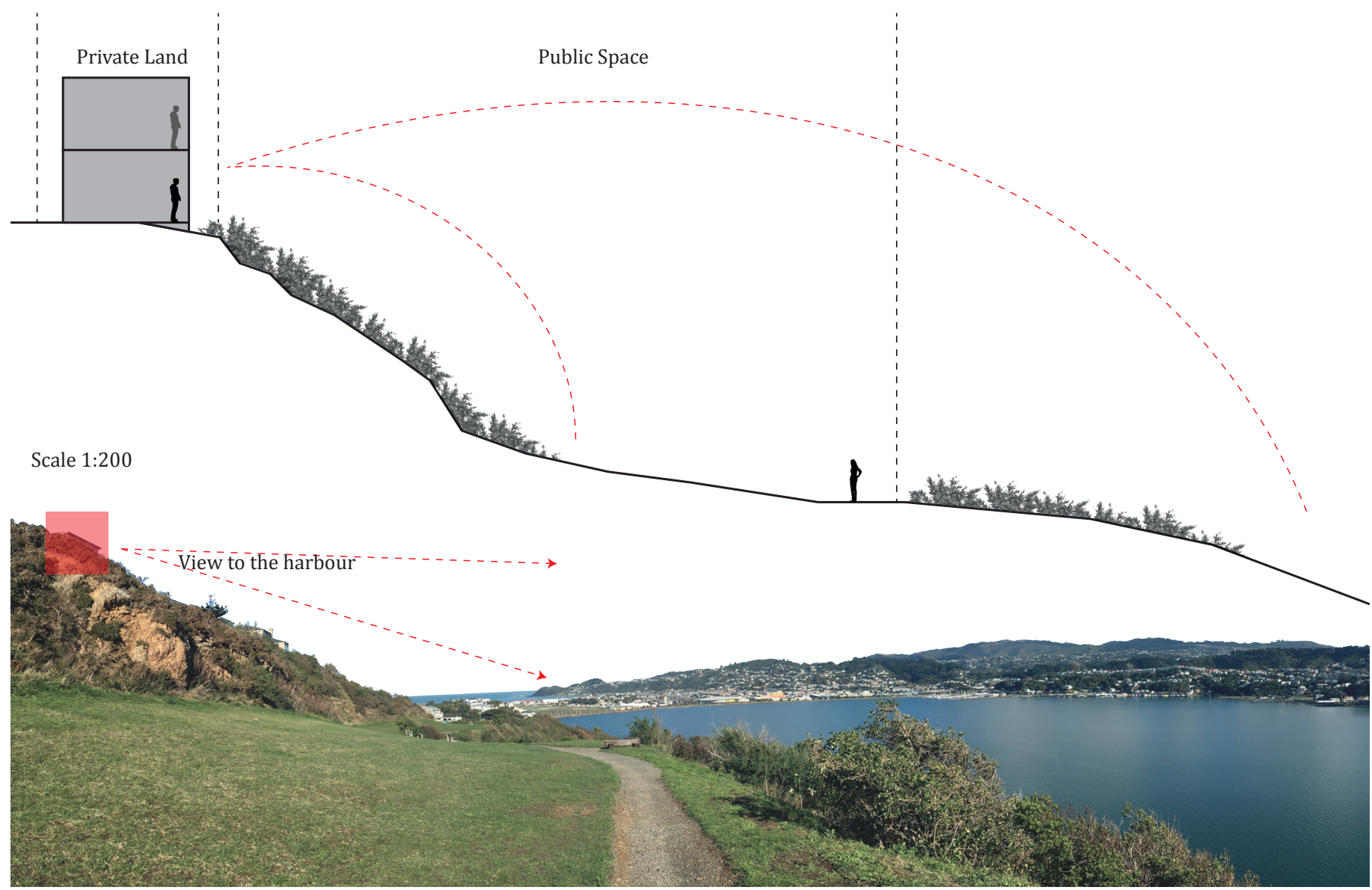




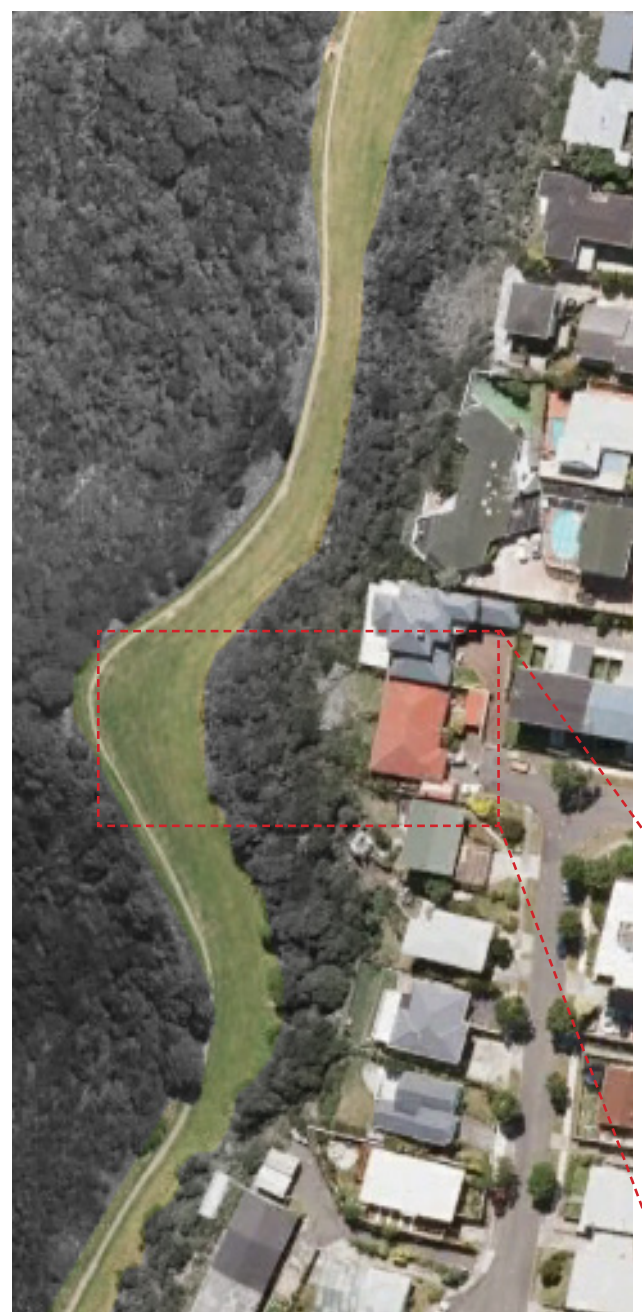

Figure 6.17 Market Evaluation

\section{Market Info}

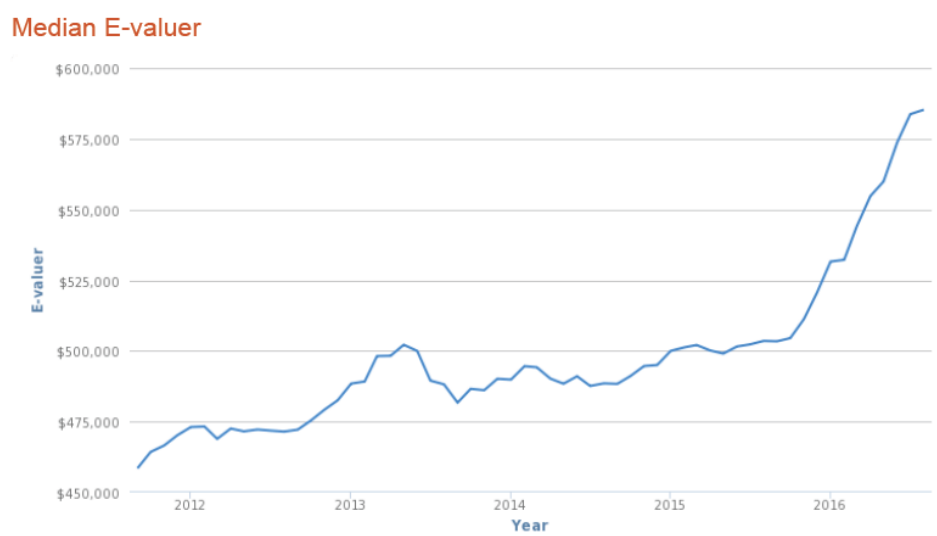

An E-valuer gives an instant estimate of the current market value for a property (QV, 2016).

$\$ 585,250$

"Quotable Value"

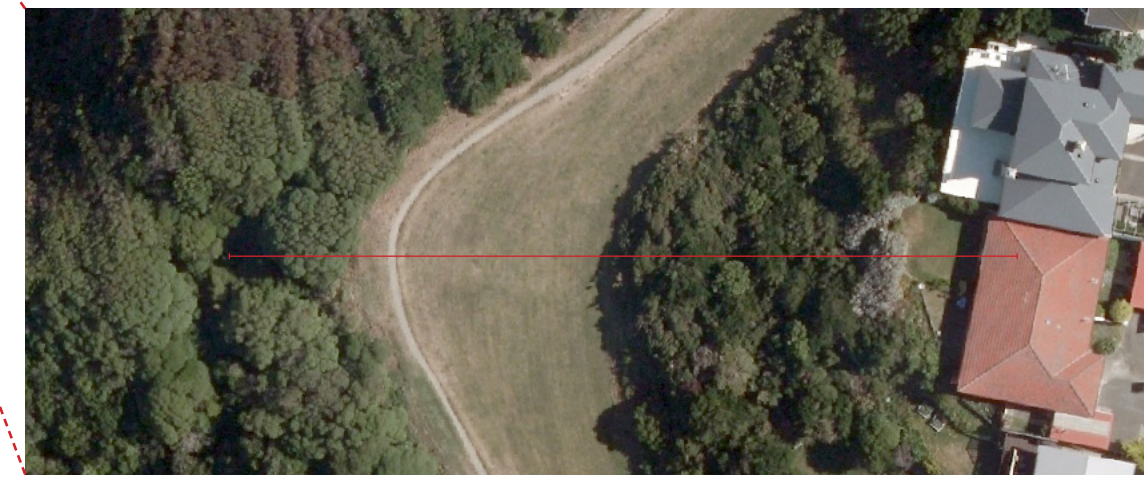

Long daily sunlight hours

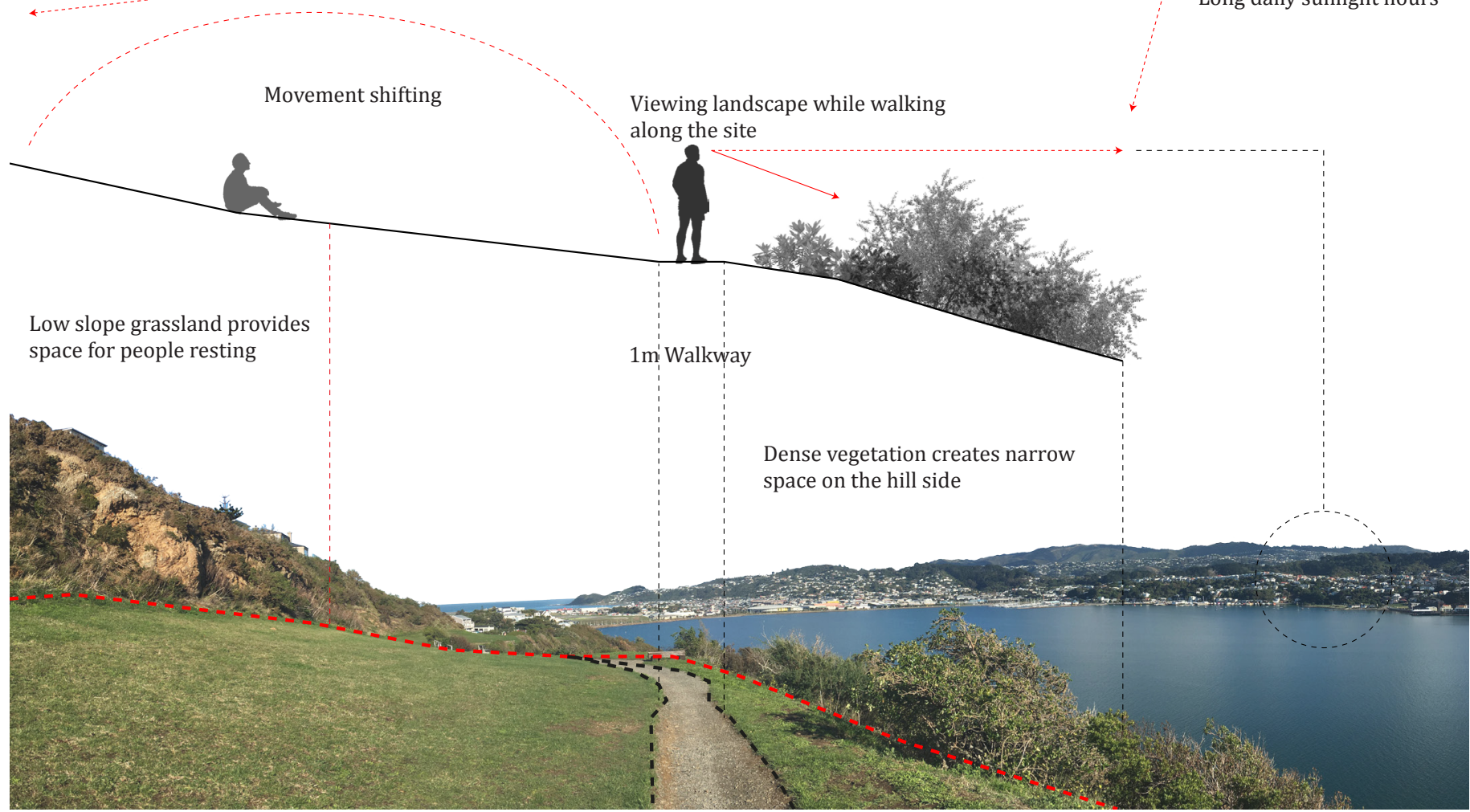




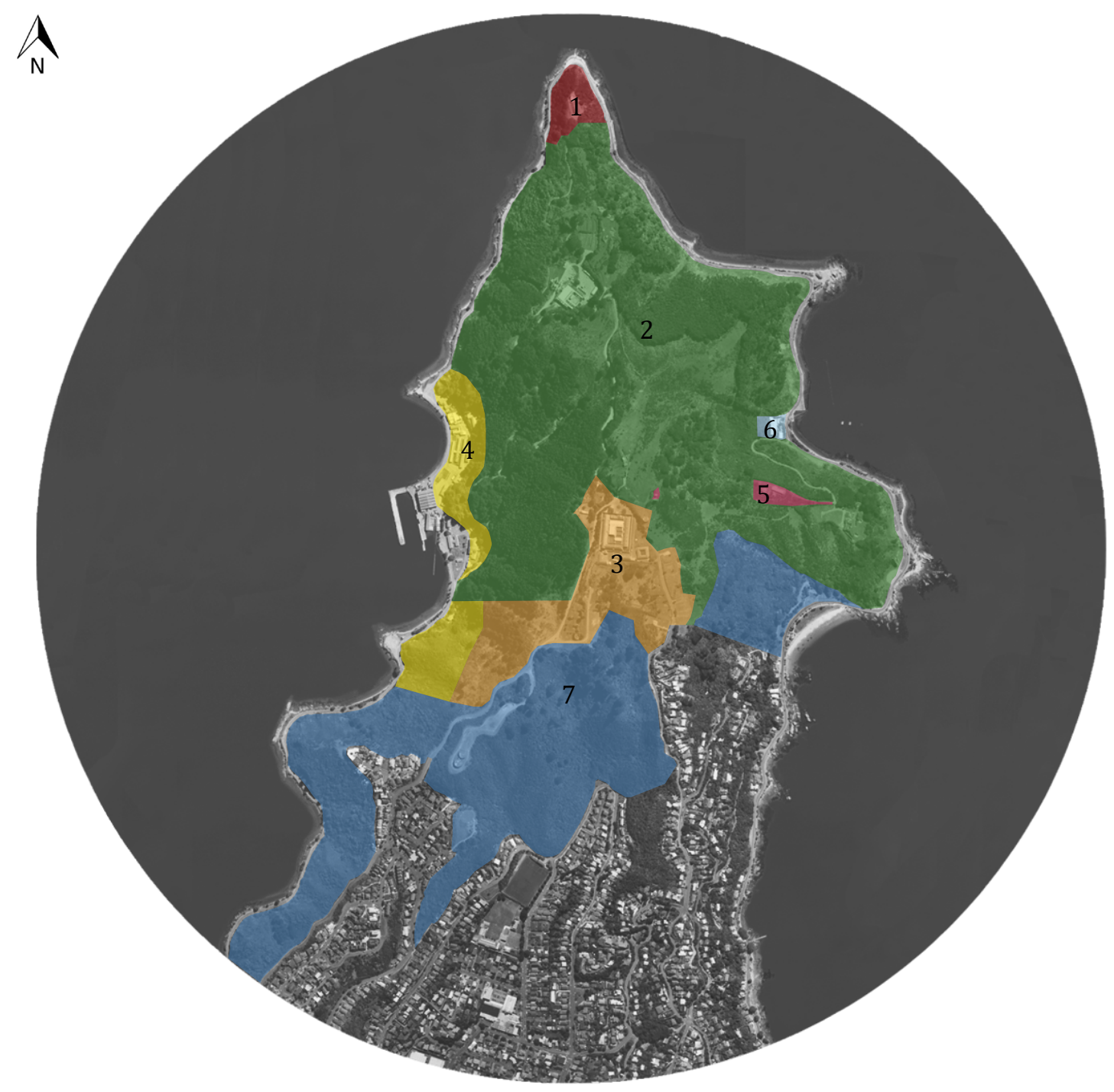

Figure 6.19 Map of land ownership.

\subsection{Ownership}

Top of Miramar owns by different landlords (Fig), New Zealand Defence Force owned the most of the land since 1885, LINZ would soon become the sole owner of the land, which was on the Miramar Peninsula, after Cabinet approved a handover from the New Zealand Defence Force. It is importance to consider the relationship between each owners, make sure any changes are benefits for each one of them.

\section{Ownership}

1. Department of Conservation/LINZ since 2016

2. New Zealand Defence Force

3. Department of Corrections

4. Shelly Bay Ltd

5. Telecome New Zealand Ltd

6. NIWA

7. Wellington City Council 


\subsection{Policy Influence}

MOU

Treaty Negotiations Minister Chris Finlayson, the Port Nicholson Block Settlement and the City Council signed a Memorandum of Understanding (MOU) in 2014 which aimed the site is protected, preserved and developed with sensitivity. But due to this complex context influences, the land is still setting in an abandoned landscape.

Wellington City Council

The reason the council had been asked to buy the other piece of land back was that the port company considered there was no ability to get a resource consent because of its heritage overlay. The property's value possibly being between $\$ 10$ million to $\$ 15$ million, it was unlikely that Wellington City ratepayers could afford to be the sole owner, meaning a mixed ownership model would need to be explored. (The Dominion Post, 20, Sep, 2016). 

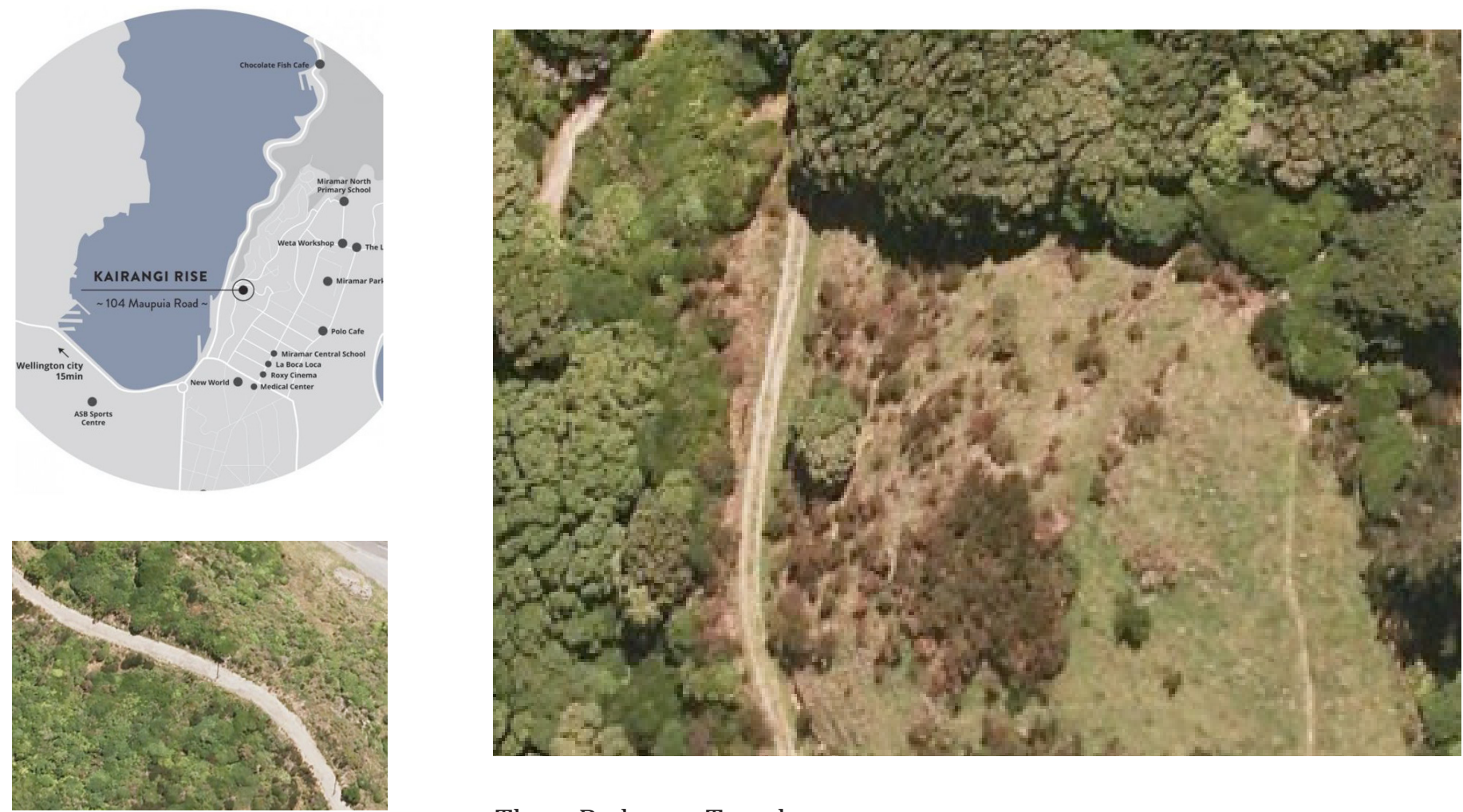

Three Bedroom Townhouse

Offers over $\$ 729,000$

104A Maupuia Road, Miramar

Figure 6.20 Render from Realestate showing the house looking (Realestate, 2016).

\subsection{Housing Development}

In 2011, the past owner New Zealand Defence Force was planning to sell a large chunk of historically significant land on Miramar Peninsula and its plans include about 150 homes in "clustered heritage communities". About 14 ha would be suitable for rezoning to create 150 residential building sites, says a report entitled Watts Peninsula: LifestyleHeritage-Community-Living Together. The homes would be a mix of detached, semi-detached and terrace-style, and owners would pay a fee to a body established to protect, enhance and maintain the heritage features. Current owner Land Information New Zealand (LINZ) said, while small pockets of Watts Peninsula might be sold and developed into housing, the vast majority would probably be converted into a public reserve. (2016).
Above Set for completion in late 2017, the first 12 houses go on sale off the plans from Saturday, with inquiries starting at between $\$ 685,000$ and $\$ 1 \mathrm{~m}$ for the three and four-bedroom homes, including standalone houses and semi-detached townhouses. 


\subsection{Conclusion}

Understand the relative relationships to the site allows for more sensitive insertion that allows the study site to work with the wider context assemblage for a richer landscape experience.

An important aspect of any development of the site is the relationship between the site and these neighbouring sites, the coastal edge, the harbour and the urban fabric of Wellington City. It is important that the site and its setting are viewed as an integrated whole. As emphasised throughout the research, it is important that all these areas of land are considered alongside the Watts Peninsula and commonalities and linkages taken into account. 


\section{HOUSING DESIGN INVESTIGATION}

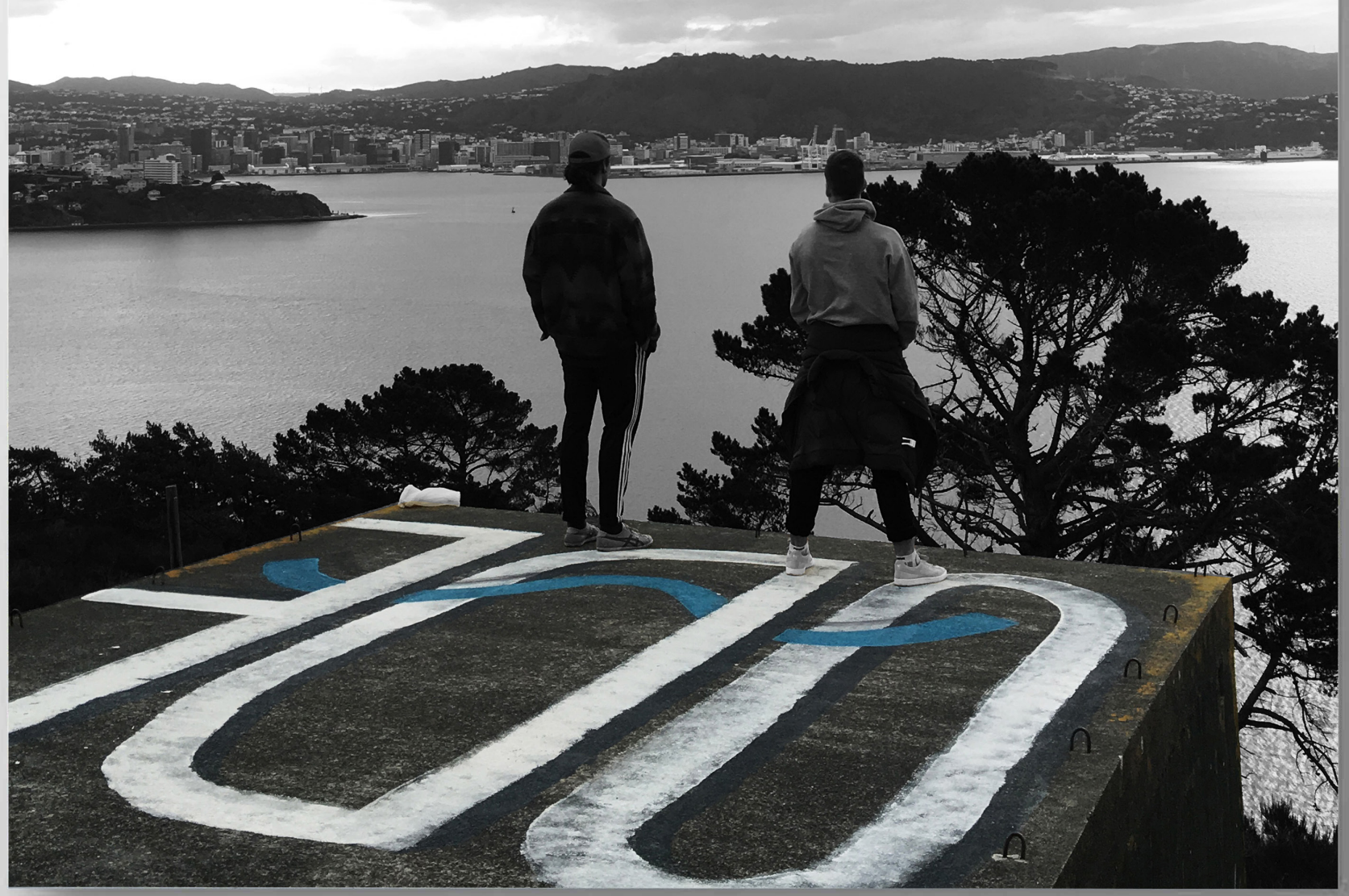




\subsection{Problem}

Previous studies highlighted the richness of Watts Peninsula, and the current intention is to make it attractive and available to the public. Housing seems to be one way to seriously offset the cost of development. This is prime real estate.

"But with its value possibly being in the range of $\$ 10$ million to $\$ 15 \mathrm{~m}$, it was unlikely that Wellington city ratepayers could afford to be the sole owner, meaning a mixed ownership model would need to be explored."- Stuff, 2016

In contrast, Watts Peninsula Feasibility Study estimated that the total cost for key recommendations to protect, preserve and develop the site would be $\$ 2,720,000$. Due to this high evaluation, it has taken a lot of time to collect and process any form of collaboration between relevant parties. How can this intention be realised and be mutually beneficial to each party. This design proposes three different scenarios to aid in the viability of this inevitably expensive project. at the same time and how site can play a part in the local residents' everyday life.

Watts Peninsula Feasibility Study pointed following key recommendations and estimated costs:

- $\quad$ Establish a governance entity - $\$ 50,000$

- Immediate works for site safety and security $-\$ 225,000$

- Reserve management planning processes - \$330,000

- $\quad$ Enable public access and recreation - $\$ 615,000$

- Upgrade trail network and complete restoration projects - $\$ 1,500,000$

- Total estimated costs: $\$ 2,720,000$

List from Watts Peninsula Feasibility Study showing the amount of money needed for introduce the site to public 


\subsection{Housing Design Scenario}

Heritage sites can be part of people's life if they are treated urbanistically. The study site's surroundings offer the potential for a housing development and infrastructural moves that allow the heritage to be explored in a more vigorous manner. The previous Watts Peninsular study mentioned that the past owner, the New Zealand Defence Force, was planning to sell a large chunk of land and build 150 houses, which points towards an already existing desire to bring a more housing to the site.

The housing development area has been chosen adjacent to Mt Crawford Prison, currently owned by Department of Conservation. The method of the housing development is to have a critical number of houses while still keeping the sites mystery which would require a denser and more compact development. The design investigation involved three parties: LINZ, Department of Conservation and Wellington City Council. The council could propose to buy a piece of land back and sell to developer, and use the money to support upgrading the greater Watts Peninsular site. By increasing the amount of people living in the area, the site will play a part in people's everyday life. The landscape qualities strengthen the house value and in turn, provide value back to the existing landscape. This design investigation explored three strategies: moderate housing numbers, maximum housing density and centre community, each strategy contributed to the influences of the following developments.

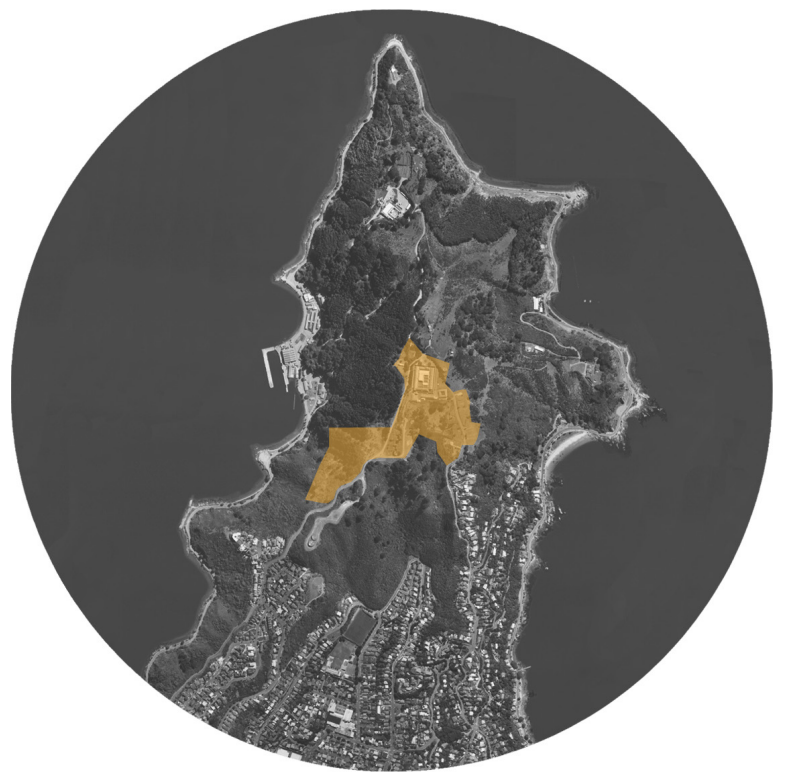

Fig 7.2 Mt Crawford Prison. In 2009, the 6.2 hectare site had a capital value of $\$ 6.9 \mathrm{~m}$. 


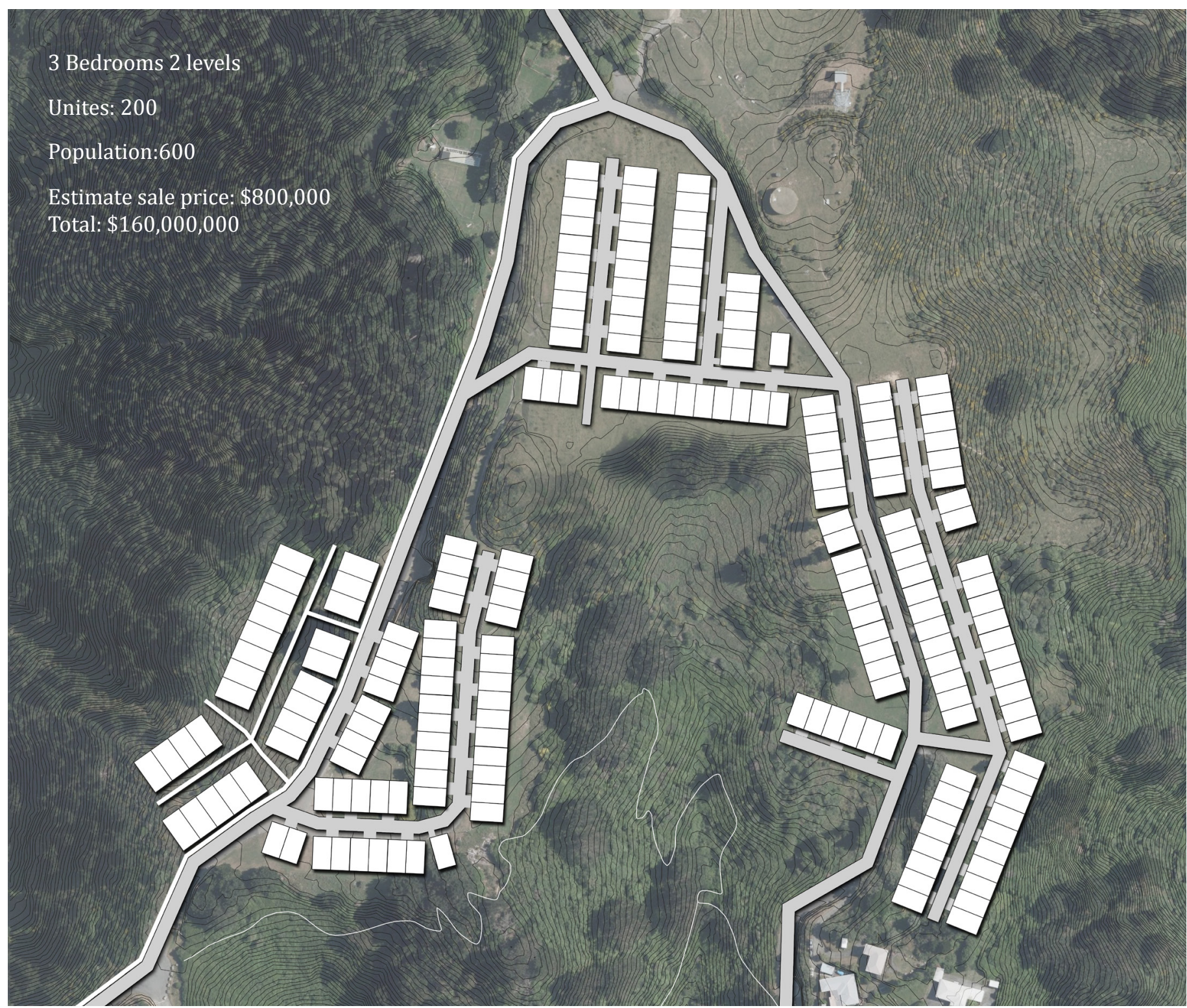

Fig 7.3 Moderate Housing plan.

\section{Moderate Housing}

\section{Strength}

- Medium density housing allows for a tight knit community.

- Access to shared public open spaces.

- Repurposing flat area where the prison was situated.

\section{Weakness}

- The existing topography makes some of the roading layout tight with some dead ends.

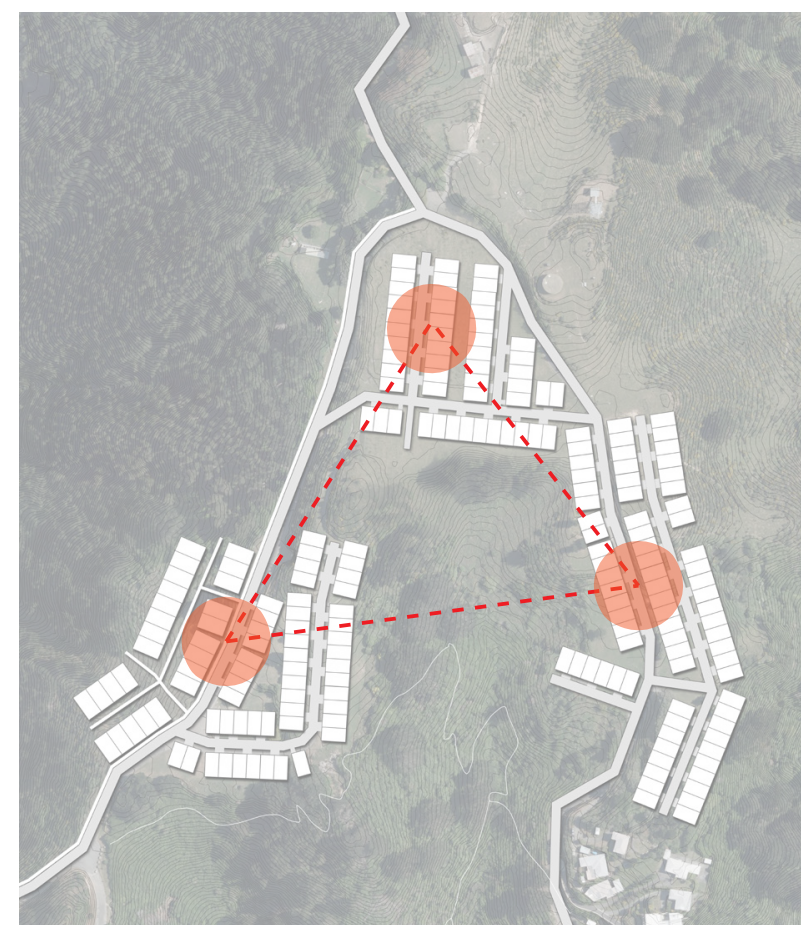




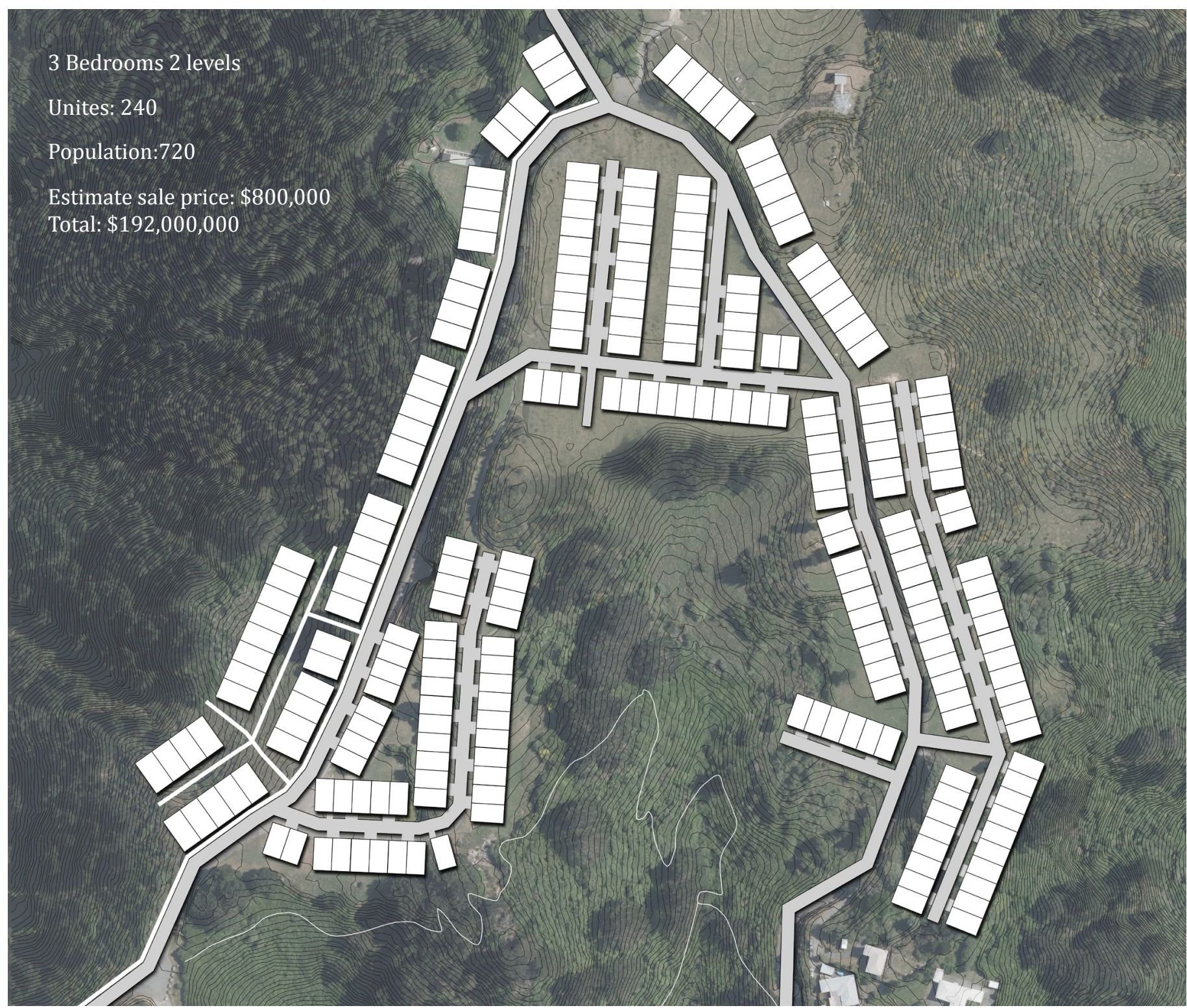

Fig 7.5 Maximum Housing plan.

\section{Maximum Housing}

\section{Strength}

- The developer has the potential to increase profit by maximising housing numbers. Therefore council could ask for higher sale price.

\section{Weakness}

- May be seen as an over development. Thereby ruining the landscape amenity.

- Shared space within housing development reduces due to higher density housing.

- Quality may be lost if developer is focused on quantity.

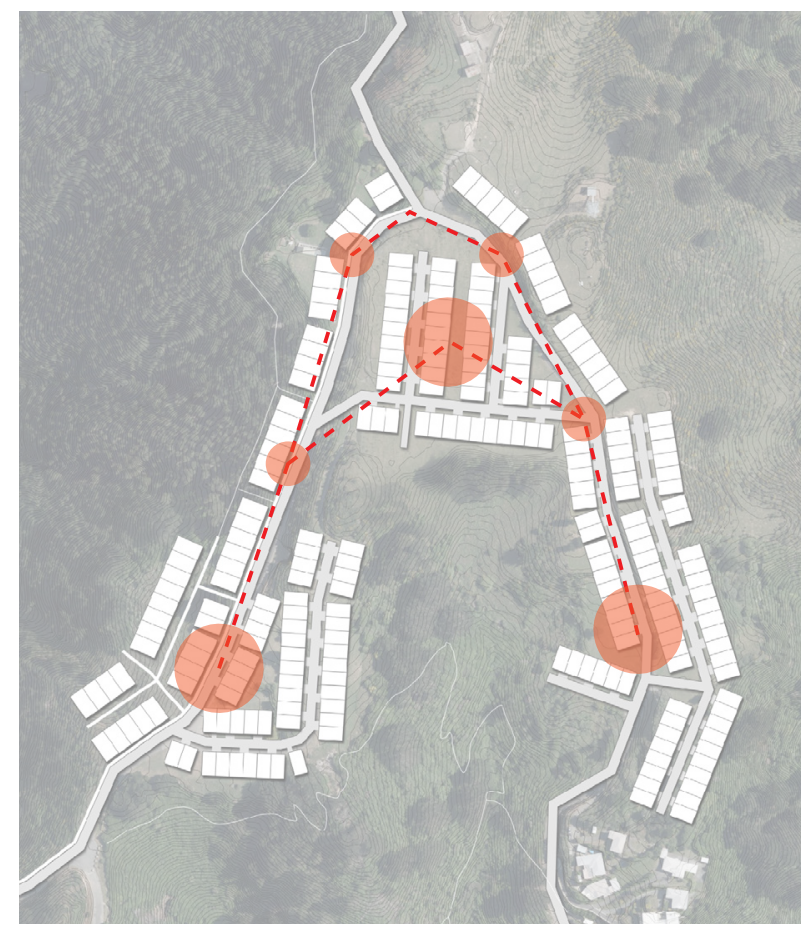




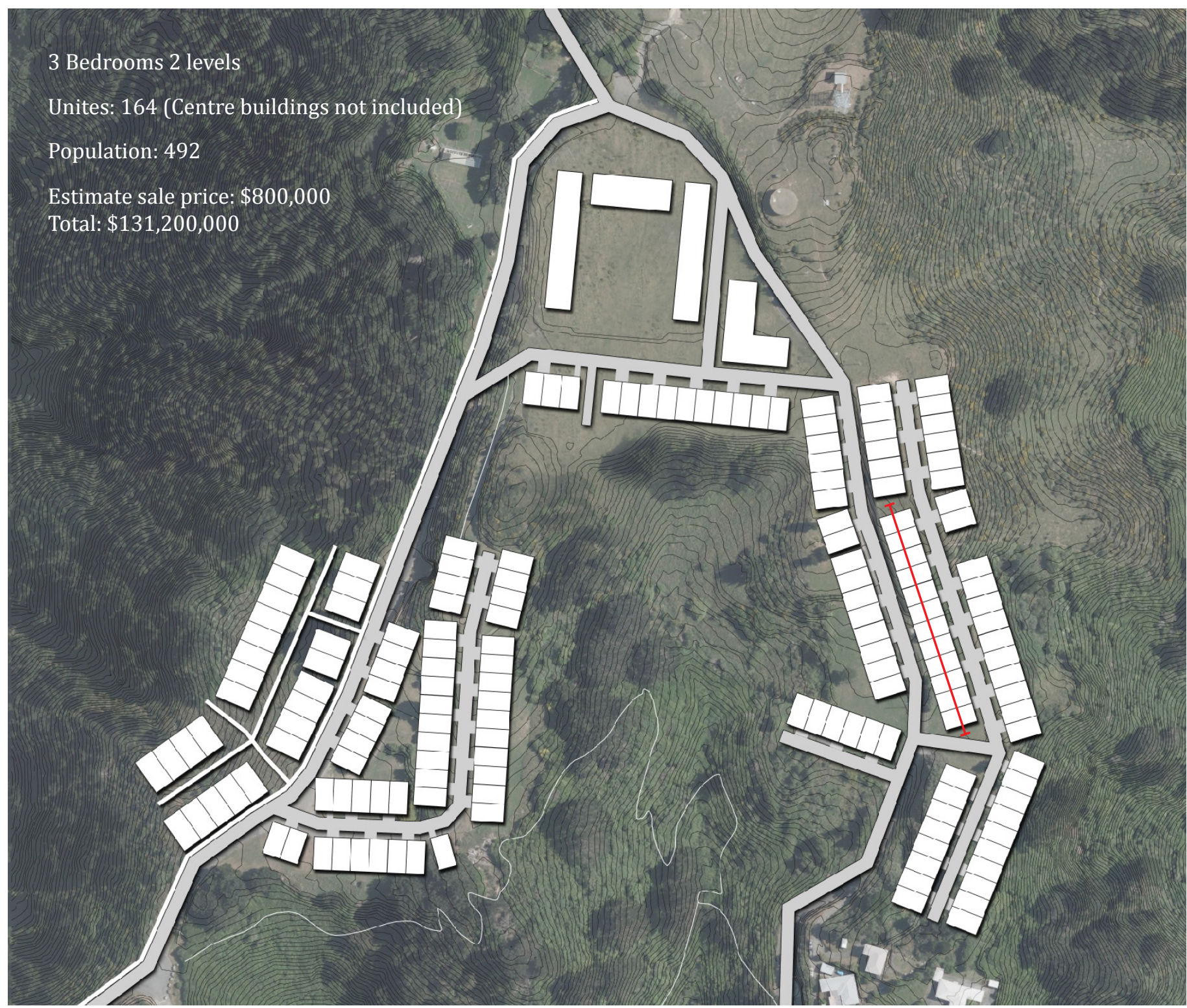

Fig 7.7 Central Housing plan.

Scale 1:2000

\section{Community Centre}

\section{Strength}

- Potential for development to includes shops, apartments and other centralised amenities.

\section{Weakness}

- Shop development may be limited as people tend to travel to Miramar shops already.

- Houses roadside may be affected negatively by the potential high number of tourists travelling to this centre along a relatively narrow road.

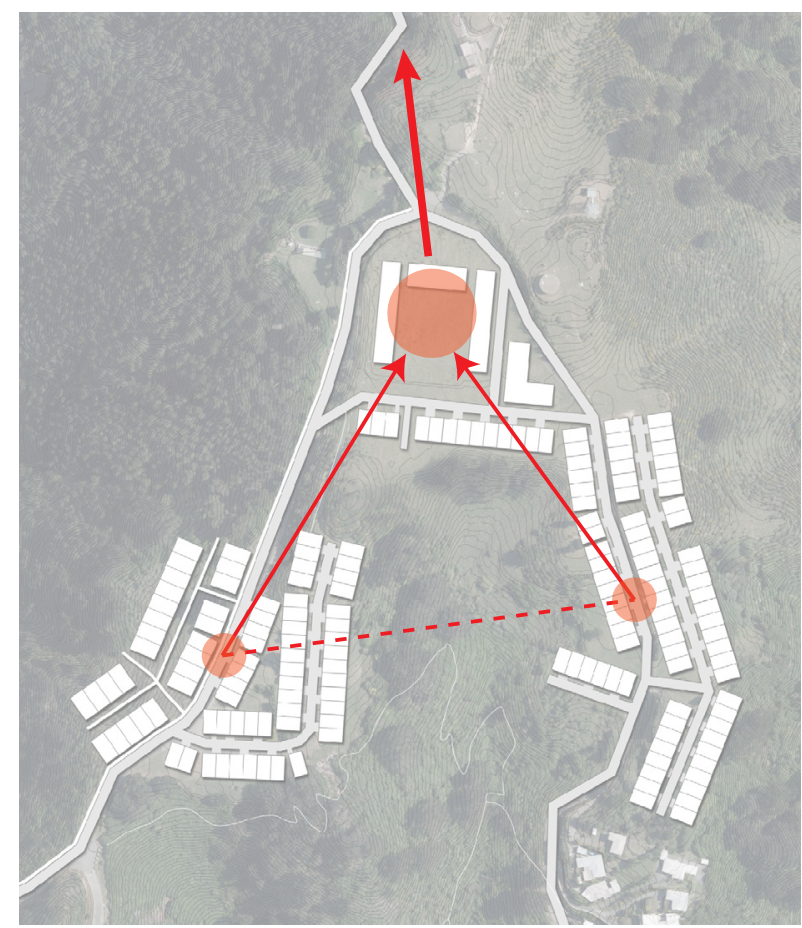



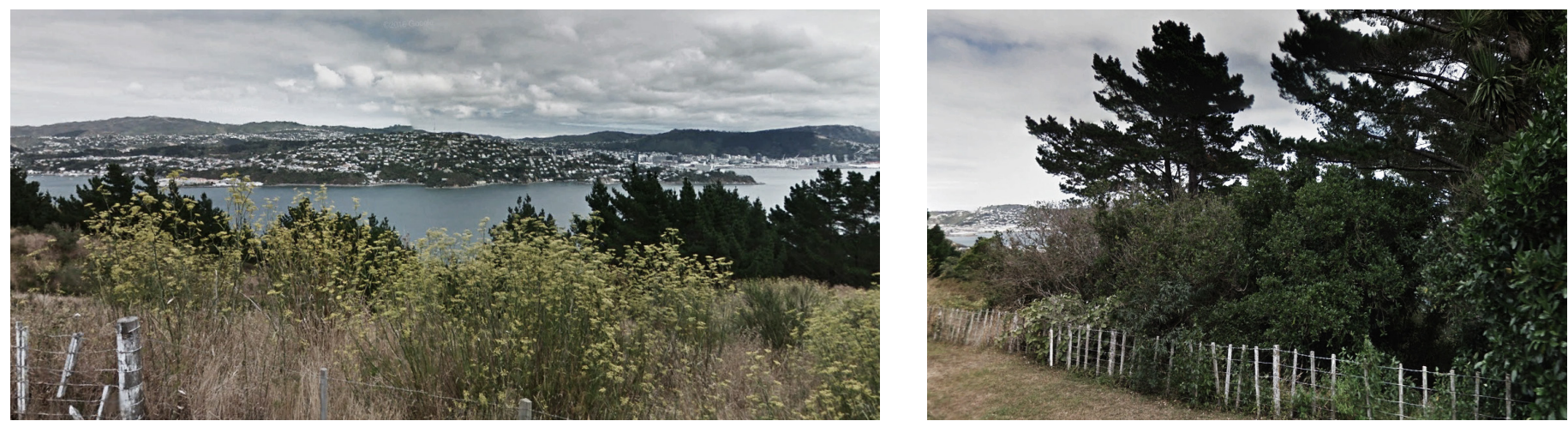

Fig 7.9 Views from Main Road, housing development area looking west to the

city. Some views are open + some obscured by vegetation.

Google Earth street view, 2016

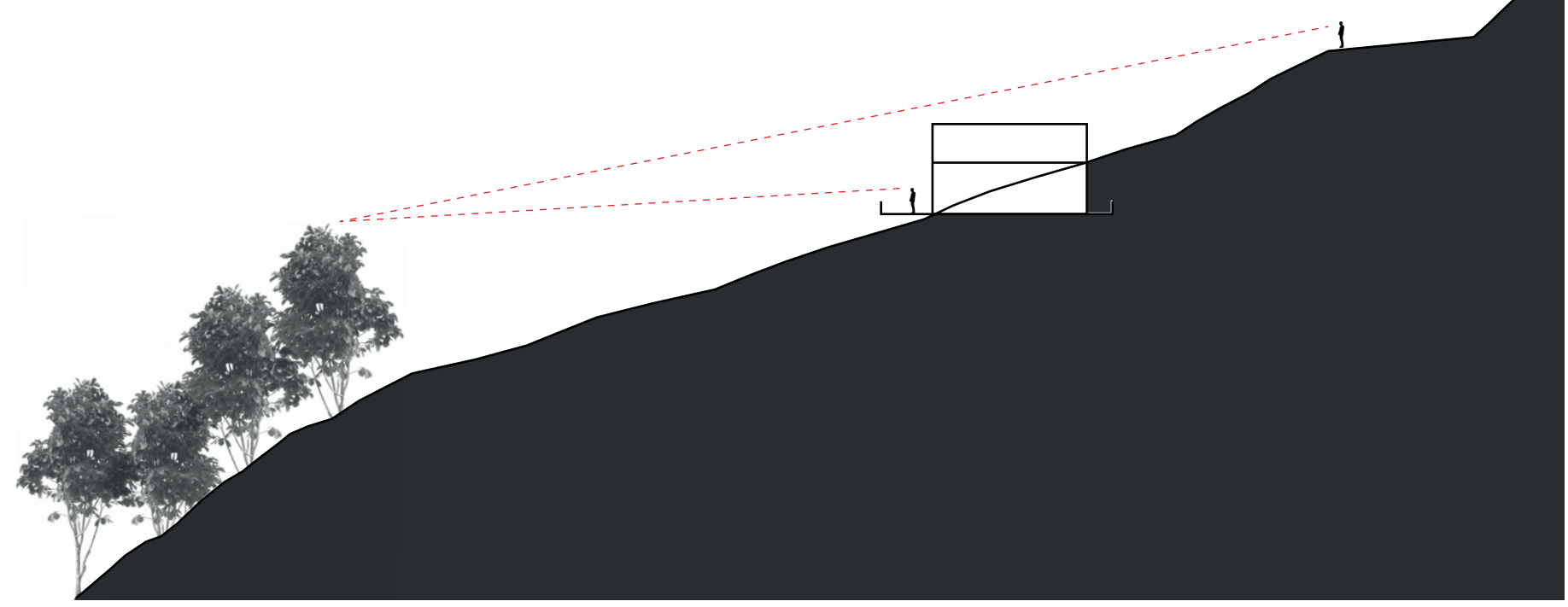

Fig 7.10 The house, to be sited is designed to allow

views over them and view from them over the trees.

Fig 7.11 Notion of the housing sited below the road allows for a

view to park, waters edge, water, and beyond from the road. 


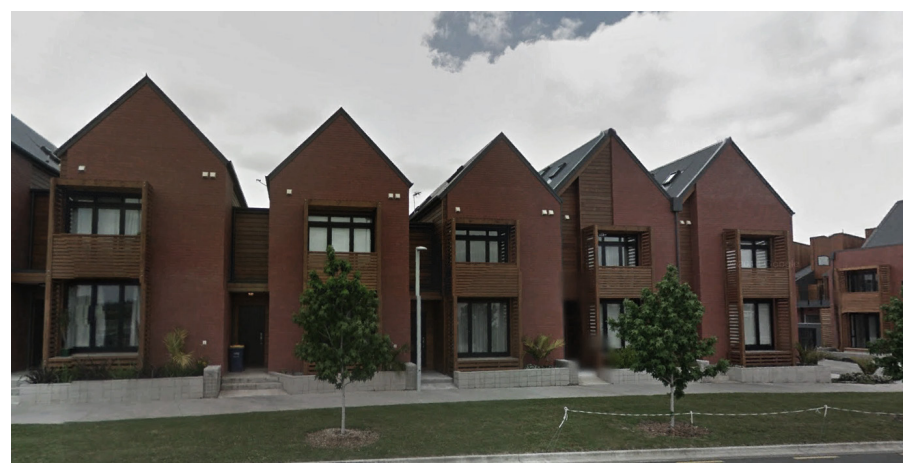

Fig 7.12 Medium density housing in Hobsonville, Auckland. Google Earth street view, 2016

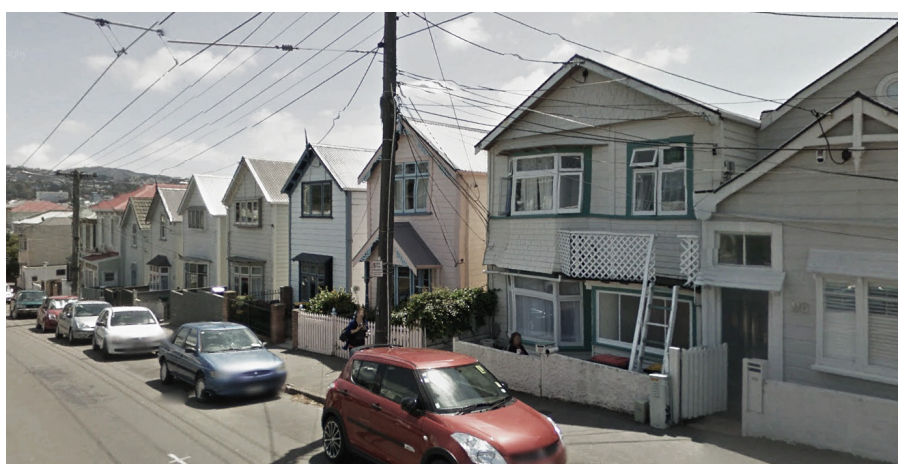

Fig 7.13 Terraced housing in Mt Cook, Wellington Google Earth street view, 2016
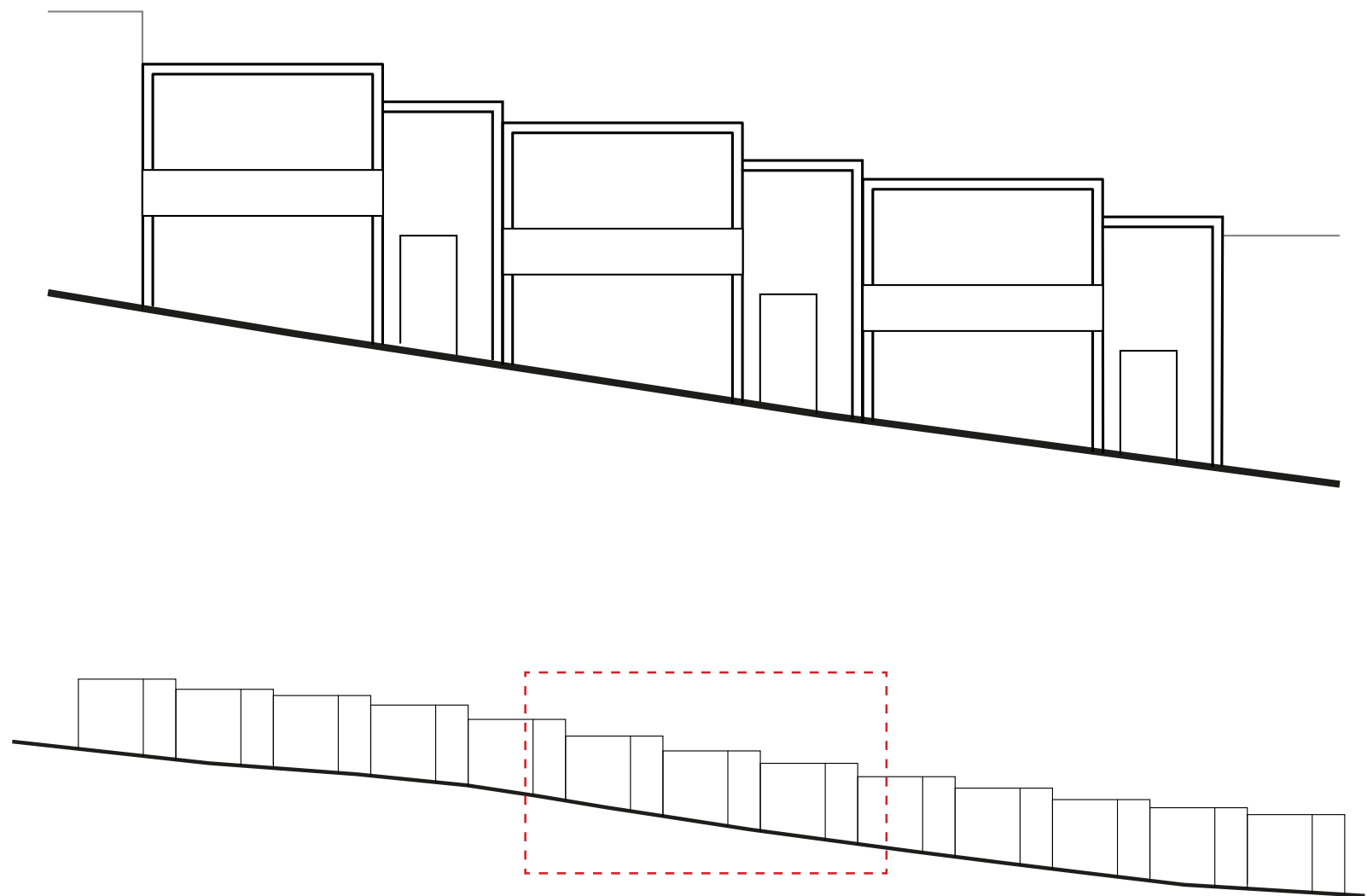

Fig 7.14 Terrace housing typology on site 


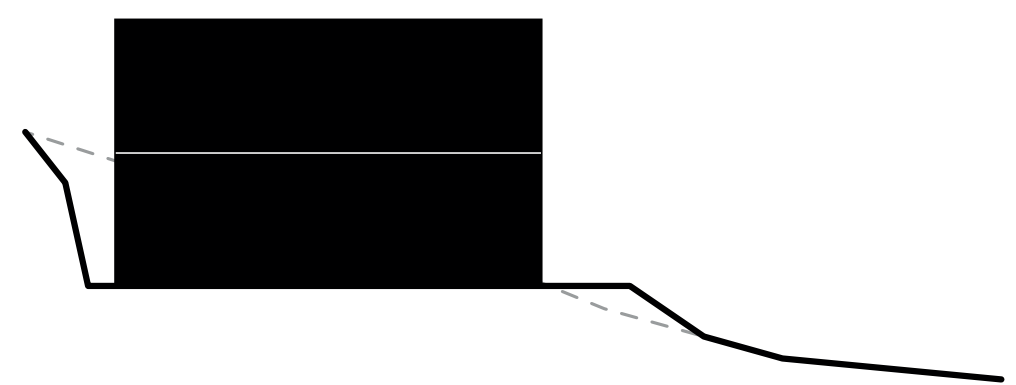

Cut and fill
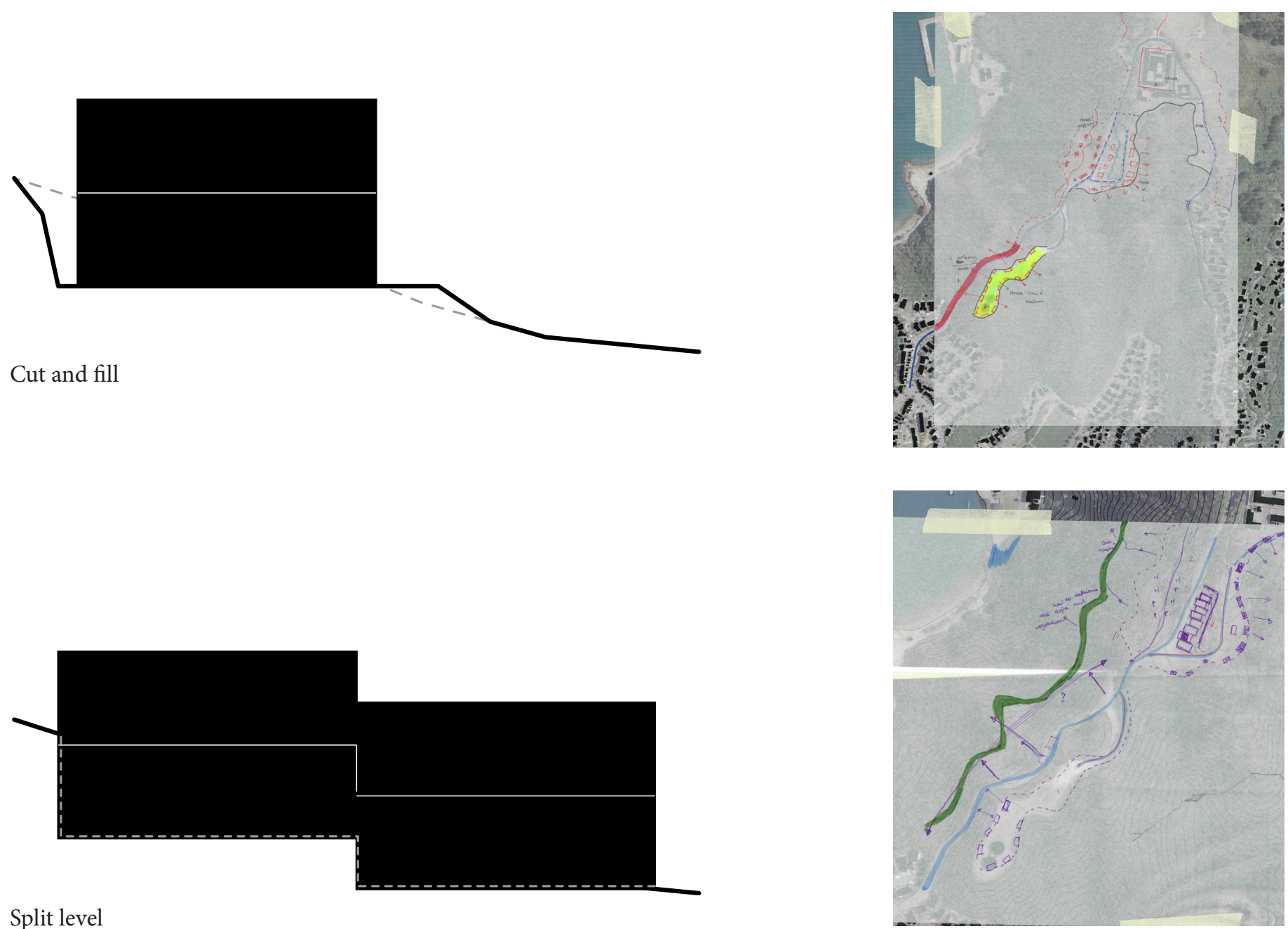

Split level
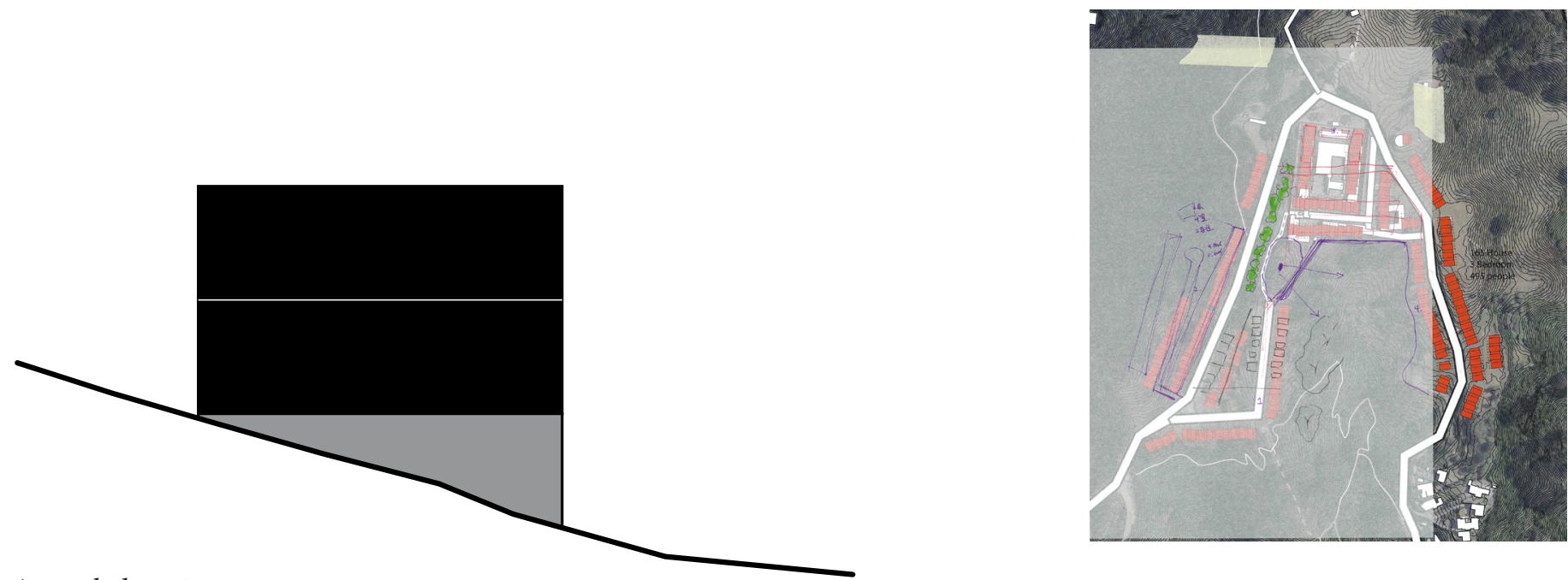

Amended section

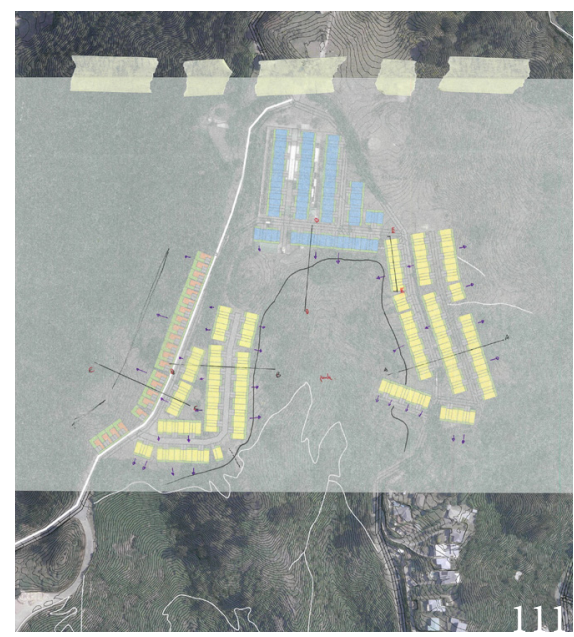

Above Fig 7.16 Due to the slope condition, there are 3 different options to build two-stories house. 


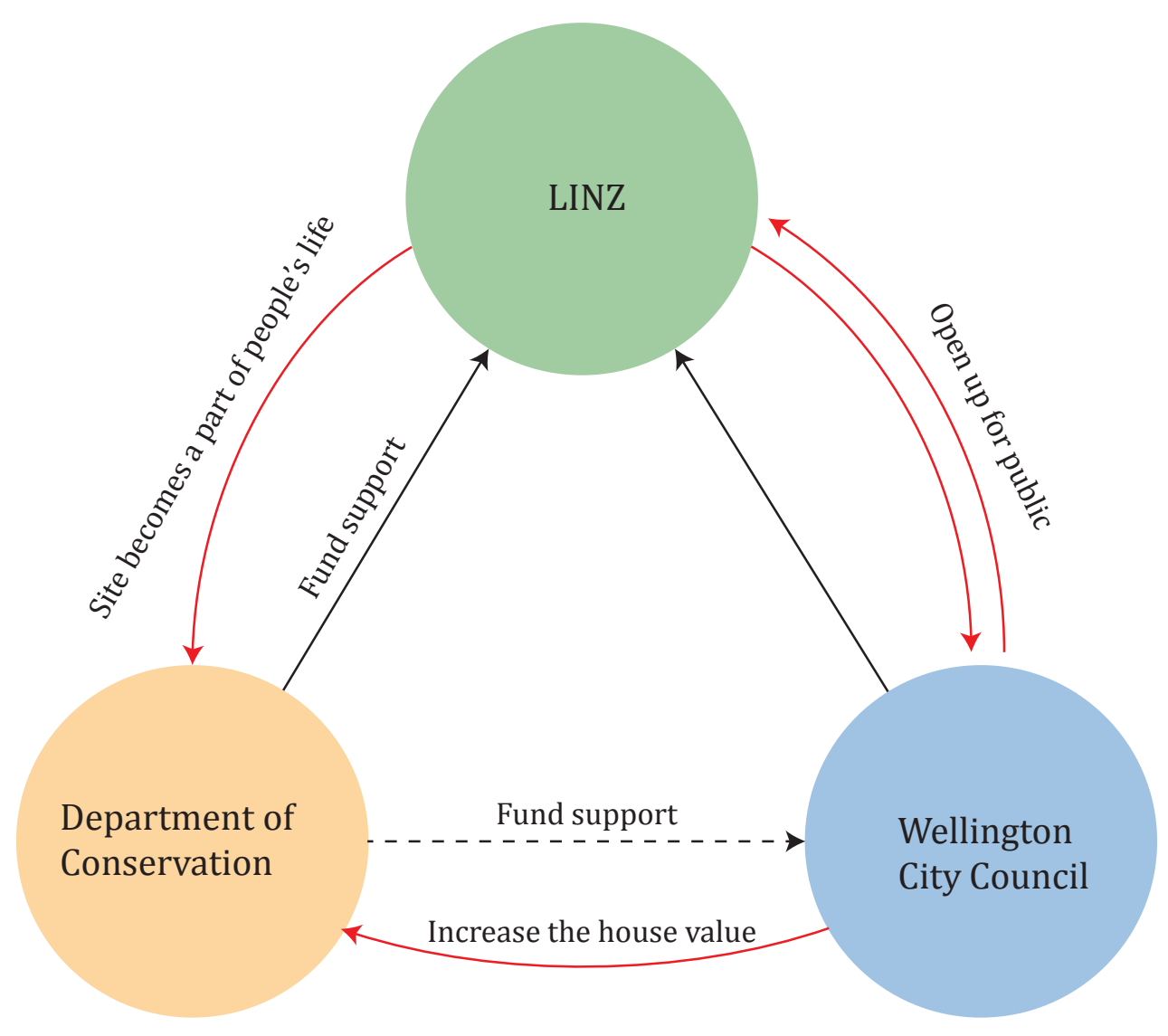

Fig 7.18 Strategy diagram.

\subsection{Relationship}

All parties involved would benefit from a housing development in the area. A development centred between each of the parties would be able to provide much of the needed funds required in order to construct some of the tracks and re-planting needed in the LINZ landholdings. These would then be able to be relinked through council land making a complete interconnected development.

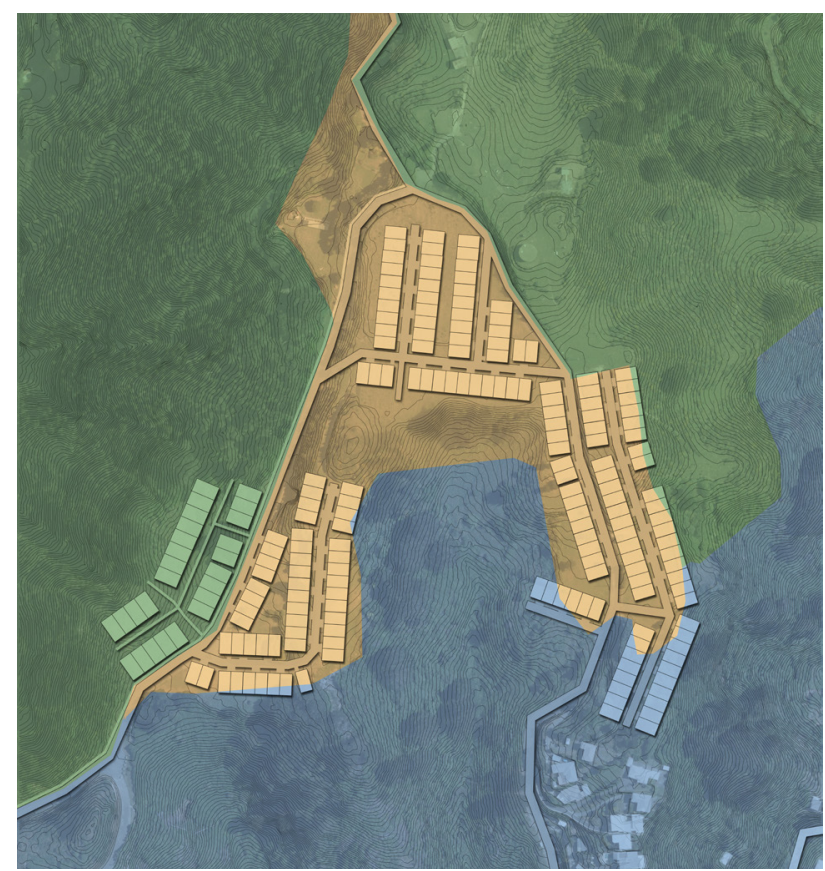

Fig 7.19 Strategy plan. 


\subsection{Conclusion}

By developing one of the housing designs, the money gained would be able to support upgrading the greater Watts Peninsular site for recreational use. The increase in people living in the area will aid in the regentrification of site becoming a part of people's everyday life and in turn well maintained. The landscape qualities are able to strengthen the house value and in turn, make the development more viable and realistic. 


\section{NETWORK DESIGN INVESTIGATION}

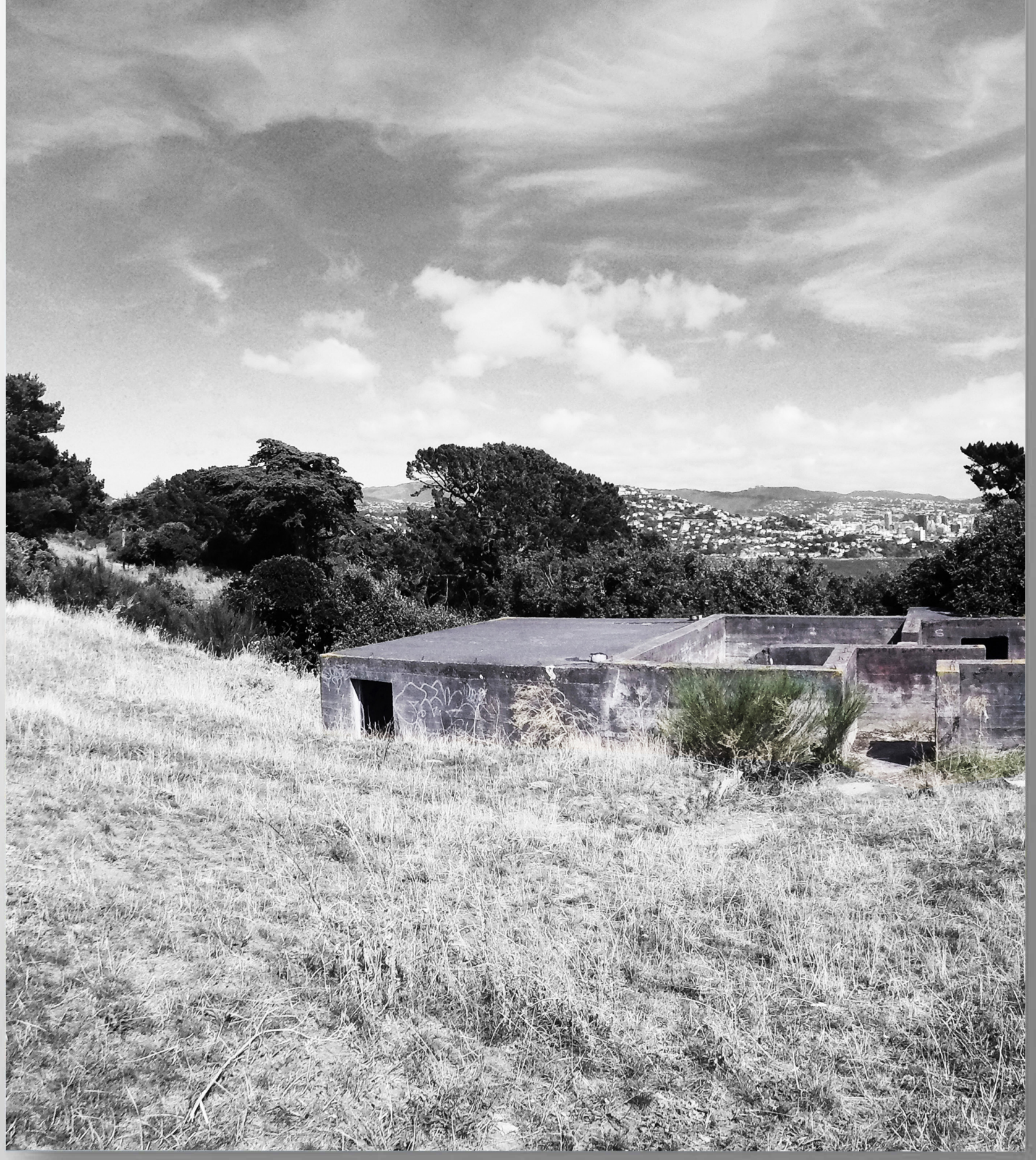




\subsection{Master Plan}

The master plan aims to explore the unique and special qualities of Watts Peninsula and ensure that the complex heterogeneous of the site as a heritage landscape are valued and expressed. The master plan provides three types of paths that explore unique and hidden landscapes while also providing an underlay for learning and understanding some of the sites history. They tell the reveal different parts of the geological formation and cultural diversity that make up the local history of Miramar Peninsula. The experiences help people understand the heritage meaning behind the military fortifications and sites environmental context. 


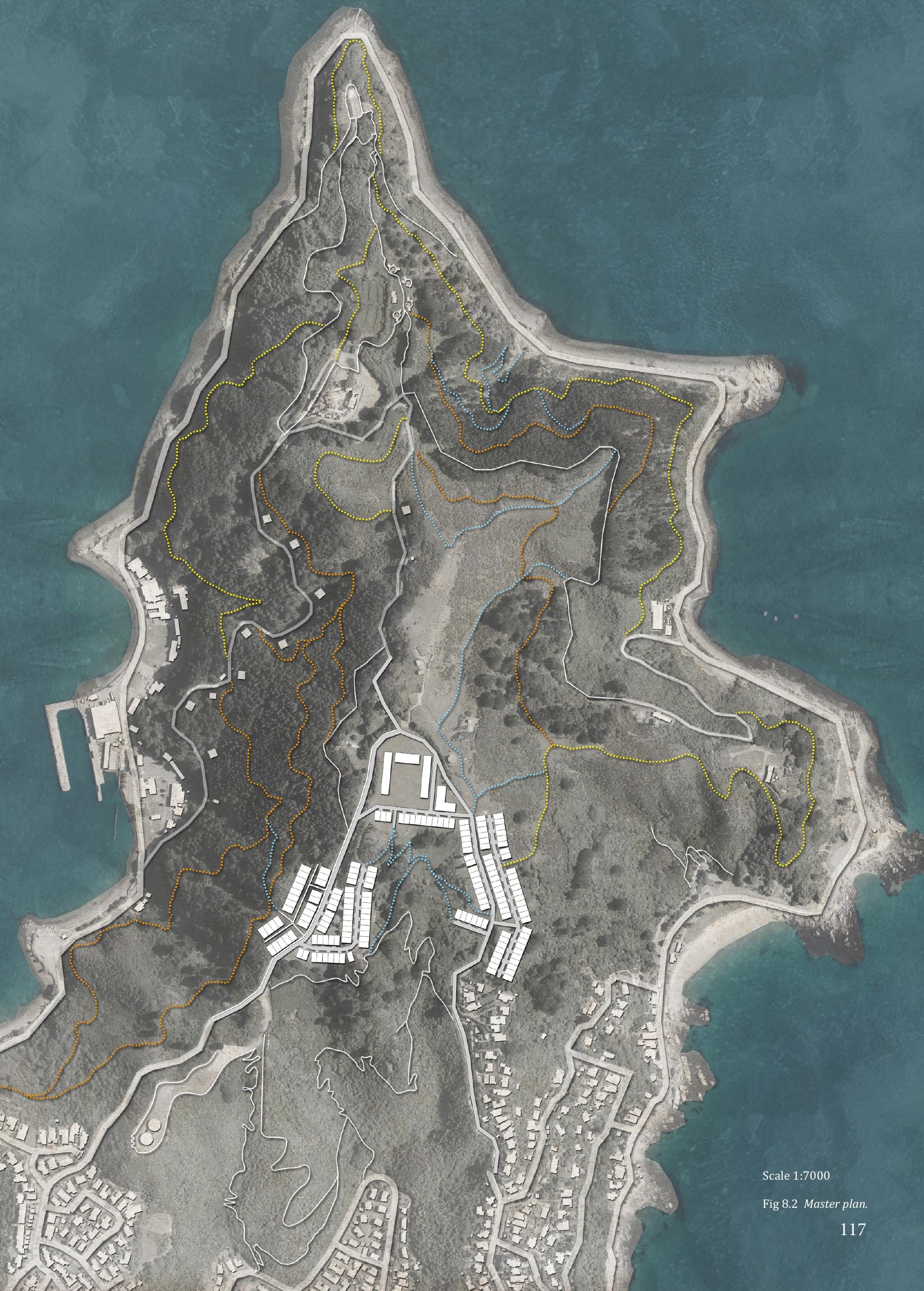




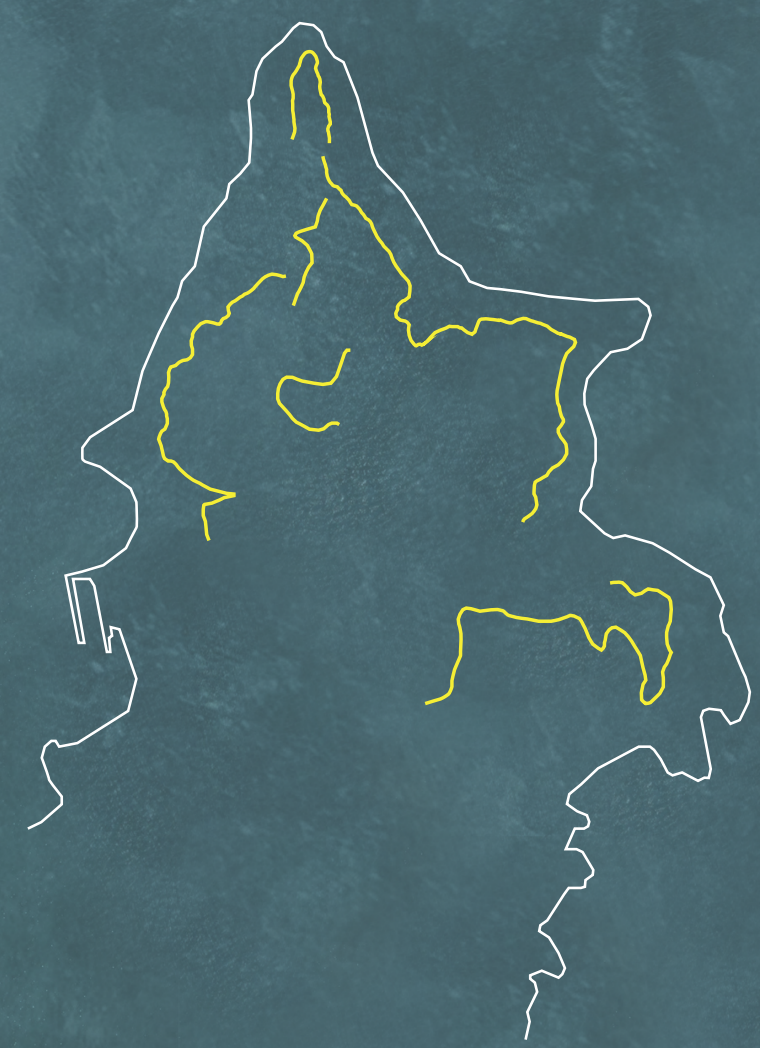

Fig 8.3 Proposed coastal trail on site.

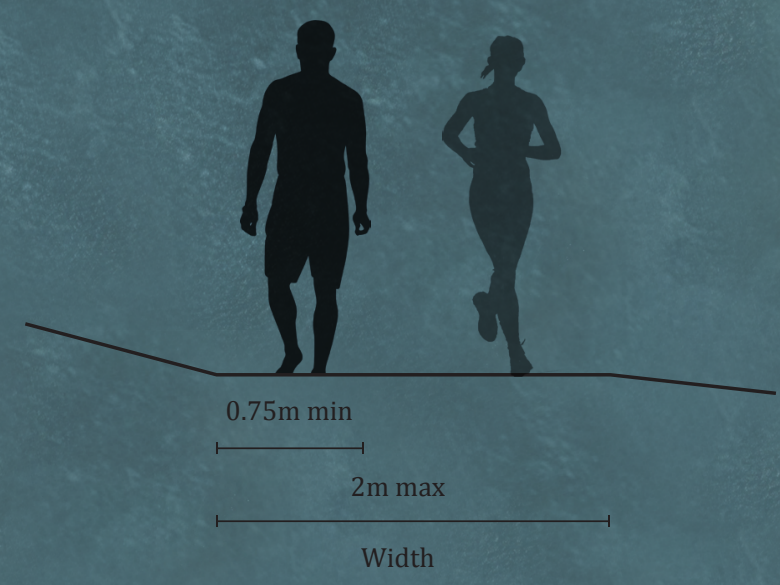

Fig 8.4 Proposed coastal trail suggests width.

\subsection{Proposed Coastal Trail}

The proposed coastal trail connects visitors to the coastal sublime, exposed and panoramic views as well as providing a safe, quiet, slow and finegrained route for users. 


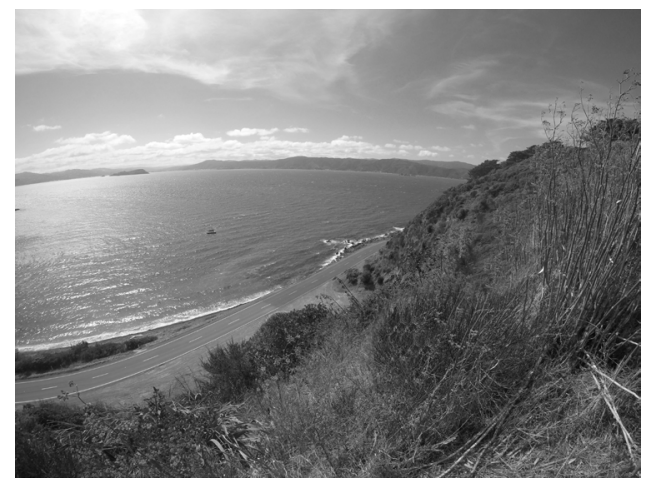

Fig 8.5 Before.

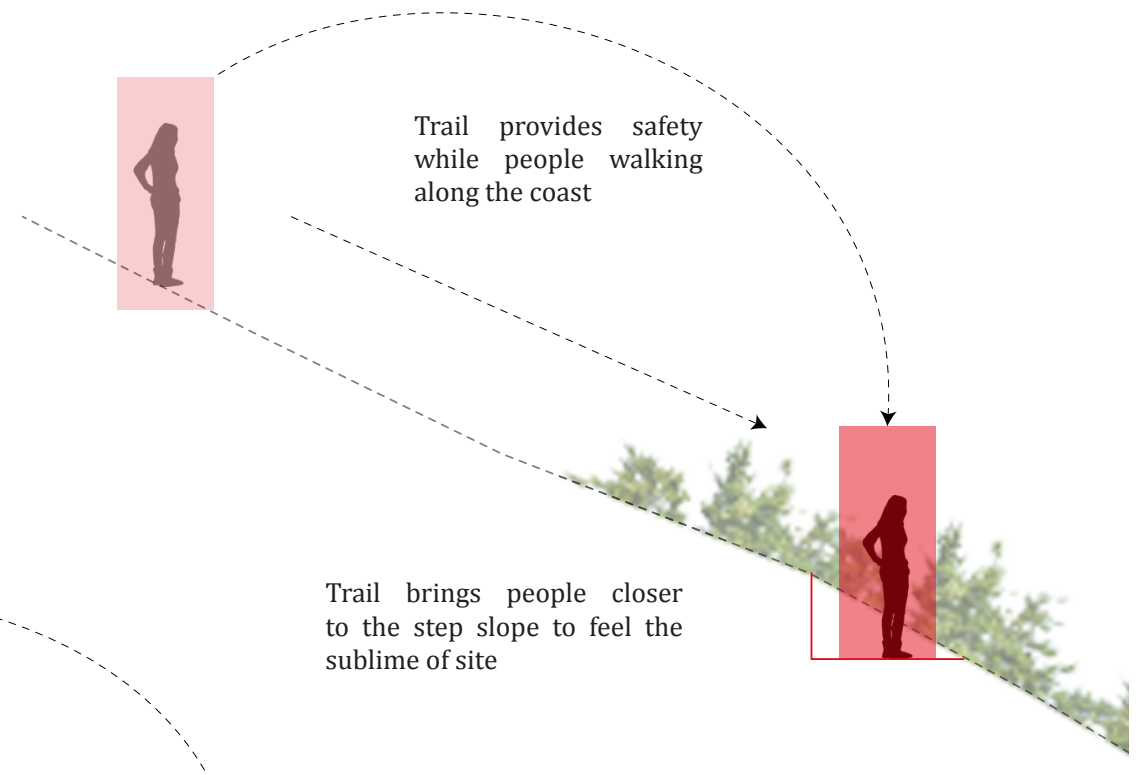

People afraid to adventure of the slope with high density vegetation cover

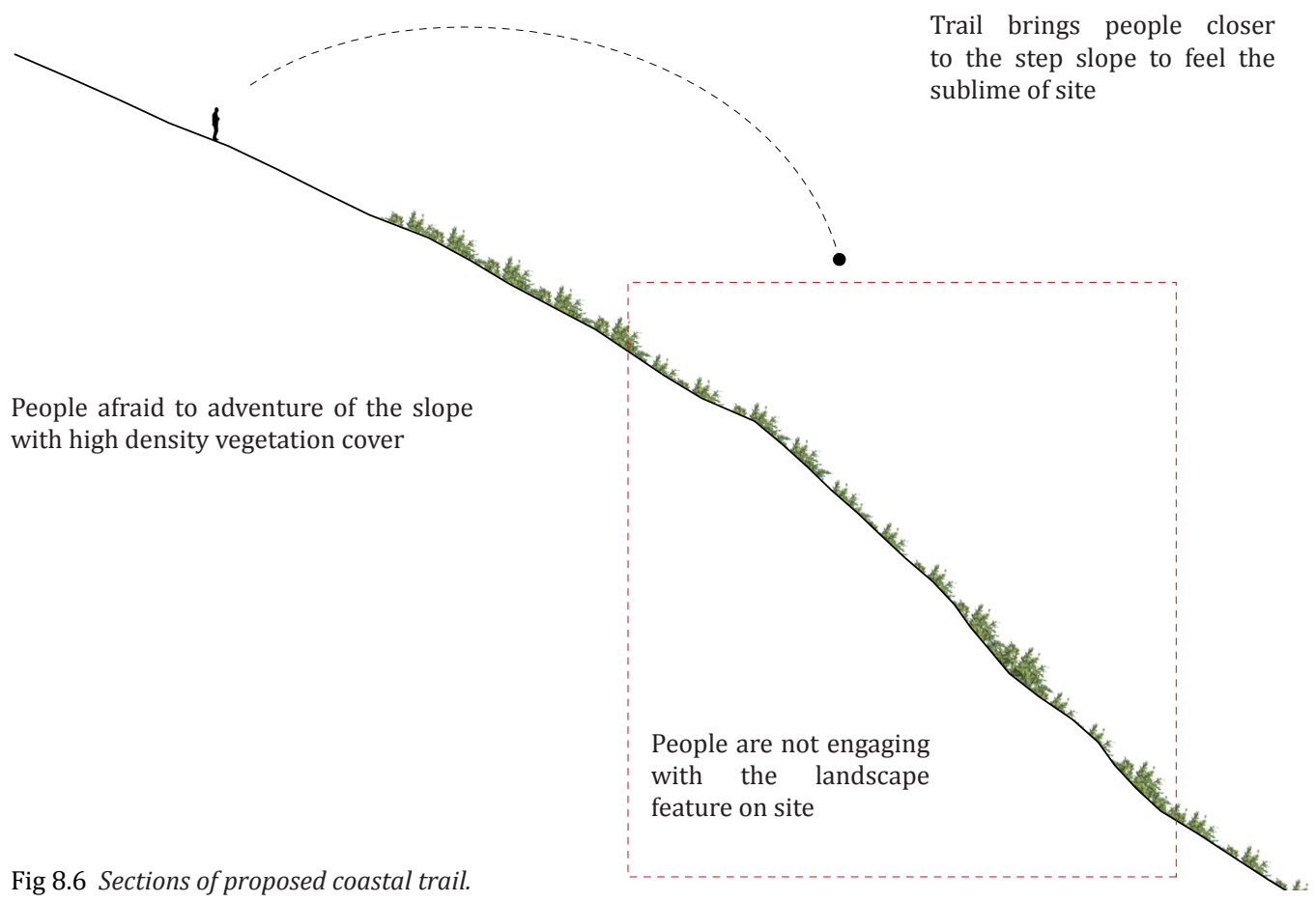

Fig 8.7 Render of proposed coastal trail.

People are not engaging with the landscape eature on site

Fig 8.6 Sections of proposed coastal trail. while people walking ong the coast 


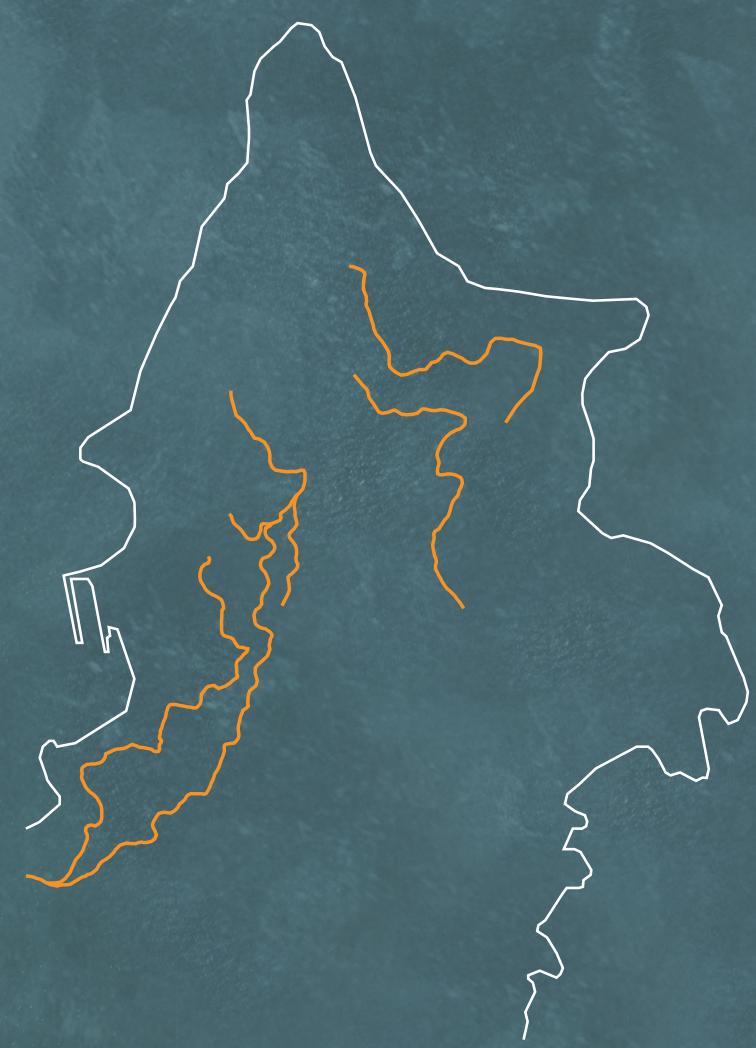

Fig 8.8 Proposed bush trail on site.

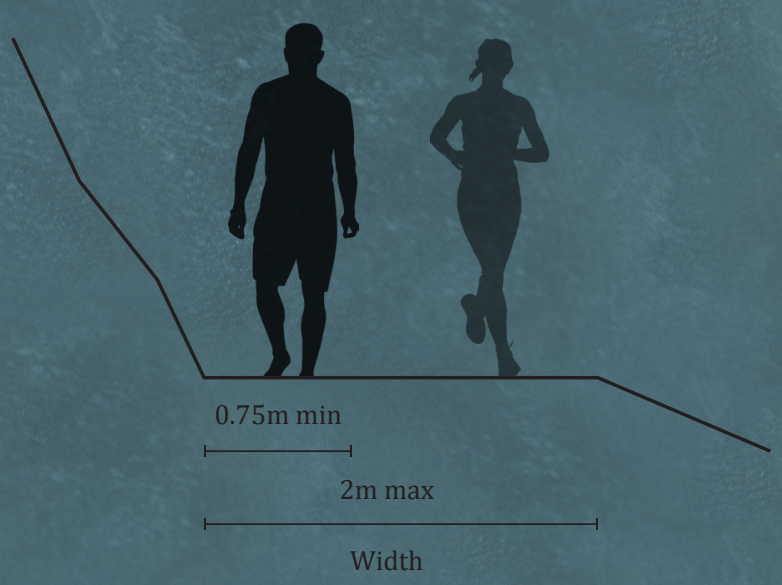

Fig 8.9 Proposed bush trail suggests width.

\subsection{Proposed Bush Trail}

The proposed bush trail brings people into an enclosed space which allows for intimate engagement with the trails topography and varied vegetation. Visitors can begin to understand this track through its settings and the senses associated with it. 

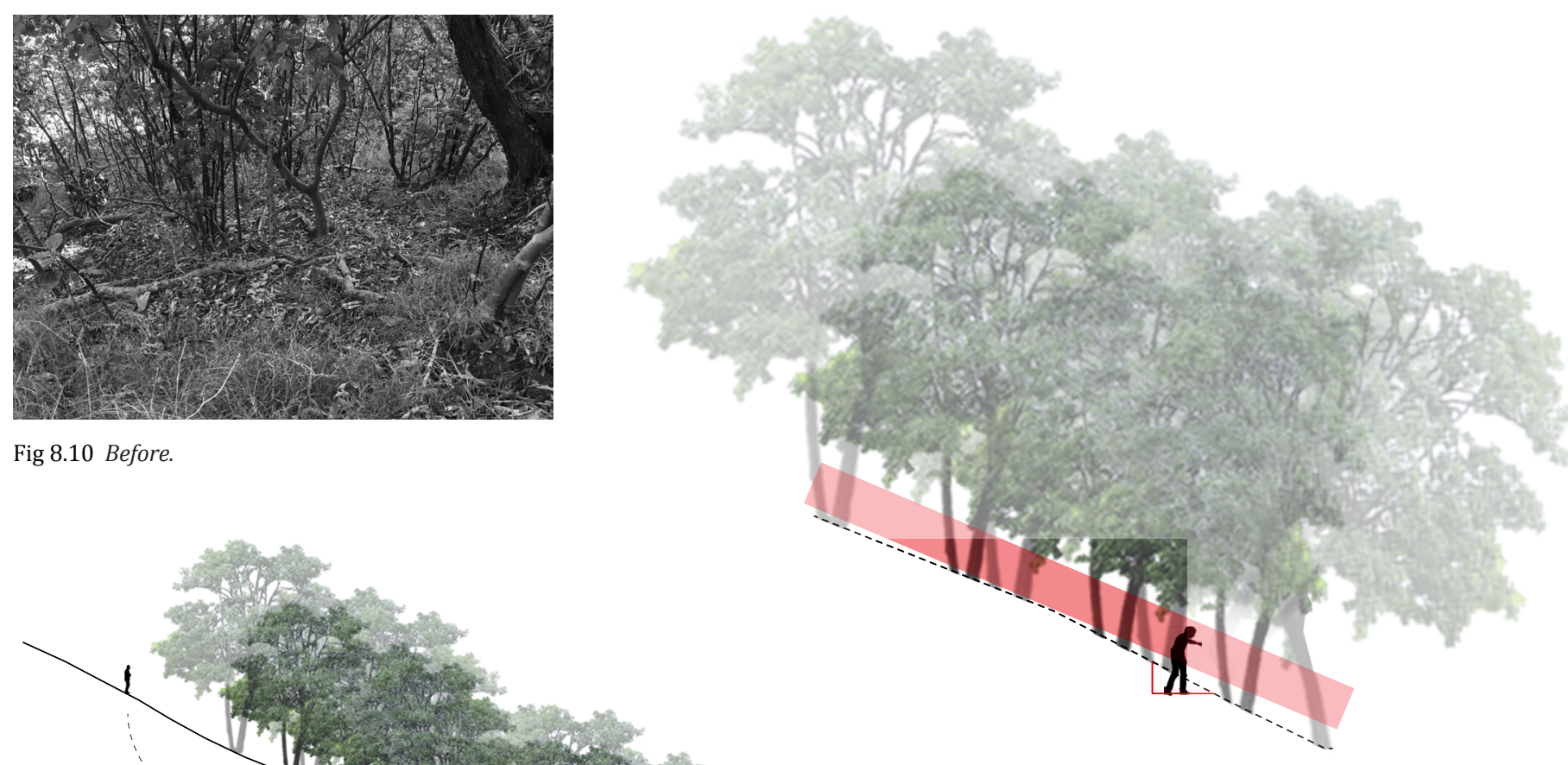

Fig 8.10 Before.

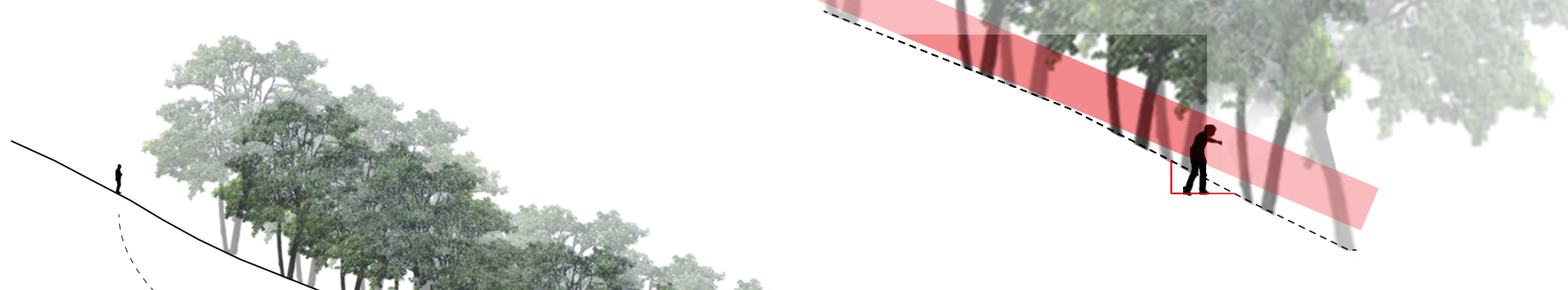

density trees are uniqueness on site, due to the branches and step slope, this area is unaccessible for most of people.

Trail gives chance for people walking through unaccessible area to experience the power of site features.

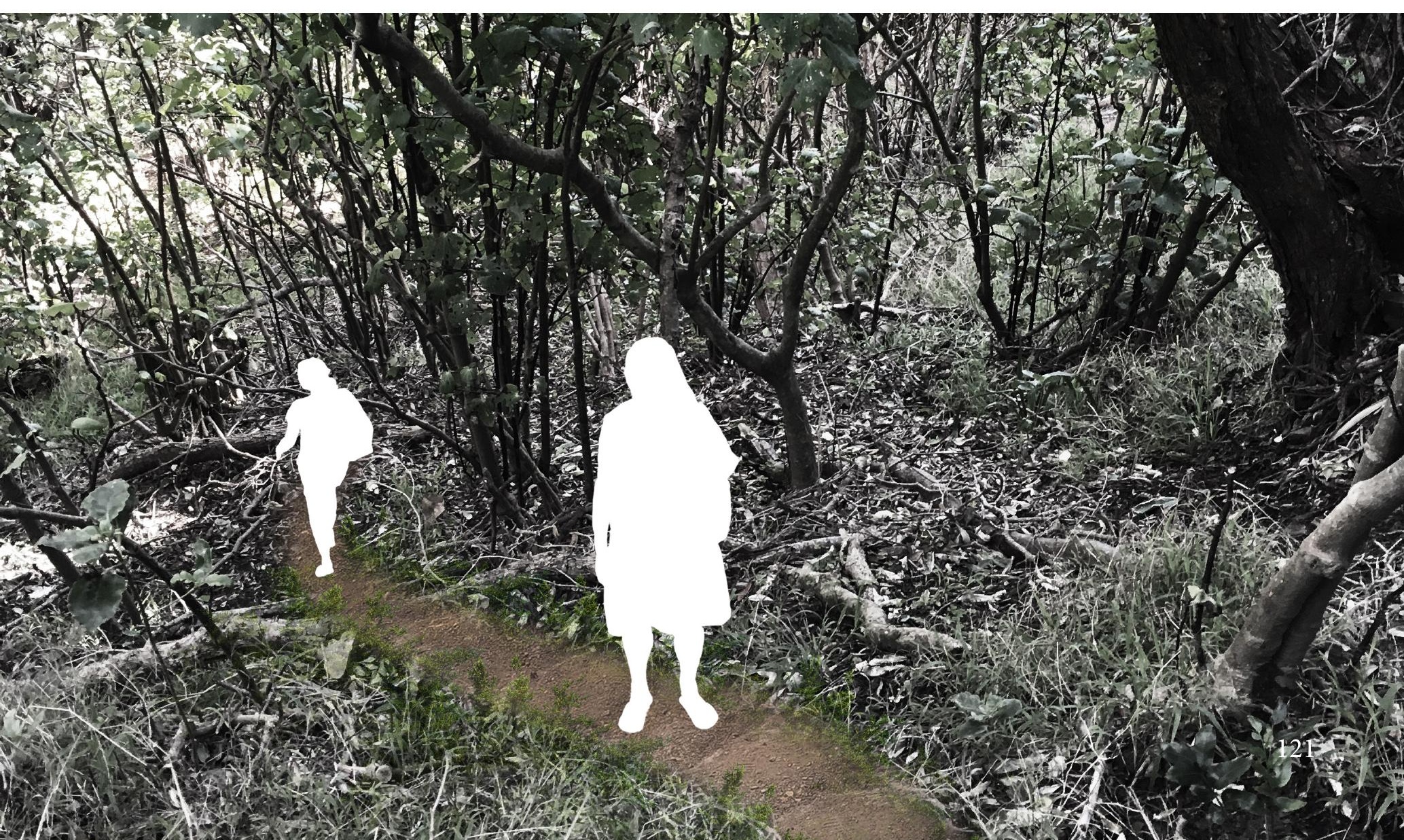





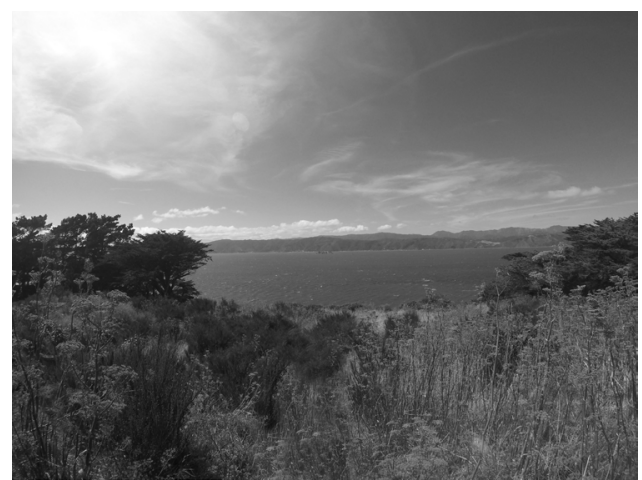

Fig 8.15 Before.
Allow people go off track to experience the difference.

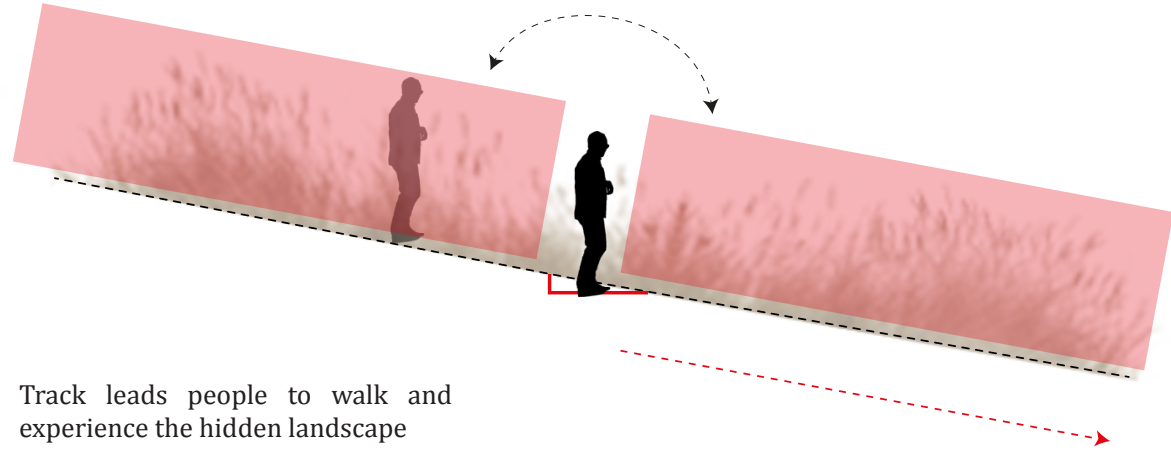

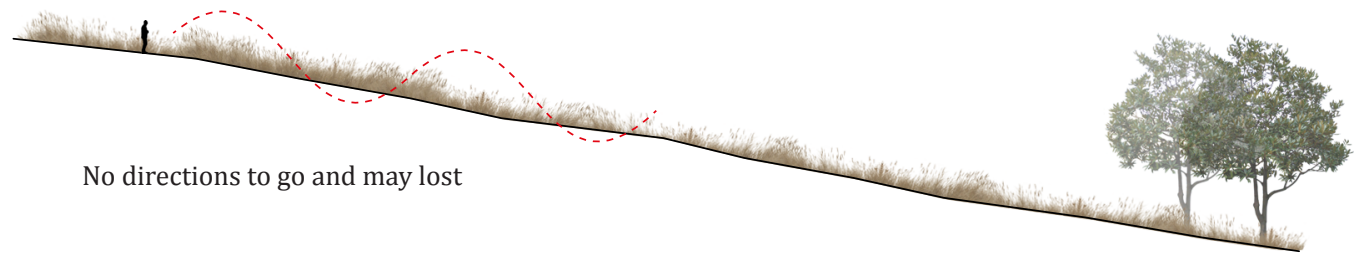

Fig 8.16 Sections of proposed tramping track.

Fig 8.17 Render of proposed tramping track.

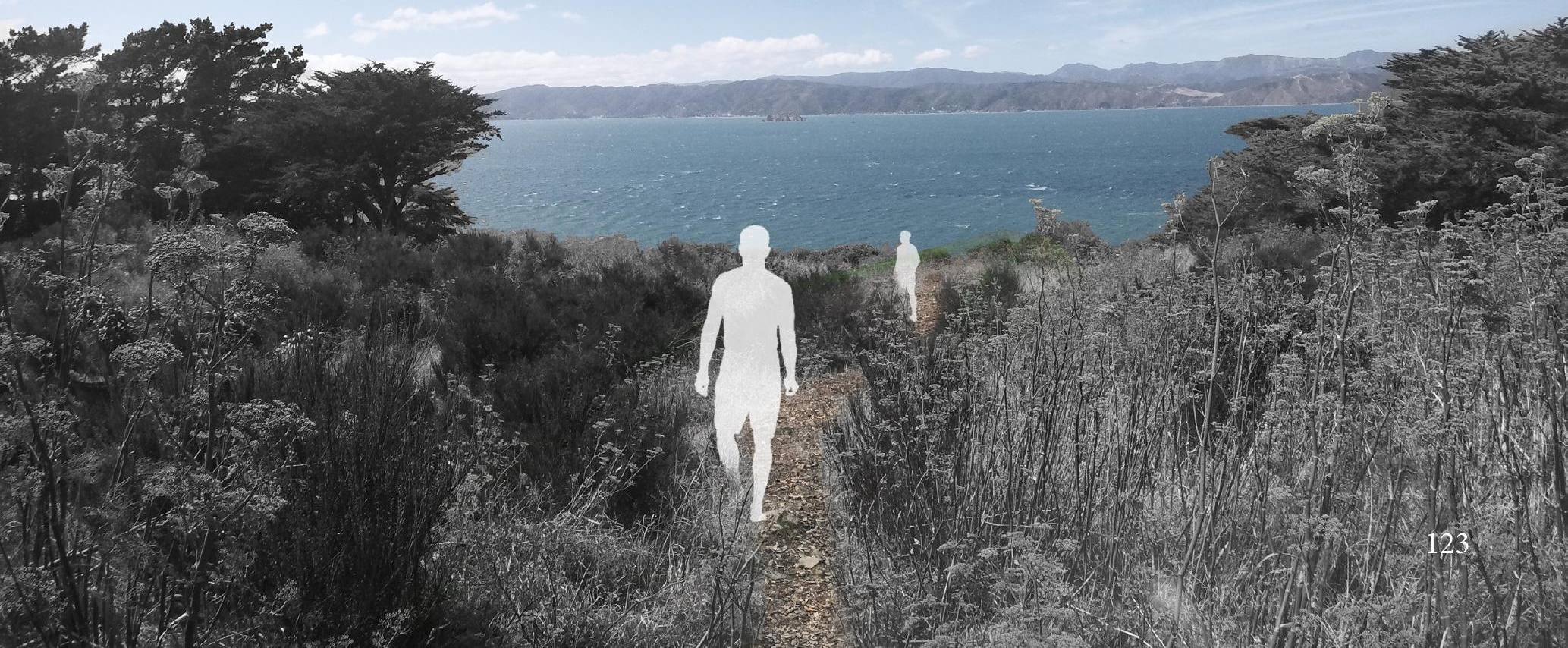




\subsection{Integrated Trails}

This pine area has the potential to allow people to adventure through each site condition on their own accord, being of particular interest to people not intending to follow any specific route through this site. The design of the integrated trails bring people into the pine forest, providing an opportunity to be immersed within the rich ecology and to feel the sublime.

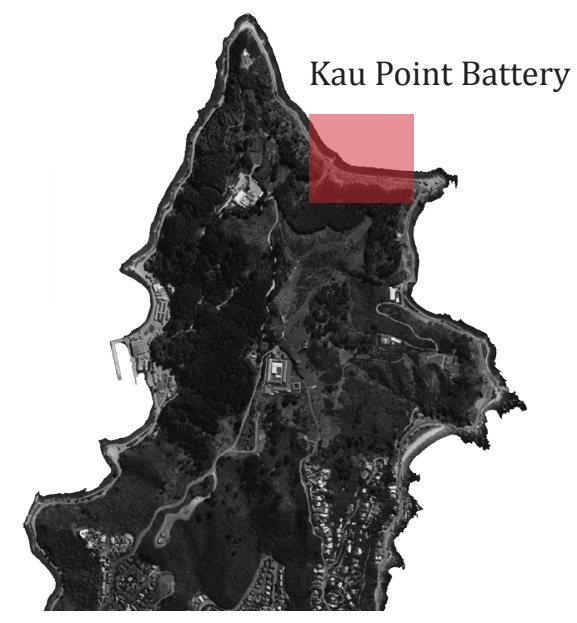

The existing topography and vegetation are the organizing frameworks of the network system.
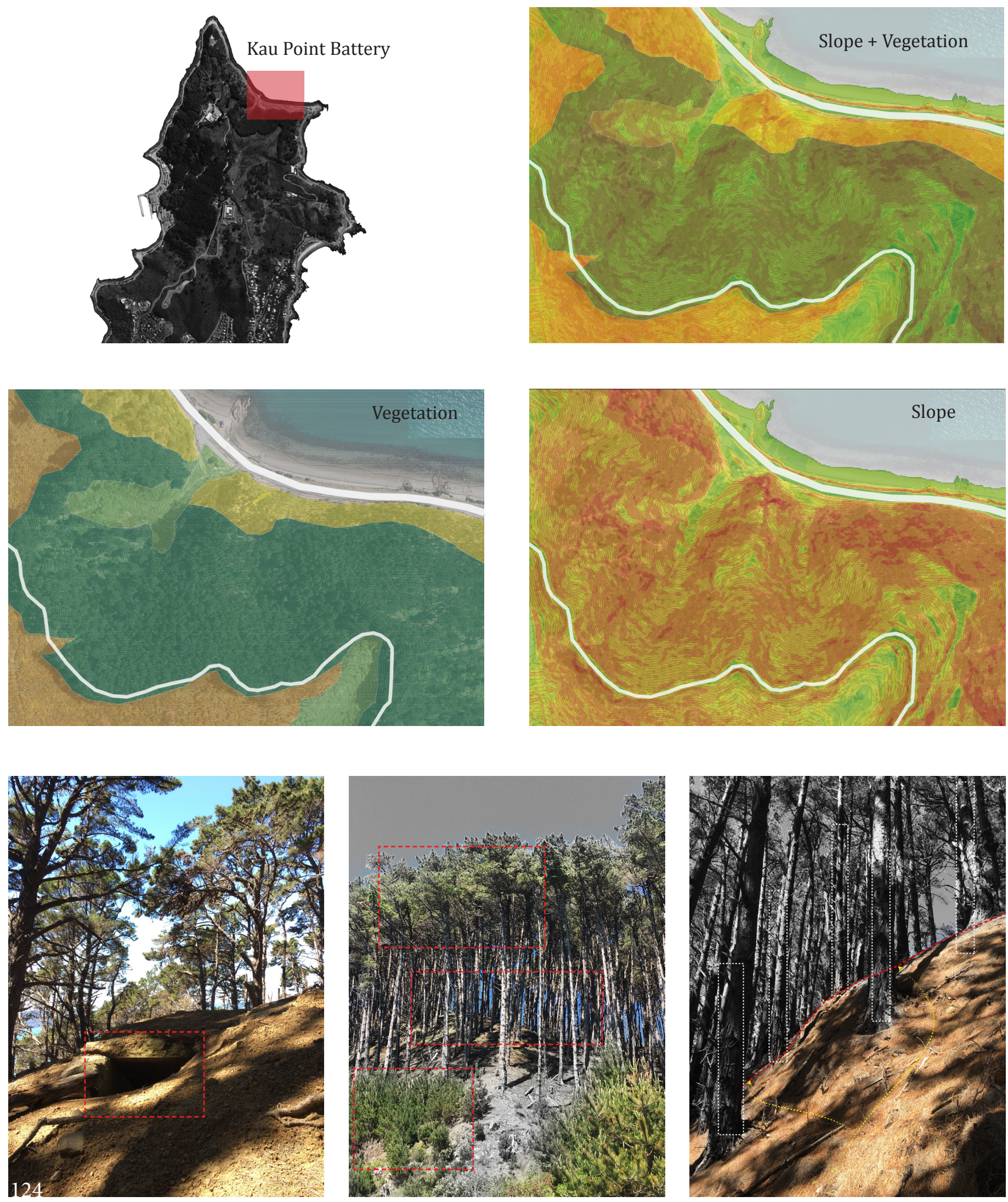

Fig 8.18 Maps and photos showing site condition. 

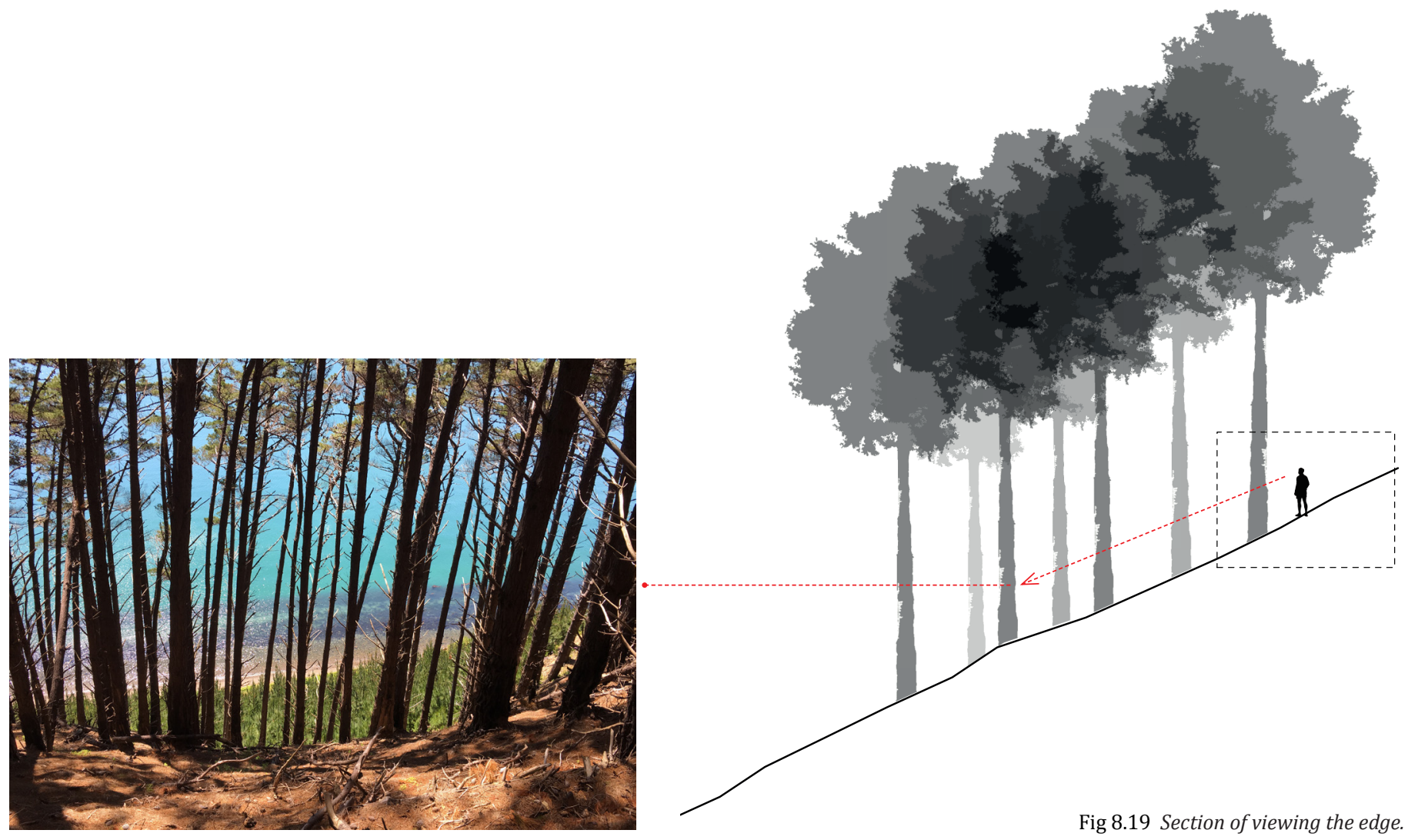

Fig 8.19 Section of viewing the edge.

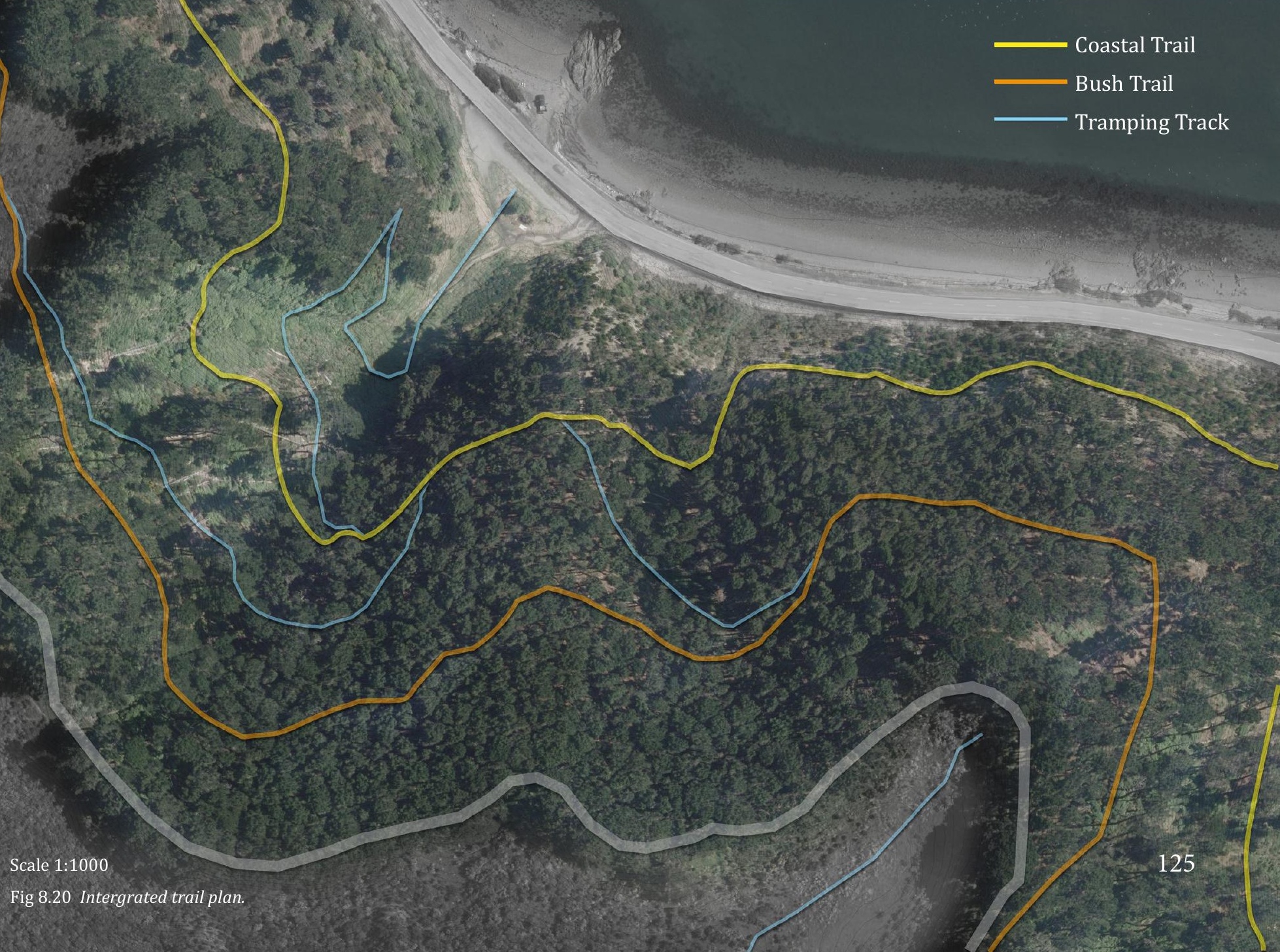




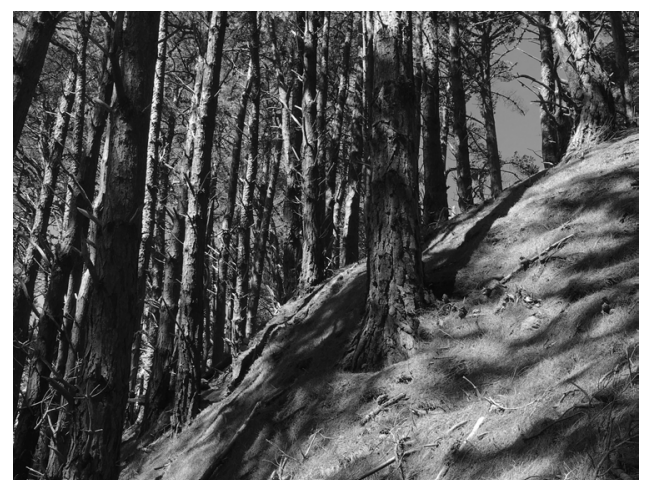

Fig 8.21 Before.

Existing topography

Insertion
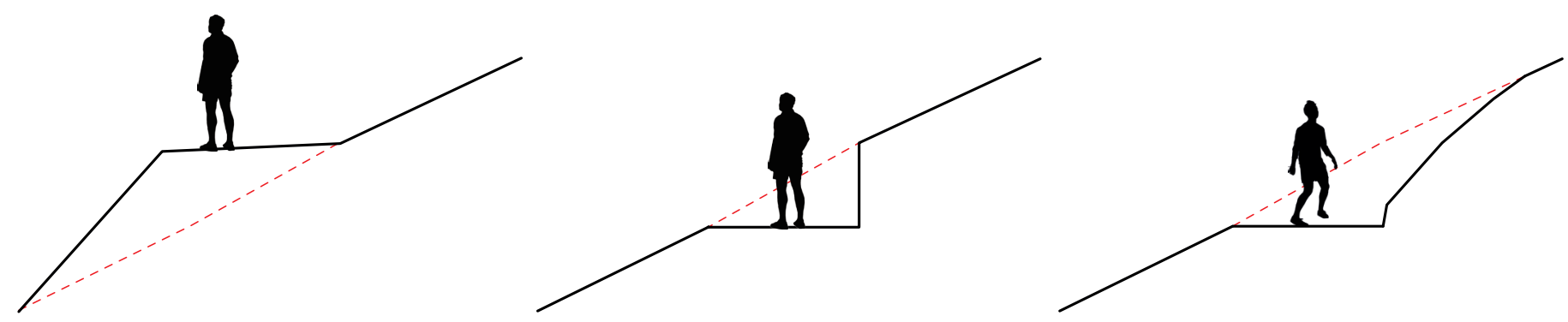

Fig 8.22 Options for creating a path.

Fig 8.23 Render of path in the pine forest.

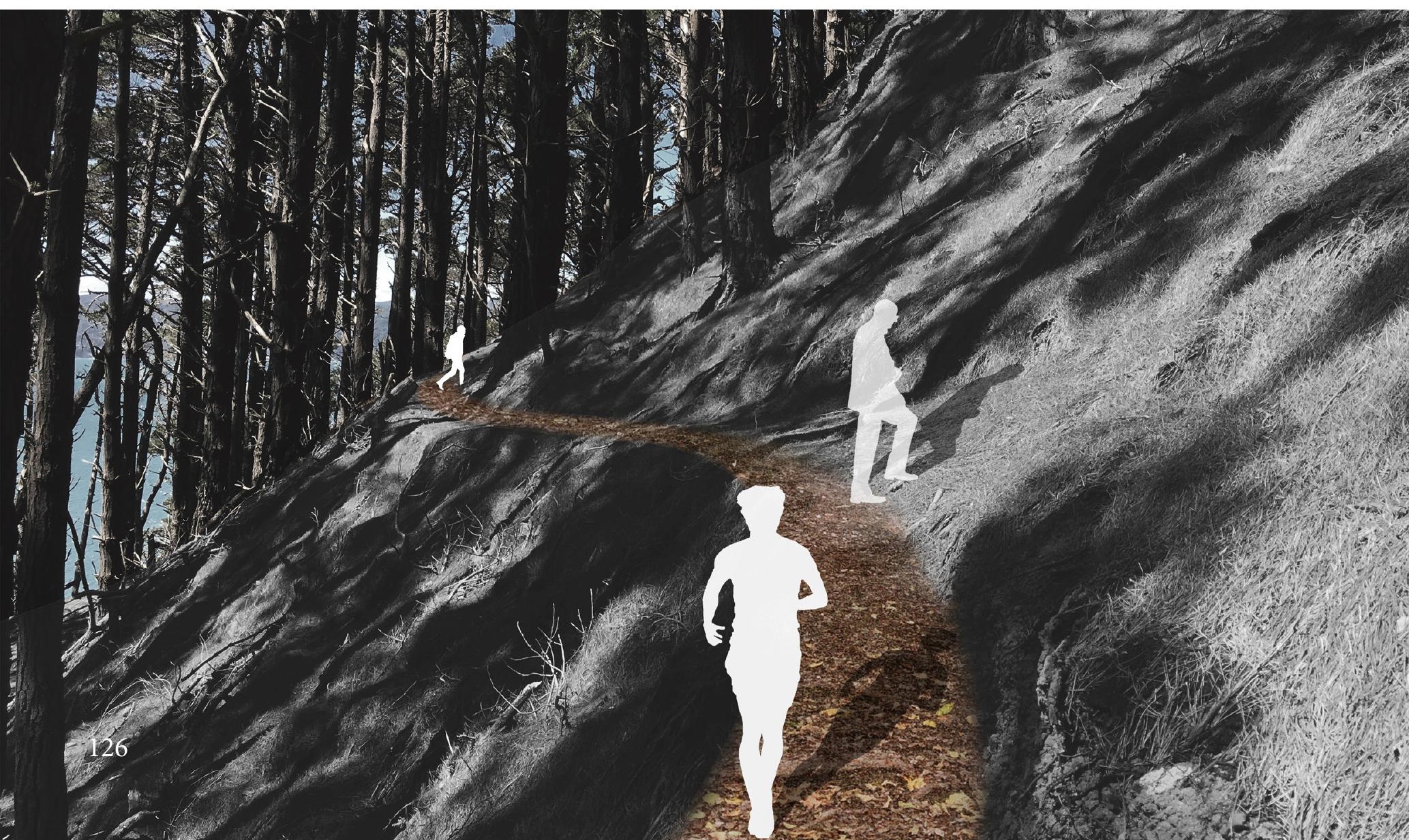




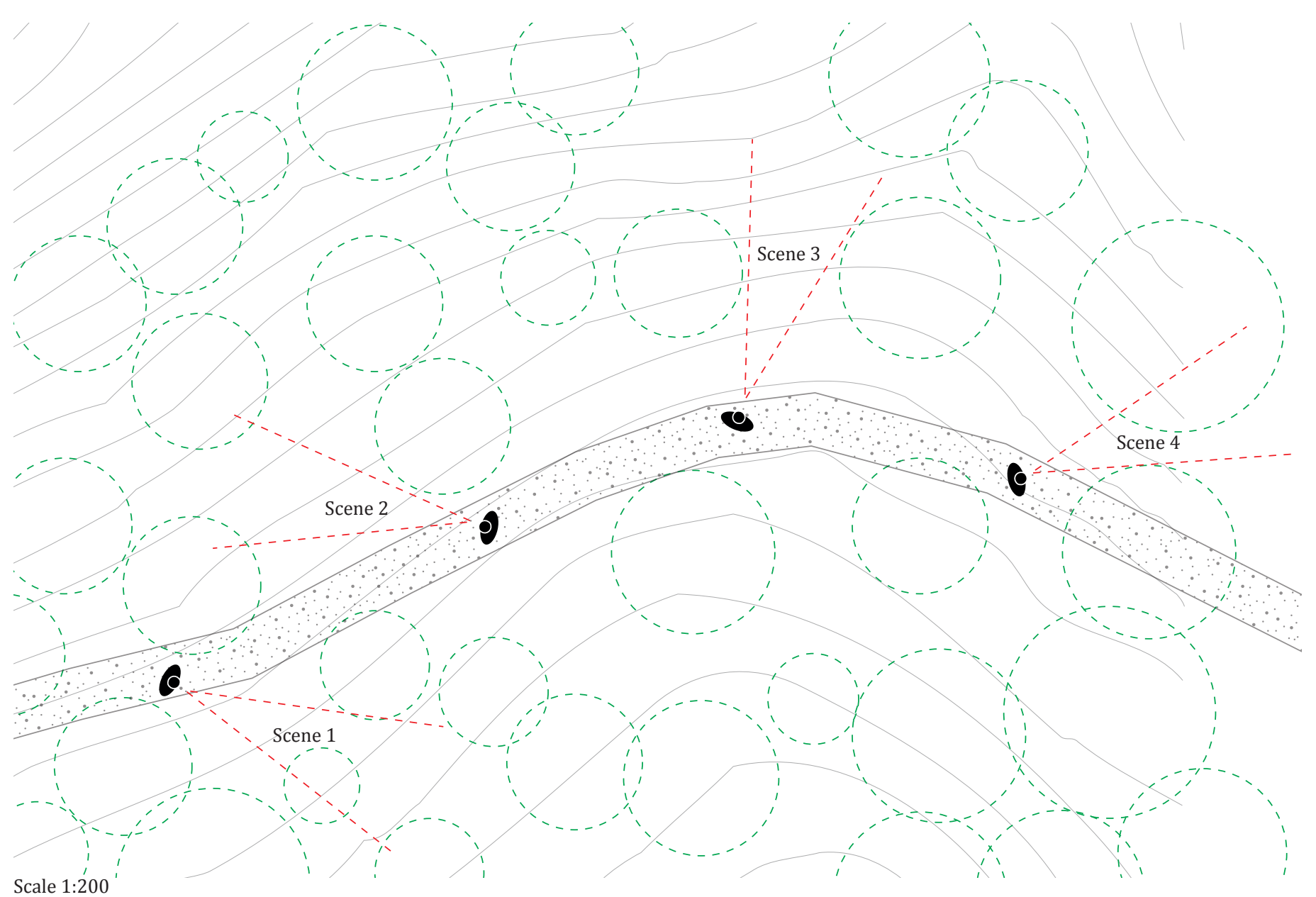

Fig 8.24 Viewshed shifts along the path.

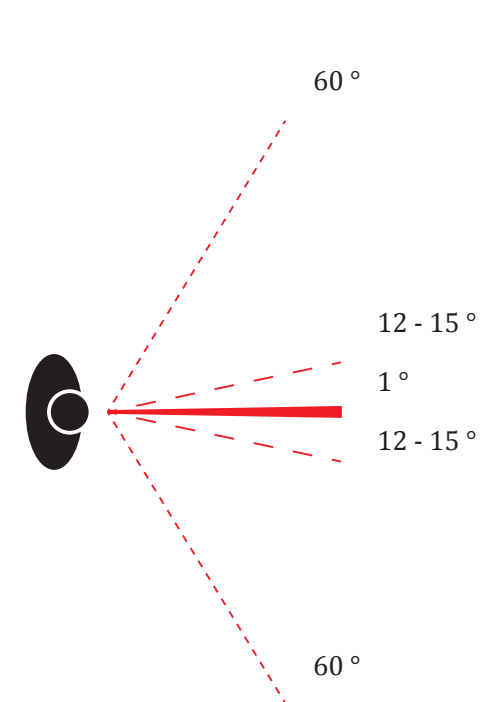

Horizontal field of vision

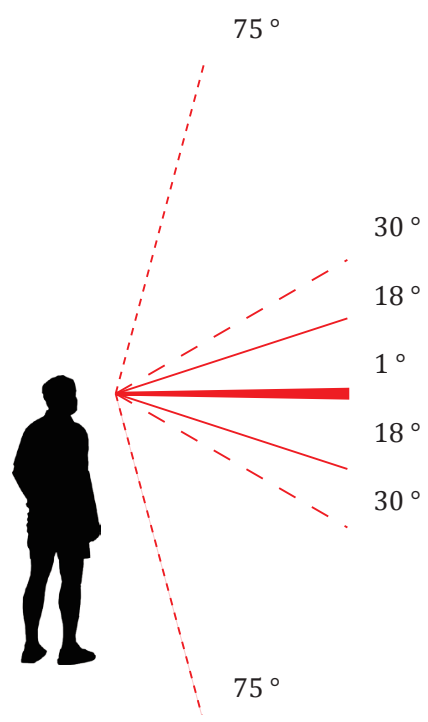

Vertical field of vision

Fig 8.25 Vision from horizontal and vertical field.
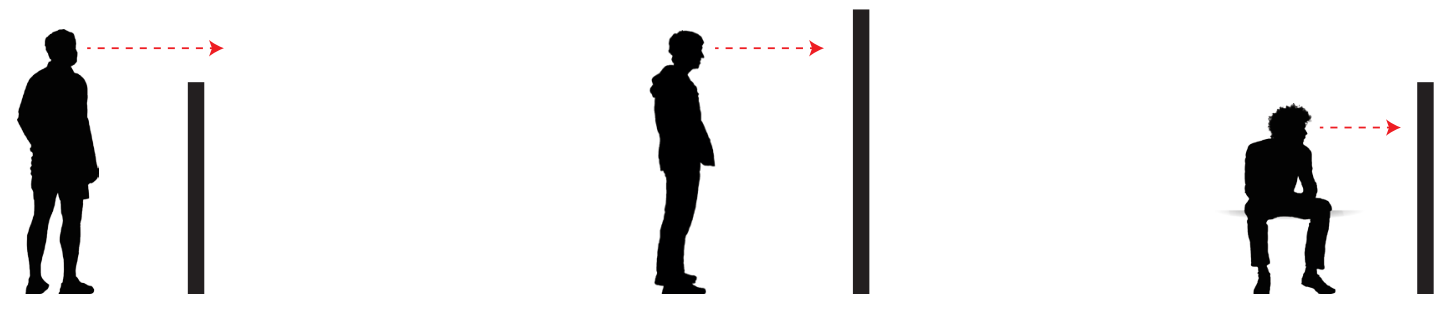


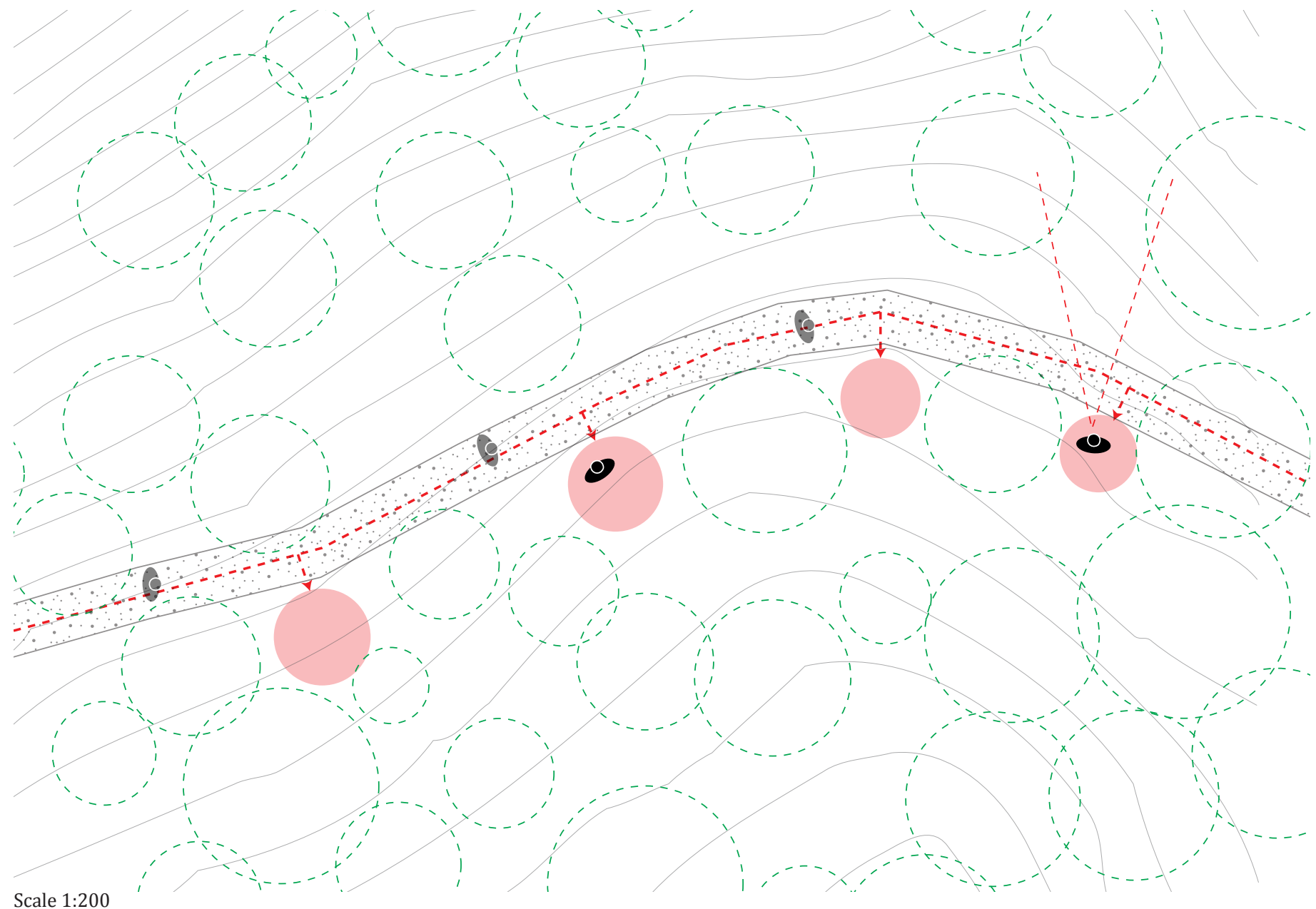

Fig 8.27 Potential seating position.
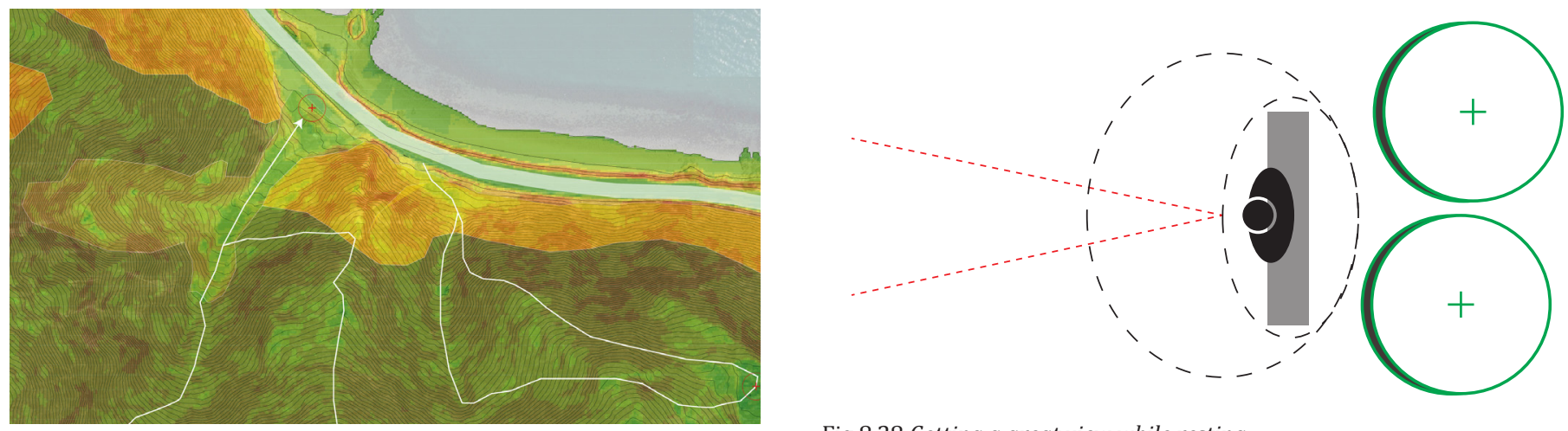

Fig 8.28 Getting a great view while resting

Fig 8.29 Example of seat positioning on Eastbourne track.

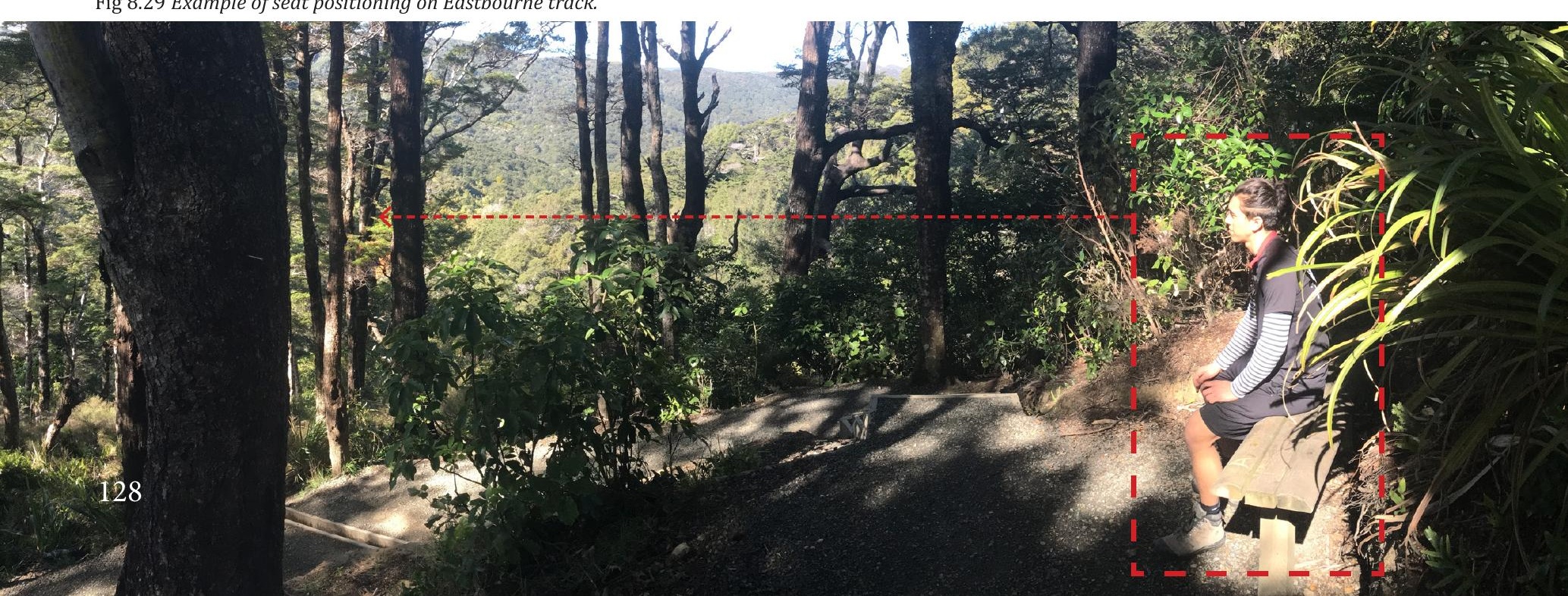



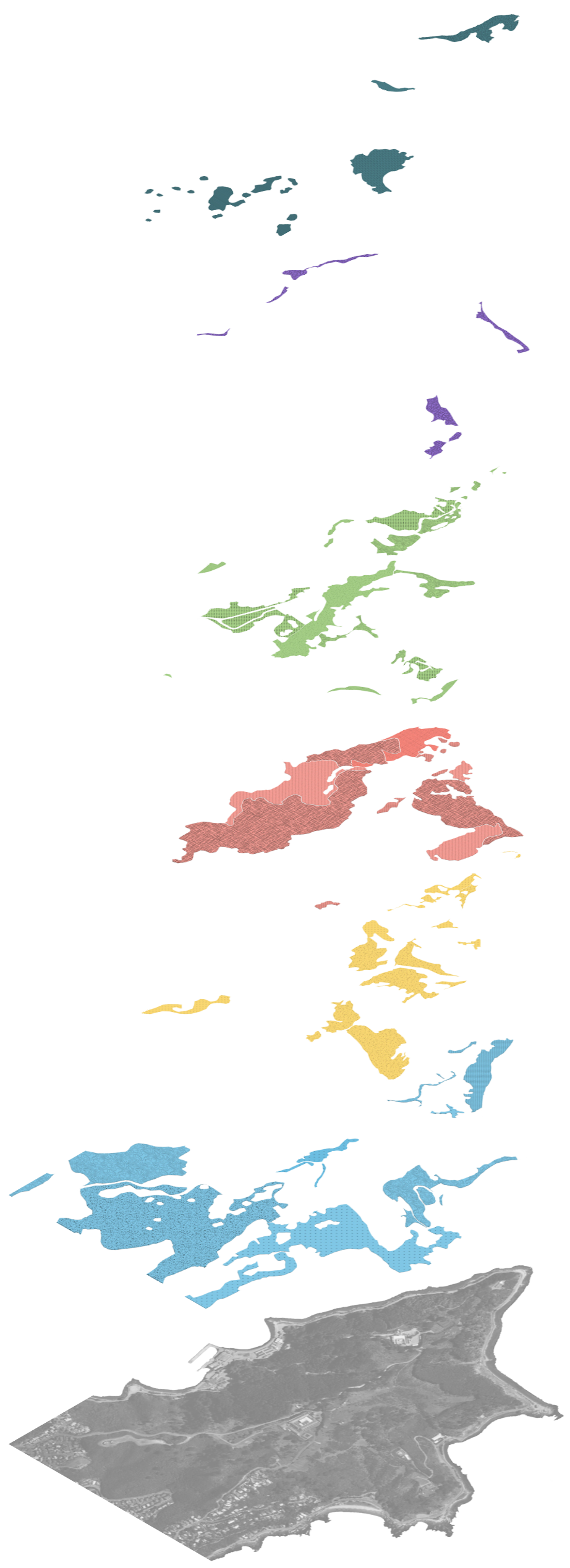

Fig 8.30 Axonometric mapping exploration of site heterogeneous.
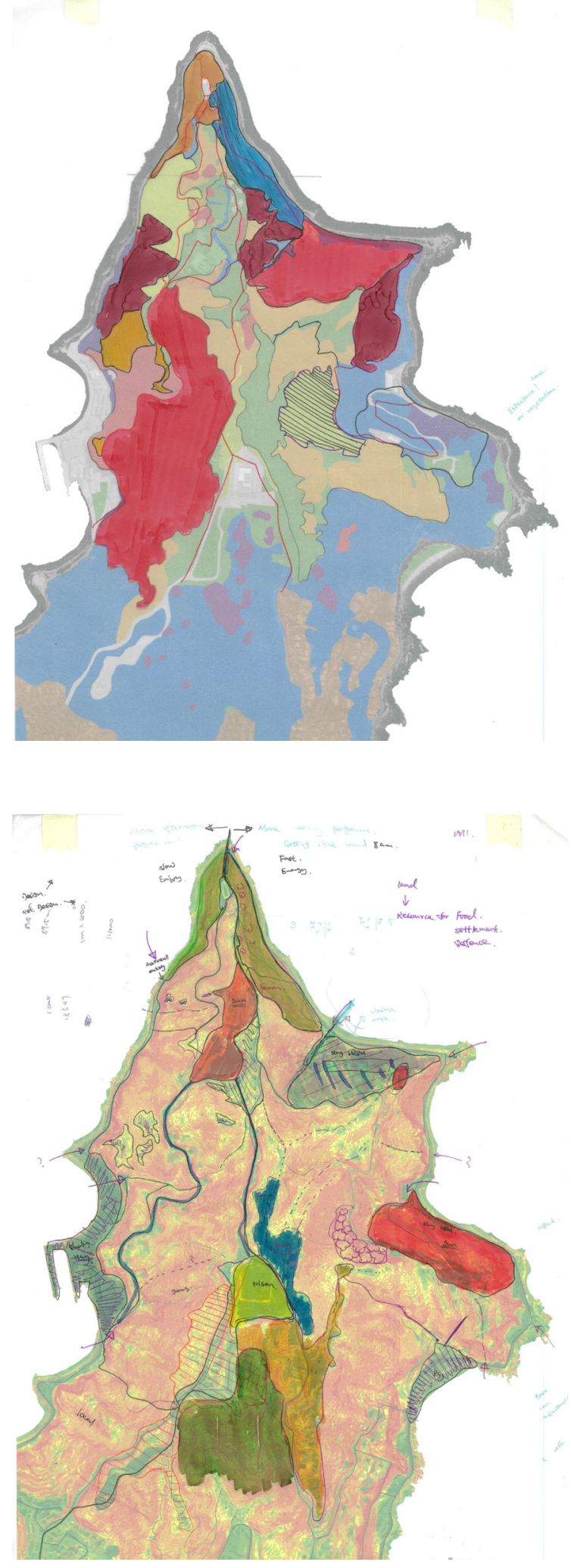

Fig 8.31 Drawing process showing how the site is made up by various heterogeneous. 


\subsection{Conclusion}

Rather than leading people to visit each key heritage location (typical heritage protection schemes), the new network attempts to create a large effect of experience in Watts Peninsula with the proposed coastal trail, bush trail and tramping track. People are invited to explore the potential experiences which they weren't intending to. For example, the paths provide opportunities to walk through the high density pine forest that is high gradient steep slope. The paths bring various heterogeneous together, pine trees, slope, movement, views, and how they interact with each other. By walking through the forest, the transition points identified (where these elements changes), shift views from the tree trunks to the sea while walking. This experience is highlighted and forms a way in which to understand the function of Kua point Battery which was designed to hidden from enemies while still being able to view the harbour.

The pine forest is only a small part of the whole Watts Peninsula, and there are more rich experiences which can also be explored. The design investigation proves Watts Peninsula is full of rich ecology and a variety of human-landscape assemblages. The heritage element cements this idea and offers an opportunity to re-integrate this fortification aspect with new life. 


\section{CONCLUSION}

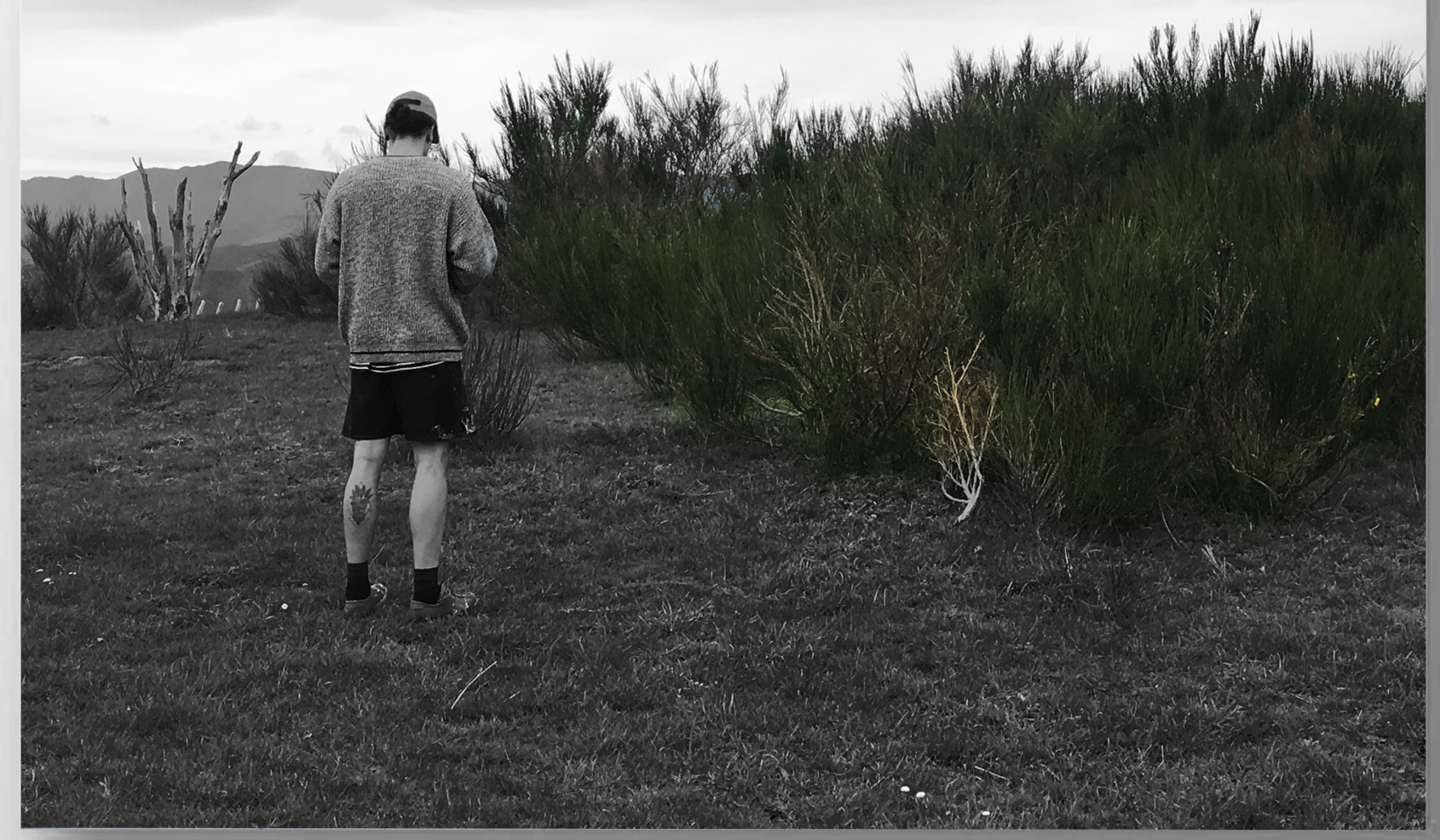




\section{1 Conclusion}

This research investigation started with a personal hunch about the Watts Peninsula military fortifications, once a key part of the Wellington coastal defence network.

The dominant way to approach these sites, because they are understood in terms of military history, involves preserving and protecting the various historical items and developing the associated site with a minimal path system that allows visitors to move around the site and experience these items and their interpretive signage. This tends to severely limit the range and richness of the experiencing potential of these, often topographically and urbanistically, interesting sites. This approach tends to pay more and precious attention to objectoriented historical value than the experiential and expansive engagement with the greater heritage sites. It would be hard to justify spending enough money to do more than minimal heritage treatment if this approach was employed at Watts Peninsula, as with many other sites.

This extraordinary site seemed to offer a great potential to side-step this approach by putting the objects aside (for a moment) and instead focus on exploring the experiential richness of the site as a way to provide an ecology or network of experiencing and movement that the heritage components would then be enlivened by and which together could then be something of a unique destination in Wellington. The previous life of the site was driven by military functionality and the challenge for Watts Peninsula seemed to be what functionality would make sense of the remnants of the former network and answer the disciplinary question or challenge of 'how to bring new life to abandoned coastal defence sites.'

Fieldstudiesidentified that the site differentiatesitself into areas, each having its own unique topographical, vegetative and ecological characteristics. It was discovered that each of these differentiated areas also promoted their own types of experiencing and altogether these areas combine to produce a mosaic of interacting ecological-topographical experience zones which was obscured and reduced in the current way that the site functioned.
Deleuze and Guattari's notion of an assemblage, an affiliation of heterogeneous components including human organisms, that produced involuntary actions and movements (affects) allowed for the identification of types of experiencing where the various heterogeneous components function as part of the experiencing. So that, for instance, a type of gingerly slow stepping downhill amongst mature Pohutakawa trees was not just walking amongst Pohutakawas but a gingerly-explorative Pohutakawan movement that we feed off and explore as part of exploring the greater landscape.

Likewise, field studies also identified that the site generated its own involuntarily-produced destinations and potential destinations produced by the relation of where you are on the site to the various options near or available to you. An understanding of all current site destinations as well as the ecology and locations of the various existing and potential experiencing zones would then invite the identification of all potential destinations, entrances and hence movement routes and movement-areas on the site.

Design would then involve intensifying the ecologicalvegetative difference of the existing zones and maximising the richness and variety of the network of destinations and movements. Strategically located interventions would act to work with and facilitate these movements and experiencings.

Housing would be provided in a manner that would minimise the negative impacts of such a development but also maximise the number of residents that would have local access to the site. If the right development arrangement could be negotiated, then the sale of the land for the housing or the sale of the housing itself, on this prime real estate location, would very possibly make this a viable development. Care would need to be taken to not make this an exclusive housing development yet still make a substantial contribution to the economic viability of the greater site development. Together, the heritage components, movement network, ecological areas and strategic interventions could very well together function as a unique exploring-adventuring ecological-heritage destination that would attract tourists, Wellingtonians and local residents. As such this exploration of experience driven heritage would be something of an answer to the challenge of 'how to bring new life to abandoned coastal defence sites.' 


\section{Figure List}

All figures not listed here are by the Author, 2016-2017

Figure 1.2: Blaschke \& Rutherford Environmental Consultants, PAOS Limited, \& TRC Tourism Limited. (2012). Watts Peninsula: Feasibility Study Identifying Options for Further Development. Wellington: Ministry of Culture \& Heritage.

Figure 2.12 Blaschke \& Rutherford Environmental Consultants, PAOS Limited, \& TRC Tourism Limited. (2012). Watts Peninsula: Feasibility Study Identifying Options for Further Development. Wellington: Ministry of Culture \& Heritage.

Figure 2.13 Blaschke \& Rutherford Environmental Consultants, PAOS Limited, \& TRC Tourism Limited. (2012). Watts Peninsula: Feasibility Study Identifying Options for Further Development. Wellington: Ministry of Culture \& Heritage.

Figure 2.20 Dodd, A. (2012). Greater wellington coastal plan review. Wellington.

Figure 2.28 Loidl, H., \& Bernard, S. (2014). Opening Spaces Design as Landscape Architecture. Berlin: Oliver Kleinschmidt.

Figure 5.2 Dumpark. (2016). Mapping hours of direct sunlight in Wellington City

Retrieved from: http://dumpark.com/\#projects/mapping-hours-of-direct-sunlight-in-wellington-city

Figure 5.3 Dumpark. (2016). Mapping hours of direct sunlight in Wellington City

Retrieved from: http://dumpark.com/\#projects/mapping-hours-of-direct-sunlight-in-wellington-city

Figure 6.17 QV. (2016). Maupuia Property Values.

Retrieved from: https://www.qv.co.nz/suburb/maupuia-wellington/2569

Figure 6.20 Realestate. (2016). Three Bedroom Townhouse - Construction Underway.

Retrieved from: http://www.realestate.co.nz/2925583 


\section{Bibliography}

Architects, E. L. (2011). Cap de Creus. Retrieved from landezine: http://www.landezine.com/index. php/2011/03/tudela-club-med-restoration-in-cap-de-creus-by-emf-landscape-architecture/

Blaschke \& Rutherford Environmental Consultants, PAOS Limited, \& TRC Tourism Limited. (2012). Watts Peninsula: Feasibility Study Identifying Options for Further Development. Wellington: Ministry of Culture \& Heritage.

Burgess, D. (2011, July 08). Miramar Peninsula: Subdivision or parkland? Retrieved from stuff.co.nz: http://www.stuff.co.nz/dominion-post/news/5252981/Miramar-Peninsula-Subdivision-or-parkland

Connolly, P. (2007). The Heterogenous: An Example. Auckland: Unitec.

Conservation, D. o. (n.d.). Maungauika/North Head Historic Reserve. Retrieved from Department of Conservation: http://www.doc.govt.nz/parks-and-recreation/places-to-go/auckland/places/ maungauika-north-head-historic-reserve/

Department of Conservation. (n.d.). The North Head Disappearing Gun . Retrieved from Department of Conservation: http://www.doc.govt.nz/parks-and-recreation/places-to-go/auckland/places/ maungauika-north-head-historic-reserve/north-head-historic-reserve-history/the-north-headdisappearing-gun/

Donovan, E. (2016, December 12). Public reserve still on cards for Wgtn's Watts Peninsula. Retrieved from Radio NZ: http://www.radionz.co.nz/news/national/320217/public-reserve-still-on-cards-forwgtn's-watts-peninsula

Hunt, T. (2016, December 08). \$500m revamp for Shelly Bay, Wellington. Retrieved from stuff.co.nz: http://www.stuff.co.nz/business/87233401/Boutique-hotel-brewery-and-350-homes-on-the-cardsfor-Wellingtons-Shelly-Bay

Landezine. (2011). EMF Landscape Architects. Retrieved from Landezine: http://www.landezine.com/ index.php/2011/03/tudela-club-med-restoration-in-cap-de-creus-by-emf-landscape-architecture/

Loidl, H., \& Bernard, S. (2014). Opening Spaces Design as Landscape Architecture. Berlin: Oliver Kleinschmidt.

Massuni, B. (1999). Strange Horizon: Buildings, Biograms, and the Body Topologic. ANU Research Publications.

Ministry for Culture and Heritage. (2014, September 02). Watts Peninsular. Retrieved from Ministry for Culture \& Heritage: http://www.mch.govt.nz/what-we-do/our-projects/current/watts-peninsula

Resources, D. o. (2017). Diamond Head Summit Trail. Retrieved from Department of Land and Natural Resources: http://dlnr.hawaii.gov/dsp/hiking/oahu/diamond-head-summit-trail/

Statistics NZ. (2013). Miramar - Population, dwellings and ethnicity. Retrieved from idcommunity demographic resources: http://profile.idnz.co.nz/wellington/population?WebID=290 
Stewart, M. (2016, October 14). New $\$ 22 \mathrm{~m}$ Miramar housing complex a boon for thriving movie suburb. Retrieved from stuff.co.nz: http://www.stuff.co.nz/dominion-post/business/residentialproperty/85346137/New-22m-Miramar-housing-complex-a-boon-for-thriving-movie-suburb

Stuff. (2016, September 19). Wellington mayoral candidate Nick Leggett promises to reclaim Fort Ballance. Retrieved from stuff.co.nz: http://www.stuff.co.nz/dominion-post/news/84423590/ wellington-mayoral-candidate-nick-leggett-promises-to-reclaim-fort-ballance

The Dominion Post. (2011, September 11). Dompost verdict: Caution urged. Retrieved from stuff.co.nz: http://www.stuff.co.nz/dominion-post/comment/editorials/5263841/Dompost-verdict-Cautionurged

Wellingtons Coastal Defences. (n.d.). Retrieved from NZ Coastal Defences: https://sites.google.com/ site/nzcoastaldefences/wellington-s-coastal-defences 